US Army Corps

of Engineers ${ }_{\circledast}$

Engineer Research and

Development Center

\title{
Wintertime Snow and Precipitation Conditions in the Willow Creek Watershed above Ririe Dam, Idaho
}

Jeremy Giovando, Chandler Engel, Steven F. Daly, Michael

April 2021

Warner, Daniel Hamill, and Evan Heisman

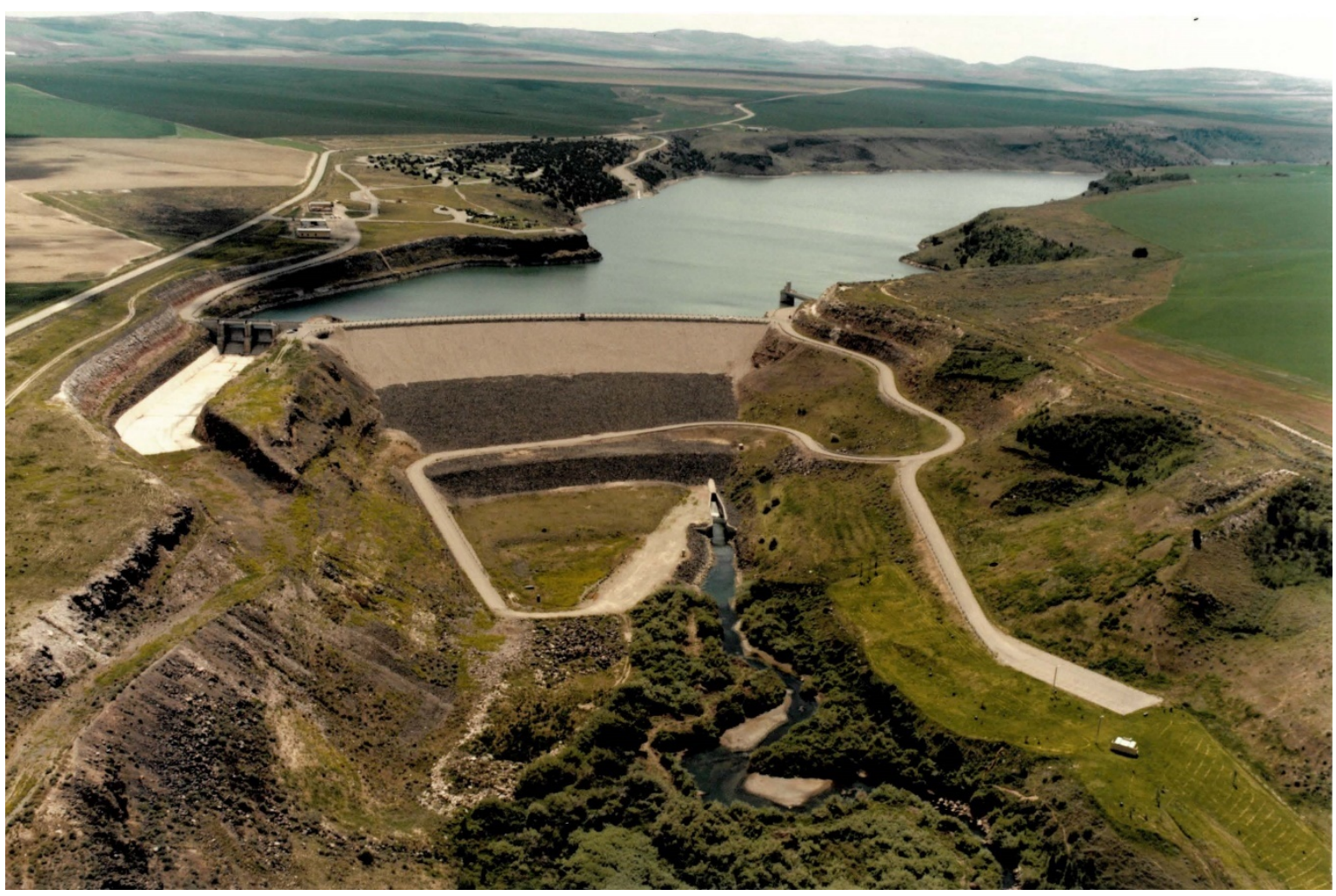


The U.S. Army Engineer Research and Development Center (ERDC) solves the nation's toughest engineering and environmental challenges. ERDC develops innovative solutions in civil and military engineering, geospatial sciences, water resources, and environmental sciences for the Army, the Department of Defense, civilian agencies, and our nation's public good. Find out more at www.erdc.usace.army.mil.

To search for other technical reports published by ERDC, visit the ERDC online library at https://erdclibrary.on.worldcat.org/discovery. 


\section{Wintertime Snow and Precipitation Conditions in the Willow Creek Watershed above Ririe Dam, Idaho}

Jeremy Giovando, Chandler Engel, Steven F. Daly, and Daniel Hamill

U.S. Army Engineer Research and Development Center (ERDC)

Cold Regions Research and Engineering Laboratory (CRREL)

72 Lyme Road

Hanover, NH 03755-1290

Michael Warner

U.S. Army Corps of Engineers-Seattle District

4735 E Marginal Way S Bldg 1202

Seattle, WA 98134

Evan Heisman

U.S. Army Corps of Engineers - Walla Walla District

201 North 3rd Avenue

Walla Walla, WA 99632

Final Report

Approved for public release; distribution is unlimited.

Prepared for U.S. Army Corps of Engineers-Walla Walla District 201 North 3rd Ave.

Walla Walla, WA 99362-1876

Under AMSCO 478350, funding account G4116713 


\section{Abstract}

The Ririe Dam and Reservoir project is located on Willow Creek near Idaho Falls, Idaho, and is important for flood risk reduction and water supply. The current operating criteria is based on fully storing a large winter runoff event. These winter runoff events are generally from large storm events, termed atmospheric rivers, which produce substantial precipitation. In addition to the precipitation, enhanced runoff is produced due to frozen soil and snowmelt. However, the need for additional water supply by local stakeholders has prompted the U.S. Army Corps of Engineers to seek to better understand the current level of flood risk reduction provided by Ririe Dam and Reservoir.

Flood risk analysis using hydrologic modeling software requires quantification of the probability for all of the hydrometeorologic inputs. Our study develops the precipitation, SWE, and frozen ground probabilities that are required for the hydrologic modeling necessary to quantify the current winter flood risk.

DISCLAIMER: The contents of this report are not to be used for advertising, publication, or promotional purposes. Citation of trade names does not constitute an official endorsement or approval of the use of such commercial products. All product names and trademarks cited are the property of their respective owners. The findings of this report are not to be construed as an official Department of the Army position unless so designated by other authorized documents. 


\section{Contents}

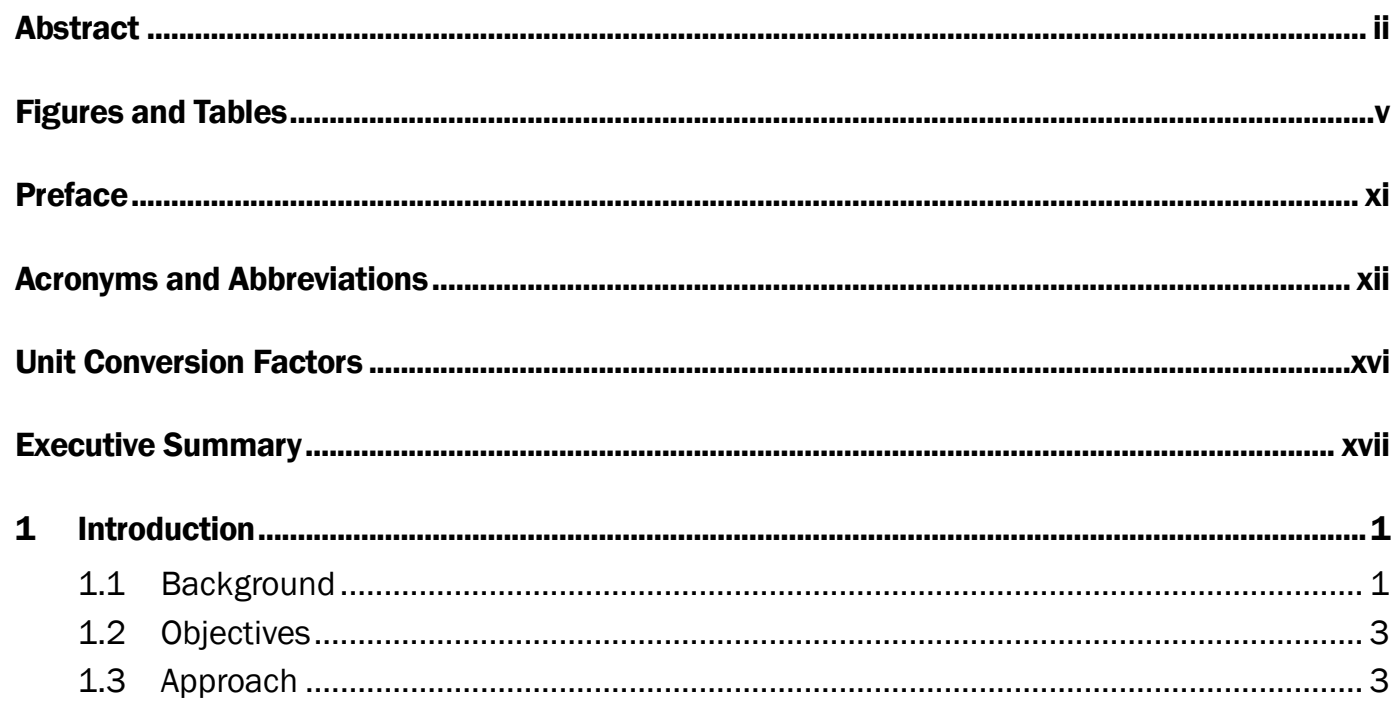

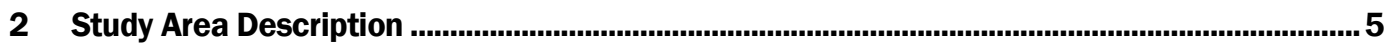

2.1 Ririe Dam summary ...................................................................................... 5

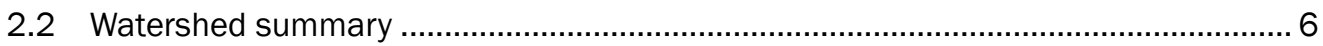

2.3 Climate summary ............................................................................................. 10

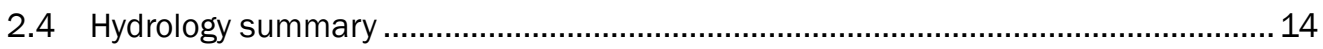

3 Precipitation Conditions for the Willow Creek Basin .............................................................19

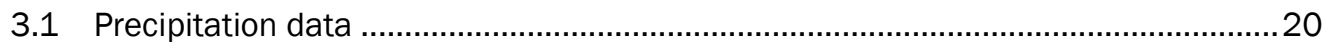

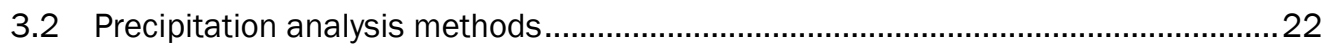

3.2.1 Statistical methods for regional frequency analysis...................................................22

3.2.2 Regional frequency analysis using ground-based stations..........................................24

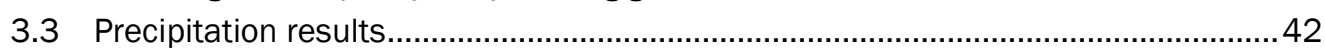

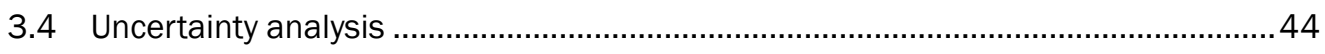

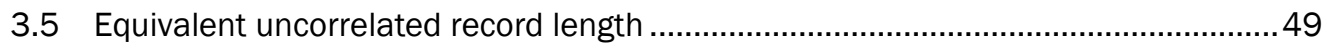

3.6 Final Willow Creek Basin precipitation quantiles......................................................51

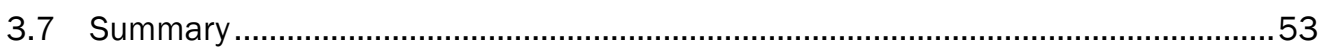

4 Snow Conditions for the Willow Creek Basin .......................................................................54

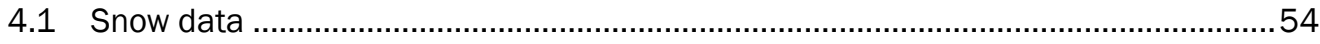

4.1.1 Ground-based observations of snow depth and SWE ..................................................54

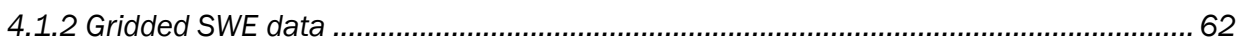

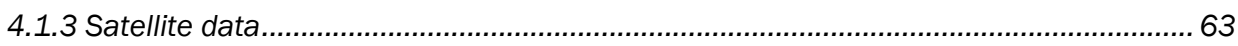

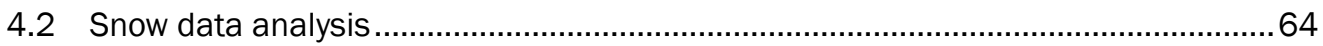

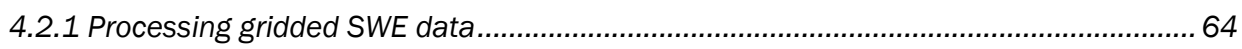

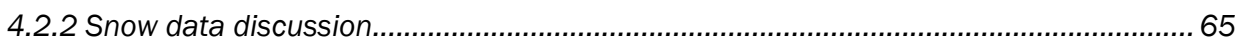

4.3 Estimating SWE exceedance probabilities ....................................................... 71

4.4 Probable maximum snow accumulation ....................................................... 78

5 Frozen Ground.......................................................................................................................81 


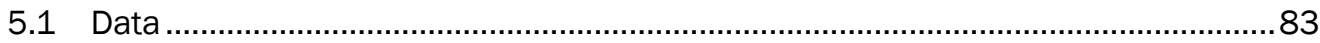

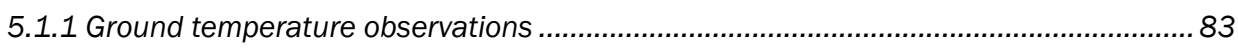

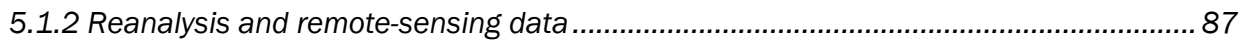

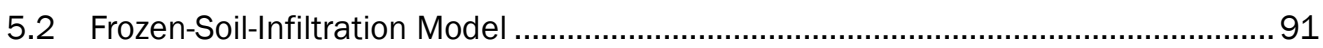

5.2.1 Description of watershed soil properties ................................................................ 92

5.2.2 Estimating Ground Temperature / Ground Freezing.................................................. 98

5.2.3 Estimating Soil Moisture ...................................................................................... 105

5.2.4 Application of FSIM-SMM and FSIM-GTM to the Willow Creek Watershed ...................109

5.2.5 Modeling Frozen Ground Infiltration.......................................................................112

5.3 Application of the FSIM model to Willow Creek Watershed .................................122

5.3.1 FSIM results for Willow Creek Watershed ................................................................. 124

5.4 Frozen ground summary............................................................................. 126

6 Large-Precipitation-Event Characterization ..........................................................................128

6.1 Large-precipitation-event data ...................................................................130

6.2 Large-precipitation-event results ................................................................132

6.3 Large-precipitation-event summary ..........................................................140

7 Summary

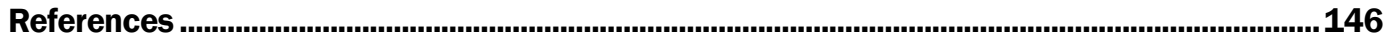

Appendix A: Willow Creek (Ririe Dam and Reservoir) Regional Frequency Analysis............... 158

Appendix B: Geographic Projection Metadata ...........................................................................188

Appendix C: SWE Quantiles ........................................................................................................189

Appendix D: Infiltration-Reduction Probabilities .................................................................193

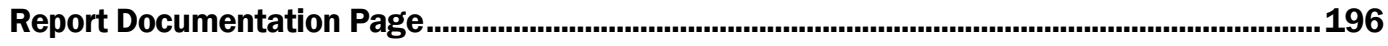




\section{Figures and Tables}

\section{Figures}

1 Ririe Dam located approximately 16 miles northeast of Idaho Falls, Idaho ........................ 5

2 Ririe HEC-HMS model subbasin delineation.................................................................... 7

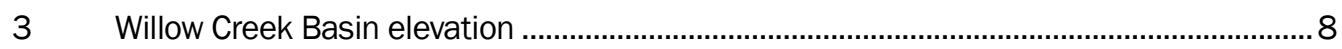

$4 \quad$ Willow Creek Subbasins hypsometric distribution. (NAVD 88 is the North American Vertical Datum of 1988.) .............................................................................

$5 \quad$ NLCD 2016 land cover distribution for Willow Creek ...................................................

6 Percent of Willow Creek area by NLCD classification.......................................................10

$7 \quad$ Location of the Idaho Falls 16 SE GHCN station ..........................................................11

8 Idaho Falls 16 SE daily temperature summary (1956-2018) ........................................11

$9 \quad$ Idaho Falls 16 SE annual total precipitation (1956-2018)............................................12

10 Idaho Falls 16 SE monthly total precipitation summary (1956-2018) ..........................13

11 Idaho Falls Fanning Field wind direction and frequency (1998-2019)...........................13

12 Idaho Falls Fanning Field relative humidity daily summary (1973-2019) ......................14

13 Willow Creek flow measurement locations .......................................................................15

14 Summary hydrograph for Willow Creek below Tex Creek (USGS 13057940) and Ririe Reservoir inflow ............................................................................15

15 Percentage of flows estimated for Willow Creek below Tex Creek streamgage by date ..............................................................................................................16

16 Willow Creek winter daily peak-flow comparison between the USGS gage and Ririe Reservoir inflow .................................................................................................17

17 Ground-based precipitation stations initially considered for the Willow

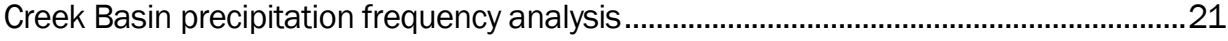

18 Daily precipitation data available by station................................................................21

19 Results from k-means clustering of ground-based climate stations near the Willow Creek Basin.......................................................................................................30

20 Stations removed after discordant analysis (shown with red stars) ................................30

21 Lag-1 serial correlation plot for annual winter maximum precipitation shown with the 5\% and 95\% confidence interval $(\mathrm{Cl})$.......................................................32

22 Station cross-correlation for 24-hour total precipitation....................................................33

23 Station cross-correlation for 48-hour total precipitation ...................................................33

24 Station cross-correlation for 72 -hour total precipitation .................................................33

25 Station cross-correlation for 96-hour total precipitation ...................................................34

26 The final stations included in each region.....................................................................35

27 The L-moment relationship for Regions 1 and 2 by event duration .................................36

28 The regional precipitation growth curve..........................................................................

29 Areal reduction factors for basin areas up to 700 square miles using the annual-maxima centered approach for a 72-hour duration ...............................................38

30 Spatial interpolation results using kriging for the precipitation analysis domain .............39 
31 The hourly to daily relationship for 24-hour annual maximums.......................................4

32 Willow Creek Basin winter precipitation AEP with 24-hour, 48-hour, $72-$ hour, and 96-hour durations using 2-year ARF values

33 The regional growth curve with confidence bounds for a 24-hour duration.....................45

34 The regional growth curve with confidence bounds for a 48-hour duration......................45

35 The regional growth curve with confidence bounds for a 72-hour duration......................46

36 The regional growth curve with confidence bounds for a 96-hour duration......................46

37 Spatially distributed $5 \%$ and $95 \%$ confidence bounds for the (a) $5 \%$ AEP, (b) $2 \%$ AEP, (c) $1 \%$ AEP, and (d) $0.5 \%$ AEP precipitation depths.

38 A comparison of the 2-year and 10-year ARF values for the Willow Creek Basin 24-hour quantiles.

39 A comparison of the 2-year and 10-year ARF values for the Willow Creek Basin 48-hour quantiles with confidence bounds

40 A comparison of the 2-year and 10-year ARF values for the Willow Creek Basin 72-hour quantiles with confidence bounds

41 A comparison of the 2-year and 10-year ARF values for the Willow Creek Basin 96-hour quantiles with confidence bounds

42 The independent record length for Region 1 48-hour duration. (RGF is the regional growth factor.)

43 The independent record length for Region 196-hour duration.

44 Cumulative probability for 72-hour GEV fitted using zonally averaged quantiles for the Willow Creek Basin.

45 Locations of SNOTEL, COOP, and WBAN stations ……....................................................54

46 Sheep Mountain SNOTEL SWE observations ...................................................................56

$47 \quad$ Somsen Ranch SNOTEL SWE observations .................................................................56

48 Elevation and average annual maximum SWE for the SNOTEL stations ..........................57

49 Observed snow depth at COOP and WBAN stations.....................................................58

50 Calculated and observed snow density at the Sheep Mountain SNOTEL station ...........60

51 Calculated SWE at COOP and WBAN stations ............................................................61

52 Average annual maximum SWE and elevation for the COOP and WBAN stations and the SNOTEL stations .......................................................................................62

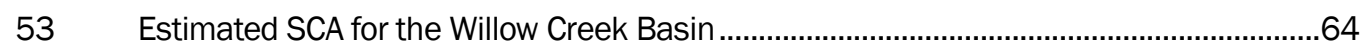

54 UA and SNODAS SWE volume of the Willow Creek Basin ...............................................65

55 Satellite images of areas surrounding Sheep Mountain and Somsen Ranch SNOTEL sites showing tree islands.

56 Snow duration and timing of SWE annual maximum at SNOTEL and COOP stations. Circles represent the annual maximum for each station

57 Average snow duration (days) by elevation and fraction based on CGF-SCA. The bottom circle for each station is the average number of days of continuous snow, and the top circle for each station is the average number of days with reported snow

58 Comparison of average annual maximum SWE for the SNOTEL and COOP sites compared to the spatially averaged UA SWE for each of the subbasins, and the average annual PRISM precipitation sum for the months of December through March for each of the subbasins. 
59 AEP of the annual maximum SWE for the Willow Creek Basin..........................................72

60 AEP of the annual maximum SWE for the Ririe Subbasin.............................................73

61 AEP of the annual maximum SWE for the Ririe Upstream Subbasin ...............................73

62 AEP of the annual maximum SWE for the Grays Lake Subbasin ......................................74

63 AEP of the annual maximum SWE for the Willow Creek Basin for November ...................75

64 AEP of the annual maximum SWE for the Willow Creek Basin for December...................75

65 AEP of the annual maximum SWE for the Willow Creek Basin for January .......................76

66 AEP of the annual maximum SWE for the Willow Creek Basin for February .....................76

67 AEP of the annual maximum SWE for the Willow Creek Basin for March..........................77

68 AEP of the annual maximum SWE for the Willow Creek Basin..........................................77

69 PMSA as a function of the accumulation time step for 12-day average storm interval..............................................................................................................

70 Locations of AgriMet, USCRN, and SNOTEL stations ...................................................83

71 Ashton AgriMet station durations and timing of mean daily soil temperatures below $32^{\circ} \mathrm{F}$

72 Ririe AgriMet station durations and timing of mean daily soil temperatures below $32^{\circ} \mathrm{F}$

73 Sheep Mountain SNOTEL durations and timing of mean daily soil temperatures below $32^{\circ} \mathrm{F}$

$74 \quad$ MERRA-2 pixels for the Willow Creek Basin ....................................................................8

75 MERRA-2 soil temperature: TSOIL1 layer representing the top $10 \mathrm{~cm}$ of the soil column averaged over the Willow Creek Watershed.

76 Time series of SMAP Level 3 Radiometer Global Daily 9 km EASE-Grid enhanced passive soil moisture product (L3_SM_P_E)

78 USDA soil texture ratings for Willow Creek Watershed ......................................................94

79 USDA-NRCS hydrologic soil group ratings for Willow Creek Watershed ............................96

80 Infiltration rates based on soil texture and hydrologic soil group (reprinted from Feldman 2000).

81 Field capacity and permanent wilting point in Willow Creek Watershed............................97

82 Example of CRREL's FSIM-GTM compared to MERRA-2 $10 \mathrm{~cm}$ layer soil temperature during a cold winter with moderate snow cover

83 Example of CRREL's FSIM-GTM compared to MERRA-2 $10 \mathrm{~cm}$ layer soil temperature during a cold winter with higher snow cover

84 FSIM-GTM and SMM model results for winter of WY 2017 108

85 FSIM-SMM soil moisture compared with SMAP (L3_SM_P_E) averaged over Ririe Upstream Subbasin of Willow Creek Watershed. Percentage volumes equal 100 times the volumetric water content $\left(\mathrm{m}^{3} \mathrm{~m}^{-3}\right)$... 109

86 November soil moistures by year from FSIM-SMM

87 Example of monthly average soil moisture estimates from FSIM-SMM for WYs 1961-1970

88 Soil moisture and ground temperature conditions from FSIM-GTM and SMM during WY 1962, which saw a significant winter runoff event in early February. 
89 Diagram of the HEC-HMS model of the Willow Creek Watershed

90 Runoff hydrograph at the Ririe Dam site. The solid blue line is the combined inflow from Ririe Local and Ririe Upstream. The solid black line is the daily averaged estimated hydrograph from USACE-NWW

91 Breakdown of direct precipitation and snow melt contributions to liquid water at the soil surface (LWASS) for the Ririe Upstream Subbasin during the February 1962 event.

92 Partitioning of the LWASS into runoff and infiltration losses during the February 1962 event.

93 Frequency of average monthly infiltration capacity reduction factors........................... 123

94 Percent exceedance plot for infiltration capacity reduction factors................................ 125

95 Top 50 3-day precipitation events at Idaho Falls 16 SE by month (left) and decade (right)

96 Integrated water vapor $\left(\mathrm{kg} / \mathrm{m}^{2}\right)$ for the top four dates for 72-hour precipitation at Idaho Falls 16 SE using the NCAR/NCEP Reanalysis tool.

97 Integrated water-vapor $\left(\mathrm{kg} / \mathrm{m}^{2}\right)$ composite of the top 46 dates in 3-day precipitation at Idaho Falls 16 SE using the NCAR/NCEP Reanalysis tool...

98 Integrated water-vapor (kg/m²) anomaly composite (1981-2010 climatology) of the top 46 dates in 3-day precipitation at Idaho Falls $16 \mathrm{SE}$ using the NCAR/NCEP Reanalysis tool

99 A $700 \mathrm{hPa}$ geopotential height $(\mathrm{m})$ composite of the top 46 dates in 3-day precipitation at Idaho Falls 16 SE using the NCAR/NCEP Reanalysis tool.

100 A $700 \mathrm{hPa}$ vector wind and wind speed (m/s) composite of the top 46 dates in 3-day precipitation at Idaho Falls 16 SE using the NCAR/NCEP Reanalysis tool

101 Vector wind and IVT $\left(\mathrm{kg} \mathrm{m}^{-1} \mathrm{~s}^{-1}\right)$ composite of the top 34 available dates in 3-day precipitation at Idaho Falls 16 SE during 1979-2017 using the NCAR/NCEP Reanalysis tool

102 An $850 \mathrm{hPa}$ temperature $\left({ }^{\circ} \mathrm{C}\right)$ anomaly composite (1981-2010

climatology) of the top 46 dates in 3-day precipitation at Idaho Falls $16 \mathrm{SE}$ using the NCAR/NCEP Reanalysis tool

103 Observed maximum (red) and minimum (blue) temperature evolution (left) for \pm 5 days surrounding the center day of 3-day precipitation for the top 50 events at Idaho Falls 16 SE, and maximum (red) and minimum (blue) temperature evolution boxplots (right) for \pm 5 days surrounding the center day of 72-hour precipitation for the top 50 events at Idaho Falls 16 SE

\section{Tables}

$1 \quad$ Willow Creek Subbasin area summary ................................................................................ 7

$2 \quad$ Willow Creek Subbasin elevation summary (elevation based on NAVD 88) ....................9

3 Winter flood events identified from the Reclamation unregulated inflow (WY 1982-2018) ........................................................................................................... 17

$4 \quad$ Ririe Dam and Reservoir design floods (USACE 1966) ....................................................18

$5 \quad$ Data quality-control tests and threshold levels..............................................................26

6 Ground-based station clustering results. Highlighted stations were removed as a result of the data quality-control process 


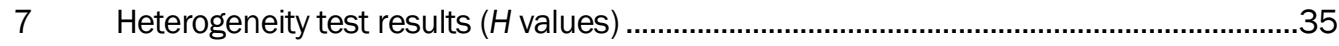

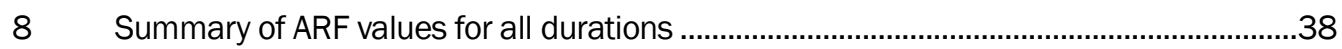

9 The stations used to develop the hourly to daily annual maximum timeseries relationships.......................................................................................................... 40

$10 \quad$ Hourly to daily factors applied to L-mean values .......................................................... 41

11 Summary of computed winter AEP quantiles for the Willow Creek Basin (precipitation depths)

12 The summary of equivalent independent record length for regional frequency analysis for the Willow Creek Basin .

13 GEV distribution parameters for zonally averaged precipitation quantiles. Final values are based on a nonlinear solver fit to precipitation totals for the Willow Creek Basin...................................................................................................52

14 SNOTEL stations in eastern Idaho and western Wyoming ..............................................55

15 SNOTEL Annual Maximum SWE Data (inches) ……..................................................56

16 COOP and WBAN stations used in the snow analysis...................................................58

17 COOP and WBAN annual maximum SWE data (inches) .....................................................61

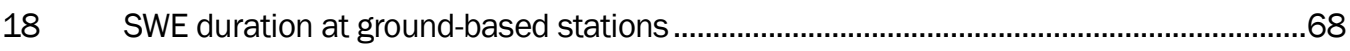

19 SWE depths (inches) for specific return periods for the Willow Creek Basin and subbasins .....................................................................................................

20 SWE depths (inches) for specific annual exceedance probabilities by month ..................74

21 PMSA, 0.2\% AEP, and 1\% AEP comparison for the Willow Creek Basin and subbasins (inches) .........................................................................................................80

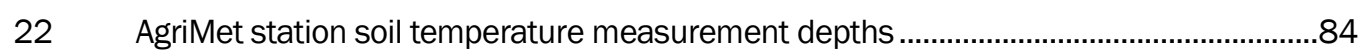

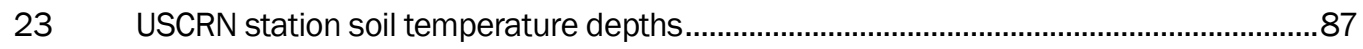

24 Summary statistics of MERRA-2 winter ground temperatures $(10 \mathrm{~cm}$ surface layer) ............................................................................................................... 88

25 USDA surface soil texture rating of Willow Creek Watershed ..........................................93

26 USDA-NRCS hydrologic soils group ratings for the Willow Creek Basin .............................96

$27 \quad$ Water content parameters for Willow Creek Watershed ..................................................98

28 Ririe AgriMet 2 in. ground temperatures compared with MERRA-2 TSOIL1 soil temperatures between November 2017 and December 2019 .............................. 101

29 Calibrated parameters for the FSIM-GTM................................................................ 102

30 Performance of potentially frozen ground classification based on FSIMGTM soil temperatures compared with MERRA-2 soil temperatures between 1981 and 2018. A positive result indicates a potentially frozen condition. Model accuracy better than 80\% is highlighted in green ............................ 103

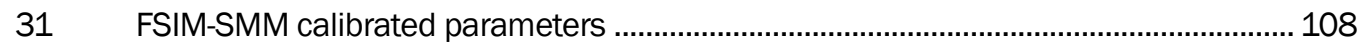

32 FSIM-SMM model error statistics. Bold numbers are the error statistics reported as soil volumetric water content

33 Average soil moisture (volumetric water content \%) for WYs 1961 to 2018 estimated by FSIM-SMM. Soil moisture averages equal to or greater than $20 \%$ are highlighted in red..

34 Basin methods used for HEC-HMS model calibration .................................................117

35 Meteorological model for the February 1962 calibration .............................................117 
36 Basin parameters used to calibrate the infiltration rate during the

February 1962 flood event............................................................................................ 119

$37 \quad$ Calibrated infiltration rates for modeled events .......................................................... 121

38 Infiltration capacity reduction factors for large winter flow events................................. 123

39 Summary statistics of the infiltration capacity reduction factor...................................... 124

40 Infiltration capacity reduction factor probabilities by month ..........................................125

41 Top 50 dates for 72 -hour precipitation totals (inches) at Idaho Falls SE 16 weather station in winter months (October-March). The date identified is Day 2 of the 72-hour period. The offset is given as the date used in the spatial composites. Dates noted by an asterisk are identified as non-AR days and are excluded from spatial composites. 


\section{Preface}

This study was conducted for the U.S. Army Corps of Engineers (USACE)Walla Walla District under AMSCO 478350, funding account G4116713.

The work was performed by the Terrain and Ice Engineering Group (Ms. Meghan Quinn, lead) of the Remote Sensing/GIS Center of Expertise (Mr. David Finnegan, Chief), U.S. Army Engineer Research and Development Center, Cold Regions Research and Engineering Laboratory, and the USACE Seattle and Walla Walla Districts. At the time of publication, the Deputy Director of ERDC-CRREL was Mr. David B. Ringelberg, and the Director was Dr. Joseph L. Corriveau.

COL Teresa A. Schlosser was Commander of ERDC, and Dr. David W. Pittman was the Director. 


\section{Acronyms and Abbreviations}

AEP

AgriMet

API

AR

$\mathrm{ARF}$

ATI

CFG-SCA

CI

COOP

CRREL

DDF

DOY

EASE-Grid

ERDC

EURL

FC

FSCA

FSIM

FSIM-GTM

FSIM-SMM

FSCA

GEOS-5
Annual Exceedance Probability

Agricultural Meteorology

Antecedent Precipitation Index

Atmospheric River

Areal Reduction Factor

Antecedent Temperature Index

Cloud-Gap-Filled Snow-Covered Area

Confidence Interval

Cooperative Observers Program

Cold Regions Research and Engineering Laboratory

Depth-Duration-Frequency

Day of Year

Equal-Area Scalable Earth Grid

U.S. Army Engineer Research and Development Center

Equivalent Uncorrelated Record Length

Field Capacity

Fractional Snow-Covered Area

Frozen-Soil-Infiltration Model

FSIM Ground Temperature Model

FSIM Soil Moisture Model

Fractional Snow-Covered Area

Goddard Earth Observing System Model, Version 5 


\begin{tabular}{|c|c|}
\hline GEV & Generalized Extreme Value \\
\hline GHCN & Global Historical Climatology Network \\
\hline GIS & Geographic Information System \\
\hline HEC-HMS & Hydrologic Engineering Center-Hydrology Modeling System \\
\hline HEC-SSP & Hydrologic Engineering Center-Statistical Software Package \\
\hline HEC-WAT & Hydrologic Engineering Center-Watershed Analysis Tool \\
\hline HSG & Hydrologic Soils Group \\
\hline ICRF & Infiltration Capacity Reduction Factors \\
\hline IDF & Intensity-Duration-Frequency \\
\hline IVT & Integrated Water-Vapor Transport \\
\hline LOESS & Local Regression \\
\hline LWASS & Liquid Water at the Soil Surface \\
\hline MERRA-2 & $\begin{array}{l}\text { Modern-Era Retrospective Analysis for Research and } \\
\text { Applications, Version } 2\end{array}$ \\
\hline MODIS & Moderate Resolution Imaging Spectroradiometer \\
\hline NARR & North American Regional Reanalysis \\
\hline NASA & National Aeronautics and Space Administration \\
\hline NAVD88 & North American Vertical Datum of 1988 \\
\hline NCAR & National Center for Atmospheric Research \\
\hline NCEI & National Centers for Environmental Information \\
\hline NCEP & National Centers for Environmental Prediction \\
\hline NDSI & Normalized Difference Snow Index \\
\hline NLCD & National Land Cover Database \\
\hline NOAA & National Oceanic and Atmospheric Administration \\
\hline
\end{tabular}




\begin{tabular}{|c|c|}
\hline NOHRSC & National Operational Hydrologic Remote Sensing Center \\
\hline NRCS & Natural Resources Conservation Service \\
\hline NSIDC & National Snow and Ice Data Center \\
\hline PMP & Probable Maximum Precipitation \\
\hline PMSA & Probable Maximum Snow Accumulation \\
\hline PRISM & $\begin{array}{l}\text { Parameter-Elevation Regressions on Independent } \\
\text { Slopes Model }\end{array}$ \\
\hline PSL & Physical Sciences Laboratory \\
\hline PWP & Permanent Wilting Point \\
\hline PX & Temperature Threshold between Rain and Snow \\
\hline RGF & Regional Growth Factor \\
\hline RMSE & Root-Mean-Square Error \\
\hline SCA & Snow-Covered Area \\
\hline SMAP & Soil Moisture Active Passive \\
\hline SNODAS & Snow Data Assimilation System \\
\hline SNOTEL & Snow Telemetry Station \\
\hline SSE & Sum of Squares Error \\
\hline $\mathrm{SSM} / \mathrm{I}$ & Special Sensor Microwave/Imager \\
\hline SSURGO & Soil Survey Geographic Database \\
\hline SWE & Snow Water Equivalent \\
\hline UA & University of Arizona \\
\hline USACE & U.S. Army Corps of Engineers \\
\hline USACE-NWW & USACE Walla Walla District \\
\hline USCRN & U.S. Climate Reference Network \\
\hline
\end{tabular}




$\begin{array}{ll}\text { USDA } & \text { U.S. Department of Agriculture } \\ \text { USGS } & \text { U.S. Geological Survey } \\ \text { VWC } & \text { Volumetric Water Content } \\ \text { WBAN } & \text { Weather Bureau Army Navy } \\ \text { WMO } & \text { World Meteorological Organization } \\ \text { WY } & \text { Water Year } \\ \text { Wx Obs } & \text { Weather Observations }\end{array}$




\section{Unit Conversion Factors}

\begin{tabular}{|l|l|l|}
\hline Multiply & By & To Obtain \\
\hline acres & $4,046.873$ & square meters \\
\hline acre-feet & $1,233.5$ & cubic meters \\
\hline bars & 100 & kilopascals \\
\hline cubic feet & 0.02831685 & cubic meters \\
\hline degrees (angle) & 0.01745329 & radians \\
\hline degrees Fahrenheit & $(\mathrm{F}-32) / 1.8$ & degrees Celsius \\
\hline feet & 0.3048 & meters \\
\hline inches & 0.0254 & meters \\
\hline miles (U.S. statute) & $1,609.347$ & meters \\
\hline miles per hour & 0.44704 & meters per second \\
\hline square miles & $2.589998 \mathrm{E}+06$ & square meters \\
\hline
\end{tabular}




\section{Executive Summary}

Ririe Dam and Reservoir in eastern Idaho is an important project for both flood risk management and water supply in the Upper Snake River Basin. The project was designed and constructed following the 1962 flood event that devastated communities in eastern Idaho and northern Nevada. The current reservoir operating criteria requires a fixed volume of reservoir storage going into the winter to reduce the chances of winter floods. However, the fixed storage requirement limits the flexibility for water managers to balance flood risk management and refill for water supply. Within this context, our study objectives are to provide input data necessary to perform hydrologic model simulations within a Monte Carlo framework for the U.S. Army Corps of Engineers-Walla Walla District (USACENWW). These inputs include zonally averaged precipitation and snow water equivalent (SWE) quantiles for a range of probabilities, estimates of flow enhancement probability due to frozen soils, and a description of the overall meteorological conditions that result in large winter precipitation events for Willow Creek.

We performed the precipitation frequency analysis using a regional frequency framework and ground-based stations. The zonally averaged values were derived using subbasin boundaries concurrent with the hydrologic model that will be used within the Monte Carlo framework. We estimated the precipitation quantiles using the generalized extreme value (GEV) distribution, which we found to be the best overall fit for the ground-based datasets. The quantile estimates were then reduced using an areal reduction factor that accounts for spatial heterogeneity within storm events. The zonally averaged data compare well with the values the National Oceanic and Atmospheric Administration (NOAA) published for the region.

There are more limited choices for SWE datasets that can be used to represent spatially averaged SWE depths. For our analysis, we selected daily spatially continuous data developed by researchers at the University of Arizona (UA). This dataset has a $4 \mathrm{~km}$ spatial resolution and has values dating back to 1982. Using both the ground-based stations and the Snow Data Assimilation System (SNODAS) product for comparison ensured that the UA dataset reasonably represented snowpack conditions within the Willow Creek Basin. The SWE quantile estimates used a lognormal distribution. The resulting quantile comparisons between UA and SNODAS 
were very similar for low- and midelevation subbasins upstream of Ririe Reservoir, especially at the lower annual exceedance probabilities. For the highest elevation subbasin in the watershed, there was some deviation between the SNODAS and UA quantiles, which was likely due to the process SNODAS uses to estimate SWE over open water. We also used the Probable Maximum Snow Accumulation (PMSA) method to develop the maximum SWE depth reasonably possible for each of the study subbasins. The study's estimation of the maximum SWE depth follows the World Meteorological Organization (WMO) process outlined in 1966. We do not suggest that the PMSA be used within the Monte Carlo framework; however, a comparison of PMSA and to the lognormal quantiles show the PMSA values are much greater than even the 500-year SWE depth for all subbasins.

The frozen soil limiting infiltration of snowmelt and precipitation was one of the potential causes of the 1962 flood in eastern Idaho. Although reduced infiltration during a precipitation event is qualitatively understood and supported by observational information, the quantification of how much flow enhancement (i.e., the increased streamflow given the same antecedent and precipitation conditions) will occur for specific frozen soil conditions is still a topic of continued research. Because frozen soil is critical for flood generation in the Willow Creek Basin, we developed a FrozenSoil-Infiltration Model to help quantify changes in infiltration capacity depending on the ground temperature and soil moisture. Though this model is based on previous research, the current formulation is novel and, to our knowledge, is the first to be used within a Monte Carlo framework for hydrologic simulations. The model results indicate that infiltration capacity can be reduced up to $70 \%$ in the Willow Creek Basin given specific temperature and precipitation conditions. Based on the model results, the likelihood of flow enhancement due to frozen soil is highest in January through February each year.

Our study also characterized large precipitation events that reach the Willow Creek Basin. In general, most of the large precipitation events in October through March are due to inland penetration of atmospheric rivers (ARs). These AR events form in the Pacific Ocean and usually make landfall on the California coast, moving from southwest to northeast. The peak precipitation intensity in the Willow Creek Basin is usually within 3 days of the storm reaching California. Although AR events are still an active area of research, changes in intensity or frequency of these storms will 
likely impact winter precipitation for areas of eastern Idaho and the Willow Creek Basin.

While we reference USACE software during our development of precipitation, SWE, and estimates of soil-infiltration reduction due to frozen soils, these results can be used in most hydrologic modeling tools that require similar inputs. Further, our results presented here focus on the Willow Creek Basin in eastern Idaho, but the methods can be used in other watersheds provided similar ground-based and gridded datasets are available. Even with climate change occurring, large regions of the U.S. will still experience freezing conditions in the winter months. The ability to better understand and quantify flooding potential due to snow and frozen ground is critical to ensure the safety of communities across the country. 



\section{Introduction}

\subsection{Background}

The Ririe Dam and Reservoir (Ririe) project is located approximately 16 miles northeast of Idaho Falls, Idaho, on Willow Creek and is part of several dams and reservoirs that provide flood risk management and water supply in the Upper Snake River Basin. Balancing flood risk management while meeting water supply demands requires substantial effort from water managers. As both population and the value of water increases in Idaho, there is additional pressure on water managers to maximize both benefits. However, the current winter storage requirement is explicit on the necessary space that must be available in the reservoir during November to March to maintain the current level of flood risk mitigation. This affords water managers limited flexibility to maximize both of these benefits.

One of the challenges is that the current level of flood risk mitigation provided by Ririe Dam is not known (e.g., 100-year level of mitigation). This is a result of the original project design in the 1960s. The current operating criteria, which is based on the 1960 s design information, was developed to capture a theoretical flood event referred to as the standard project flood. The USACE definition of the standard project flood is a runoff hydrograph resulting from the standard projection precipitation event. This precipitation event is "the most severe flood-producing rainfall depth-area-duration relationship and isohyetal pattern of any storm that is considered reasonably characteristic of the region ..." (USACE 1965). Using a standard project flood event for design was not uncommon in that era; however, the current risk-based design used by the U.S. Army Corps of Engineers (USACE) and others relies on flood event probabilities to inform both the design and operating criteria. Therefore, without understanding of the current level of flood risk, any changes in risk from the proposed modifications to the winter operating criteria at Ririe cannot be quantified.

The catalyst for constructing Ririe Dam was the February 1962 flood. This event flooded large areas of eastern Idaho and northeastern Nevada. The U.S. Geological Survey (USGS) provided thorough documentation of this event in a report that was published only a few months following the flood 
(USGS 1962). USGS estimated a peak discharge of over $5000 \mathrm{cfs}^{*}$ in Willow Creek during this event. Subsequently, while designing Ririe Dam, USACE used this information to estimate the winter standard project flood $(14,500$ cfs peak flow and 47,600 acre-ft of volume) and associated reservoir operating criteria for winter flood risk mitigation (USACE 1966). The standard project flood estimate is substantially larger than the 1962 event because additional precipitation and snowmelt were included in the hydrograph development based on maximizing those variables for a winter event.

Stakeholders, water managers, and others interested in Ririe have raised concerns that the hydrology used for the winter standard project flood provided excessive flood risk reduction. This event is considered a rare occurrence even with current streamflow information. More recent studies have attempted to quantify the probability of the 1962 flood event to further demonstrate how the winter standard project flood probability is extremely low for the Willow Creek Basin. These studies have all relied on streamflow information to perform the flow statistical analysis. The $\mathrm{Bu}-$ reau of Reclamation (Reclamation 2010) used both systematic and paleoflood information to estimate the peak-flow probability for Ririe Reservoir. They concluded that the 1962 flood event would have an average return period of over 400 years and that 11,000 cfs peak flow has not been exceeded in the last 7500 to 10,000 years. The USACE Walla Walla District (USACE-NWW) performed a flow frequency study in 2010 using only winter peak-flow events and concluded that the winter standard project flood was between the 200-year to 1000-year return interval (USACE 2010). Even with the results of these studies, establishing a methodology to quantify how flood risk changes with any proposed winter operating change is difficult.

It is within this context that we are performing the current study. The purpose of our study is to develop information that is required by numerical hydrology models for streamflow simulations. The information we have developed consists of precipitation and snow water equivalent (SWE) depths for various return periods, antecedent frozen ground probabilities,

\footnotetext{
* For a full list of the spelled-out forms of the units of measure used in this document, please refer to U.S. Government Publishing Office Style Manual, 31st ed. (Washington, DC: U.S Government Publishing Office, 2016), 248-252, https://www.govinfo.gov/content/pkg/GPO-STYLEMANUAL-2016/pdf/GPOSTYLEMANUAL-2016.pdf.
} 
and air temperature sequences commonly observed with large storm systems that have reached eastern Idaho.

Subsequently, we anticipate that USACE-NWW will use our results for hydrologic simulations within a Monte Carlo framework, which will probabilistically define the winter inflow volume probability with uncertainty bounds. Our results, along with the hydrologic simulations from USACENWW, is Phase I of the overall flood risk quantification for Ririe. Based on results from Phase I, USACE-NWW and their stakeholders will decide whether to proceed with Phase II of the flood risk quantification. Phase II will use hydraulic and economic data to quantify the level of flood risk reduction currently provided by Ririe.

\subsection{Objectives}

The overall objective of our study is to develop probabilistic input data to use in hydrology model simulations within the HEC-WAT (Hydrologic Engineering Center-Watershed Analysis Tool) framework. This study has several specific objectives:

- Produce precipitation frequency estimates for each subbasin and the entire watershed.

- Produce for each subbasin monthly SWE frequency estimates to use as the antecedent snow condition during the winter period.

- Produce monthly probability estimates of frozen ground conditions for the watershed during the winter period.

- Analyze temperature sequences that are associated with large precipitation events (i.e., atmospheric rivers).

- Describe the current storms that impact the watershed and how those relate to the 1962 storm event used for the project design.

\subsection{Approach}

Our study used as much historical data as practically feasible to inform the analysis. This included using ground-based, reanalysis, and remote-sensing data. The concept is that every dataset has uncertainty, and cross referencing results from independent data sources that reach the same conclusions gives more confidence in the results. We used many well-established engineering methods for determining both precipitation and SWE frequency estimates, while at the same time pushing the edge of the current research with development of a novel frozen-soil-infiltration model. We 
characterized these large total precipitation events by summarizing synoptic mechanisms that cause large winter flood events in eastern Idaho. We also thoroughly characterized the types of large precipitation events that have occurred in the Willow Creek Basin. Our approach provides detailed results for the Willow Creek Basin in eastern Idaho. Some of the information we have included in this report extends beyond the Willow Creek Basin boundaries and may be useful for other nearby areas in the region.

We would also like to clarify the choice of units for our study. Typically, studies related to water management or flood risk performed by USACE are reported in imperial units. However, many of the data sources and methods we present natively have metric units. When possible, we report imperial units; but for context and clarity of our descriptions, we include both unit systems, especially when the original data sources are in metric. In certain sections, the methods and parameters we use have been developed with only metric data. In these instances, there is not a direct conversion between unit systems; therefore, only the metric values are reported. For a list of conversions, please refer to the Unit Conversion Factors at the beginning of this report. 


\section{Study Area Description}

\subsection{Ririe Dam summary}

Ririe Dam is located approximately 16 miles northeast of Idaho Falls, Idaho (Figure 1). The dam is $253 \mathrm{ft}$ high with a crest length of $1070 \mathrm{ft}$. It is an embankment structure made of homogenous material with a rockfill shell. It includes a fine-grained impervious core and transition sand filters (USACE-NWW 1978). USACE constructed Ririe Dam between 1970 and 1976 and subsequently transferred it to Reclamation for operations and maintenance responsibilities in October 1976.

Figure 1. Ririe Dam located approximately 16 miles northeast of Idaho Falls, Idaho.

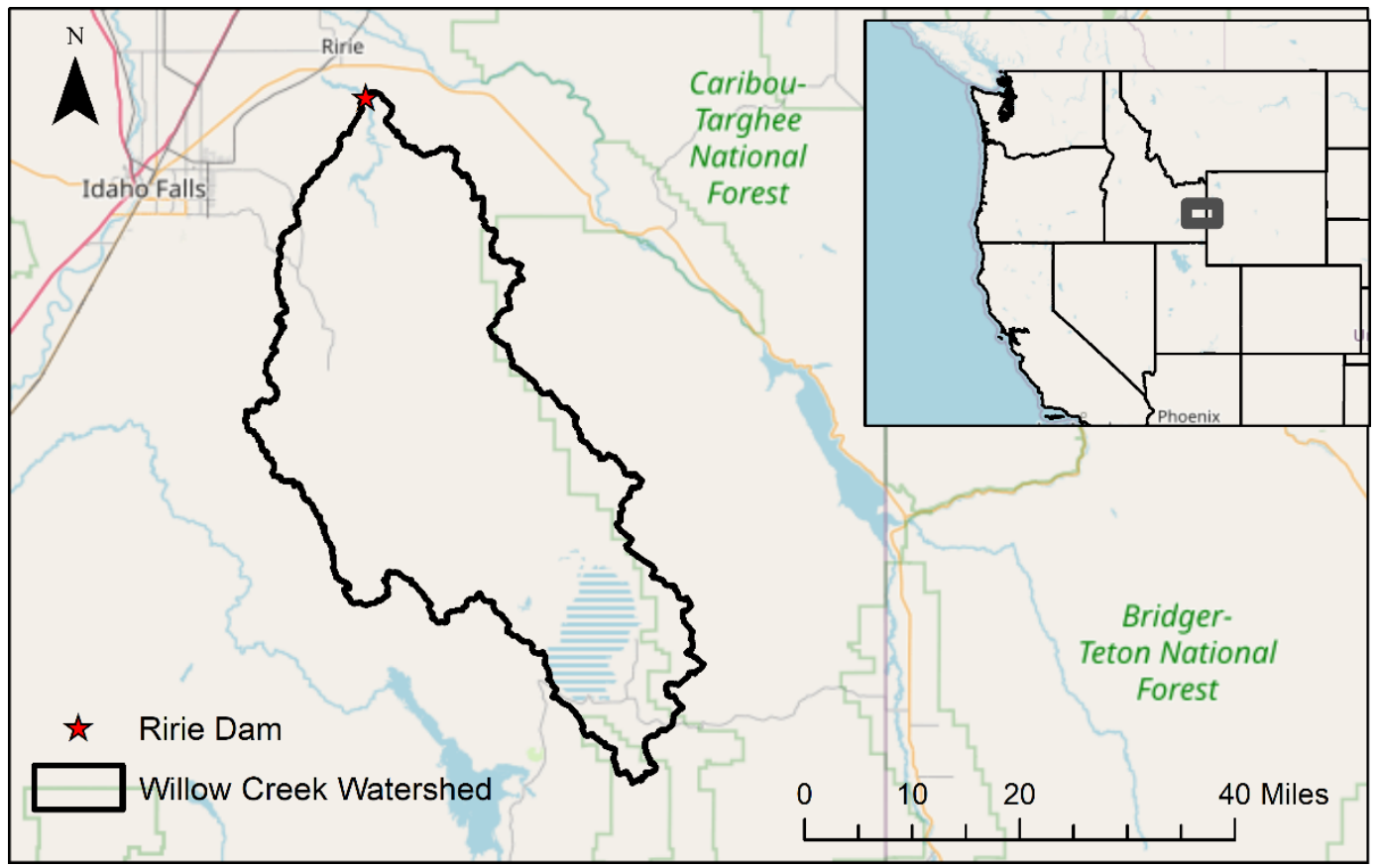

During the spring (1 March-30 June) season, the normal lake operating range elevation is between $5023 \mathrm{ft}$ and $5112.8 \mathrm{ft}$. This range is referred to as Joint Use Space and is governed by a variable rule curve. The space between 5112.8 and $5119 \mathrm{ft}$ is flood space for managing flash floods like the one in 2011. During the winter (1 November-28 February), this space is split into irrigation carryover space $(5023-5082 \mathrm{ft}$ ) with approximately 40,500 acre-ft and winter flood space required for regulating winter rain floods $(5082-5119 \mathrm{ft})$ with 50,000 acre-ft. The maximum water surface the dam was designed for is $5119 \mathrm{ft}$. Water can be released from Ririe Dam through either the outlet works or the gated spillway. The outlet works consists of two 3.75 by $7.0 \mathrm{ft}$ slide valves while the spillway has two $40.5 \mathrm{ft}$ 
wide by $27.32 \mathrm{ft}$ high tainter gates. The total discharge capacities at a maximum pool elevation of $5119 \mathrm{ft}$ are $4250 \mathrm{cfs}$ and 40,000 cfs for the outlet works and spillway, respectively (USACE-NWW 1978). The total reservoir storage at an elevation of $5112.8 \mathrm{ft}$ is approximately 80,500 acre-ft (Reclamation, n.d.).

The purposes of Ririe Dam and Reservoir include flood risk management, water supply, and recreation. The operating criteria provide winter and spring flood risk management followed by refill of the reservoir for water supply purposes. The regulation objective is $1200 \mathrm{cfs}$ discharge out of Ririe Dam in all cases unless there is high inflow and storage space is less than the operating rule curves require. In these instances, discharge may be increased up to $1900 \mathrm{cfs}$. The winter regulation objective, which is the focus of this study, is to have sufficient reservoir storage evacuated by 1 November so that no releases would be required for any flood up to and including the winter standard project flood (47,600 acre-ft). Releases through the outlet works are made during flood events larger than the standard project flood until such time as the reservoir filling rate requires use of the spillway. This determination will be made with joint coordination between Reclamation and USACE. Recently, up to 8000 acre-ft of the winter flood space was made available for irrigation carryover due to greater abilities to forecast storms 10 days out, when certain mitigation actions are taken. This agreement between USACE and Reclamation is made annually and may not occur in every water year.

\subsection{Watershed summary}

The total watershed area above Ririe Dam is approximately 637 square miles. We divided this total area between three subbasins that were coincident with the Hydrologic Engineering Center-Hydrology Modeling System (HEC-HMS) Willow Creek model subbasin delineation used by USACE-NWW (Figure 2). Table 1 summarizes the area of each subbasin in the HEC-HMS model for Willow Creek above Ririe Dam. The largest contributing subbasin is the area between the Grays Lake outlet and the confluence of Tex Creek with Willow Creek, which we term "Ririe Upstream."

Based on survey information taken at the outlet of Grays Lake, USACENWW concluded that the Grays Lake Subbasin would contribute to flows in Willow Creek only during very high runoff events due to the interbasin transfer diversion between the Grays Lake outlet and the Blackfoot River to the south, which removes water from Willow Creek during the majority 
of hydrologic conditions. Previous studies generally reference the watershed size to be approximately 500 square miles of drainage area. This equates to the contributing areas of the Ririe and Ririe Upstream Subbasins. However, since the Grays Lake Subbasin is within the delineated Willow Creek Watershed, results from our analysis include information for this subbasin.

Figure 2. Ririe HEC-HMS model subbasin delineation.

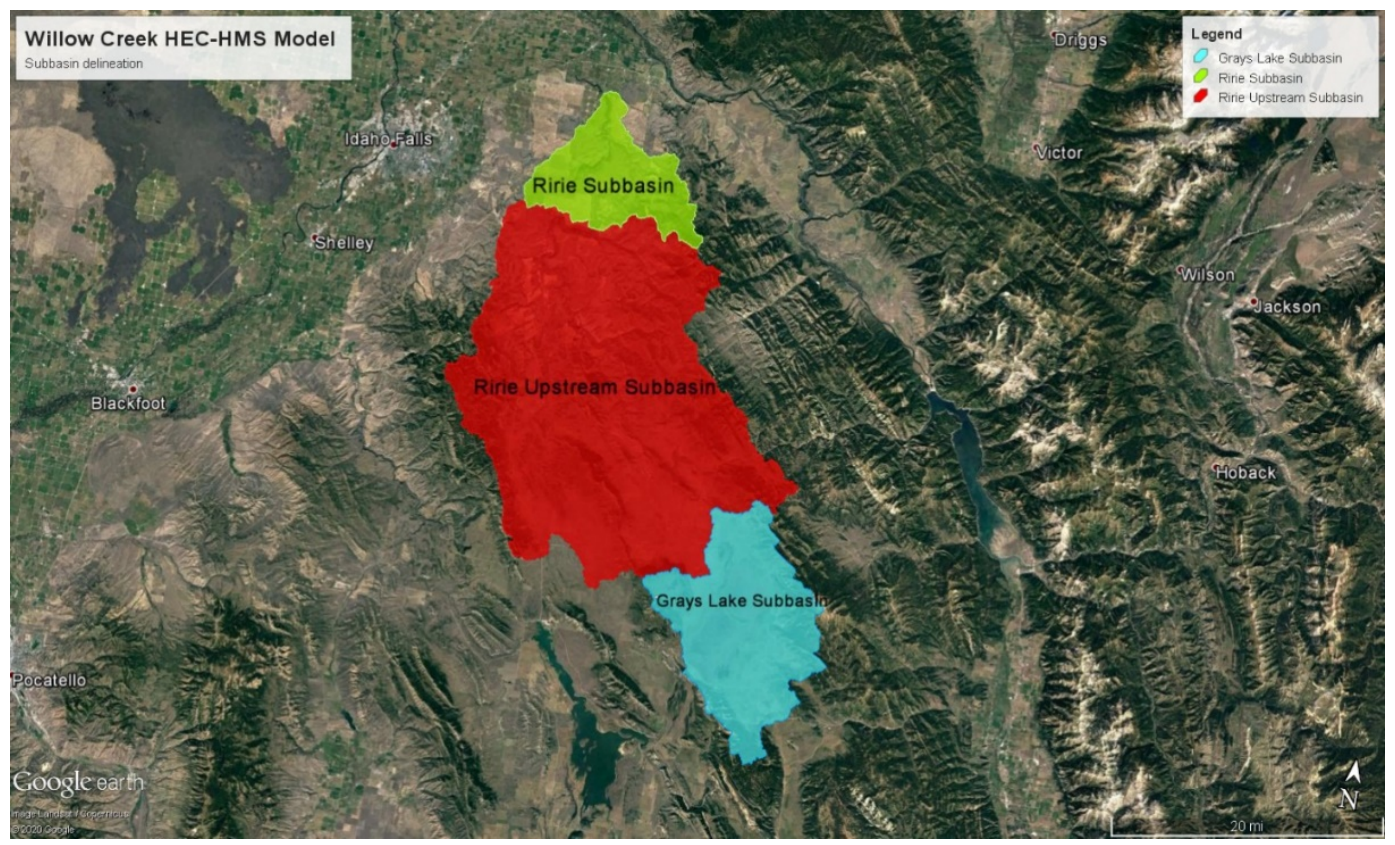

Table 1. Willow Creek Subbasin area summary.

\begin{tabular}{|l|c|c|}
\hline \multirow{2}{*}{\multicolumn{1}{|c|}{ Subbasin }} & \multicolumn{2}{|c|}{ Area } \\
\cline { 2 - 3 } & $\left.\mathbf{( k m}^{2}\right)$ & (square miles) \\
\hline Ririe & 183 & 69 \\
\hline Ririe Upstream & 1124 & 436 \\
\hline Grays Lake & 342 & 132 \\
\hline Total & 1649 & 637 \\
\hline
\end{tabular}

Figures 3 and 4 show the elevation distribution for the entire watershed and the three subbasins. We used the USGS $30 \mathrm{~m}$ digital elevation model to develop the hypsometry for all three subbasins. Figure 4 indicates that Grays Lake has the highest average elevation followed by the Ririe Upstream and Ririe Subbasins. Both of the lower elevation subbasins have a hypsometric distribution with a defined outlet at the lowest elevation (100\% of the subbasin area). However, the Grays Lake distribution is 
unique in that over half of the subbasin is at the same elevation. This is because the Grays Lake Subbasin is largely composed of a high-elevation bulrush marsh. The marsh provided natural storage of precipitation and snowmelt; however, in 1924, an outlet structure was constructed on Grays Lake, which stored additional water and allowed for interbasin diversion of water to the Blackfoot River (U.S. Fish and Wildlife Service 2020). Table 2 summarizes the elevations for each subbasin.

Figure 3. Willow Creek Basin elevation.

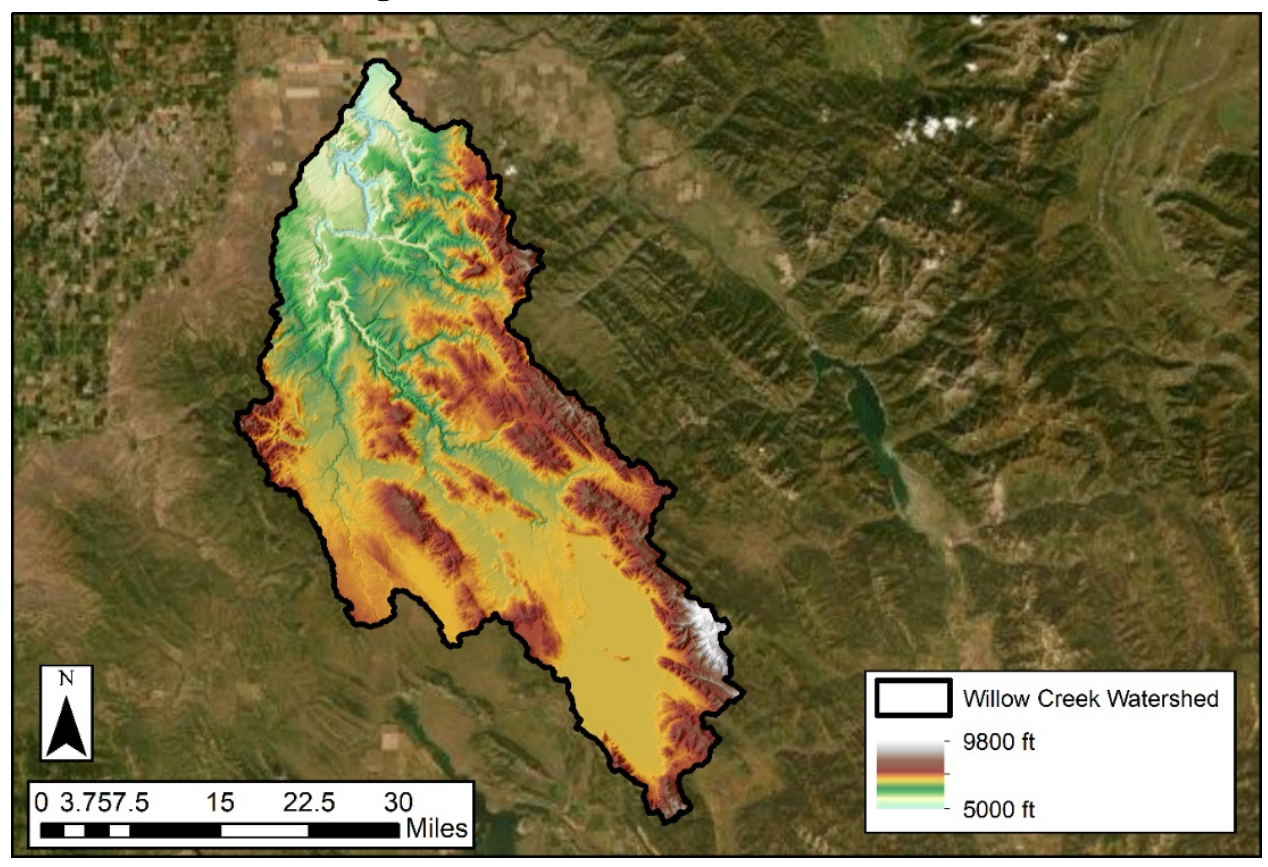

Figure 4. Willow Creek Subbasins hypsometric distribution. (NAVD 88 is the North American Vertical Datum of 1988.)

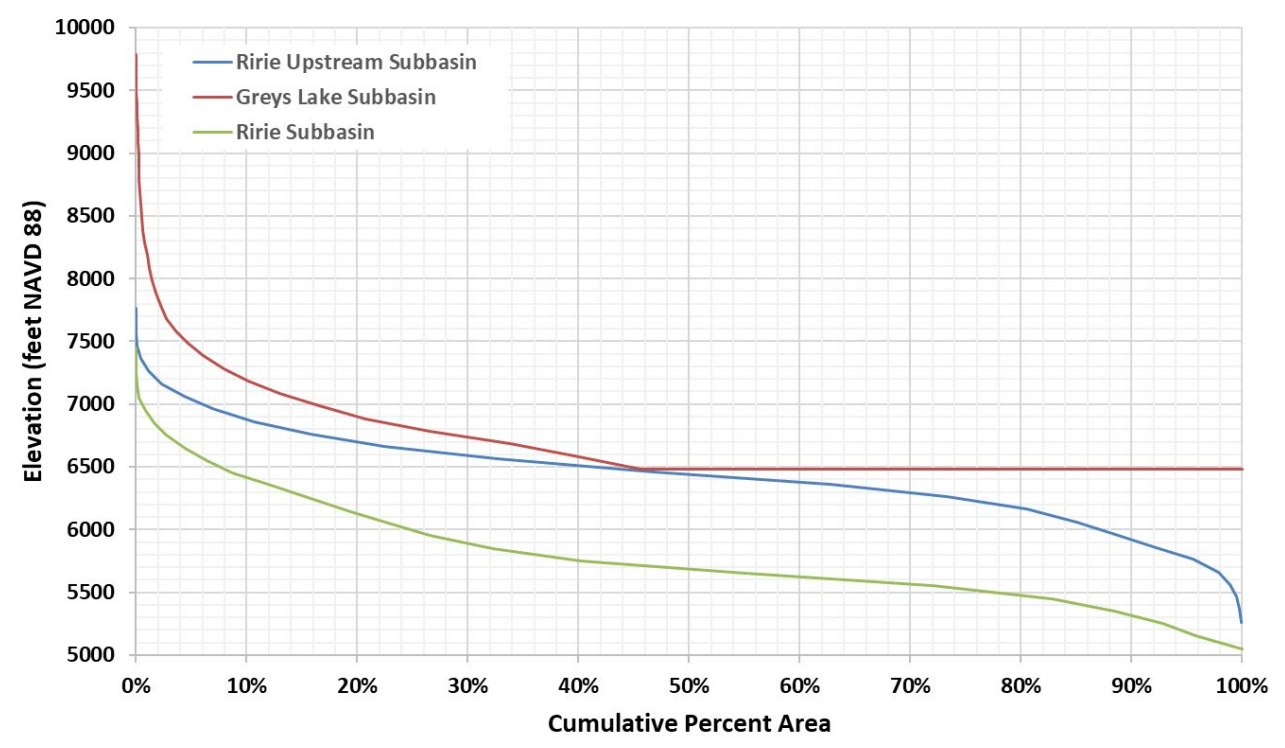


Table 2. Willow Creek Subbasin elevation summary (elevation based on NAVD 88).

\begin{tabular}{|l|c|c|c|}
\hline \multicolumn{1}{|c|}{ Subbasin } & $\begin{array}{c}\text { Mean Elevation } \\
(\mathrm{ft})\end{array}$ & $\begin{array}{c}\text { Minimum Elevation } \\
(\mathrm{ft})\end{array}$ & $\begin{array}{c}\text { Maximum Elevation } \\
(\mathrm{ft})\end{array}$ \\
\hline Ririe & 5780 & 4950 & 7380 \\
\hline Ririe Upstream & 6430 & 5160 & 7700 \\
\hline Grays Lake & 6660 & 6380 & 9790 \\
\hline
\end{tabular}

Based on the National Land Cover Database (NLCD) 2016 classification, the land cover in the Willow Creek Watershed is dominated by shrub or scrub vegetation (Figures 5 and 6) (Yang et al. 2018). The next most common land cover type is evergreen forests followed by emergent wetlands. The wetlands are generally all located in the Grays Lake Subbasin, while the evergreen forest cover is limited to higher elevations. The majority of the cultivated land is located in the Ririe Subbasin, which is the smallest of the three contributing to reservoir inflow. Based on the vegetation type, we expect canopy interception of rain or snow to be very small. Therefore, we do not make any correction for canopy influences on temperature and precipitation in the historical datasets.

Figure 5. NLCD 2016 land cover distribution for Willow Creek.

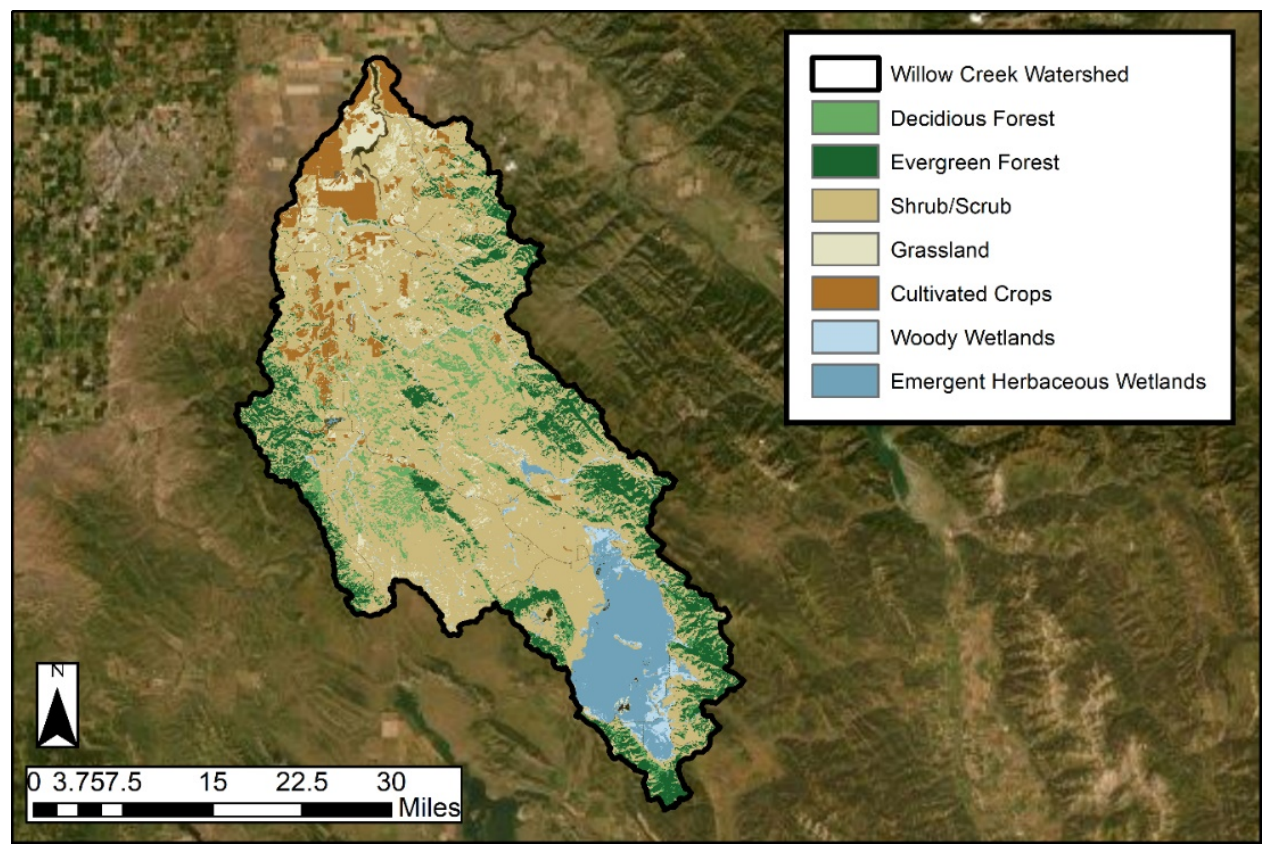


Figure 6. Percent of Willow Creek area by NLCD classification.

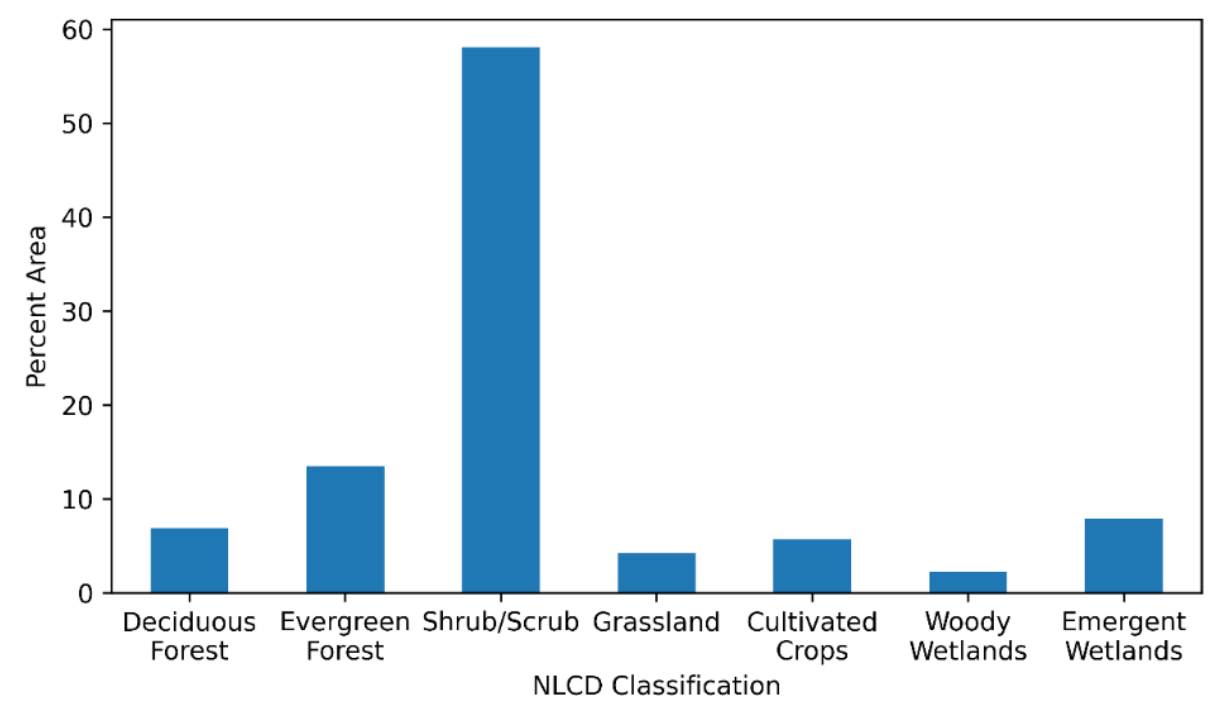

\subsection{Climate summary}

We based the general summary of temperature and precipitation for the Willow Creek Basin on data from the National Centers for Environmental Information (NCEI) Global Historical Climatology Network (GHCN) measurement station Idaho Falls 16 SE (USCo0104456), which is located within the watershed (Figure 7). This station is part of the Cooperative Observer Program (COOP) managed by the National Oceanic and Atmospheric Administration (NOAA) and has a nearly complete record for temperature and precipitation since water year (WY) 1956. Based on the data from this station, the climate in the Willow Creek Basin is typical for many higher-latitude western U.S. watersheds. It is characterized by hot, dry summers, which are followed by cold winters (Figure 8). There is also substantial interannual precipitation variability. Annual total precipitation can range from under $10 \mathrm{in}$. to over $25 \mathrm{in}$. (Figure 9). The precipitation total from October through March accounts for over half of the annual total and determines the total snowpack that will contribute to the freshet period. 
Figure 7. Location of the Idaho Falls $16 \mathrm{SE}$ GHCN station.

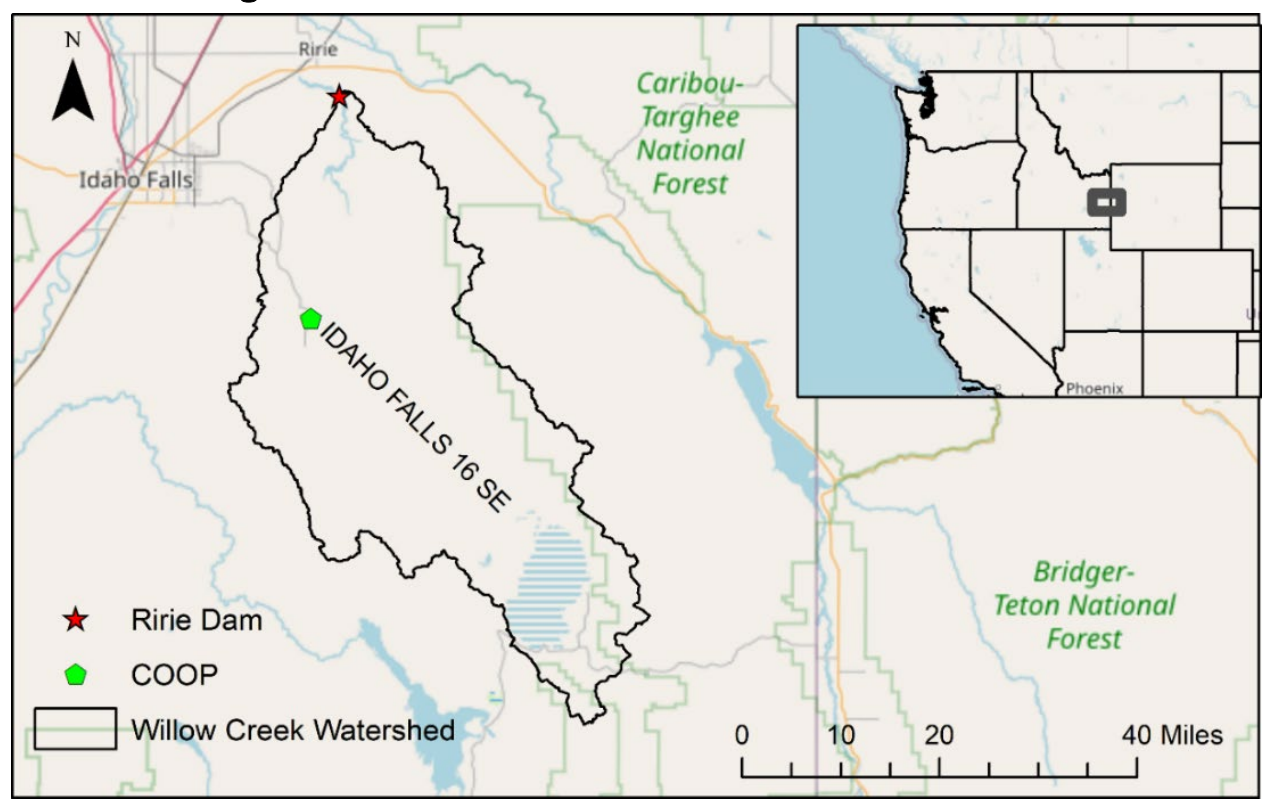

Figure 8. Idaho Falls 16 SE daily temperature summary (1956-2018).

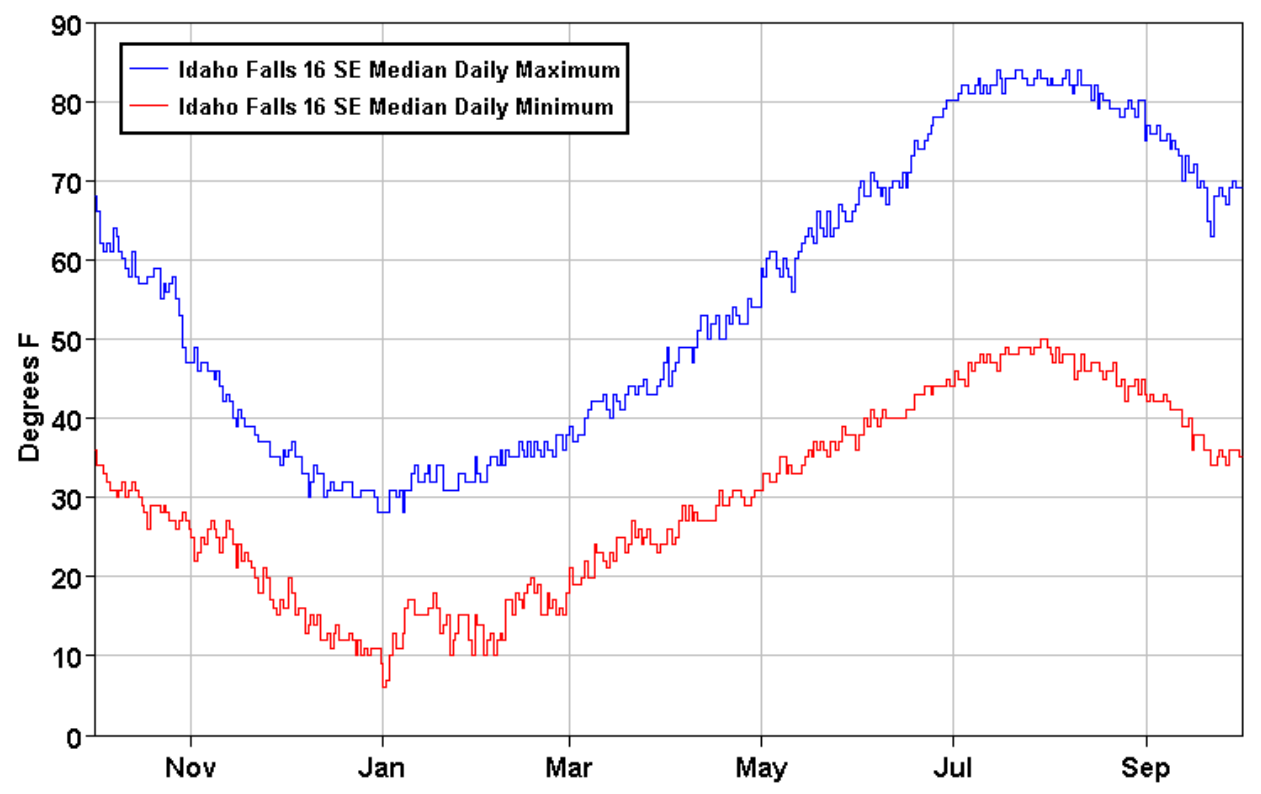


Figure 9. Idaho Falls 16 SE annual total precipitation (1956-2018).

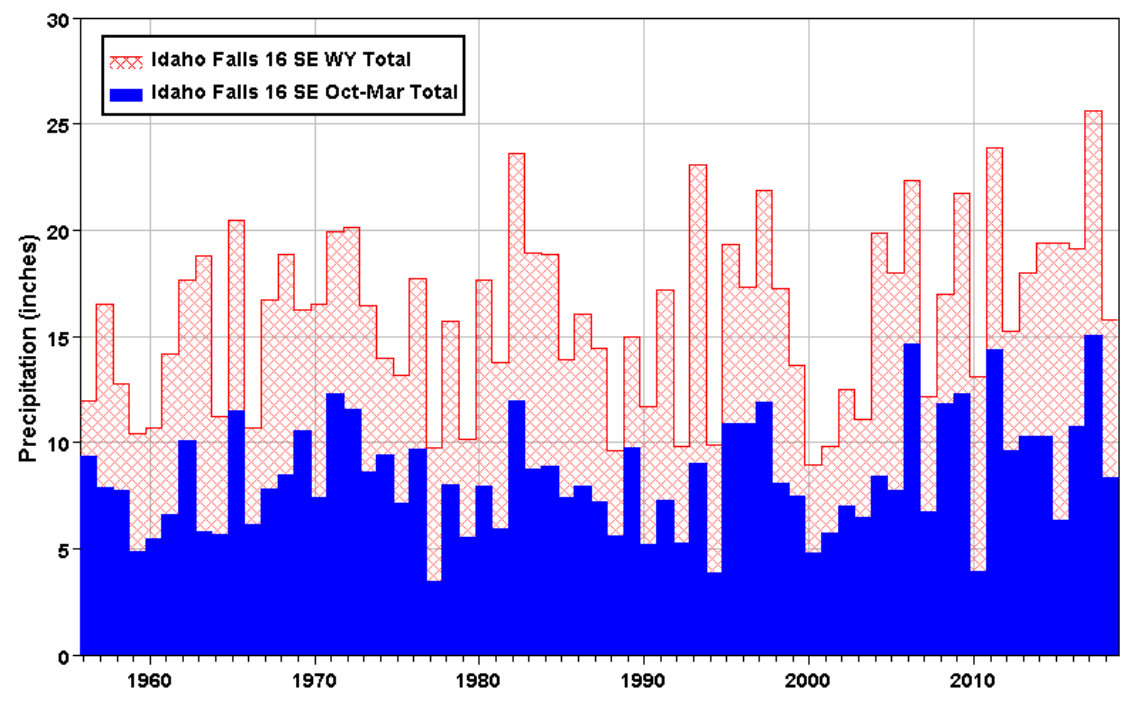

The monthly precipitation pattern for the Willow Creek Basin indicates that spring months of April through June are the wettest; however, starting in November, the winter months can also have substantial precipitation (Figure 10). Moreover, when we consider the 9oth percentile precipitation values for each month, there is a strong bimodal signal with wettest periods during the year being May through June and December through January. Heavy precipitation events during the winter often originate from synoptic storm systems that move inland from the west coast of the U.S. These are the events that are most relevant for our assessment of winter floods in this watershed. Chapter 5.4 will discuss additional details related to very large winter precipitation events.

Other climate variables that are important for water management are wind speed and direction as well as relative humidity because these impact snowmelt and the overall water balance. These variables were not available at the Idaho Falls 16 SE station; however, there was data available at the regional airport (USWooo24145 Fanning Field) located in Idaho Falls. The majority of wind for this region comes from the southwest (Figure 11), which is due to the prevailing westerly winds along with the large mountain ranges to the east of the watershed. The larger wind-speed magnitudes (20 to $30 \mathrm{mph}$ ) also come mostly from this direction. Another important climatological variable for summarizing hydrology for the Willow Creek Basin is relative humidity. There is a distinct seasonal pattern in relative humidity for this region. The maximum values occur in November through March (Figure 12). As seasonal temperatures begin to warm in early spring, the relatively humidity decreases until reaching the minimum 
values in mid to late summer. The low summer relative humidity corresponds to the hottest and driest period in the year.

Figure 10. Idaho Falls 16 SE monthly total precipitation summary (1956-2018).

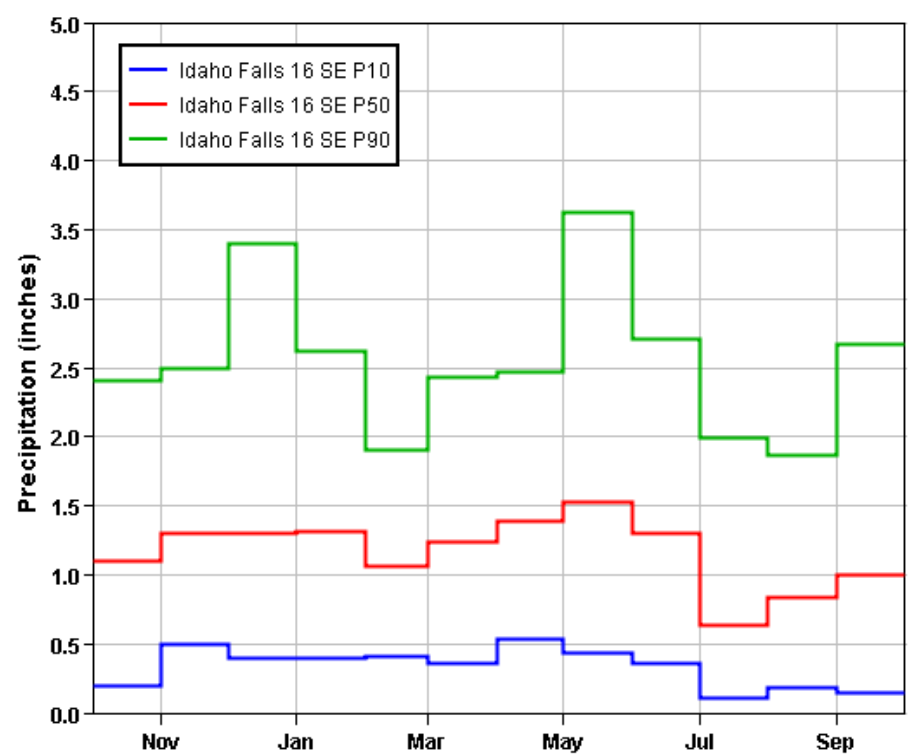

Figure 11. Idaho Falls Fanning Field wind direction and frequency (1998-2019).

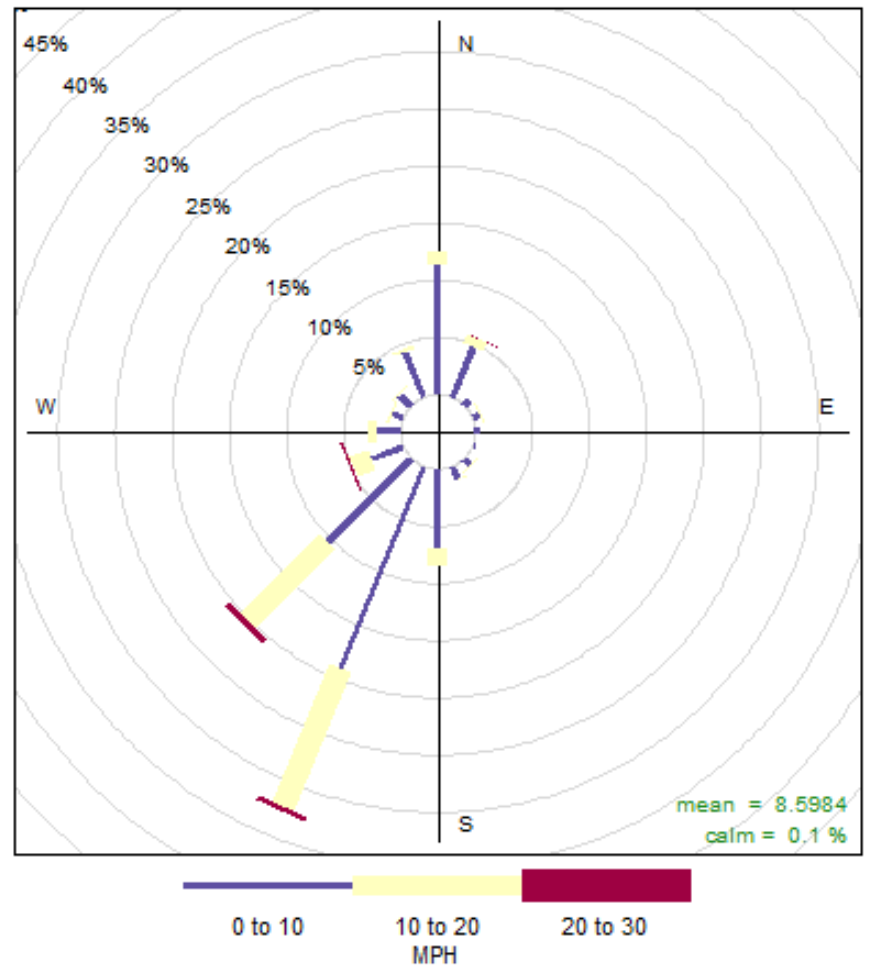


Figure 12. Idaho Falls Fanning Field relative humidity daily summary (1973-2019).

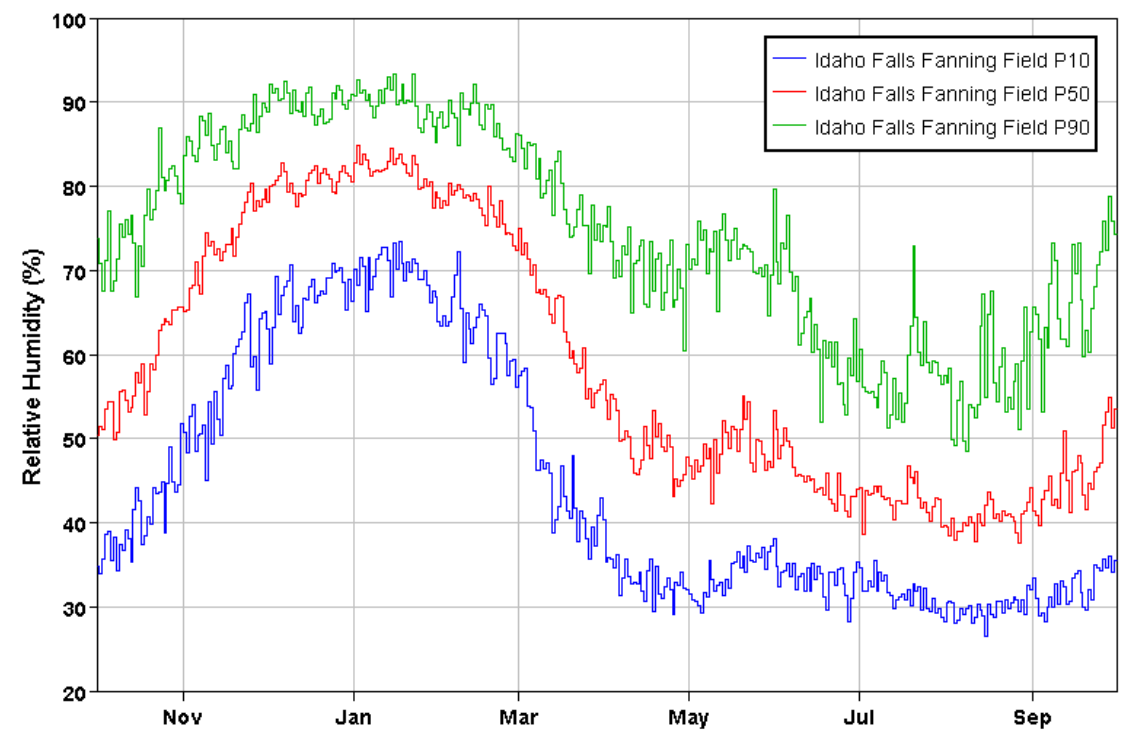

\subsection{Hydrology summary}

The Willow Creek Watershed is characterized as an area that produces relatively low runoff (USACE 1966). In winter months, the largest amounts of runoff are generated at lower elevations because persistent snow cover prevents runoff generation. Occasional rainstorms and warming trends can result in high streamflow for brief periods in the winter or early spring months.

There are limited locations in the watershed above Ririe Reservoir that collect flow data. The two locations used in our study are the USGS Willow Creek below Tex Creek location (Station ID: 13057940) and Ririe Reservoir inflow provided by Reclamation (Figure 13). The USGS site has data from WYs 1977 through 2019 although there is missing data during WYs 1980-1985 (USGS 2020). The Reclamation reservoir inflow time series has continuous data for WYs 1976 through 2019 (Reclamation 2020b). Using the daily flow data available at these sites, it is evident there is a strong snowmelt signature in the hydrographs and that the majority of annual flow volume is derived from snowmelt during April through July. The summary hydrographs in Figure 14 indicate the range of flows during the freshet can vary substantially between high- and low-runoff years. During baseflow periods (summer and winter) there is much less difference between WY types. 
Figure 13. Willow Creek flow measurement locations.

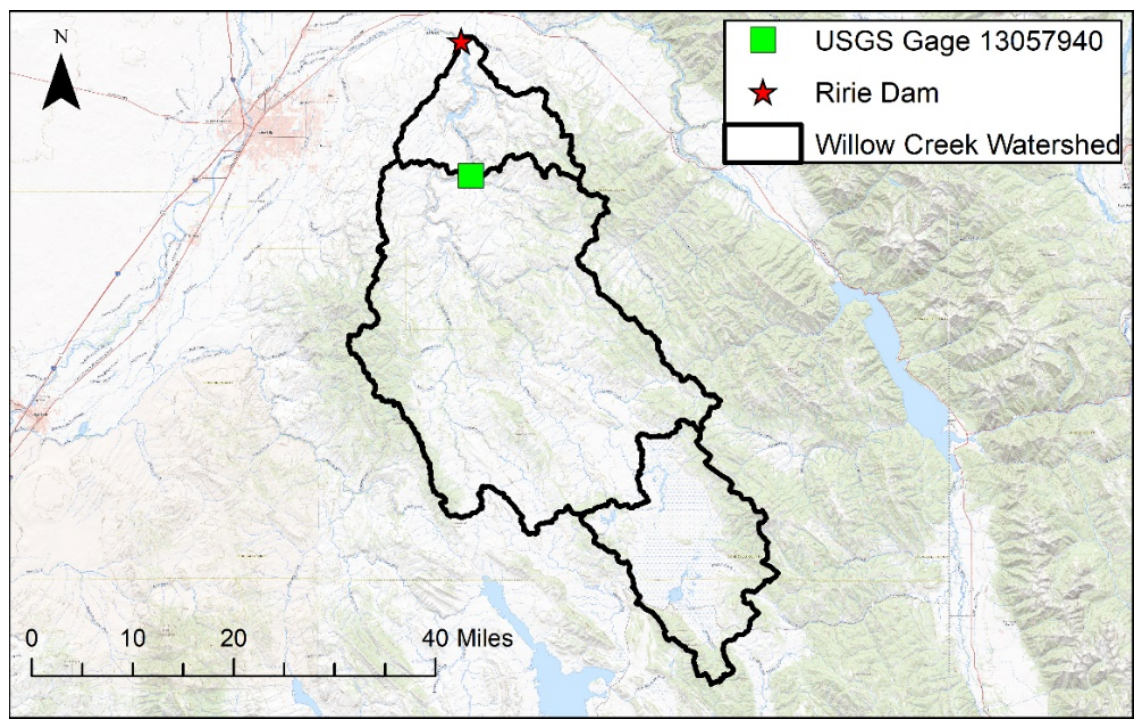

Figure 14. Summary hydrograph for Willow Creek below Tex Creek (USGS 13057940) and Ririe Reservoir inflow.

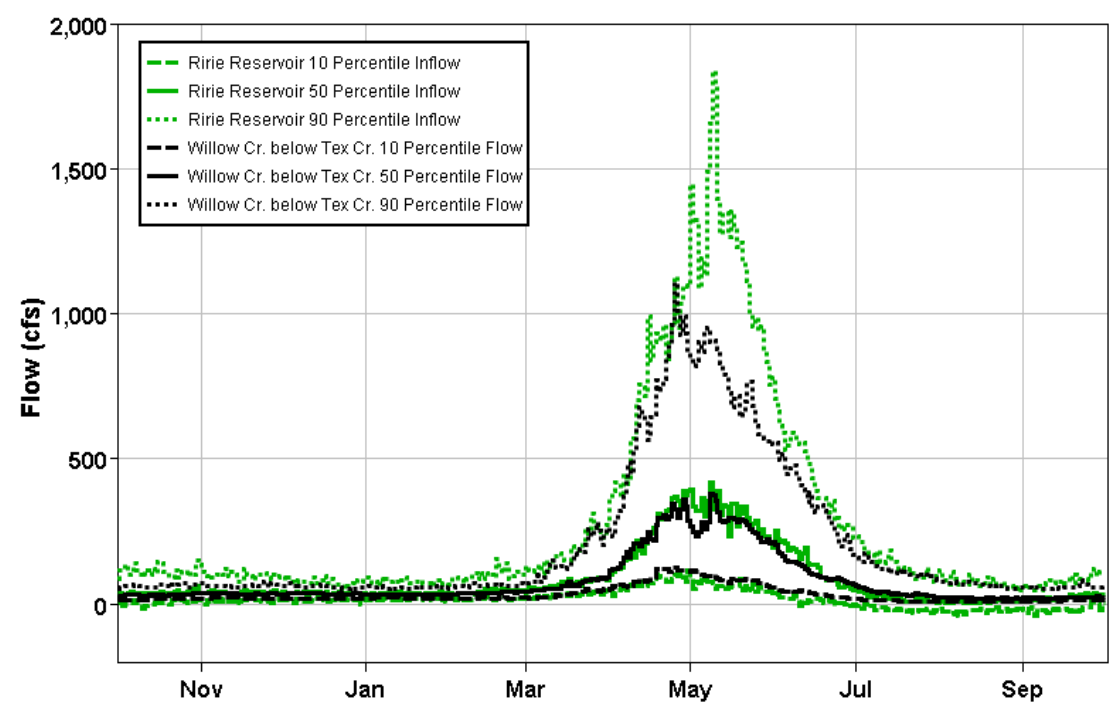

The published records for the USGS flag with an "e" the days on which the discharge was estimated. This practice began in November 1986 and has continued to the present. Figure 15 tabulates the days with "e" discharge entries. Based on this review, it appears that the USGS gage is often affected by the presence of ice in the channel during winter. The ice cover changes the relationship between discharge and stage in unpredictable ways so that the open water rating curve is not accurate. In this case, the discharges are estimated based on a variety of techniques that USGS has developed and refined over many years (Rantz et al. 1982). 
Figure 15. Percentage of flows estimated for Willow Creek below Tex Creek streamgage by date.

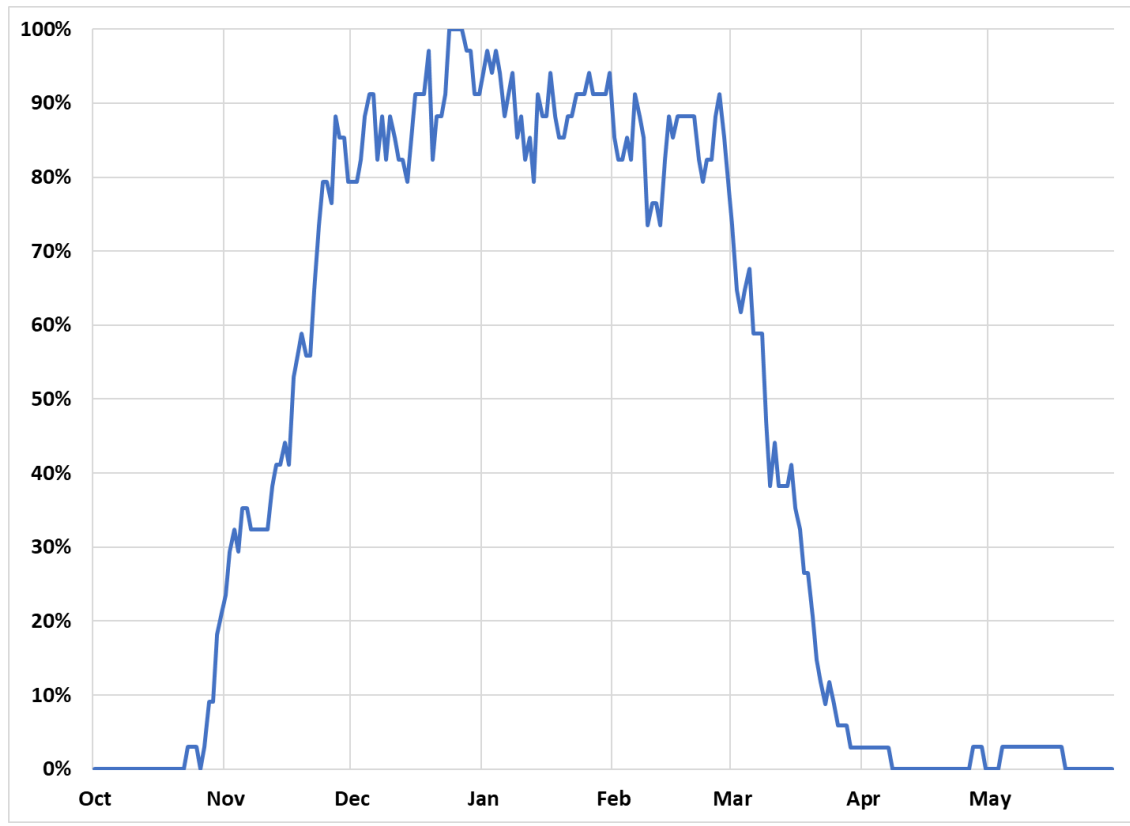

In general, the USGS and Reclamation datasets closely match; however, there are some differences in the annual maximum daily flows during the winter months (Figure 16). Consequently, we used inflow data from Reclamation when performing analysis of historical information. We reviewed the Reclamation daily unregulated inflows beginning in WY 1982 for more recent winter flood events. We identified a total of 15 winter flood events (Table 3), with magnitudes ranging from 155 to $775 \mathrm{cfs}$. Unfortunately, the systematic flow record does not extend back far enough to have captured additional information during the February 1962 event. A peak flow of that magnitude has not been observed in Willow Creek since. The Reclamation unregulated inflows are derived using changes in reservoir storage along with outflow from the dam. Therefore, mass-balance components at the reservoir, such as evaporation and seepage, often can exceed the actual streamflow making into the reservoir. This is reflected in the tenth percentile flows in Figure 14, which indicate negative inflows during summer and fall months when evaporation is highest. These effects should be less during winter and spring inflows because potential evaporation is lower. 
Figure 16. Willow Creek winter daily peak-flow comparison between the USGS gage and Ririe Reservoir inflow.

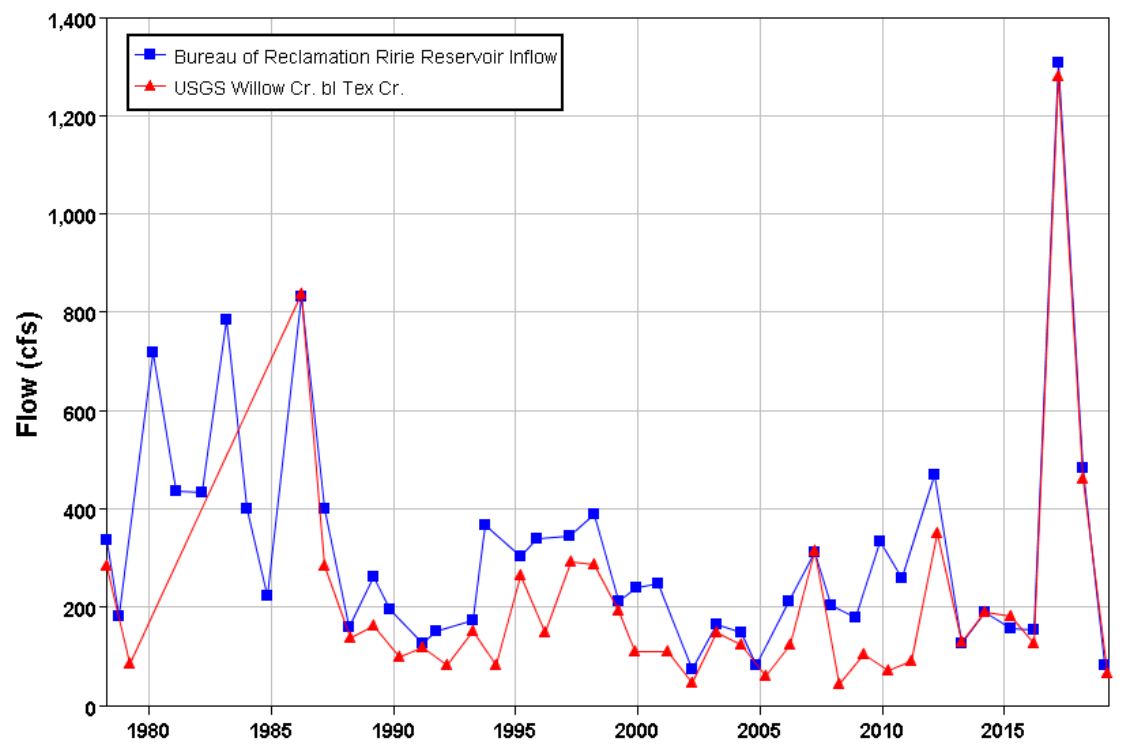

Table 3. Winter flood events identified from the Reclamation unregulated inflow (WY 1982-2018).

\begin{tabular}{|c|c|}
\hline Event Date & $\begin{array}{c}\text { Peak Discharge } \\
\text { (cfs) }\end{array}$ \\
\hline 18-Feb-82 & 376 \\
\hline 22-Feb-82 & 428 \\
\hline 2-Mar-83 & 775 \\
\hline 8-Mar-87 & 389 \\
\hline 29-Feb-88 & 160 \\
\hline 27-Feb-94 & 130 \\
\hline 1-Feb-95 & 215 \\
\hline 28-Feb-06 & 212 \\
\hline 18-April-11 & 200 \\
\hline 22-Feb-12 & 157 \\
\hline 14 March-13 & 120 \\
\hline 16-Feb-14 & 115 \\
\hline 7-Mar-14 & 188 \\
\hline 10-Feb-17 & 417 \\
\hline
\end{tabular}

As the focus of this study is to provide information that will be used in a hydrology model, it is important to understand not only the observed peak flows but also the design floods for Ririe Dam and Reservoir. The 1962 flood was the catalyst for constructing Ririe Dam and was used as the basis for the winter design flood. The February 1962 flood has been described as follows: The winter of 1961-1962 had temperatures lower than seasonal 
averages through December. In January, warmer air resulted in a freezing-thawing cycle at lower elevations that melted the light snow cover and subsequently refroze as a thin layer of ice. Near the beginning of February 1962, a large precipitation event accompanied by warmer air resulted in 0.54 in. of water above the Ririe Dam site and a peak discharge of $5080 \mathrm{cfs}$ (Thomas and Lamke 1962). Note that local reports claim that much of the flow in Willow Creek during this event was runoff from the foothills east of the towns of Iona, Ammon, and Taylor and therefore would have entered the channel downstream of Ririe Reservoir.

For our study, the winter standard project flood represents the critical hydrologic conditions that the current winter storage space requirement is based upon. The winter standard project flood assumed 2.54 in. for the 84 hours of precipitation and 1.99 in. of snowmelt (USACE 1966). The hydrograph development included frozen ground conditions by limiting infiltration through the precipitation event. This theoretical flood hydrograph had a peak discharge of $14,500 \mathrm{cfs}$ and a runoff volume of 47,500 acre-ft. Table 4 summarizes the design floods (winter and spring) for the project.

Table 4. Ririe Dam and Reservoir design floods (USACE 1966).

\begin{tabular}{|l|c|c|}
\hline \multicolumn{1}{|c|}{ Design Flood } & $\begin{array}{c}\text { Peak Flow } \\
\text { (cfs) }\end{array}$ & $\begin{array}{l}\text { Volume } \\
\text { (acre-ft) }\end{array}$ \\
\hline 1962 Flood & 5080 & 14,000 \\
\hline Standard Project Flood-Winter & 14,500 & 47,600 \\
\hline Standard Project Flood-Spring & 5000 & 240,000 \\
\hline Probable Maximum Flood & 47,000 & 178,000 \\
\hline
\end{tabular}




\section{Precipitation Conditions for the Willow Creek Basin}

Design of large water resources infrastructure, specifically storage dams, requires a thorough understanding of the hydrology and climatic regimes. This ensures that both safety of the structure and design performance are adequately assessed. To accomplish these assessments, we first need to analyze the key climatic variables (i.e., precipitation and temperature) that are the primary inputs controlling snowpack accumulation, streamflow volume, and streamflow timing. More specifically, we need to define the precipitation regime for a watershed upstream of the dam location because this allows us to characterize the primary hydrologic forcing variable for seasonal and annual streamflow.

There are two basic types of precipitation events that are considered in the design of storage dams: the Probable Maximum Precipitation (PMP) and the lesser events with known exceedance probabilities. We define the PMP as the largest storm (maximum precipitation depth) that is physically possible for a given location. This design storm is often used in studies to assess the dam's structural stability and performance during extreme hydrologic loading situations. These storm events are not often used when evaluating project benefits because of their very rare and extreme conditions. The precipitation events that are more commonly used for evaluating project benefits, specifically those related to water management and flood risk reduction, are rare events that have an estimated probability. These event probabilities are often reported as return periods (e.g., 100-year), which simply means they have an assumed fixed probability of occurring in any given year.

Deriving estimates of precipitation depths and the associated probabilities is commonly performed during design of engineered structures. The design storms used for these analyses will depend on cost of the project and consequences related to failure of the structure. Many of these infrastructure projects utilize precipitation frequency publications developed by NOAA. For the majority of the United States, this publication is NOAA Atlas 14, which provides estimates for a range of storm durations (e.g., 5min, 1-hour, 6o-day, etc.) with recurrence intervals starting at the 1-year event and going to the extremely rare 1000-year event (Bonnin et al. 
2011). Using Atlas 14 for design provides a standardized source of information and ensures reasonable precipitation estimates regardless of the project scale or location within the United States.

Although Atlas 14 provides updated precipitation frequency estimates for the majority of the U.S., the Pacific Northwest states have yet to be completed. This means the only standardized publications of precipitation frequency in this region are very dated documents. For storm events less than 24 hours, the standard is the much older NOAA Atlas 2 (Miller et al. 1973); and for event durations greater than 24 hours, the design publication is Technical Paper 49 (Miller 1964), which was published in the mid-1960s. Consequently, engineering design projects in these states often perform ad hoc updates based on the project location and specific purpose of the analysis.

The last precipitation frequency analysis that was performed for Ririe was during the initial design of the project in the 1960s. The 1962 winter flood event that was used to determine winter storage requirements resulted in widespread flooding through northeastern Nevada and eastern Idaho. The cumulative precipitation totals during this event were estimated to range from 1.5 to over 2 in. for areas above Ririe (USACE 1966).

Given that Atlas 14 precipitation depths are not available for the Willow Creek Basin, the current study requires an updated analysis for precipitation frequency above Ririe Dam.

\subsection{Precipitation data}

Data selection is a very important step in the process of estimating precipitation-depth probabilities. Depth-duration-frequency (DDF) analysis and precipitation intensity-duration-frequency (IDF) have traditionally relied on ground-based measurement stations (Khan et al. 2017; Parida and Moalafhi 2008; Rosenberg et al. 2010; Sveinsson et al. 2002; Wallis et al. 2007). The use of IDF or DDF mainly depends on the intended use of the frequency analysis since IDF provides rainfall intensities while DDF reports total depths. For hydrologic modeling, we will often use DDF since the depth estimate is fixed for a specified time period, usually coincident with the hydrology model time step.

The ground-based station information initially considered for use in our study is available through NOAA's National Centers for Environmental Information. These stations are located within an approximately 140-mile 
radius of Ririe Dam and are composed of COOP, Natural Resources Conservation Service (NRCS) Snow Telemetry (SNOTEL), and Weather Bureau Army Navy (WBAN) locations (Figure 17). Many of the stations we initially selected for this analysis have over 30 years of data although with varying continuity in the daily time series (Figure 18). We provide additional details related to the data quality control in subsequent sections.

Figure 17. Ground-based precipitation stations initially considered for the Willow Creek Basin precipitation frequency analysis.

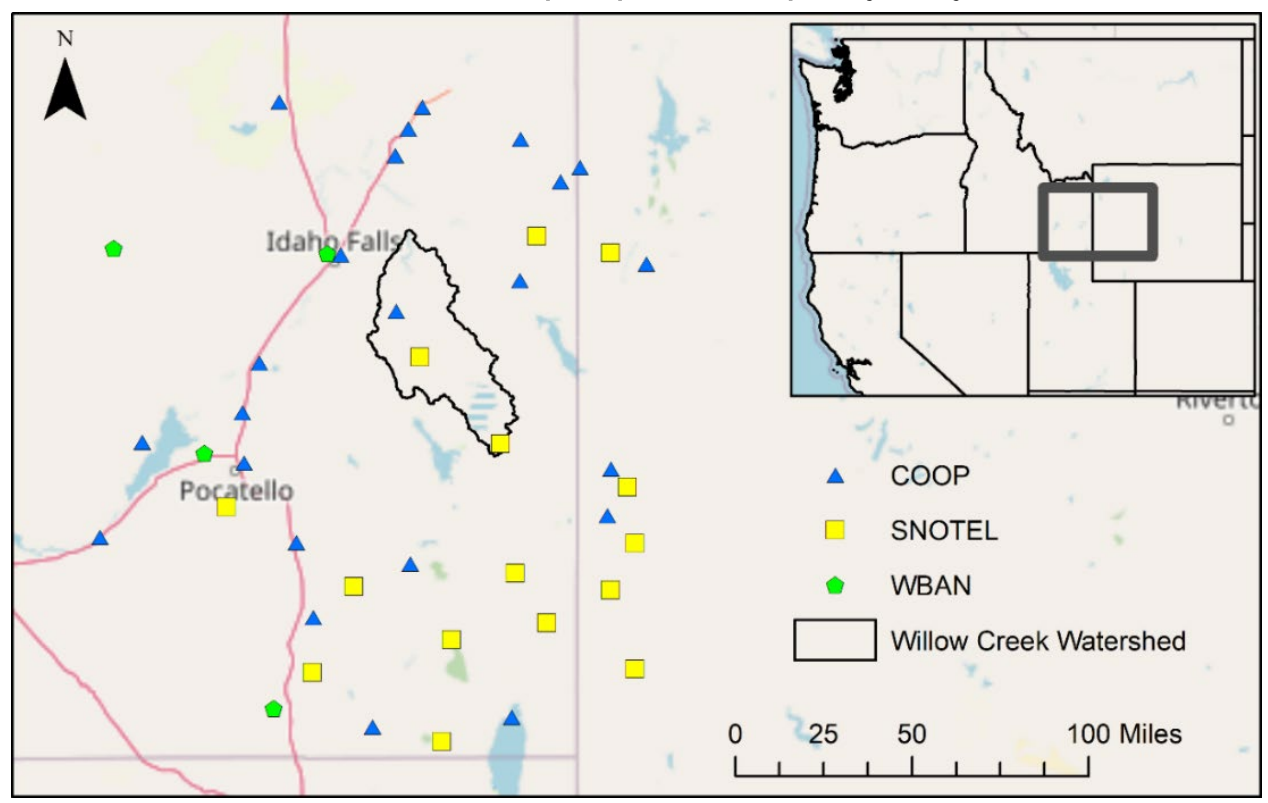

Figure 18. Daily precipitation data available by station.
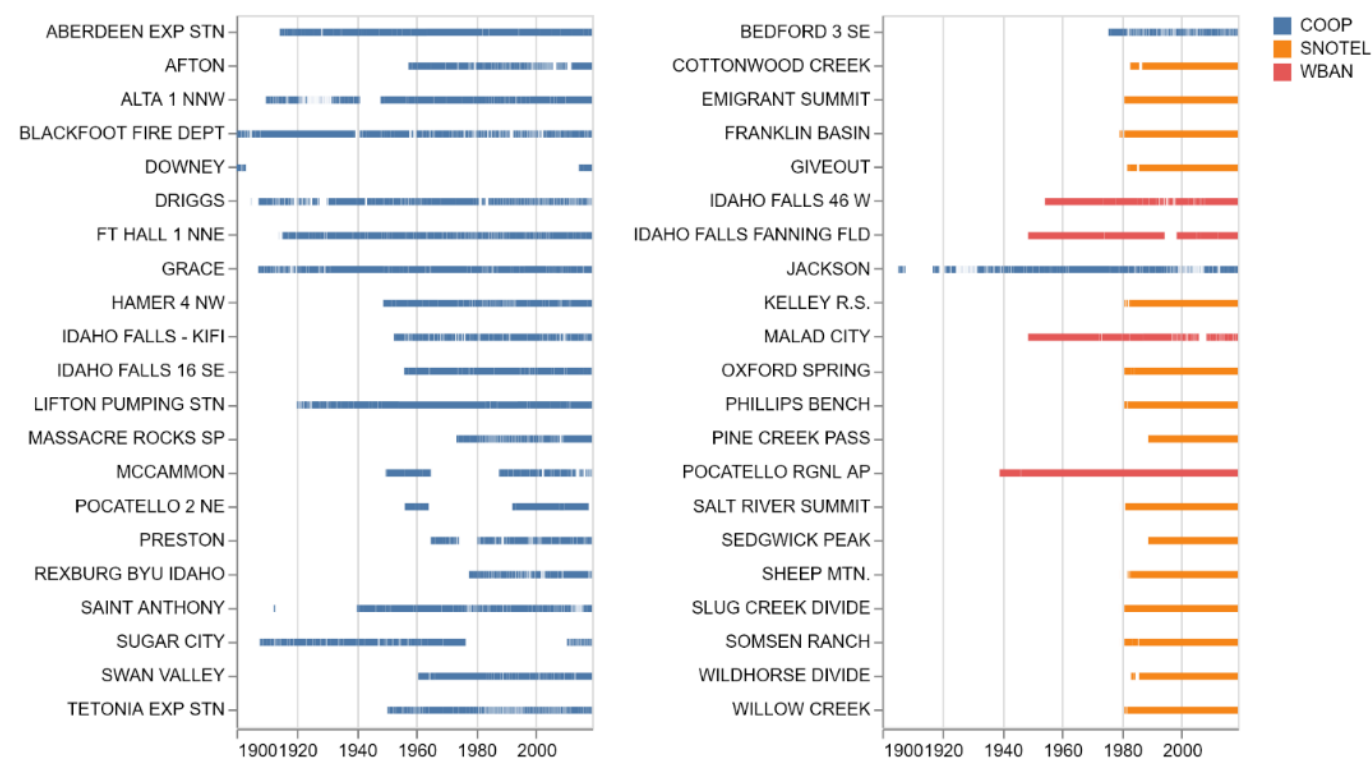


\subsection{Precipitation analysis methods}

We commonly use probability as a general term, but specific definitions are important in the context of this study. We define annual exceedance probability (AEP) of an event as the percent chance of exceedance (e.g., 1\%, 5\%, $99 \%$, etc.) in a given year. AEP can also be stated in terms of return periods, which is simply 1/AEP (e.g., 100-year, 20-year, 1.01-year, etc.).

Precipitation frequency analysis is often performed at a single groundbased station following a few general steps. First, we review the precipitation data for completeness and recording errors. Second, the data is temporally aggregated to various durations that are important to the projection design (e.g., 12-hour, 24-hour, 48-hour, 72-hour, etc.). Once we have a time series of cumulated precipitation amounts, the maximum values for the annual or seasonal period are calculated, and several quality-control tests are performed. Finally, we use the quality-controlled maximum precipitation totals to fit either an empirical or analytical statistical distribution to the data. These distributions can be used to estimate the precipitation totals for any return period needed for engineering design; or conversely, they can be used to determine the probability of a specific rainfall amount. The end result of this process is a DDF relationship for the station location.

When preforming precipitation frequency analysis in the context of producing streamflow estimates for critical infrastructure, there are two data limitations to address to appropriately quantify risk. These limitations are the relatively short temporal record (compared to the desired return period) and the spatial heterogeneity of precipitation. We addressed both of these issues by regionalizing the frequency analysis for winter maximum precipitation events in the Willow Creek Watershed. The regional frequency analysis was completed using the R package "lmomRFA", which allows for a straightforward implementation of the aforementioned steps (Hosking 2019).

\subsubsection{Statistical methods for regional frequency analysis}

\subsubsection{L-moment parameter estimation}

Linear combinations of the probability-weighted moments (L-moments), as shown in equation (1), have often been used in precipitation frequency analysis (Parida and Moalafhi 2008; Pilon et al. 1991; Sveinsson et al. 
2002; Wallis et al. 2007). L-moments are more convenient than probability-weighted moments because they are more easily related to measures of the data distribution (Hosking and Wallis 1993). In addition, this method of estimating the distribution parameters is less affected by sampling variability than conventional product moments and is more efficient than the method of maximum likelihood (Hosking 1990). For example, $l_{1}$ is the sample mean of the data, while $l_{2}$ is a measure of scale for the sample data:

$$
l_{r+1}=\sum_{k=0}^{r} p_{r, k}^{*} b_{k},
$$

where

$$
p_{r, k}^{*}=(-1)^{r-k}\left(\begin{array}{l}
r \\
k
\end{array}\right)\left(\begin{array}{c}
r+k \\
k
\end{array}\right)
$$

and

$$
b_{r}=n^{-1} \sum_{j=1}^{n} \frac{(j-1)(j-2) \cdots(j-r)}{(n-1)(n-2) \cdots(n-r)} x_{j} .
$$

Within this equation,

$$
\begin{aligned}
l_{r} & =\text { the unbiased estimator of the L-moment, } \\
p^{*} r, k & =\text { the linear combination of probabilities, and } \\
b_{r} & =\text { weight for each order sample }\left(x_{j}\right) \text { from the data. }
\end{aligned}
$$

The ratios of L-moments, equation (2), are also useful in describing wellknown measures of the data distribution. For example, $t_{3}$ and $t_{4}$ are measures of sample skewness and kurtosis, respectively:

$$
t_{r}=\frac{l_{r}}{l_{2}} \quad r=3,4, \ldots
$$

\subsubsection{Analytical distributions}

The generalized extreme value (GEV) distribution is a three-parameter distribution, equation (3), that is often used for precipitation frequency analysis. The three parameters for this distribution are location $(\xi)$, scale $(\alpha)$, and shape $(\kappa)$ and can be estimated using the method of moments (probability-weighted moments, L-moments, LH-moments) or maximum likelihood estimation. For this analysis, we used the L-moment method to determine estimates of the GEV parameters. A concise description of the 
GEV distribution can also be found in the HEC-SSP (Hydrologic Engineering Center-Statistical Software Package) user manual (Bartles 2019).

$$
f(x \mid \xi, \alpha, \kappa)=a^{-1} \exp (-(1-\kappa) y-\exp (-y)),
$$

where

$$
y=\left\{\begin{array}{c}
-\kappa^{-1} \ln \left[1-\frac{\kappa(x-\xi)}{\alpha}\right], \kappa \neq 0 \\
\frac{(x-\xi)}{\alpha}, \kappa=0
\end{array} .\right.
$$

These parameter estimate methods can all be used to estimate the GEV distribution $\xi$ (location), $\alpha$ (scale), and $\kappa$ (shape) parameters following the equations outlined in Hosking (1990). Equations (4) through (6) are used for estimating the parameters using L-moments:

$$
\kappa=7.859 C+2.9559 C^{2},
$$

where $C$ is given by

$$
\begin{gathered}
C=\frac{2}{3+t_{3}}-\frac{\log 2}{\log 3} ; \\
\alpha=\frac{l_{2} \kappa}{\Gamma(1+\kappa)\left(1-2^{-\kappa}\right)}, \\
\xi=l_{1}+\frac{\alpha}{\kappa}[\Gamma(1+\kappa)-1],
\end{gathered}
$$

where $l_{1}$ is the first sample L-moment and $t_{3}$ is the third L-moment ratio. Additional details on these equations are available in Singh (1998). We provide a brief description of both the GEV distribution and L-moment parameter estimates in this section, but additional details can be found in the large body of literature related to both of these topics (Hosking and Wallis 1993; Kotz and Nadarajah 2000; Maidment 1993)

\subsubsection{Regional frequency analysis using ground-based stations}

We performed a regional precipitation frequency analysis using the ground-based stations shown in Figure 17. The regionalization framework uses multiple stations from a defined geographic domain that have similar 
precipitation characteristics. These groups of stations, or regions, increase the data sample size by effectively substituting space for time within the frequency analysis. In addition, the regionalization helps address the spatially heterogeneous characteristics of precipitation by using data from ground-based stations with varying topography, elevation, and land cover.

This analysis used the steps outlined in Hosking and Wallis (1993) with the additional step of computing the areal reduction factor for each location:

1. Screen data to ensure there are not gross errors with the time series. This would include data that have known equipment malfunctions or are beyond the reasonable limits for precipitation in the area. In addition, this step uses the discordancy measure, $D_{i}$, to identify sites that have sample Lmoments substantially different than all of the other stations.

2. Identify homogenous regions by computing the at-site variability of summary statistics. The heterogeneity of the region is measured by $H$ statistic, which uses at-site sample L-moment coefficient of variation to compare the weighted standard deviation to the simulated mean using regions with no cross-correlation or serial correlation.

3. Select a regional frequency distribution for the homogeneous region. The final distribution selection is based on goodness-of-fit measures.

4. Estimate the regional frequency distribution and regional factors that are then applied to each station within the homogeneous region.

5. Estimate the areal reduction factor for each station using the annual-maxima center approach as described by Asquith and Famiglietti (2000).

Additional details of how we performed each of these steps are described in the following subsections.

\subsubsection{Data processing}

We initially processed the daily precipitation records for each station by temporally aggregating the values to create the 48-, 72-, and 96-hour-duration time series. This summation used a backward-looking timeframe. For example, the 72-hour summation was calculated for each day using the current date precipitation amount plus the daily totals from the previous 2 days. This same process was repeated for the other durations while no additional aggregation was necessary to create the 24-hour time series. 
We then extracted the maximum precipitation values between October and March, designated as the winter season for our study. Our data processing resulted in four time series for each of the 42 stations, which consisted of a maximum value for each water year and duration $(24,48,72$, and 96 hours).

\subsubsection{Data quality control}

The data quality control we used for the precipitation analysis consisted of using several threshold tests to remove individual data values or in some cases the entire station dataset. Our data quality control follows the process used by Karlovits et al. (2017) and helped us to minimize data errors that could affect the frequency analysis. Table 5 summarizes the qualitycontrol tests that we performed.

In our study area, we did not combine any station records as none were colocated. This can often be an issue if the ground-based station is moved a relatively short distance and two separate datasets are reported by NCEI. Karlovits et al. (2017) suggested combining station records that were separated by less than $5 \mathrm{~km}$ (3.1 miles) using geodesic distance (or "as the crow flies”). Our initial set of ground-based stations were all more than $5 \mathrm{~km}$ apart with the exception of Idaho Falls Fanning Field (USWoo034145) and Idaho Falls KIFI (USC00104455), which are $4.5 \mathrm{~km}$ (2.8 miles) apart. Due to the already limited number of quality precipitation stations and limited information on how the $5 \mathrm{~km}$ threshold was established, we elected to keep both of these station records separate.

Table 5. Data quality-control tests and threshold levels.

\begin{tabular}{|l|l|}
\hline \multicolumn{1}{|c|}{ Test } & \multicolumn{1}{c|}{ Threshold Level } \\
\hline Record Length & Minimum 15 years \\
\hline Largest Observation Ratio & Largest observation $>2 \times$ next largest \\
\hline Outlier & $>2.5$ standard deviations from mean \\
\hline Nonstationarity & Trend $p<0.05$ \\
\hline Extreme L-Moment Ratio & Outside middle 95\% \\
\hline
\end{tabular}

\subsection{Record length}

According to Hosking and Wallis (1997) the 15-year threshold is long enough to avoid bias in the site frequency analysis. We reviewed the precipitation records for each site, and the only station with less than 15 years of data was Downey (USC00102667). Therefore, we removed this station 
from the analysis. In addition, water years were removed for locations that had more than $10 \%$ of the daily values missing during October through March after stations with less than 15 -years of record were removed.

\subsection{Largest observation ratio}

This test compares the largest and second largest values for each duration and station. The primary purpose of this test is to ensure that no major recording errors from NCEI are in the time series. When the ratio of the first to the second largest value exceeds 1.5 to 2 , then a precipitation value in the data record may be incorrect, requiring further inspection. A total of two values, both at the 24-hour duration, were removed from our analysis due to apparent systematic measurement errors. The ratio test was also applied to the second and third largest values for each station and duration dataset. No additional values were removed from the analysis based on these results.

\subsection{Lognormal outlier test}

The purpose of this test is to see if any outliers exist that are not due to data recording errors. For this test, we first transformed all of the annual maximum time-series datasets using the natural logarithm. The transformed values were then standardized by subtracting the mean of the transformed values and dividing by the standard deviation of transformed values. This process creates a normal variate in log space, which we then compared to a z-score test value with 2.5 standard deviations. Within this range, we should have $99 \%$ percent of all annual maximum values. Therefore, any values that are outside of this range require further evaluation to see if the precipitation depth is possible given nearby stations. Using this test, we removed an additional 26 values.

\subsection{Nonstationarity test}

Although there are presently no prescriptive methods for handling nonstationarity in precipitation frequency analysis, this test does provide insight to stations that may have data trends through time. For this evaluation, we used the Mann-Kendall trend test, which detects monotonic trends in the dataset. The Mann-Kendall test is a nonparametric method that is not sensitive to any underlying data distribution. We used a significance threshold of $p<0.05$ to determine if a monotonic trend is present in the annual maximum time series. 
Our results indicate that very few of the station and duration combinations had a statistically significant monotonic trend. Two stations (Tetonia Experiment Station [USC00109065] and Alta 1 NNW [USC00480140]) did indicate significant trends for all durations. After further inspection of the data, we did not remove these stations or adjust the length of the annual maximum time series. This is because the statistically significant monotonic trend was isolated at those stations and did not seem to be consistent with other nearby stations. In addition, there are several missing years for both of these locations after applying the $10 \%$ missing daily data criteria. Therefore, we assumed that any uncertainty introduced into the analysis due to the potential nonstationarity was less than the uncertainty associated with a reduced sample size in the regional analysis.

\subsection{Extreme L-moment ratio test}

We used this test to determine if any of the station L-skew or L-kurtosis values were lower than the 2.5 percentile or higher than the 97.5 percentile computed from all stations' L-moments. If these L-moments were outside of these bounds, then closer inspection of the dataset was required. In our analysis, there were a few station and duration combinations that were outside of these bounds, but there was no consistency with the locations. As stated in Karlovits et al. (2017), if stations with short records passed the length test, they were kept even if the L-skew and L-kurtosis were flagged. One of the advantages of using the extreme L-moment ratio test, especially for stations with longer records, is that it can reveal more than one observation that would potentially fail the largest observation ratio test. As noted previously, we performed the largest observation ratio test on both the first and second largest values in each dataset. Therefore, we did not remove any additional values beyond the results of the largest observation ratio test.

\subsubsection{Initial region delineation}

Our data screening also included evaluation related to grouping of sites to create homogeneous regions. Although defining homogeneous regions is formally handled in the next step of the process, we decided that using a kmeans clustering method would provide useful information even in the screening process. The clustering used all stations that passed the Record Length Test and was completed using the R package "fpc", which performs 
partitioning around medoids based upon the average silhouette width criterion (Hennig 2020). The metrics used for the clustering of stations are the following:

- Mean winter total precipitation

- Mean winter daily maximum precipitation

- Historical daily maximum precipitation (highest amount in the period of record)

- Coefficient of variation for winter total precipitation

- Coefficient of variation for winter daily maximum precipitation

- Station elevation

- Station slope (ground slope at the station location)

- Station aspect (topographic aspect at the station location)

- National Land Cover Dataset tree canopy percent

- National Land Cover Dataset vegetation code

The results of the k-means clustering indicated that there are two groups of stations in the region surrounding the Willow Creek Watershed (Figure 19). Based on the metadata available for each of these sites, they can basically be divided by elevation. Region 1 includes locations below $6500 \mathrm{ft}$ elevation (orange), and Region 2 (aqua blue) includes those above $6500 \mathrm{ft}$. Based on this elevation, the regions are generally made up of WBAN/COOP and SNOTEL stations for Regions 1 and 2, respectively.

Using the stations included in each cluster, we calculated a discordancy measure, $D_{i}$, to determine if any locations within the regions were still considered outliers based on Wilks' outlier test (Wilks 1963). Discordant sites are those that have statistical measures, L-moments in this situation, that are too far away from the centroid of the group point cloud. Using the threshold of outlier identification from Hosking and Wallis (1993), any $D_{i}$ greater than 3 would be considered for removal from the previously identified cluster. This process is repeated after each station is removed because the point cloud centroid changes once a station is removed. Based on the results of discordant measure, five stations were removed from Region 1 while Region 2 remained unchanged. Figure 20 and Table 6 highlight the removed stations. 
Figure 19. Results from k-means clustering of ground-based climate stations near the Willow Creek Basin.

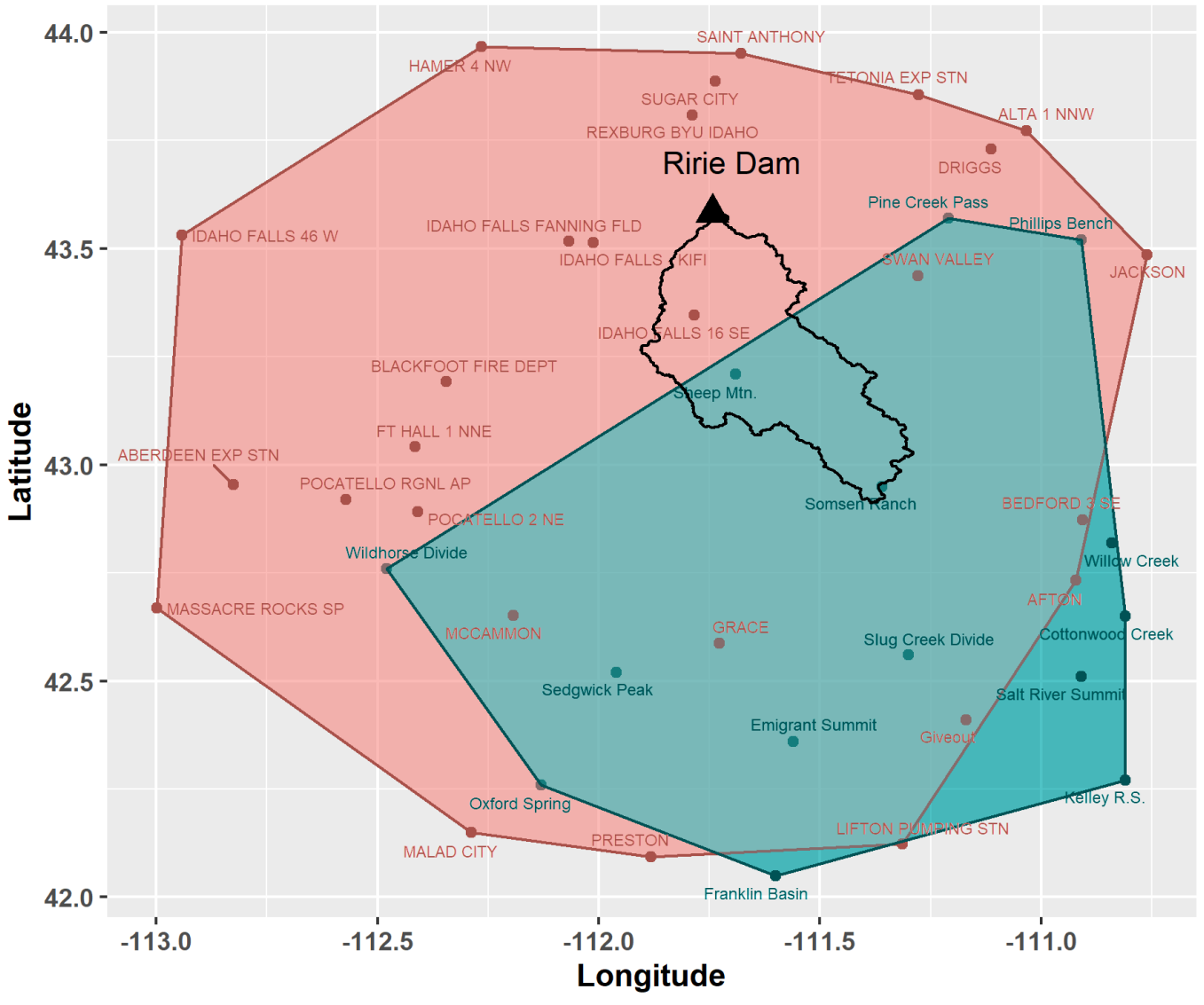

Figure 20. Stations removed after discordant analysis (shown with red stars).

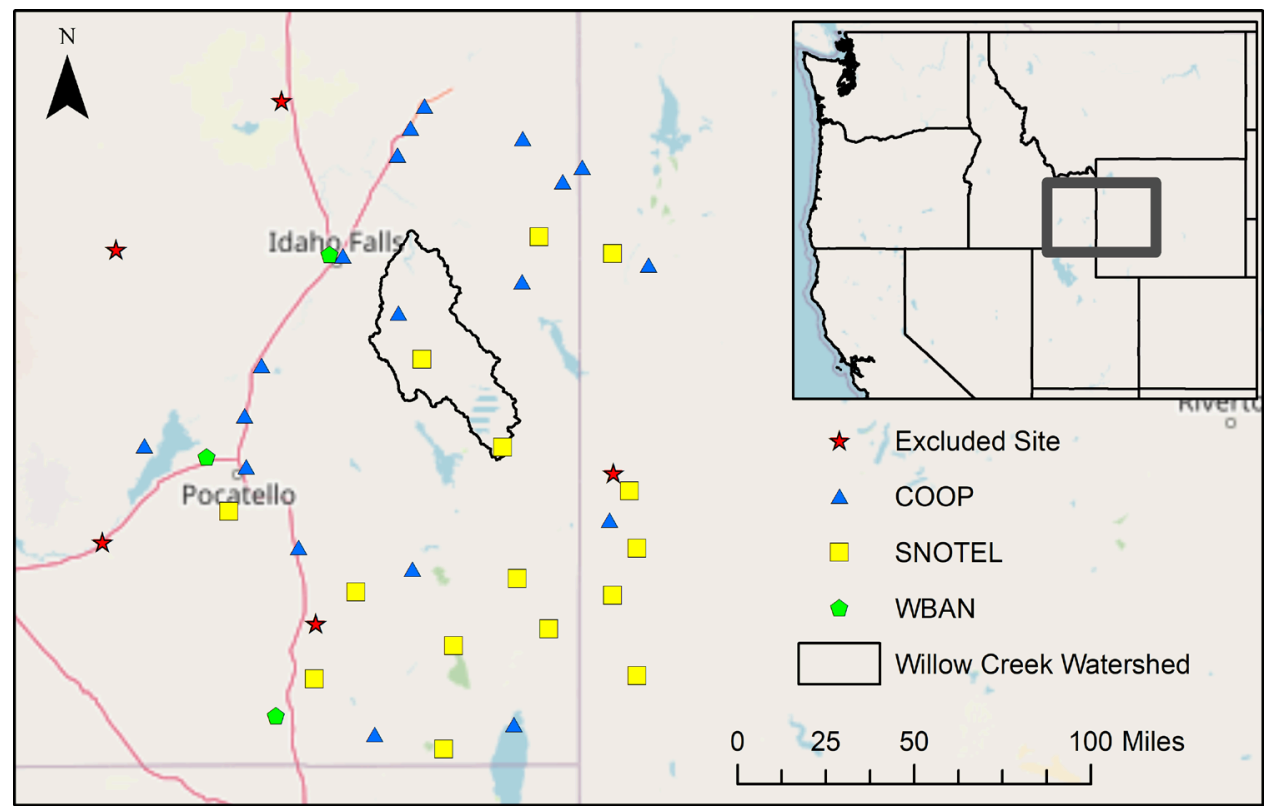


Table 6. Ground-based station clustering results. Highlighted stations were removed as a result of the data quality-control process.

\begin{tabular}{|c|c|c|c|}
\hline ID & Station & $\begin{array}{c}\text { Period of Record } \\
\text { (years) }\end{array}$ & Region \\
\hline USC00100010 & Aberdeen Exp Stn & 102 & 1 \\
\hline USC00100915 & Blackfoot Fire Dept & 89 & 1 \\
\hline USC00102667 & Downey & 7 & 1 \\
\hline USC00102676 & Driggs & 78 & 1 \\
\hline USC00103297 & Ft Hall 1 NNE & 99 & 1 \\
\hline USC00103732 & Grace & 94 & 1 \\
\hline USC00103964 & Hammer 4 NW & 64 & 1 \\
\hline USC00104455 & Idaho Falls-KIFI & 44 & 1 \\
\hline USC00104456 & Idaho Falls 16 SE & 57 & 1 \\
\hline USC00105275 & Lifton Pumping Stn & 93 & 1 \\
\hline USC00105678 & Massacre Rocks SP & 34 & 1 \\
\hline USC00105716 & McCammon & 37 & 1 \\
\hline USC00107208 & Pocatello $2 \mathrm{NE}$ & 32 & 1 \\
\hline USC00107346 & Preston & 33 & 1 \\
\hline USC00107644 & Rexburg BYU Idaho & 29 & 1 \\
\hline USC00108022 & Saint Anthony & 66 & 1 \\
\hline USC00108818 & Sugar City & 57 & 1 \\
\hline USC00108937 & Swan Valley & 54 & 1 \\
\hline USC00109065 & Tetonia Exp Stn & 39 & 1 \\
\hline USC00480027 & Afton & 47 & 1 \\
\hline USC00480140 & Alta 1 NNW & 83 & 1 \\
\hline USC00480603 & Bedford 3 SE & 24 & 1 \\
\hline USC00484910 & Jackson & 73 & 1 \\
\hline USS0010F23S & Phillips Bench & 38 & 2 \\
\hline USS0010G08S & Salt River Summit & 38 & 2 \\
\hline USS0010G12S & Kelley R.S. & 37 & 2 \\
\hline USS0010G23S & Willow Creek & 38 & 2 \\
\hline USS0010G25S & Cottonwood Creek & 35 & 2 \\
\hline USS0011F02S & Pine Creek Pass & 30 & 2 \\
\hline USS0011F11S & Sheep Mtn & 37 & 2 \\
\hline USS0011G01S & Somsen Ranch & 39 & 2 \\
\hline USS0011G05S & Slug Creek Divide & 39 & 2 \\
\hline USS0011G06S & Emigrant Summit & 38 & 2 \\
\hline USS0011G30S & Sedgwick Peak & 30 & 2 \\
\hline USS0011G32S & Franklin Basin & 39 & 2 \\
\hline USS0011G33S & Giveout & 36 & 1 \\
\hline USS0012G17S & Wildhorse Divide & 35 & 2 \\
\hline USS0012G18S & Oxford Spring & 37 & 2 \\
\hline USW00024145 & Idaho Falls Fanning Fld & 66 & 1 \\
\hline USW00024151 & Malad City & 61 & 1 \\
\hline USW00024156 & Pocatello Rgnl AP & 80 & 1 \\
\hline USW00094143 & Idaho Falls 46 W & 57 & 1 \\
\hline
\end{tabular}


The data screening also evaluated the independence of the data from each station. This is important because the underlying assumption in a regional analysis is that each measurement for annual winter maximum precipitation is independent and identically distributed. We evaluated the lag-1 serial correlation for each duration at all the stations. Figure 21 shows the sample correlation along with the $90 \%$ probability bounds of an uncorrelated series (Jenkins and Watts 1968). Overall, results indicate that all stations are within the $90 \%$ bounds and that no lag-1 correlation is included in our data. Another measure to determine if the winter maximum precipitation values in the region around the Willow Creek Watershed are independent is by evaluating the station cross-correlation versus distance. The literature has shown that stations are considered uncorrelated if the correlation measure is below $1 / e$, which is referred to as the decorrelation distance (Osborn and Hulme 1997). Based on the results in Figures 22 through 25, the decorrelation distance is $5^{-10}$ miles for all durations. This would suggest that independence between winter maximum precipitation values is likely for all the stations included in both Regions 1 and 2.

Figure 21. Lag-1 serial correlation plot for annual winter maximum precipitation shown with the $5 \%$ and $95 \%$ confidence interval $(\mathrm{Cl})$.

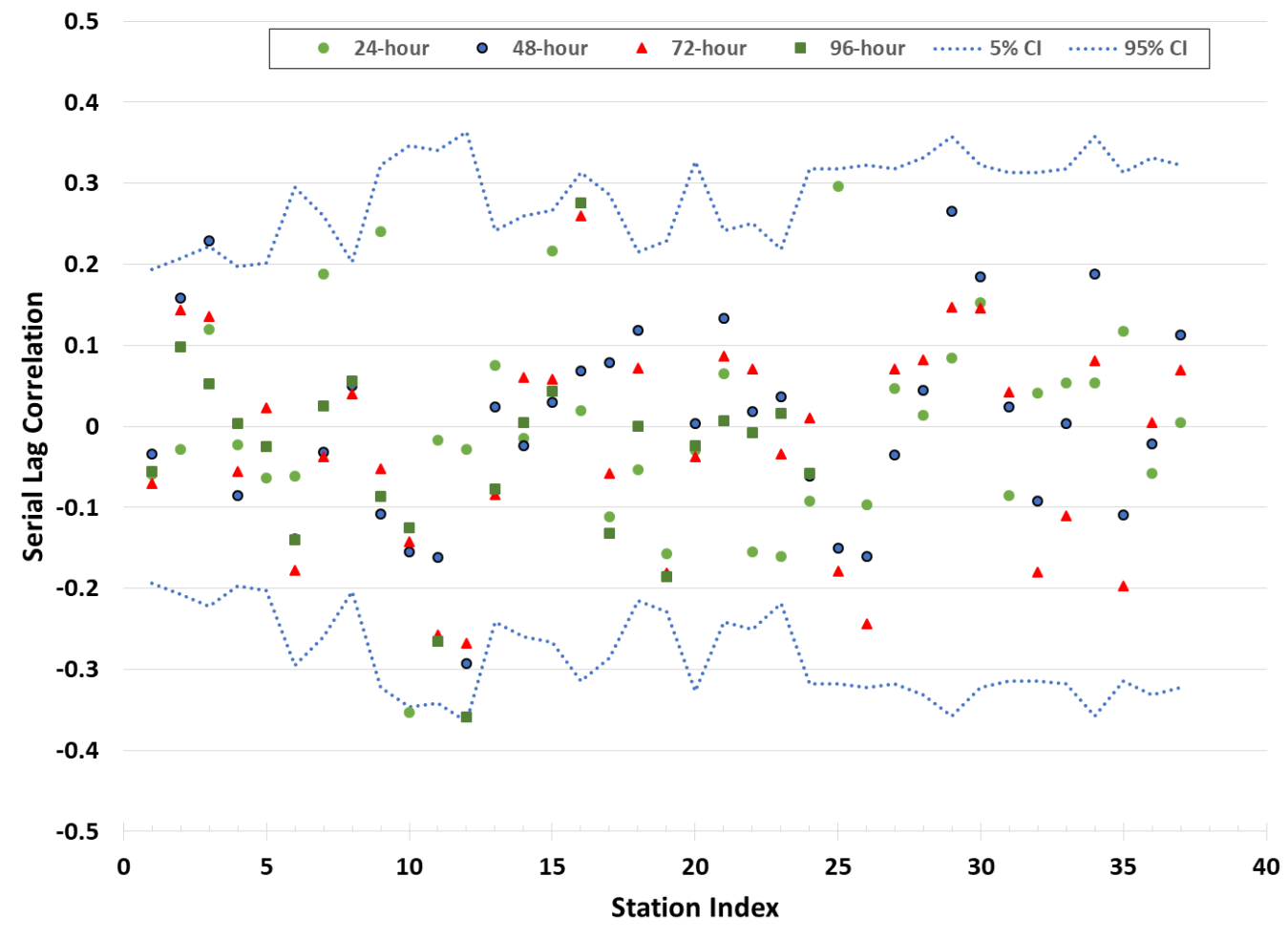


Figure 22. Station cross-correlation for 24-hour total precipitation.

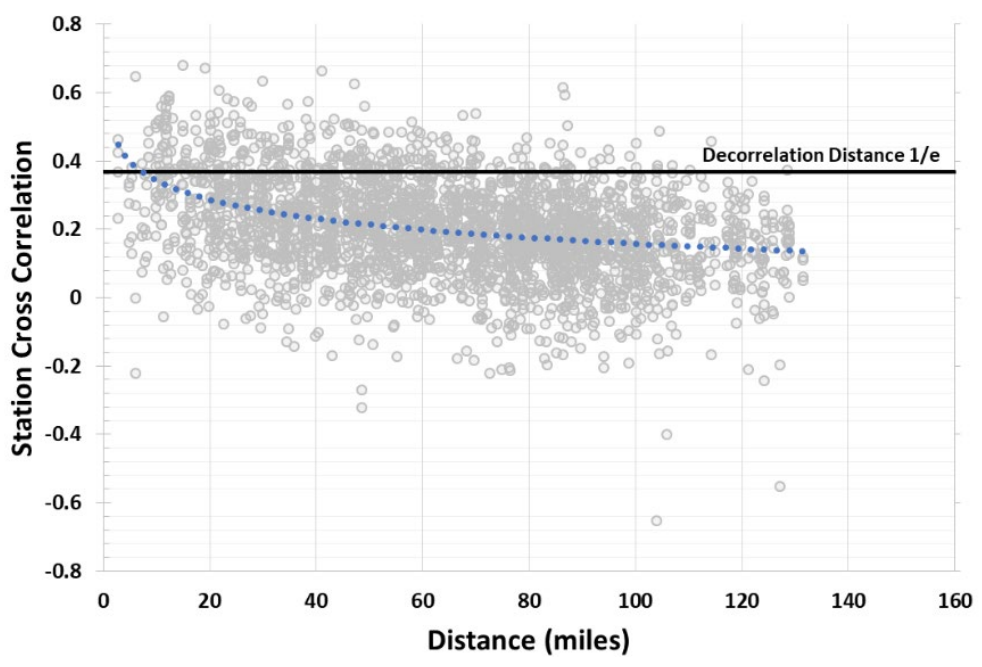

Figure 23. Station cross-correlation for 48-hour total precipitation.

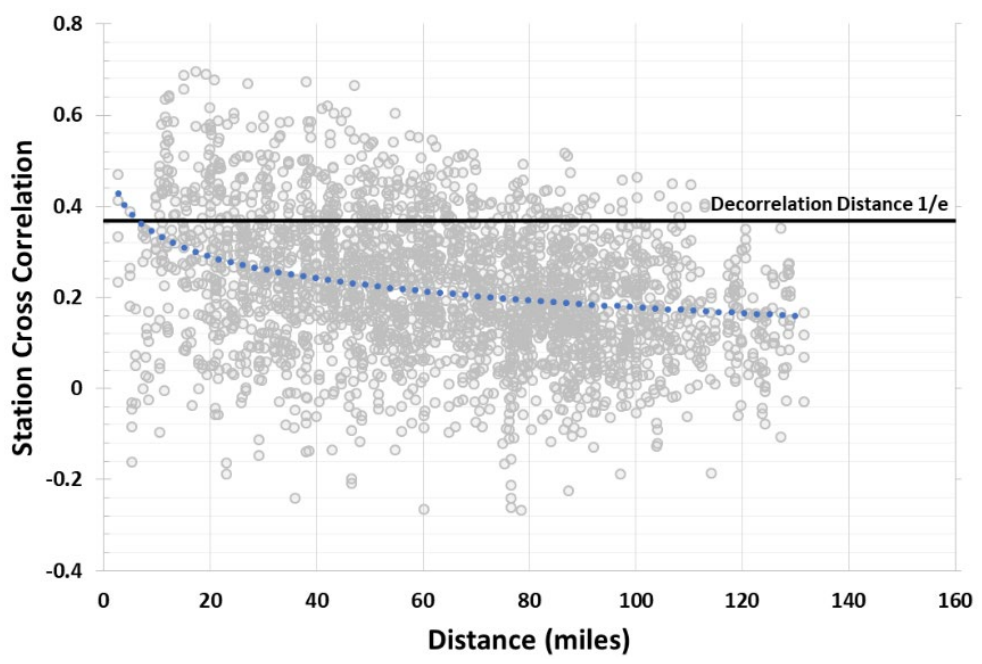

Figure 24. Station cross-correlation for 72-hour total precipitation.

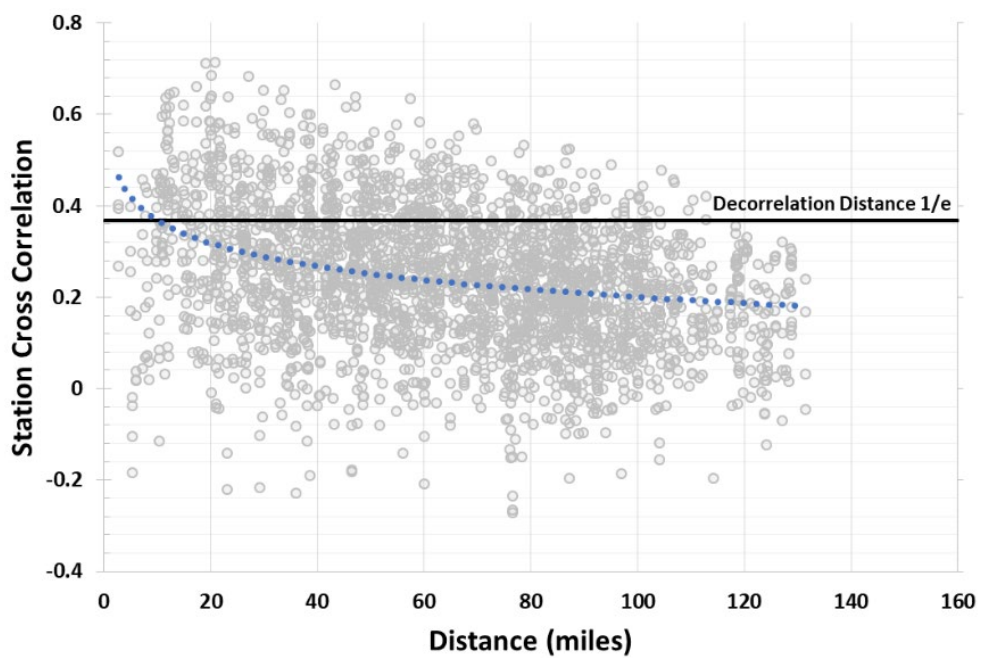


Figure 25. Station cross-correlation for 96-hour total precipitation.

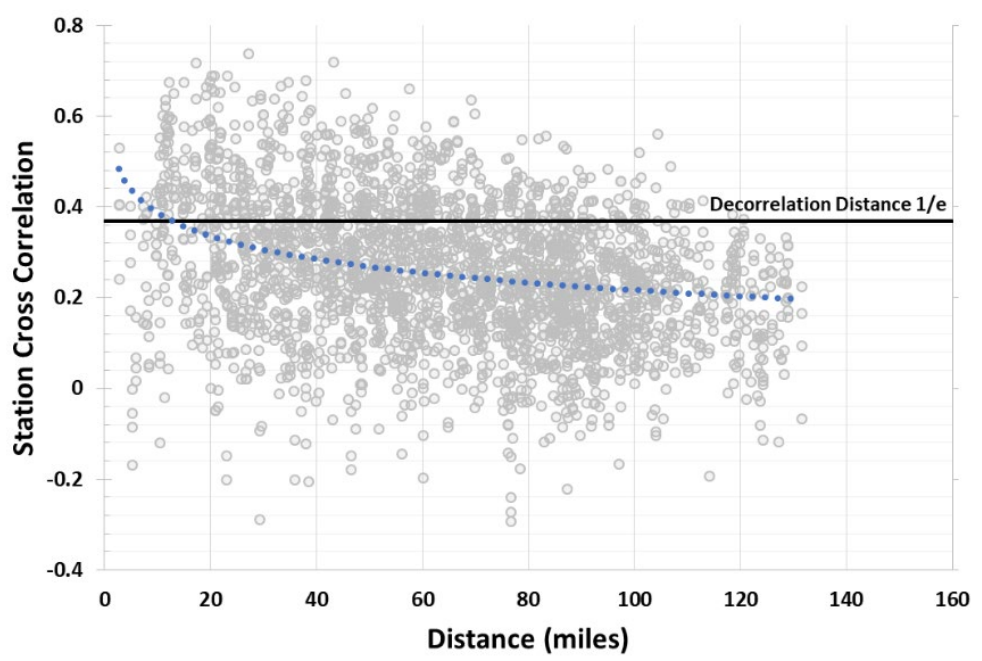

\subsubsection{Homogeneous regions}

One of the challenges with regional precipitation frequency is the grouping of ground-based stations into homogeneous regions (Sveinsson et al. 2002). These regions will inform the factors that are applied to all of the precipitation quantiles calculated at each station. The main idea with this process is to substitute spatial information (more stations) for time since the record lengths for all of these stations are relatively short when compared to the timeframe of geomorphic processes.

Determining homogeneity in a set of station records can be done with several different methods as outlined by Viglione et al. (2007). For our study, we used the heterogeneity measures described by Hosking and Wallis (1993), which compares the between-site variations in sample L-moments to what would be expected for a homogeneous region. The heterogeneity measure, $H$, is used as a guideline for whether a region is sufficiently homogenous. Hosking and Wallis (1993) recommends that when $H<1$, the region is acceptably homogeneous; and when $H \geq 2$, the region is heterogeneous. Values of $H$ between these thresholds could be heterogeneous, but there are not clear criteria in handling this situation.

The results of our analysis produced an $H$ measure of less than 1 for all durations using the Region 2 stations. In contrast, the $H$ values for Region 1 varied from less than 1 to greater than 1 . Table 7 summarizes the $H$ values. The Region 1 96-hour $H$ value indicates there may be some heterogeneity, but it did not surpass the threshold of 2 defined by Hosking and Wallis (1993); therefore, we kept all stations used to define Region 1. Figure 26 
shows the final delineation of regions that our precipitation frequency analysis used.

Table 7. Heterogeneity test results ( $H$ values).

\begin{tabular}{|l|c|c|}
\hline \multicolumn{1}{|c|}{ Duration } & Region 1 & Region 2 \\
\hline 24-hour & -1.634 & 0.002 \\
\hline 48-hour & 0.049 & -0.215 \\
\hline 72-hour & 0.706 & -1.313 \\
\hline 96-hour & 1.368 & -0.865 \\
\hline
\end{tabular}

Figure 26. The final stations included in each region.

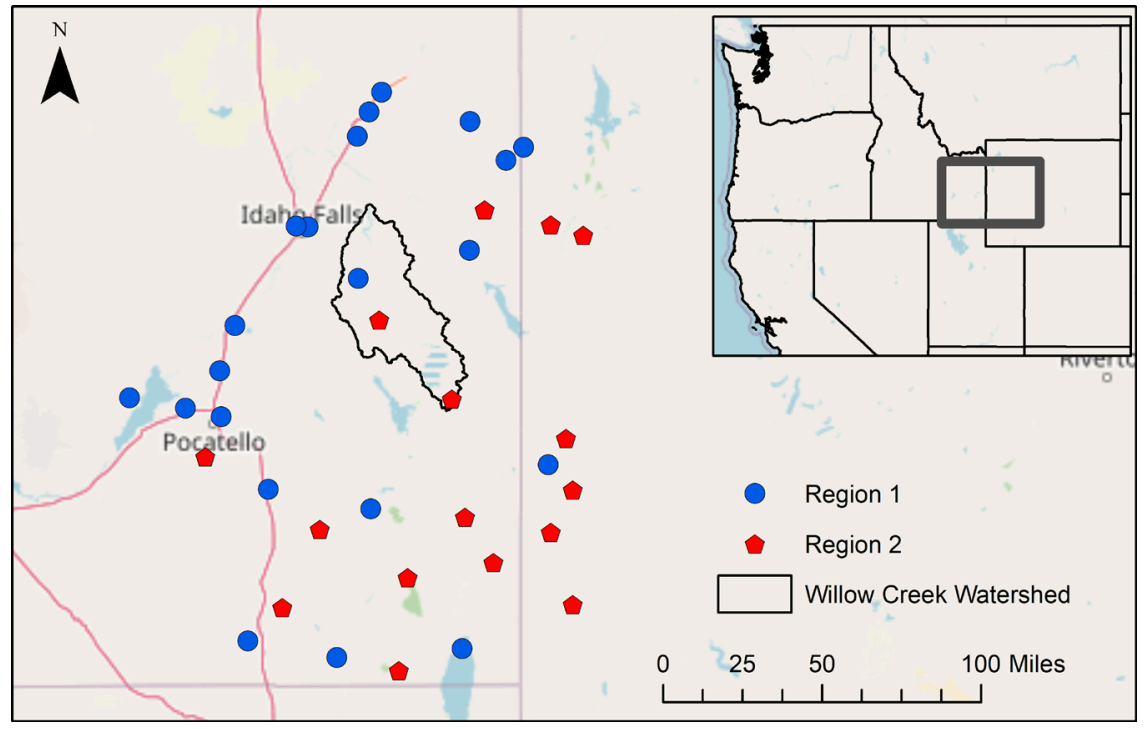

\subsubsection{Selection of the regional frequency distribution}

We used both graphical output and a goodness-of-fit measure (Kolmogorov-Smirnov) to select the distribution for each region. We concluded that the GEV distribution was the best fit for all durations and used it to develop the regional factors that are applied to each station quantile. Figure 27 shows the L-moment relationship for each duration associated with both Regions 1 and 2. The regional L-moments shown in Figure 27 are based on a weighted average of site-specific L-moments. The weighting is proportional to the record length for the individual site. This graphical output indicates that the GEV distribution provides a reasonable fit for the precipitation data in eastern Idaho. We also spatially interpolated the Lskew and L-kurtosis for the full domain of our analysis. Appendix A shows these plots for each duration. 
Figure 27. The L-moment relationship for Regions 1 and 2 by event duration.

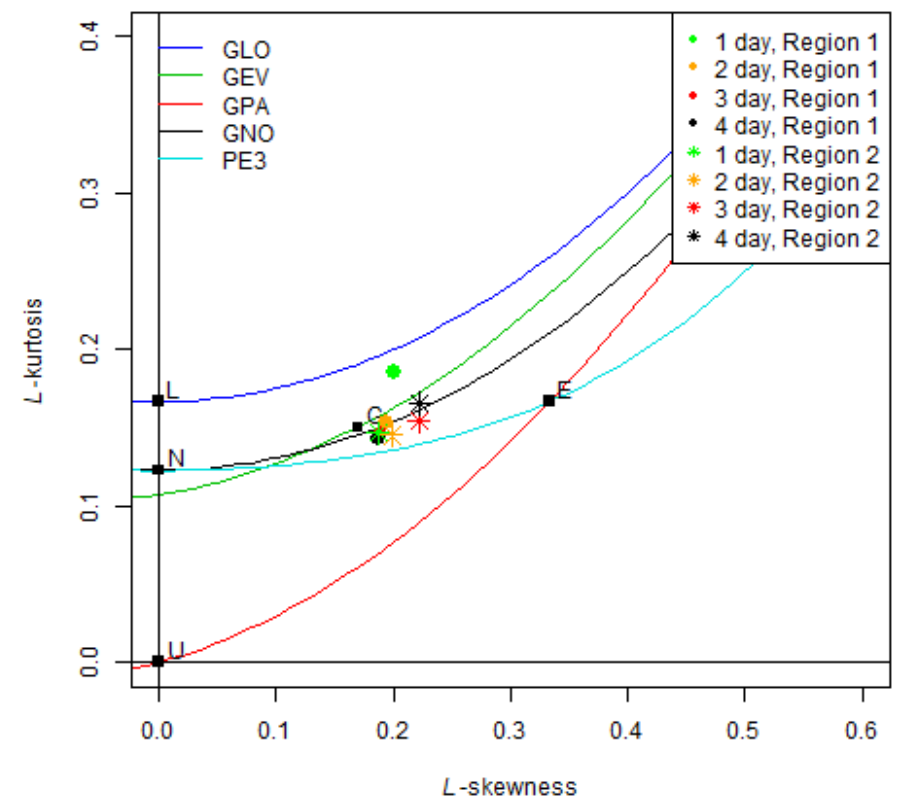

\subsubsection{Estimating regional frequency distribution quantiles}

Once we selected a distribution for each region, we computed the regional growth curves for both Regions 1 and 2. The growth curves provide a factor that is then applied to each station mean precipitation value (for a specific duration) to produce the station quantiles that include information from other locations in the region. Figure 28 shows the curve for each region. Section 3.3 describes the results for the regional quantiles, while Appendix A summarizes the regionally factored quantiles for each station.

Figure 28. The regional precipitation growth curve.

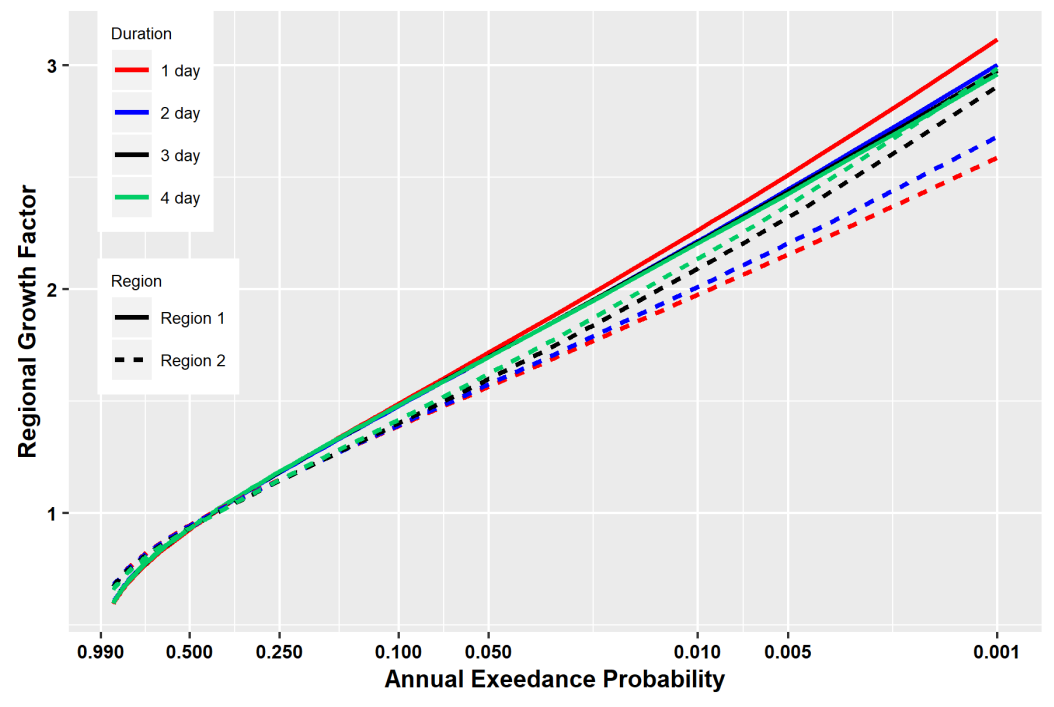




\subsubsection{Areal reduction factor}

Our analysis includes developing adjustments of point precipitation totals from ground-based stations to represent a zonally averaged total over a watershed. Due to heterogeneous characteristics of precipitation reaching the land surface during storm events, this adjustment, or areal reduction, varies by watershed area, geographic location, and storm duration. Our areal reduction estimates are derived from the ground-based stations discussed in section 3.1.

The existing literature proposes several methods for determining areal reduction factors (ARF) by using a range of data types. We selected the annual-maxima-centered approach described by Asquith and Famiglietti (2000) because it directly uses ground-based station data. Many other methods that are available utilize spatial datasets (e.g., PRISM [Parameter-Elevation Regressions on Independent Slopes Model], radar, etc.) to develop the ARF values. A review of ARF methods performed by Svensson and Jones (2010) did not identify any significant issues with the annualmaxima centered approach. For completeness, we provide in subsequent paragraphs a brief overview of the ARF process as described in Asquith and Famiglietti (2000).

We developed the ARF estimates by using winter seasonal maximum depths for each duration considered in our analysis. The process begins by cycling through each station included in the area of interest and designating this location the "base" station. We then used the annual winter maximum values over an established return period threshold (i.e., 2-year, 5year, and 10-year) to determine the precipitation dates at the base station. Higher return periods are generally not used in the ARF process because of the reduced sample size. Using those same dates, we then filtered precipitation depths at all other "alternative" locations on those same dates and calculated the depth ratio of alternative station to the base station. This process is repeated for each base station, 42 stations were used for the Willow Creek Basin, to create a sample of precipitation-depth ratios (relative to the base station) and distances between stations. Using the pooled sample, the median depth ratios were calculated for each distance. We plotted the median depth ratios against the station distances and fit an exponential decay curve to the data, which was then used to determine the ARF values. 
We compared our ARF results with those described in Hydrometeorological Report No. 57 (Hansen et al. 1994). The ARF from that report for a 72hour storm are approximately $83 \%, 97 \%, 86 \%$, and $93 \%$ for the entire watershed, Ririe, Ririe Upstream, and Grays Lake Subbasins, respectively. Our ARF results for the 72-hour storm (Figure 29) are very close to those in the Hydrometeorological Report No. 57 (Hansen et al. 1994). Table 8 summarizes the results of the ARF analysis using the annual maximum precipitation for 24-hour, 48-hour, 72-hour, and 96-hour durations.

Figure 29. Areal reduction factors for basin areas up to 700 square miles using the annual-maxima centered approach for a 72-hour duration.

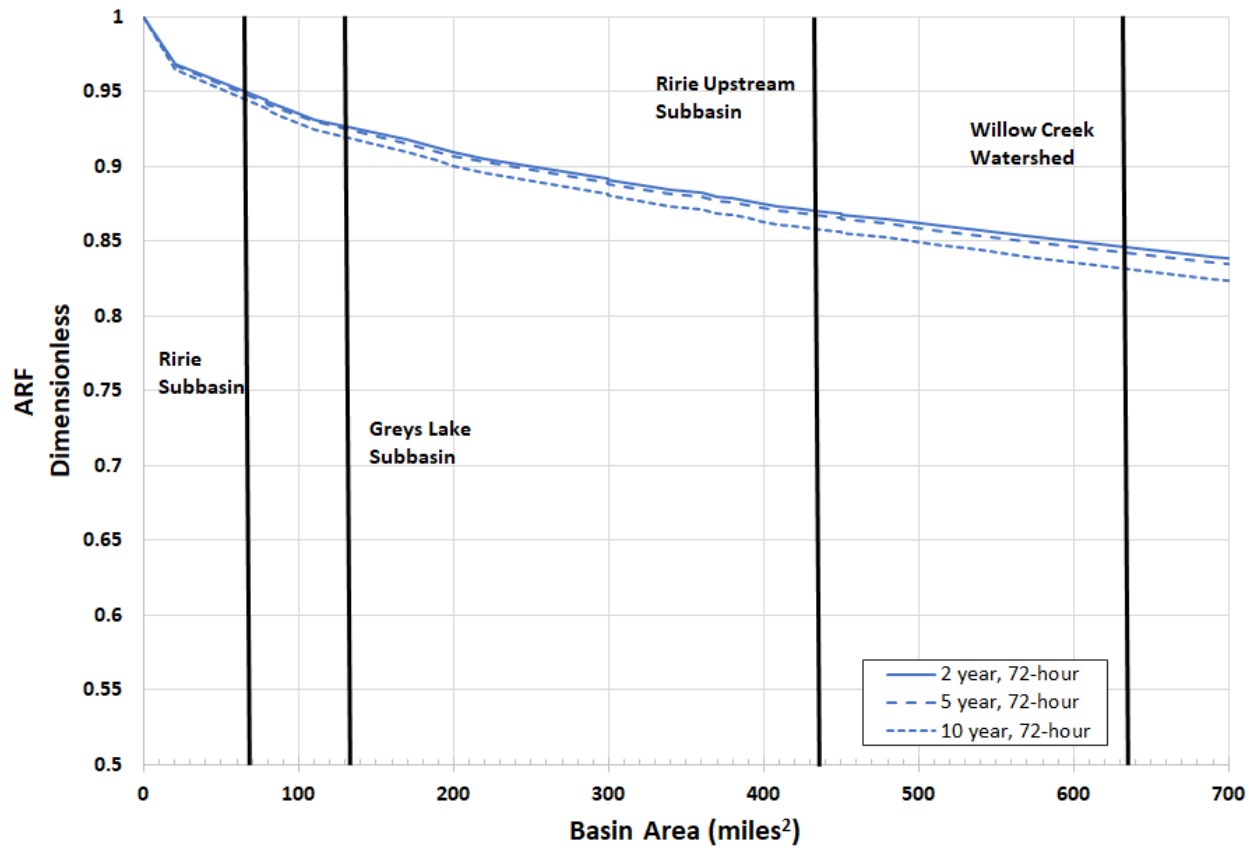

Table 8. Summary of ARF values for all durations.

\begin{tabular}{|c|c|c|c|c|c|c|c|c|c|c|c|c|c|}
\hline \multirow[b]{2}{*}{ Domain Limits } & \multirow{2}{*}{$\begin{array}{c}\text { Area } \\
\text { (square } \\
\text { miles) }\end{array}$} & \multicolumn{3}{|c|}{ 24-hour } & \multicolumn{3}{|c|}{ 48-hour } & \multicolumn{3}{|c|}{ 72-hour } & \multicolumn{3}{|c|}{ 96-hour } \\
\hline & & $\begin{array}{c}2- \\
\text { year }\end{array}$ & $\begin{array}{c}5- \\
\text { year }\end{array}$ & $\begin{array}{l}10- \\
\text { year }\end{array}$ & $\begin{array}{c}2- \\
\text { year }\end{array}$ & $\begin{array}{c}5- \\
\text { year }\end{array}$ & $\begin{array}{l}10- \\
\text { year }\end{array}$ & $\begin{array}{c}2- \\
\text { year }\end{array}$ & $\begin{array}{c}5- \\
\text { year }\end{array}$ & $\begin{array}{l}10- \\
\text { year }\end{array}$ & $\begin{array}{c}2- \\
\text { year }\end{array}$ & $\begin{array}{c}5- \\
\text { year }\end{array}$ & $\begin{array}{l}10- \\
\text { year }\end{array}$ \\
\hline Ririe Subbasin & 69 & 0.914 & 0.906 & 0.902 & 0.939 & 0.931 & 0.926 & 0.948 & 0.947 & 0.943 & 0.953 & 0.952 & 0.951 \\
\hline Ririe Upstream & 436 & 0.790 & 0.771 & 0.762 & 0.848 & 0.828 & 0.818 & 0.870 & 0.867 & 0.858 & 0.882 & 0.878 & 0.877 \\
\hline Grays Lake & 132 & 0.878 & 0.867 & 0.861 & 0.913 & 0.901 & 0.896 & 0.926 & 0.925 & 0.919 & 0.934 & 0.931 & 0.931 \\
\hline Watershed & 640 & 0.752 & 0.731 & 0.721 & 0.819 & 0.796 & 0.785 & 0.845 & 0.842 & 0.831 & 0.860 & 0.855 & 0.854 \\
\hline
\end{tabular}

\subsubsection{Spatial interpolation of quantiles}

The objective of our analysis was to develop precipitation quantiles that could be used within a hydrologic model. Therefore, we used ordinary kriging as the spatial interpolation method to create a continuous surface 
of precipitation depths over the regional domain. Once the interpolation was completed, the zonal mean values were determined for each subbasin and for the entire watershed.

Ordinary kriging incorporates the covariance structure of the groundbased station precipitation values into the weights that are used to predict other locations away from the station. The weights include the covariance between locations in the data sample. In this study, the kriging interpolation was completed with the python package "pyKrige" (Murphy et al. 2020) using a spherical variogram. A more detailed explanation of ordinary kriging can be found in Maidment (1993). Figure 30 shows the spatial interpolation of regionally factored quantiles. The zonal average values for each AEP are based on these interpolation surfaces. The zonal average values will be used to determine the Willow Creek Watershed precipitation distribution parameters that can be used within the HEC-WAT software.

Figure 30. Spatial interpolation results using kriging for the precipitation analysis domain.

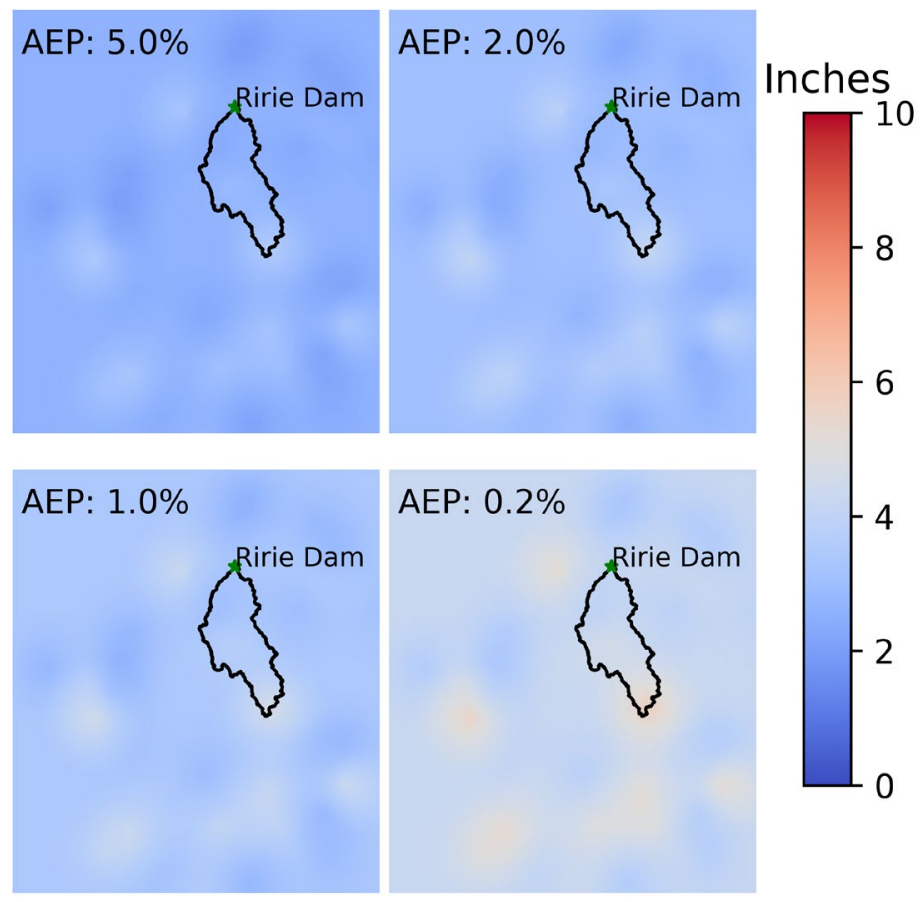

\subsubsection{Hourly to daily maximum value adjustment}

In environments where there are storms that have significant variability in hourly intensity, adjustments to the annual maximum time series may be needed because the maximum 24-hour storm duration (or any other duration being evaluated) may not correspond with the time interval reported in 
daily precipitation data. For example, the annual maximum 24-hour depth may cross over between dates; but due to the resolution of daily data reported by NCEI, this event may not be computed as the maximum for the year. To correct for this, Wallis et al. (2007) suggest that a relationship between the annual maximum depths derived from hourly and daily time series can be developed to adjust for this time-resolution discrepancy. Wallis et al. (2007) reports that a ratio of 1.13 is often applied to the daily data.

The procedure requires that both hourly and daily data from the same stations be used. For our analysis, there were limited locations within the regions that reported both time intervals (Table 9). We computed the annual maximum values for the 24-hour, 48-hour, 72-hour, and 96-hour durations using aggregated hourly data. We then plotted this data against the annual maximums for the same durations derived from daily data at these specific locations and fit a line using the least-squares method.

Table 9. The stations used to develop the hourly to daily annual maximum time-series relationships.

\begin{tabular}{|l|l|}
\hline \multicolumn{1}{|c|}{ ID } & \multicolumn{1}{c|}{ Location } \\
\hline USC00103732 & Grace \\
\hline USC00104456 & Idaho Falls 16 SE \\
\hline USC00109065 & Tetonia Exp Stn \\
\hline USC00484910 & Jackson \\
\hline USW00024145 & Idaho Falls Fanning Fld \\
\hline USW00024156 & Pocatello Rgnl Ap \\
\hline USS0010F23S & Phillips Bench \\
\hline USS0010G08S & Salt River Summit \\
\hline USS0010G12S & Kelley R.S. \\
\hline USS0010G23S & Willow Creek \\
\hline USS0010G25S & Cottonwood Creek \\
\hline USS0011F02S & Pine Creek Pass \\
\hline USS0011F11S & Sheep Mtn \\
\hline USS0011G01S & Somsen Ranch \\
\hline USS0011G05S & Slug Creek Divide \\
\hline USS0011G06S & Emigrant Summit \\
\hline USS0011G30S & Sedgwick Peak \\
\hline USS0011G32S & Franklin Basin \\
\hline USS0011G33S & Giveout \\
\hline USS0012G17S & Wildhorse Divide \\
\hline USS0012G18S & Oxford Spring \\
\hline
\end{tabular}


Figure 31 shows the results of our hourly to daily comparison. Table 10 summarizes the final factors that were applied to the L-mean values for all stations during the distribution fitting process.

Figure 31. The hourly to daily relationship for 24-hour annual maximums.

(a) 24-hour

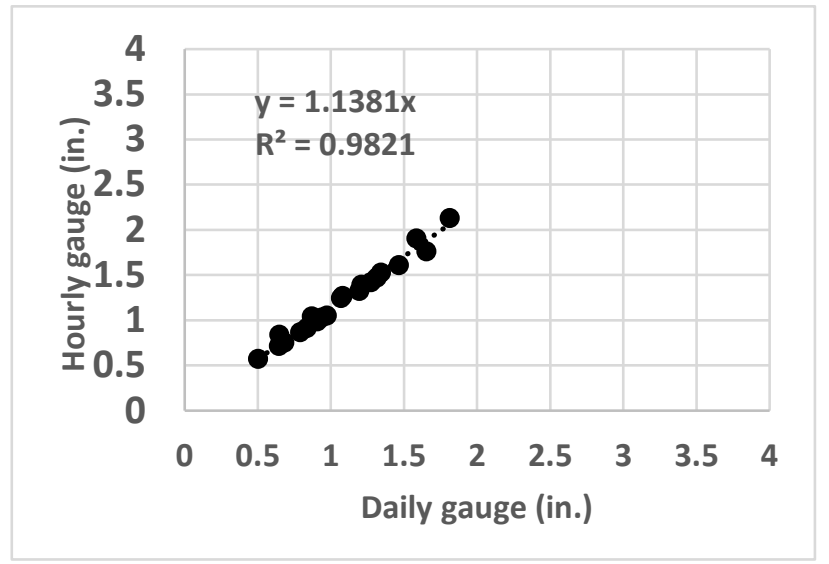

(c) 72-hour

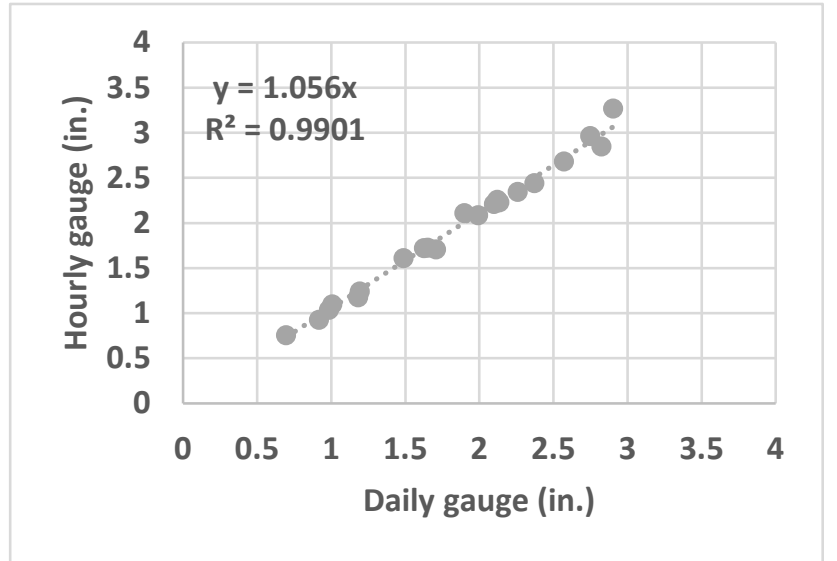

(b) 48-hour

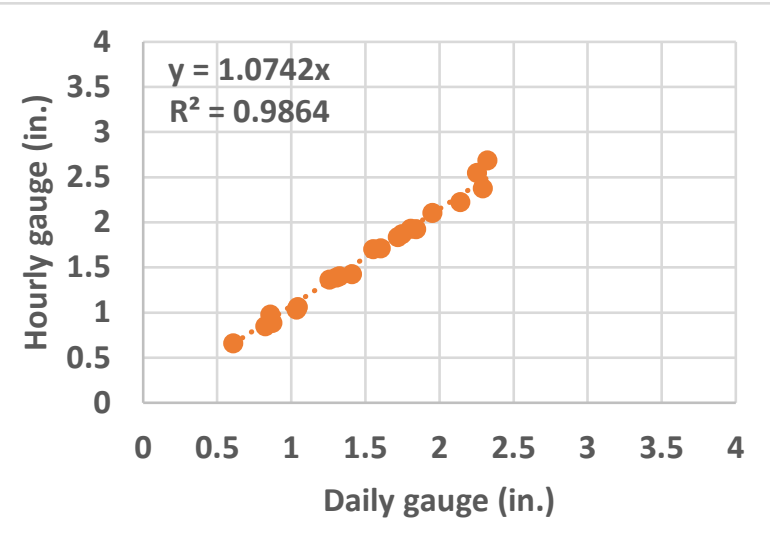

(d) 96-hour

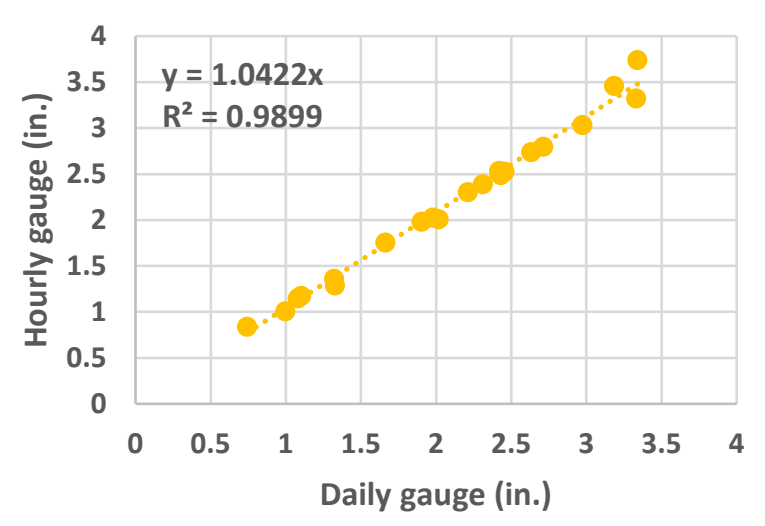

Table 10. Hourly to daily factors applied to L-mean values.

\begin{tabular}{|c|c|}
\hline Duration & L-Mean Factor \\
\hline $24-h o u r$ & 1.138 \\
\hline 48 -hour & 1.074 \\
\hline 72 -hour & 1.056 \\
\hline $96-$ hour & 1.042 \\
\hline
\end{tabular}




\subsection{Precipitation results}

The results we show in this section are for all durations (24-hour, 48-hour, 72-hour, and 96-hour), using the boundaries for the entire watershed and the three subbasins (Ririe, Ririe Upstream, and Grays Lake). We anticipated that the hydrology modeling that uses the information from our study will focus on the 72-hour events; however, we include other durations in this report for completeness.

Figure 32 show the ARF-adjusted quantiles for the Willow Creek Basin. The ARF adjustments are based on the 2-year values for each duration shown in Table 11. The plots demonstrate internal consistency (i.e., longer durations have greater depths) for each of the subbasins. Additional plots with ARF-adjusted quantiles for each subbasin are in Appendix A.

As we discussed previously, there have been no updates to NOAA Atlas 2 or Technical Paper 49 (Miller et al. 1973; Miller 1964)for Idaho, and the published values are maximums from all seasons (not just winter). However, it is still worthwhile to compare these precipitation quantiles to the values found in our analysis to ensure our results are reasonable compared to past studies. The only event duration that coincides with Atlas 2 is the 24-hour duration. The values for the Willow Creek Basin from Atlas 2 are point estimates that still need reduction using an ARF value. The Atlas 2 depths, after applying the 2-year total watershed ARF value for a 24-hour event from Table 8, range from 1.8 to $1.9 \mathrm{in}$. for the 50-year event and from 1.9 to $2.1 \mathrm{in}$. for the 100-year event. Based on Figure 32, our values are near the lower end of each of these ranges but are still reasonably close in comparison. The standard error reported in Atlas 2 for the area that contains the Willow Creek Basin is 0.32 in., which indicates that our results would be within the error bounds for the Atlas 2 values.

We also compared results for longer-duration events to the values in Technical Paper 49 (Miller 1964). There are two published durations that coincide with our analysis: the 48-hour and 96-hour events. Again, we applied the 2-year total watershed ARF values from Figure 9 that correspond to the duration in Technical Paper 49. The values from Technical Paper 49 for the 48-hour 50-year and 100-year return periods are approximately 2.1 and 2.5 in., respectively. The 50-year and 100-year values for a 96-hour event are approximately 2.6 and 3.0 in., respectively. Our 48 -hour results are nearly identical to those found in Technical Paper 49 for both return periods. However, our 96-hour results are higher than what is reported in Technical 
Paper 49. Due to the large number of years that our analysis included compared to the period of record used to develop Technical Paper 49, these higher values may be due to inclusion of more atmospheric-river events in the record than what was available in the mid-196os. In addition, high-elevation precipitation from SNOTEL sites was not available when Technical Paper 49 was developed. Further investigation of these differences may be required if the 96-hour duration will be used in hydrologic modeling.

Table 11 summarizes the ARF-adjusted quantiles for the Willow Creek Basin. Appendix A provides additional tabular results, which include the quantiles for each subbasin.

Figure 32. Willow Creek Basin winter precipitation AEP with 24-hour, 48-hour, 72-hour, and 96-hour durations using 2-year ARF values.

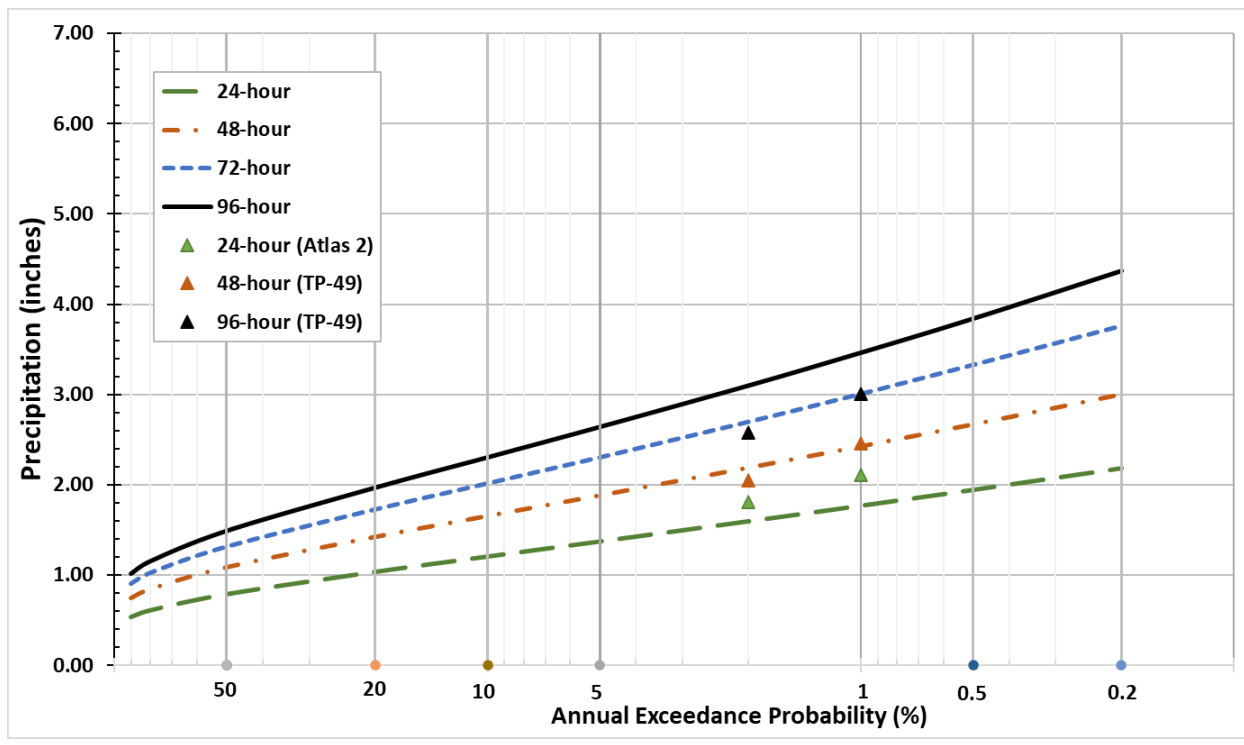

Table 11. Summary of computed winter AEP quantiles for the Willow Creek Basin (precipitation depths).

\begin{tabular}{|l|c|c|c|c|}
\hline AEP (\%) & 24-hour & 48-hour & 72-hour & 96-hour \\
\hline 90 & 0.54 & 0.75 & 0.90 & 1.01 \\
\hline 80 & 0.61 & 0.85 & 1.02 & 1.15 \\
\hline 50 & 0.79 & 1.09 & 1.31 & 1.49 \\
\hline 20 & 1.04 & 1.43 & 1.72 & 1.97 \\
\hline 10 & 1.21 & 1.66 & 2.01 & 2.30 \\
\hline 5 & 1.37 & 1.89 & 2.30 & 2.64 \\
\hline 2 & 1.60 & 2.19 & 2.70 & 3.10 \\
\hline 1 & 1.77 & 2.43 & 3.01 & 3.46 \\
\hline 0.5 & 1.94 & 2.67 & 3.33 & 3.84 \\
\hline 0.2 & 2.18 & 3.01 & 3.76 & 4.37 \\
\hline
\end{tabular}




\subsection{Uncertainty analysis}

Quantifying the uncertainty associated with the regional analysis followed the procedure outlined in Hosking and Wallis (1997). The general concept is to find the confidence bounds on the estimate of the regional growth factors. Then, either increase (upper confidence bound) or decrease (low confidence bound) the regional growth factor to define the uncertainty associated with each region and duration. We applied kriging to spatially distribute the precipitation depths for both the upper and lower confidence bounds at each return period. We then computed the zonal mean to determine the values, which can be used in the hydrology model.

To perform this analysis, the function "regsimq" was used from the "lmomRFA" package in R (Hosking 2019). This function randomly permutates the frequency distributions for the ground-based stations using intersite correlation to generate a realization. For our study, we used the average correlation for each region and duration as input to this function. Once data have been generated, a GEV distribution is fit to the simulated data. The sample mean and quantiles for the regional growth curve are estimated from each realization for each user-defined probability. In our analysis, we generated 10,000 realizations from which the $5 \%$ and $95 \%$ confidence bounds are inferred at the $0.99,0.5,0.25,0.1,0.05,0.01,0.005$ AEP values. Figures 33 through 36 show the results generating confidence bounds on the regional growth curves using this method.

Figure 37 shows the spatial interpolation for the 20-year, 50-year, 100year, and 500-year return intervals at both the $5 \%$ and $95 \%$ confidence bounds. Again, we computed the zonal average values for each return period and confidence bound. Figures 38 through 41 show the final precipitation regional frequency quantiles (with confidence bounds) for the Willow Creek Basin using different ARF values. The uncertainty in the quantiles is primarily due to the regional growth factors. The uncertainty of the growth factors does vary by region due to the intersite correlation, which reduces the number of independent annual maximum values. Region 2, which is mostly values from SNOTEL stations, has a much lower total station-year sample size and therefore has larger confidence bounds.

As we discussed in section 3.2.2.7, there is additional uncertainty associated with the ARF values depending on the threshold return period used. However, when we applied the limits of the ARF values to the quantiles for the watershed, there was minimal difference in depths. This demonstrates 
that using the ARF method we selected, there is not high sensitivity to that threshold value. In addition, the uncertainty associated with the ARF is much less than the uncertainty associated with the regional growth factors.

Figure 33. The regional growth curve with confidence bounds for a 24-hour duration.

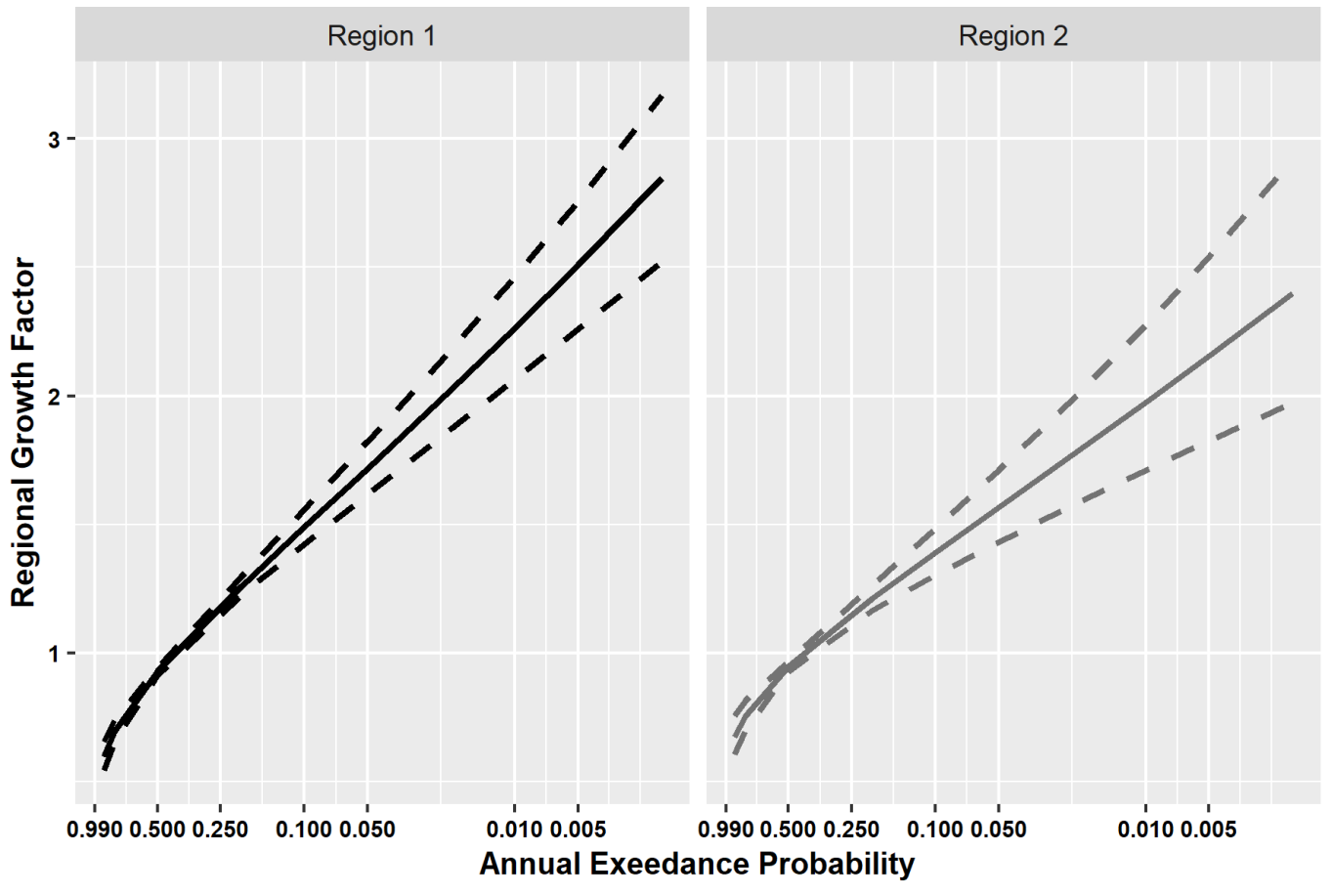

Figure 34. The regional growth curve with confidence bounds for a 48-hour duration.

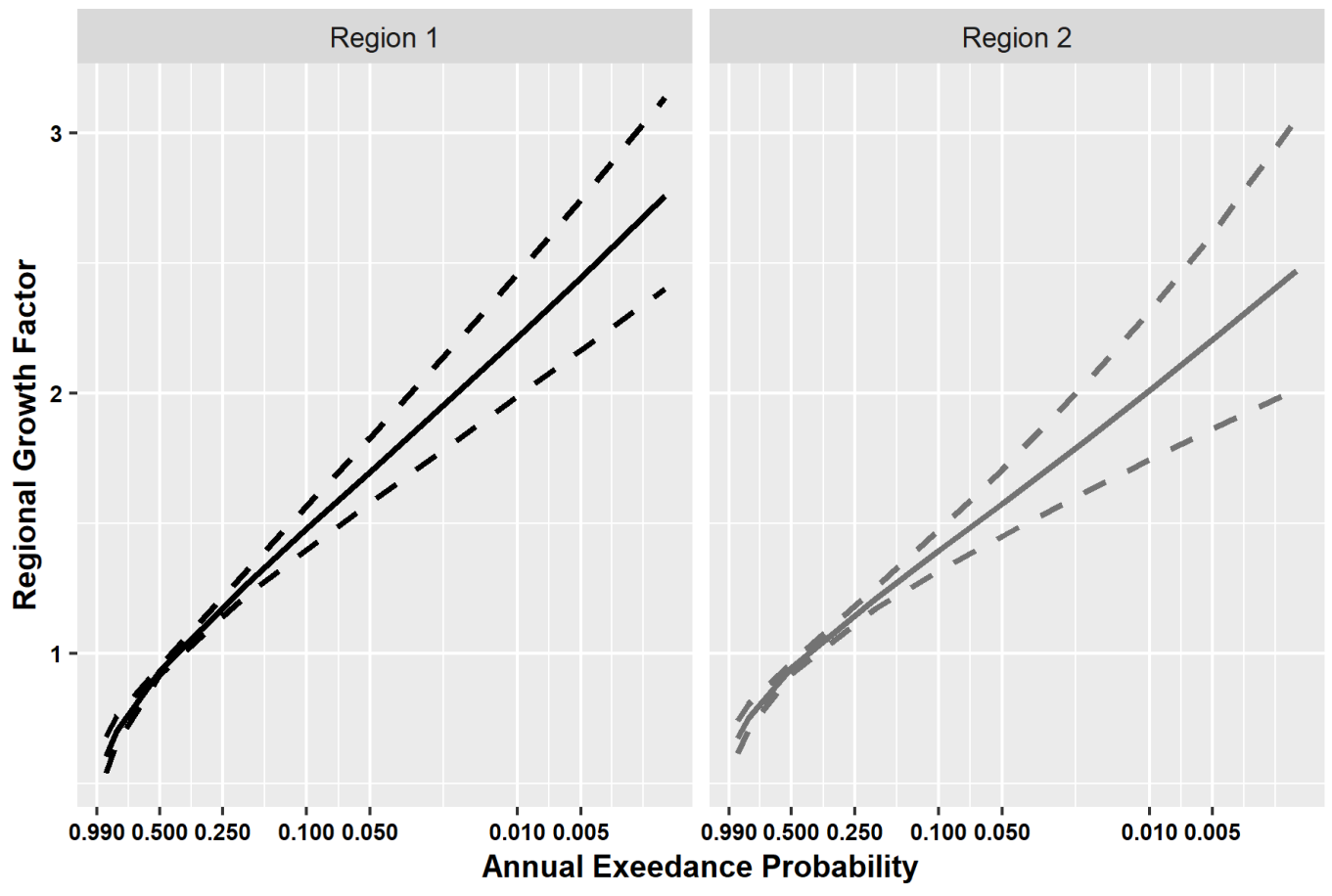


Figure 35. The regional growth curve with confidence bounds for a 72-hour duration.

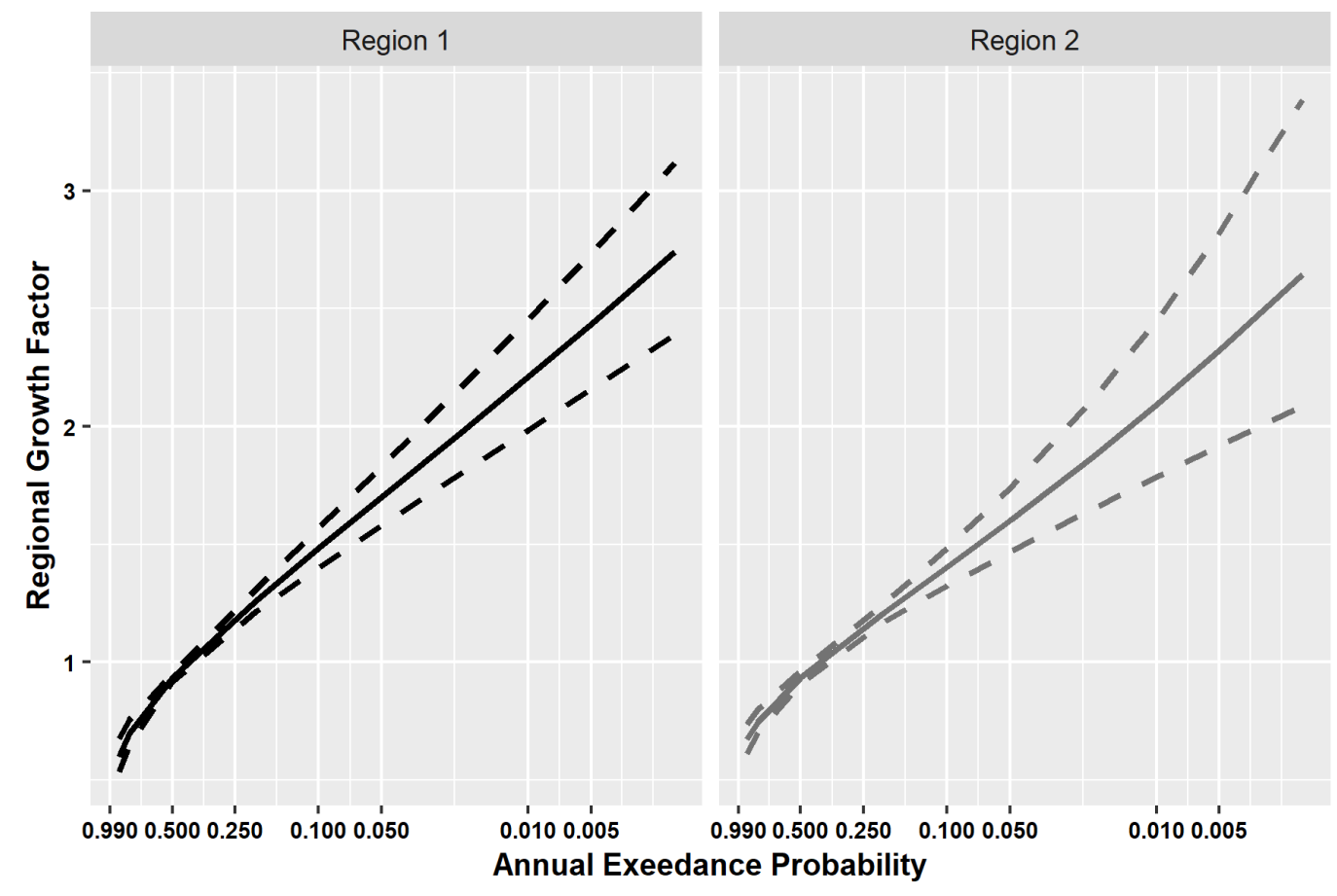

Figure 36. The regional growth curve with confidence bounds for a 96-hour duration.

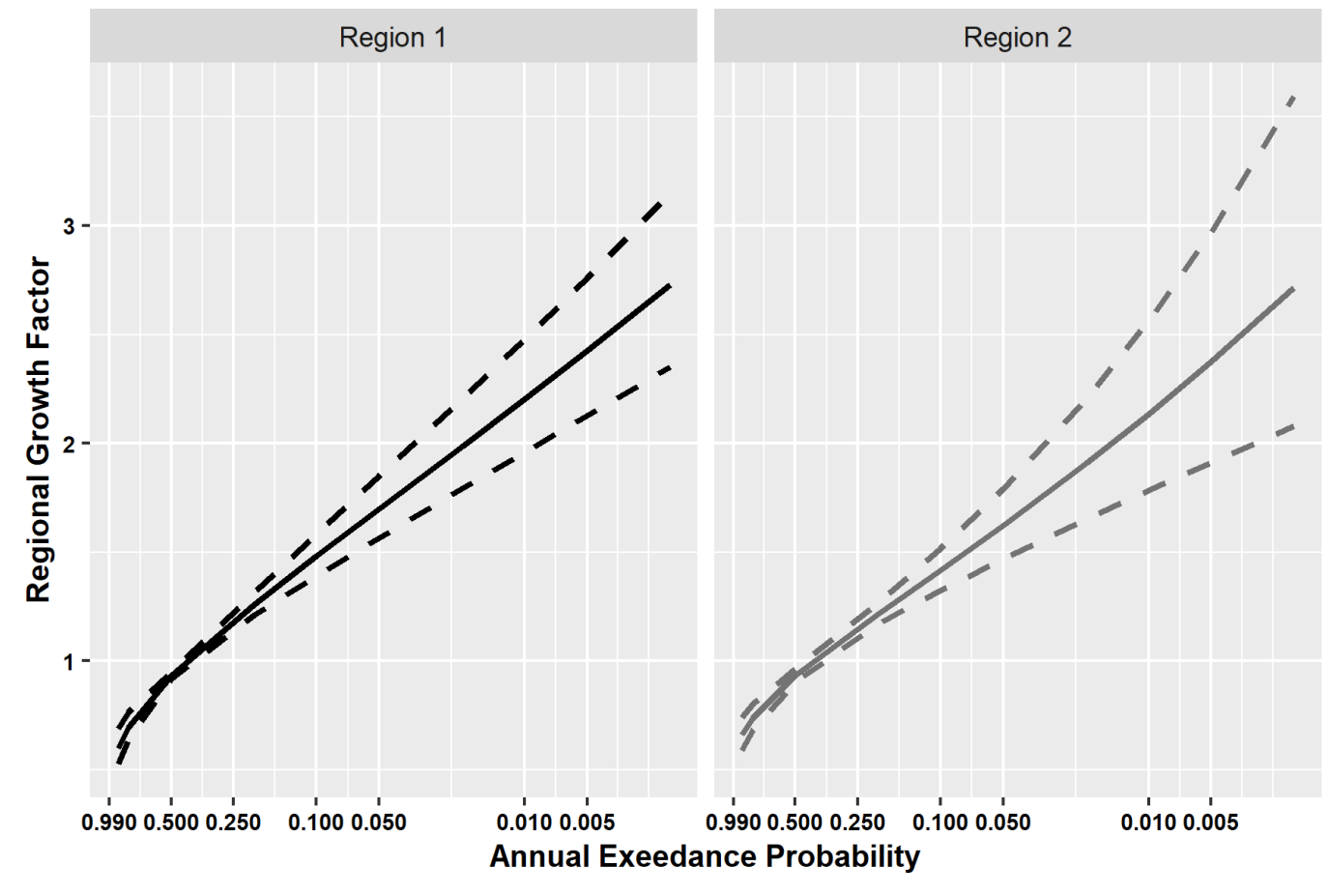


Figure 37 . Spatially distributed $5 \%$ and $95 \%$ confidence bounds for the (a) $5 \%$ AEP, (b) $2 \%$ AEP, (c) 1\% AEP, and (d) $0.5 \%$ AEP precipitation depths.

(a)
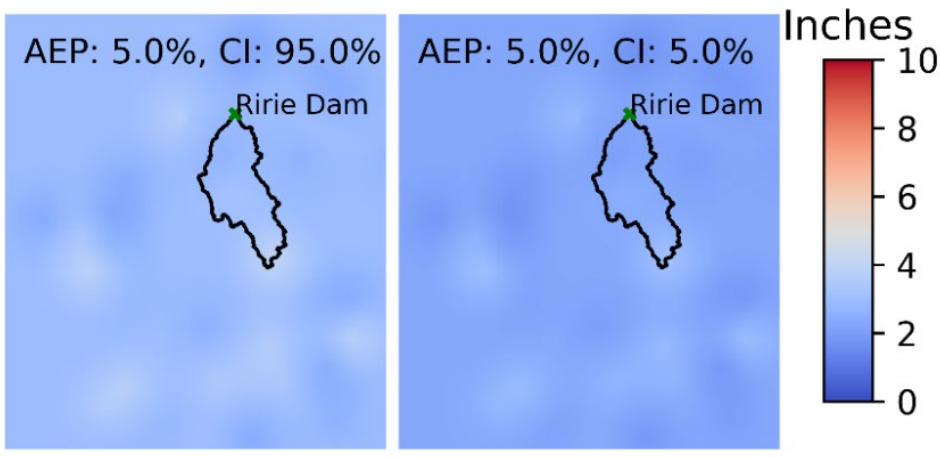

(b)

AEP: $2.0 \%, \mathrm{Cl}: 95.0 \%$
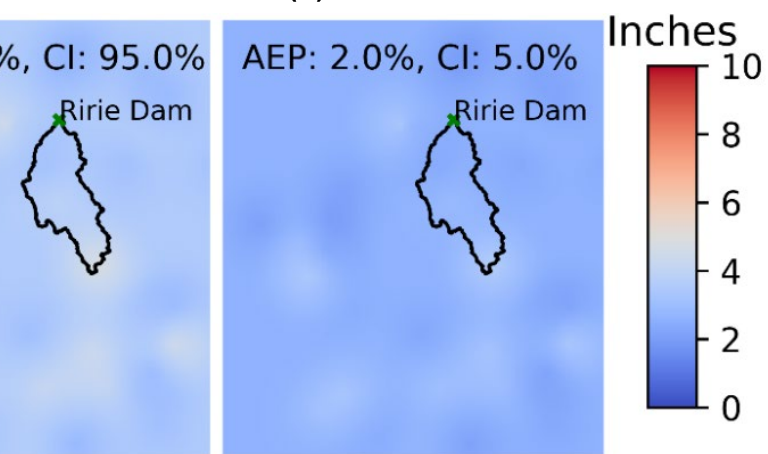

(c)

AEP: $1.0 \%, \mathrm{Cl}: 95.0 \%$
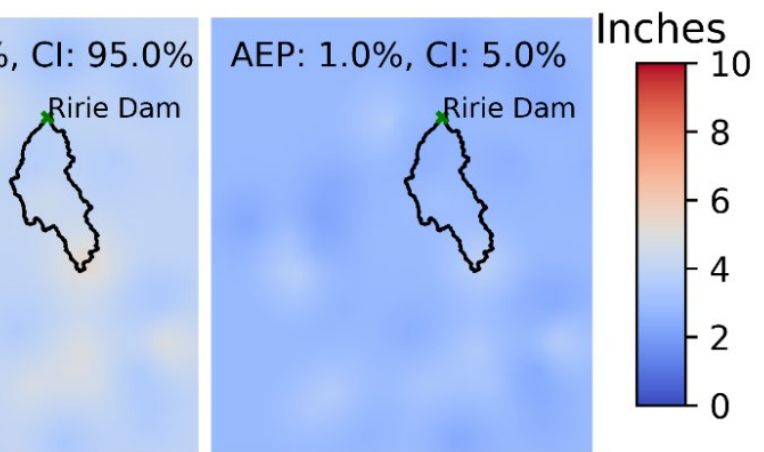

(d)

AEP: $0.2 \%, \mathrm{Cl}: 95.0 \%$
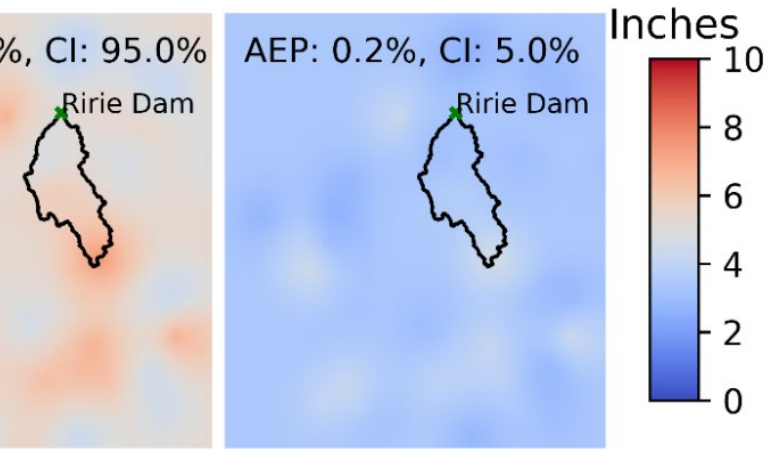
Figure 38. A comparison of the 2-year and 10-year ARF values for the Willow Creek Basin 24-hour quantiles.

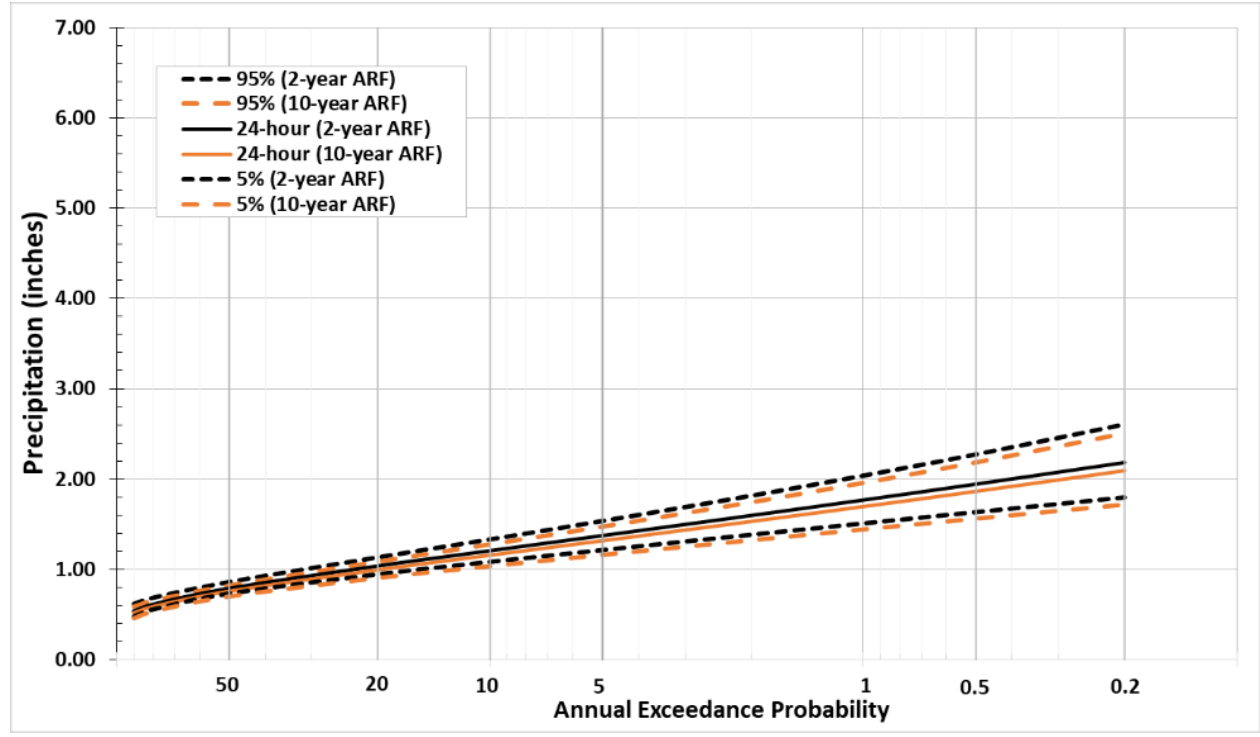

Figure 39. A comparison of the 2-year and 10-year ARF values for the Willow Creek Basin 48-hour quantiles with confidence bounds.

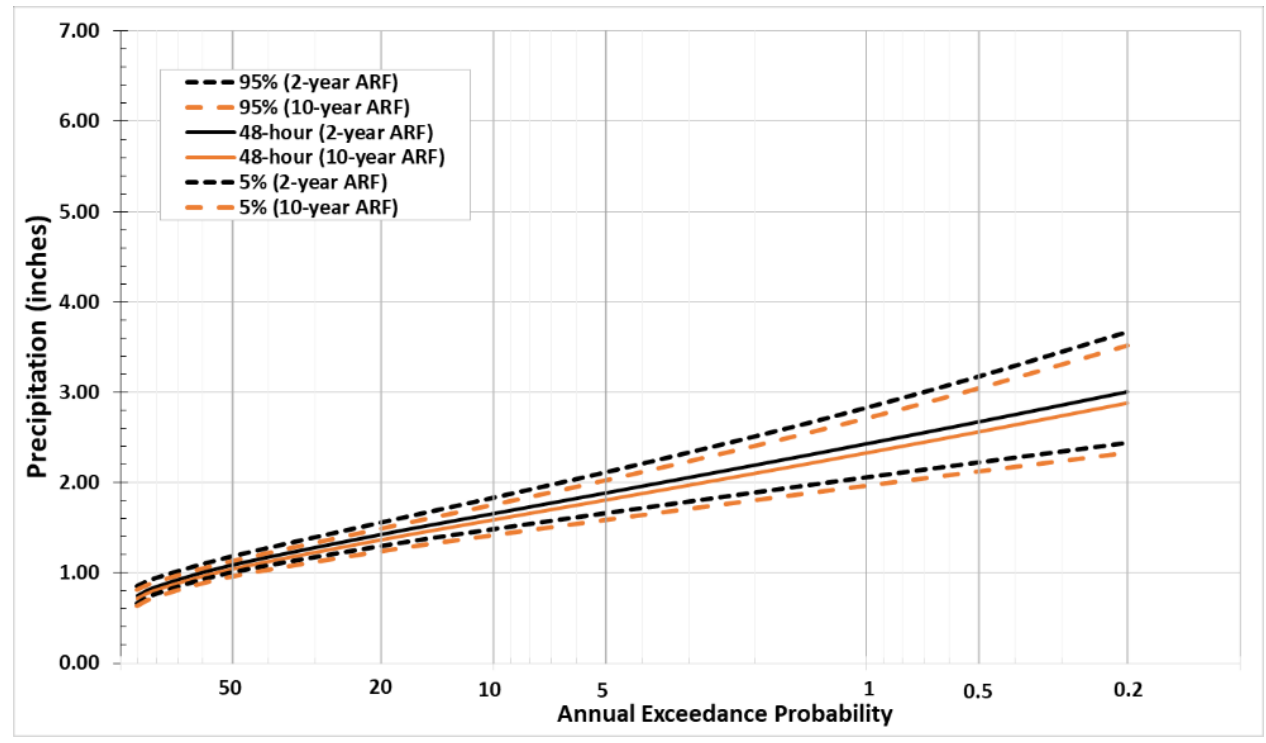


Figure 40. A comparison of the 2-year and 10-year ARF values for the Willow Creek Basin 72-hour quantiles with confidence bounds.

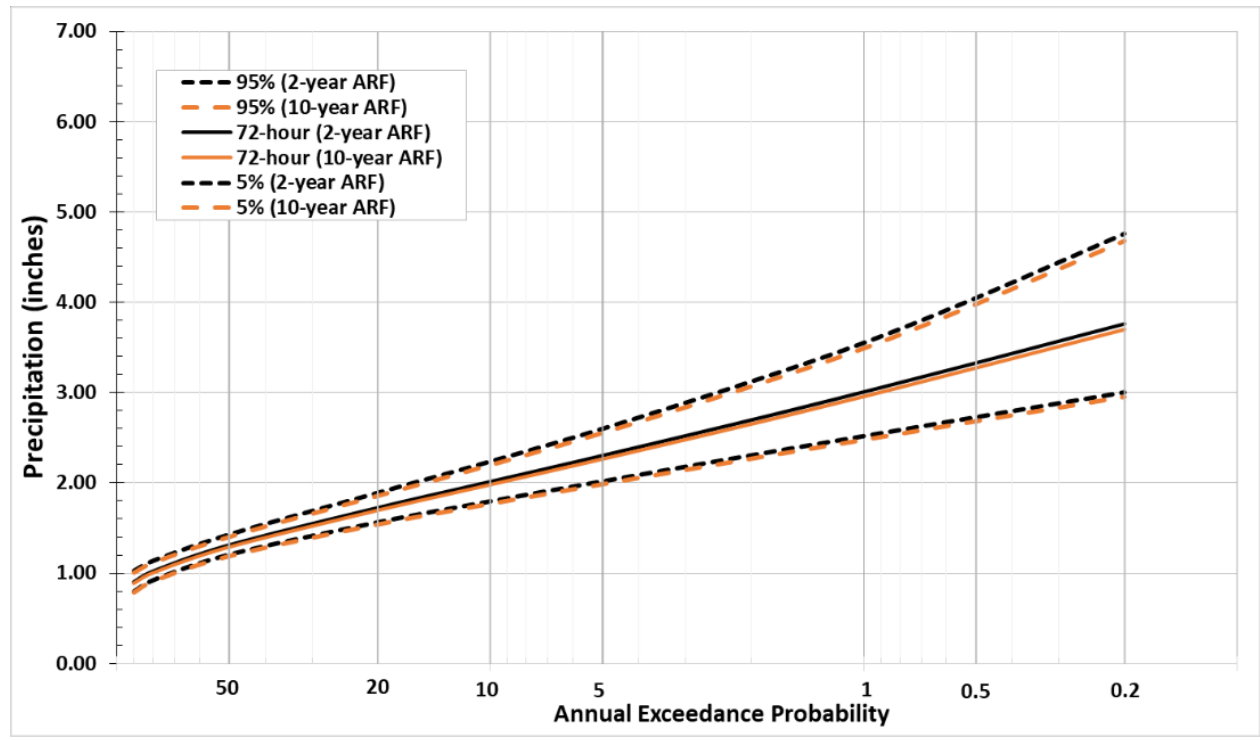

Figure 41. A comparison of the 2-year and 10-year ARF values for the Willow Creek Basin 96-hour quantiles with confidence bounds.

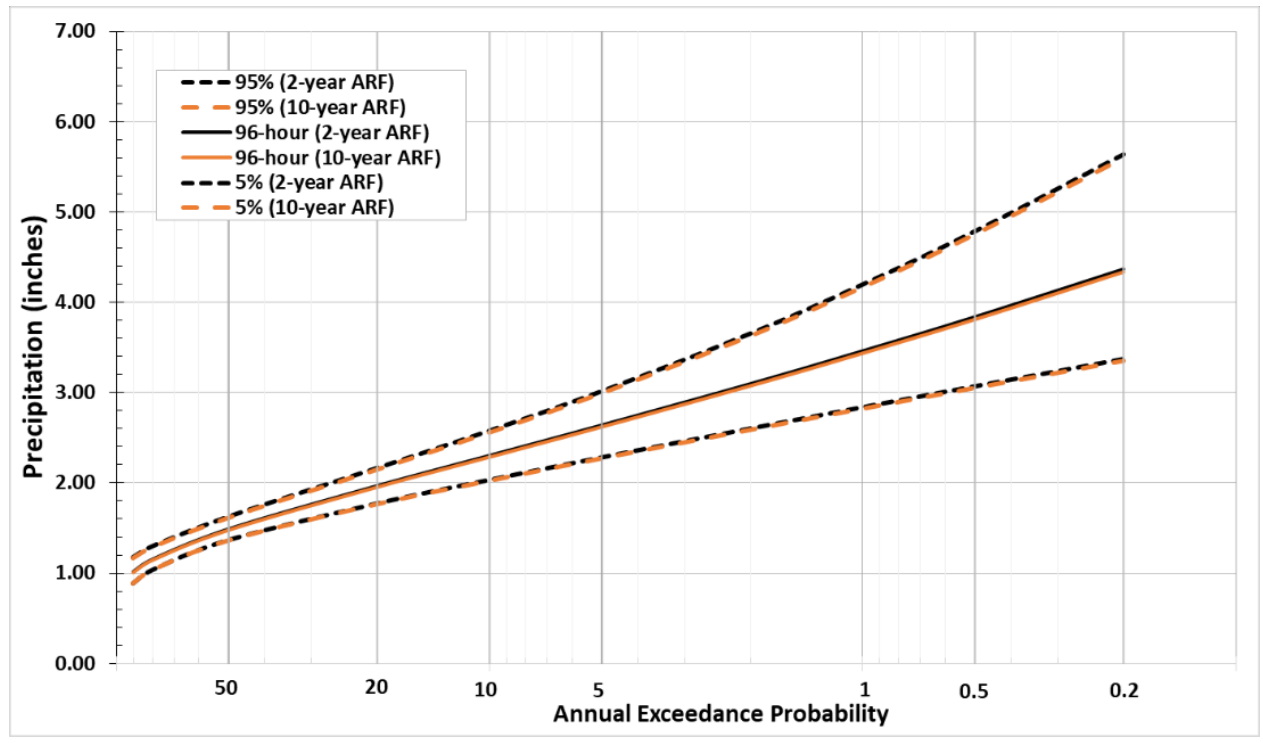

\subsection{Equivalent uncorrelated record length}

The purpose of performing a regional frequency analysis is to increase the sample size that is used to estimate distribution parameters and thus reduce uncertainty in the resulting quantiles. This increase in sample size is accomplished by using multiple ground-based stations, therefore substituting space for time. The sample size for each duration analyzed in our study is shown in Table 12 as the total station-years. If the intersite correlation between pairs of ground-based stations was zero (not correlated at 
all), the number of independent station-years would simply be equal to the sum of annual maximum values for all stations.

However, when pairs of stations have nonzero correlation for the annual maximum values, the number of truly independent values decreases because the same storm may have caused the annual maximum at both sites. The larger intersite correlation value results in fewer independent station-years in the sample. We need to account for this correlation by evaluating the equivalent uncorrelated record length (EURL) as described by Karlovits et al. (2017). Development of the EURL uses simulations to estimate the rootmean-square error (RMSE) of 2-year regional rainfall variance. Variance depends on both the correlation and record length. The EURL procedure computes variance by isolating each variable and simulating changes to the other. The two specific cases are when the record length is held constant while the intersite correlation is increased and when the record length is decreased assuming zero intersite correlation. In general, the RMSE increases as the correlation increases and record length decreases. Figures 42 and 43 show examples of this for Region 1 when comparing the 48-hour-duration event to the 96-hour duration. The correlation increased from 0.173 to 0.209 , which resulted in EURL decreasing by 61 years. Table 12 summarizes the final EURL values for each region and event duration. The code used to process the EURL is described in Appendix A of Karlovits et al. (2017).

Figure 42. The independent record length for Region 1 48-hour duration. (RGF is the regional growth factor.)

Region_1

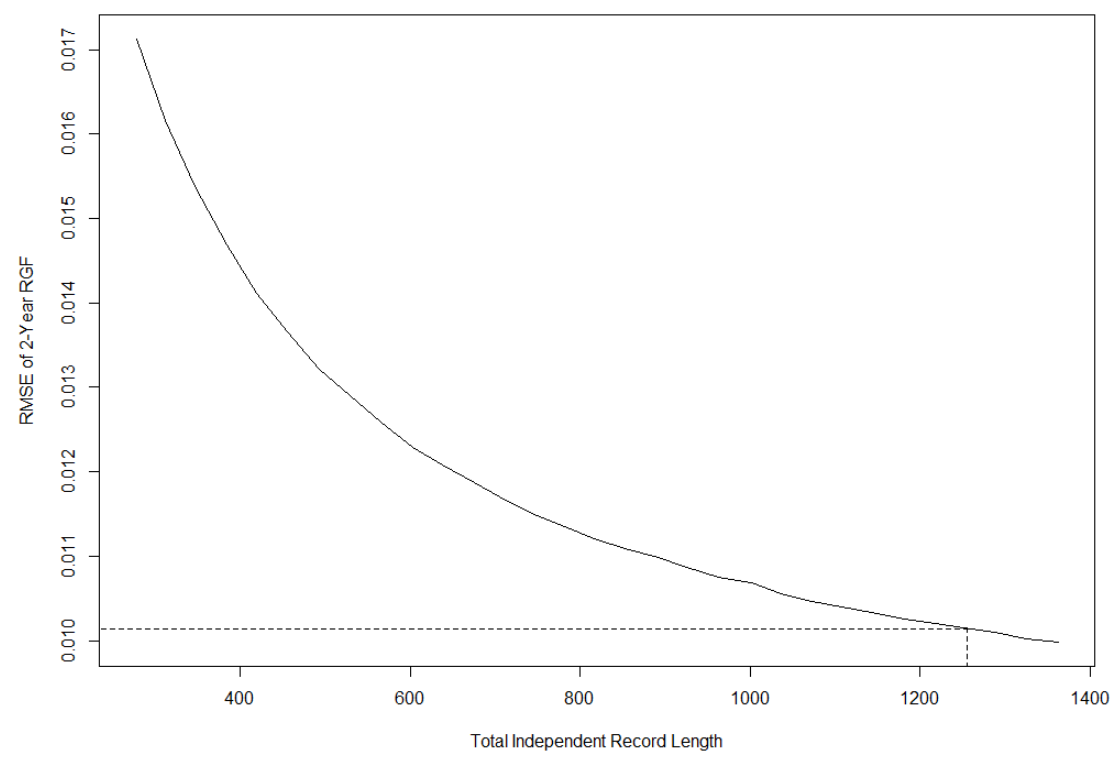


Figure 43. The independent record length for Region 196 -hour duration.

Region_1

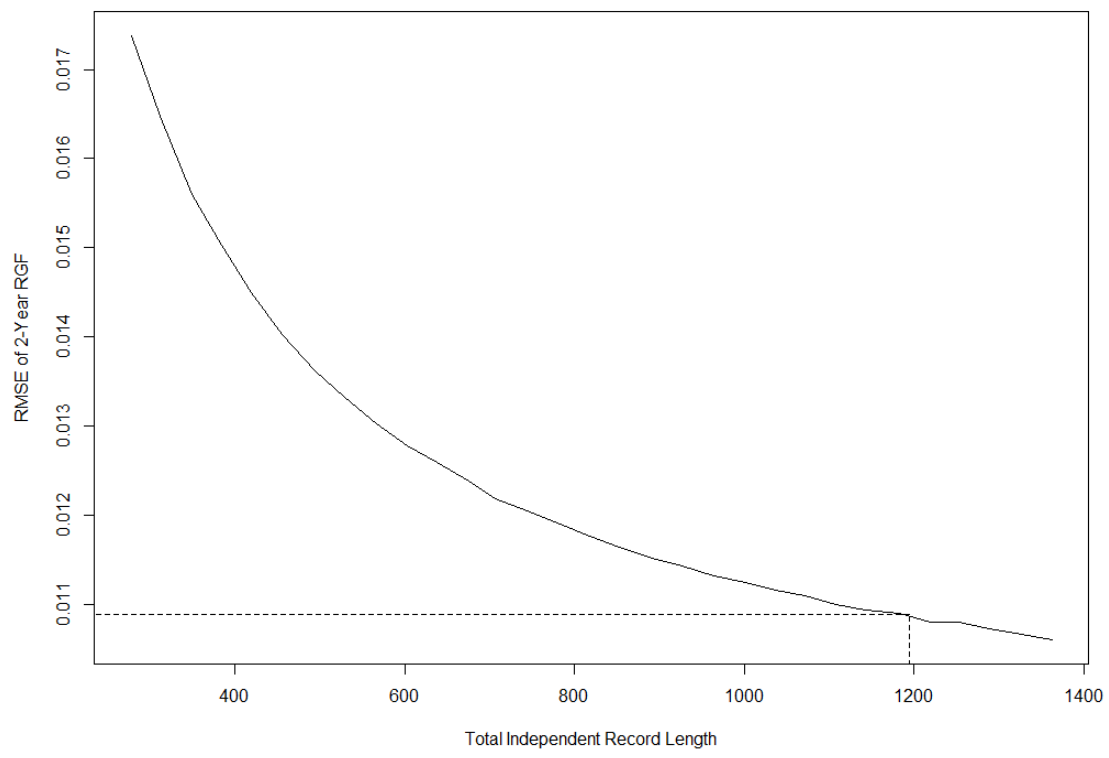

Table 12. The summary of equivalent independent record length for regional frequency analysis for the Willow Creek Basin.

\begin{tabular}{|c|c|c|c|c|}
\hline Storm Duration & $\begin{array}{c}\text { Total } \\
\text { Station-Years }\end{array}$ & $\begin{array}{l}\text { Regional Average } \\
\text { Correlation }\end{array}$ & EURL & $\%$ Unique Years \\
\hline \multicolumn{5}{|c|}{ Region 1} \\
\hline 24-hour & 1445 & 0.131 & 1333 & 92 \\
\hline 48-hour & 1443 & 0.172 & 1255 & 87 \\
\hline 72-hour & 1444 & 0.196 & 1209 & 84 \\
\hline 96-hour & 1444 & 0.209 & 1194 & 83 \\
\hline \multicolumn{5}{|c|}{ Region 2} \\
\hline 24-hour & 508 & 0.430 & 263 & 52 \\
\hline 48-hour & 509 & 0.525 & 201 & 39 \\
\hline 72-hour & 509 & 0.590 & 167 & 33 \\
\hline 96-hour & 509 & 0.645 & 146 & 29 \\
\hline \multicolumn{5}{|c|}{ Summary } \\
\hline 24-hour & 1953 & 0.280 & 1596 & 82 \\
\hline 48-hour & 1952 & 0.349 & 1456 & 75 \\
\hline 72-hour & 1953 & 0.393 & 1376 & 70 \\
\hline 96-hour & 1953 & 0.427 & 1360 & 69 \\
\hline
\end{tabular}

\subsection{Final Willow Creek Basin precipitation quantiles}

After we spatially interpolated the quantiles and applied the ARF, we then calculated the final Willow Creek Basin zonally averaged precipitation 
quantiles (Table 11). Since the HEC-WAT software requires statistical distribution parameters (as compared to precipitation quantiles), we have summarized the GEV parameters for each duration (Table 13). We fit the zonally averaged quantiles using a nonlinear solver tool, which iterates through parameter combinations in order to minimize the sum of squared errors. Figure 44 shows an example of the fitted GEV distribution compared to the zonally average quantiles.

Table 13. GEV distribution parameters for zonally averaged precipitation quantiles. Final values are based on a nonlinear solver fit to precipitation totals for the Willow Creek Basin.

\begin{tabular}{|l|l|c|c|}
\hline Duration & \multicolumn{1}{|c|}{ Location } & Scale & Shape \\
\hline 24-hour & 0.71293307 & 0.21080716 & -0.0366187 \\
\hline 48-hour & 0.9823779 & 0.28623996 & -0.0406939 \\
\hline 72-hour & 1.18349025 & 0.34620836 & -0.0570073 \\
\hline 96-hour & 1.33923644 & 0.39759162 & -0.0630844 \\
\hline
\end{tabular}

Figure 44. Cumulative probability for 72-hour GEV fitted using zonally averaged quantiles for the Willow Creek Basin.

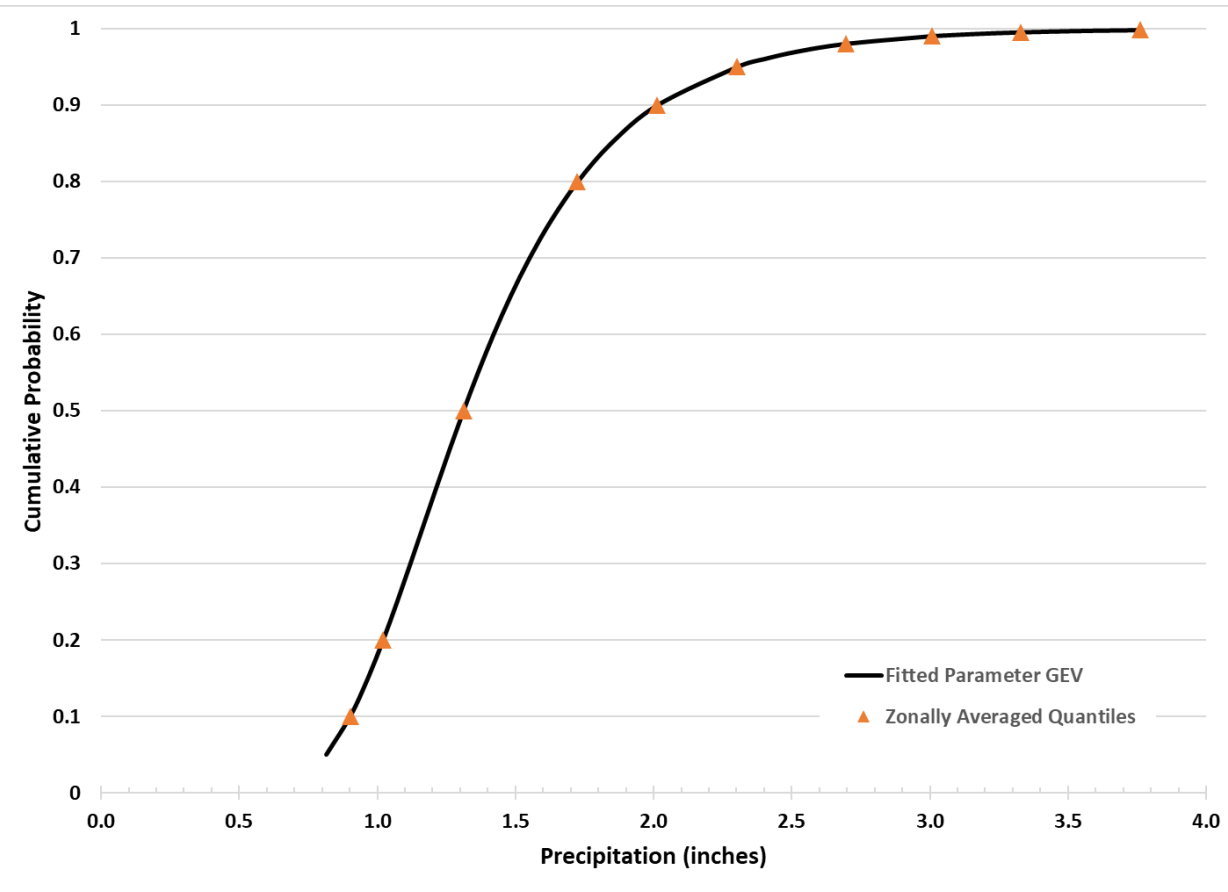




\subsection{Summary}

In this analysis, we determined the annual winter maximum precipitation depths and probabilities using ground-based stations within a regional frequency analysis framework. Once the time series of winter maximum values was developed for various durations, the R package "lmomRFA" was used to fit analytical distributions and to estimate quantiles for several $A E P$ values. We verified the results of this process for internal consistency and compare the results to the current NOAA publications for Idaho.

We developed the precipitation quantiles using the stepwise process described in Hosking and Wallis (1997). Following these steps, we performed several data quality-control tests to ensure that no systematic data errors existed in the records. We fit analytical distribution using the quality-controlled data for each station by using L-moments parameter estimates. Once the regionally factored quantile for each station was calculated, we performed spatial interpolation over the domain of our analysis. Using this spatially continuous surface from the interpolation, we computed zonal mean values for each return period. We also computed confidence bounds for each event duration.

We validated our results based on the published NOAA Atlas 2 and Technical Paper 49 (Miller et al. 1973; Miller 1964) values. We demonstrated that using similar ARF, the NOAA-published quantiles were similar to our results with the exception of the 96-hour durations. In this case, our values were higher than what is currently published. One potential reason for this difference is the total sample size used in our analysis compared to those available in the 1960 os and 1970s. Additionally, our sample include many more atmospheric-river events, which are generally multiday precipitation storms. Finally, the spatial distribution of stations available for our study was greater than those used in the NOAA publications. This allows more information from the region to be included in the quantile estimates.

The zonally averaged regional quantiles were used to fit a GEV distribution for precipitation for the entire basin. The parameters from fitted distribution can be used in the HEC-WAT software to perform the risk-based analysis of winter floods in the Willow Creek Basin. 


\section{Snow Conditions for the Willow Creek Basin}

The distribution of SWE over the Willow Creek Watershed is an important antecedent condition impacting the quantity of runoff during winter storm events. This chapter describes the available sources of information on the SWE distribution in the Willow Creek Watershed. These sources included ground-based observations, gridded data based on observations and models, and satellite information. In this chapter, we investigate the consistency and representativeness of the SNOTEL station SWE observations. We concluded that the gridded SWE data developed by the University of Arizona (described in section 4.1.2) serves as the best estimate of spatially distributed SWE information for the Willow Creek Watershed. With this, we determined the annual maximum SWE and the monthly annual maximum SWE for the watershed and each subbasin. We also determined the Probable Maximum Snow Accumulation for the watershed and each subbasin.

\subsection{Snow data}

\subsubsection{Ground-based observations of snow depth and SWE}

This study used three types of ground-based observations of snow. These are the NRCS SNOTEL stations, the National Weather Service COOP stations, and WBAN stations. The SNOTEL stations report SWE and snow depth, while the COOP and WBAN stations report only snow depth. Figure 45 shows the locations of the ground-based stations.

Figure 45. Locations of SNOTEL, COOP, and WBAN stations.

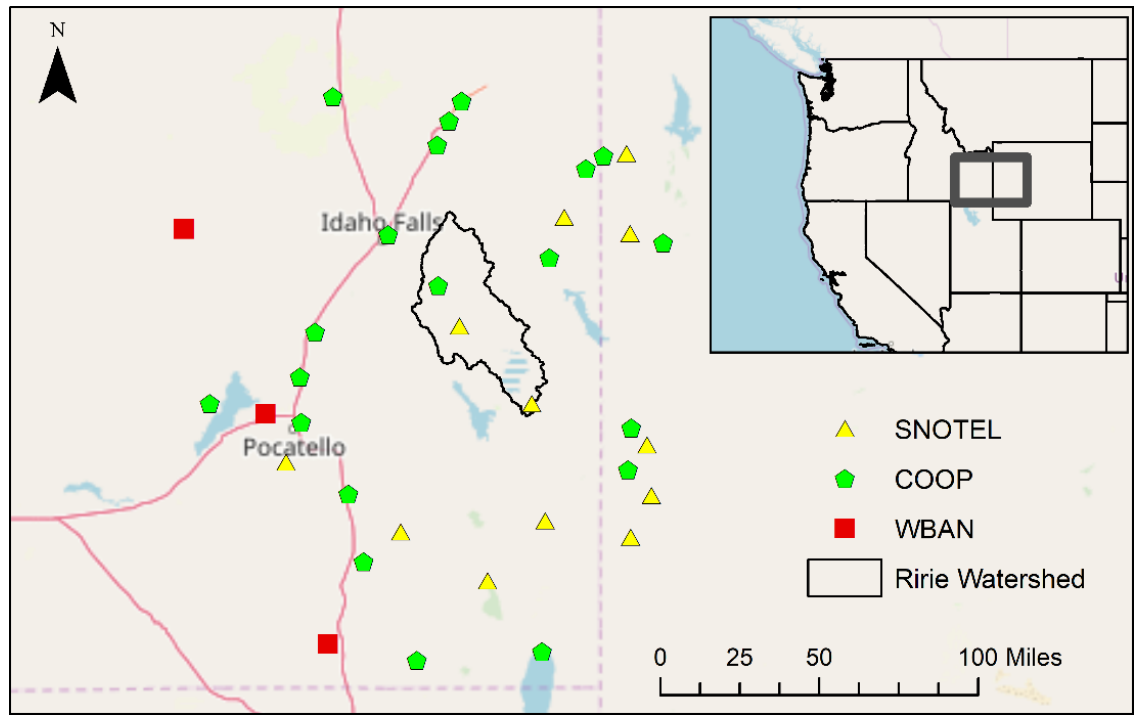




\subsubsection{SNOTEL}

NRCS collects snow data on the ground through its extensive, automated SNOTEL network located at the higher elevations in the western United States and Alaska (NRCS 2016). The basic SNOTEL station provides SWE data via a pressure-sensing snow pillow. Snow pillows are generally accurate for measuring SWE to the nearest $0.1 \mathrm{in}$. NRCS personnel review daily SNOTEL measurements of SWE for temporal and spatial consistency.

Table 14 lists the SNOTEL stations included in this study. All the stations we used were established in the 1980s, and many have close to 40 years of data. The station elevations range from about 6500 to $8200 \mathrm{ft}$. Only one station, Sheep Mountain, is located in the Willow Creek Basin. Another SNOTEL station, Somsen Ranch, is located about 0.25 miles beyond the southern boundary of the watershed and is often used to evaluate SWE conditions in the basin. For the purpose of our study, we used both of these stations as ground-based references to assess the validity of gridded remote sensing and modeled SWE in the watershed.

Table 14. SNOTEL stations in eastern Idaho and western Wyoming.

\begin{tabular}{|l|c|c|c|c|c|c|}
\hline \multicolumn{1}{|c|}{ Name } & ID & State & Elevation & Lat & Long & Start Year \\
\hline Cottonwood Creek & 419 & Wyoming & 7670 & 42.64590 & -110.8148 & 1982 \\
\hline Emigrant Summit & 471 & Idaho & 7390 & 42.36055 & -111.5608 & 1981 \\
\hline Grand Targhee & 1082 & Wyoming & 9260 & 43.78333 & -110.9333 & 2006 \\
\hline Phillips Bench & 689 & Wyoming & 8200 & 43.51687 & -110.9125 & 1980 \\
\hline Pine Creek Pass & 695 & Idaho & 6720 & 43.56998 & -111.2115 & 1988 \\
\hline Salt River Summit & 730 & Wyoming & 7640 & 42.50750 & -110.9099 & 1980 \\
\hline Sedgwick Peak & 741 & Idaho & 7850 & 42.52497 & -111.9563 & 1988 \\
\hline Sheep Mountain & 749 & Idaho & 6650 & 43.21030 & -111.6879 & 1981 \\
\hline Slug Creek Divide & 761 & Idaho & 7225 & 42.56248 & -111.2979 & 1980 \\
\hline Somsen Ranch & 770 & Idaho & 6800 & 42.95275 & -111.3593 & 1980 \\
\hline Wildhorse Divide & 867 & Idaho & 6490 & 42.75743 & -112.4773 & 1981 \\
\hline Willow Creek & 868 & Wyoming & 8080 & 42.81513 & -110.8351 & 1980 \\
\hline
\end{tabular}

Figures 46 and 47 show the daily SWE observed at Sheep Mountain and Somsen Ranch, respectively. Each station has a clearly defined accumulation period leading to an annual maximum and then an ablation period during which SWE declines. Table 15 provides the average annual maximum SWE observed at all the SNOTEL stations used in this study. The average annual maximum SWE observed at Sheep Mountain and Somsen Ranch are 13.4 in. and 13.0 in. The annual maximum SWE observed at each 
of these stations are highly correlated. This is not unusual given that the two stations are located about 24 miles apart and are at similar elevations.

Figure 46. Sheep Mountain SNOTEL SWE observations.

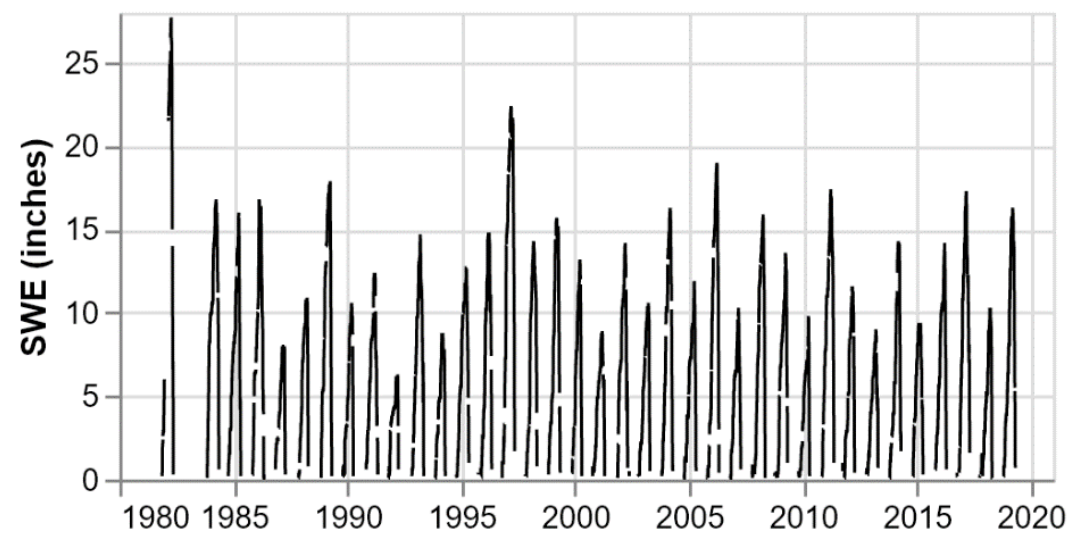

Figure 47. Somsen Ranch SNOTEL SWE observations.

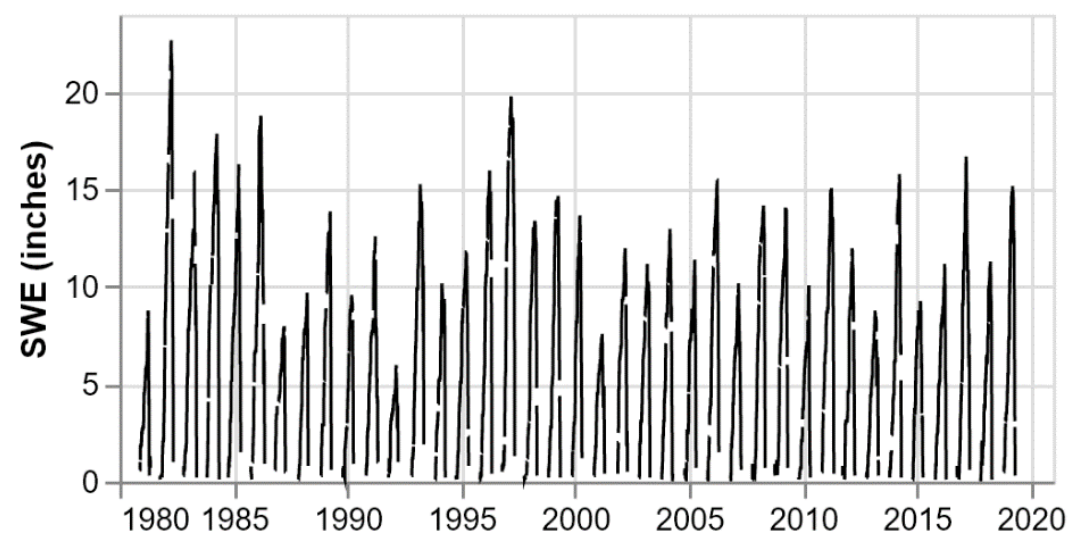

Table 15. SNOTEL Annual Maximum SWE Data (inches).

\begin{tabular}{|l|c|c|c|c|}
\hline \multicolumn{1}{|c|}{ Name } & Average & Maximum & Minimum & Standard Deviation \\
\hline Cottonwood Creek & 22.8 & 37.2 & 6.7 & 6.5 \\
\hline Emigrant Summit & 24.8 & 47.6 & 13.3 & 9.5 \\
\hline Grand Targhee & 50.83 & 72.9 & 37.9 & 10.62 \\
\hline Phillips Bench & 29.9 & 50.4 & 17.3 & 8.7 \\
\hline Pine Creek Pass & 15.8 & 25.3 & 9.1 & 4.0 \\
\hline Salt River Summit & 13.9 & 22.5 & 7.6 & 3.9 \\
\hline Sedgwick Peak & 20.3 & 33.0 & 9.8 & 6.0 \\
\hline Sheep Mountain & 13.4 & 27.7 & 6.0 & 4.3 \\
\hline Slug Creek Divide & 16.7 & 32.1 & 7.8 & 5.4 \\
\hline Somsen Ranch & 13.0 & 22.6 & 6.6 & 3.6 \\
\hline Wildhorse Divide & 16.9 & 29.5 & 9.2 & 5.4 \\
\hline Willow Creek & 31.1 & 48.8 & 12.5 & 9.3 \\
\hline
\end{tabular}


There is a general trend for the average annual maximum SWE observed at the SNOTEL stations to increase with the elevation of the station as shown in Figure 48. The annual maximum SWE increases approximately $8 \mathrm{in}$. per $1000 \mathrm{ft}$ of elevation gain at the SNOTEL sites.

Figure 48. Elevation and average annual maximum SWE for the SNOTEL stations.

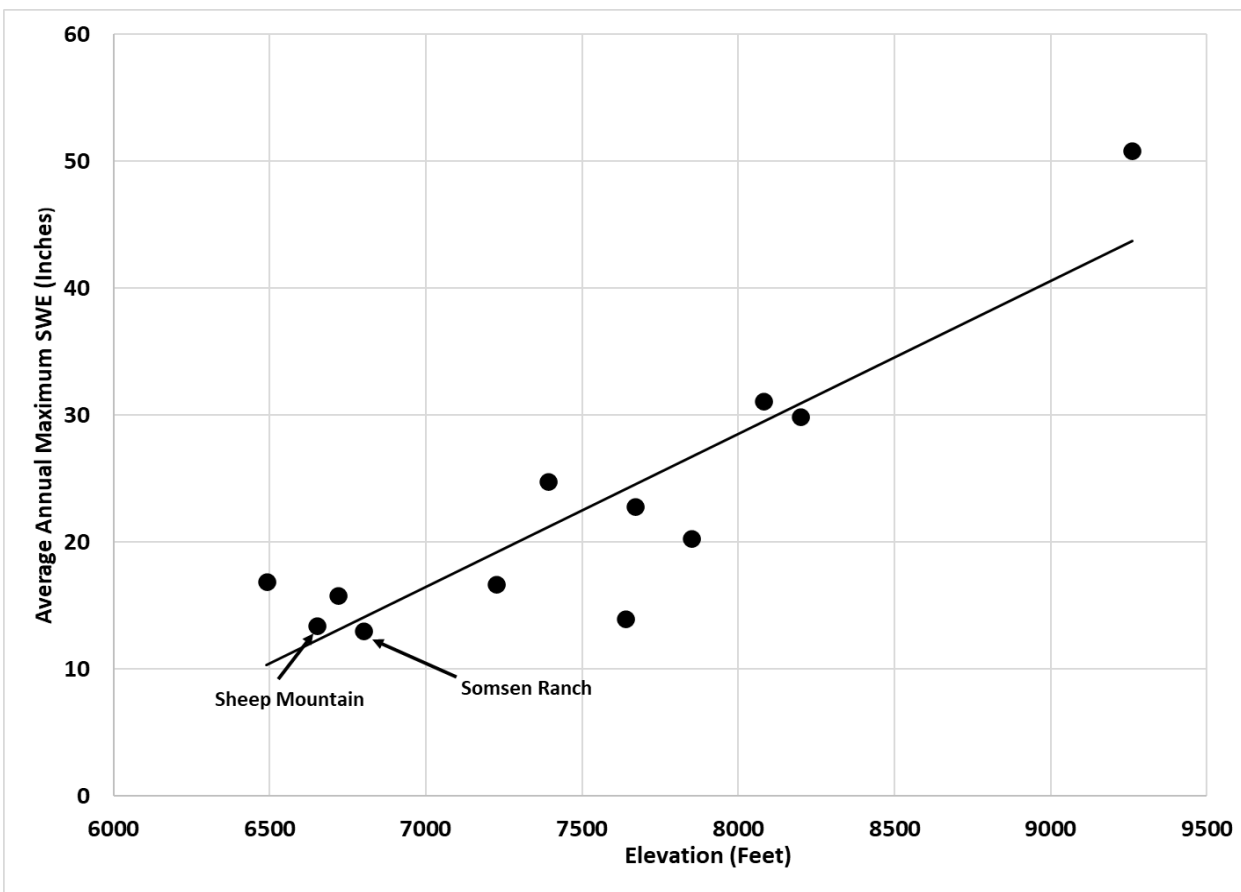

\subsubsection{COOP and WBAN stations}

In the vicinity of the Willow Creek Basin are 23 COOP and WBAN stations that report snow depth but not SWE. Table 16 lists the metadata for these stations. The COOP stations IDs start with "USC," and the WBAN stations IDs start with "USW." Figure 49 shows the time series of snow depth measurements at the COOP and WBAN stations.

We used snow depth observations to estimate SWE by using the approach of Sturm et al. (2010). This approach estimates SWE based on the snow depth and day of year (DOY) and uses separate parameters for each snow class. There are six classes (tundra, taiga, alpine, maritime, prairie, and ephemeral); and each class is defined by a unique ensemble of characteristics, including the sequence of snow layers, their thickness, density, crystal morphology, and grain characteristics within each layer. The classes can also be derived using a binary system of three climate variables: wind, precipitation, and air temperature. The Willow Creek Basin and surrounding areas are classified as prairie. 
Table 16. COOP and WBAN stations used in the snow analysis.

\begin{tabular}{|l|l|c|c|c|c|}
\hline \multicolumn{1}{|c|}{ Site ID } & Location Name & Lat & Long & $\begin{array}{c}\text { Elevation } \\
\text { (ft) }\end{array}$ & Start Year \\
\hline USC00100010 & Aberdeen Exp Stn & 42.9536 & -112.8253 & 4406 & 1914 \\
\hline USC00100915 & Blackfoot Fire Dept & 43.1917 & -112.3453 & 4498 & 1900 \\
\hline USC00102667 & Downey & 42.4261 & -112.1253 & 4865 & 1901 \\
\hline USC00102676 & Driggs & 43.7306 & -111.1125 & 6119 & 1904 \\
\hline USC00103297 & Ft Hall 1 NNE & 43.0425 & -112.4144 & 4465 & 1914 \\
\hline USC00103964 & Hamer 4 NW & 43.9664 & -112.2642 & 4790 & 1948 \\
\hline USC00104455 & Idaho Falls - Kifi & 43.5139 & -112.0125 & 4741 & 1952 \\
\hline USC00104456 & Idaho Falls 16 SE & 43.3456 & -111.7847 & 5827 & 1955 \\
\hline USC00105275 & Lifton Pumping Stn & 42.1231 & -111.3133 & 5935 & 1919 \\
\hline USC00105716 & Mccammon & 42.6522 & -112.1936 & 4770 & 1949 \\
\hline USC00107208 & Pocatello 2 NE & 42.8917 & -112.4086 & 4833 & 1956 \\
\hline USC00107346 & Preston & 42.0933 & -111.8825 & 4718 & 1964 \\
\hline USC00107644 & Rexburg BYU Idaho & 43.8083 & -111.7892 & 5007 & 1977 \\
\hline USC00108022 & Saint Anthony & 43.9517 & -111.6789 & 4911 & 1940 \\
\hline USC00108818 & Sugar City & 43.8867 & -111.7367 & 4925 & 1909 \\
\hline USC00108937 & Swan Valley & 43.4372 & -111.2792 & 5397 & 1960 \\
\hline USC00480027 & Afton & 42.7331 & -110.9217 & 6247 & 1957 \\
\hline USC00480140 & Alta 1 NNW & 43.7728 & -111.0339 & 6440 & 1909 \\
\hline USC00480603 & Bedford 3 SE & 42.8731 & -110.9069 & 6345 & 1975 \\
\hline USC00484910 & Jackson & 43.4864 & -110.7614 & 6211 & 1905 \\
\hline USW00024151 & Malad City & 42.1492 & -112.2872 & 4472 & 1948 \\
\hline USW00024156 & Pocatello Rgnl AP & 42.9203 & -112.5711 & 4478 & 1942 \\
\hline USW00094143 & Idaho Falls 46 W & 43.5317 & -112.9422 & 4938 & 1954 \\
\hline
\end{tabular}

Figure 49. Observed snow depth at COOP and WBAN stations.

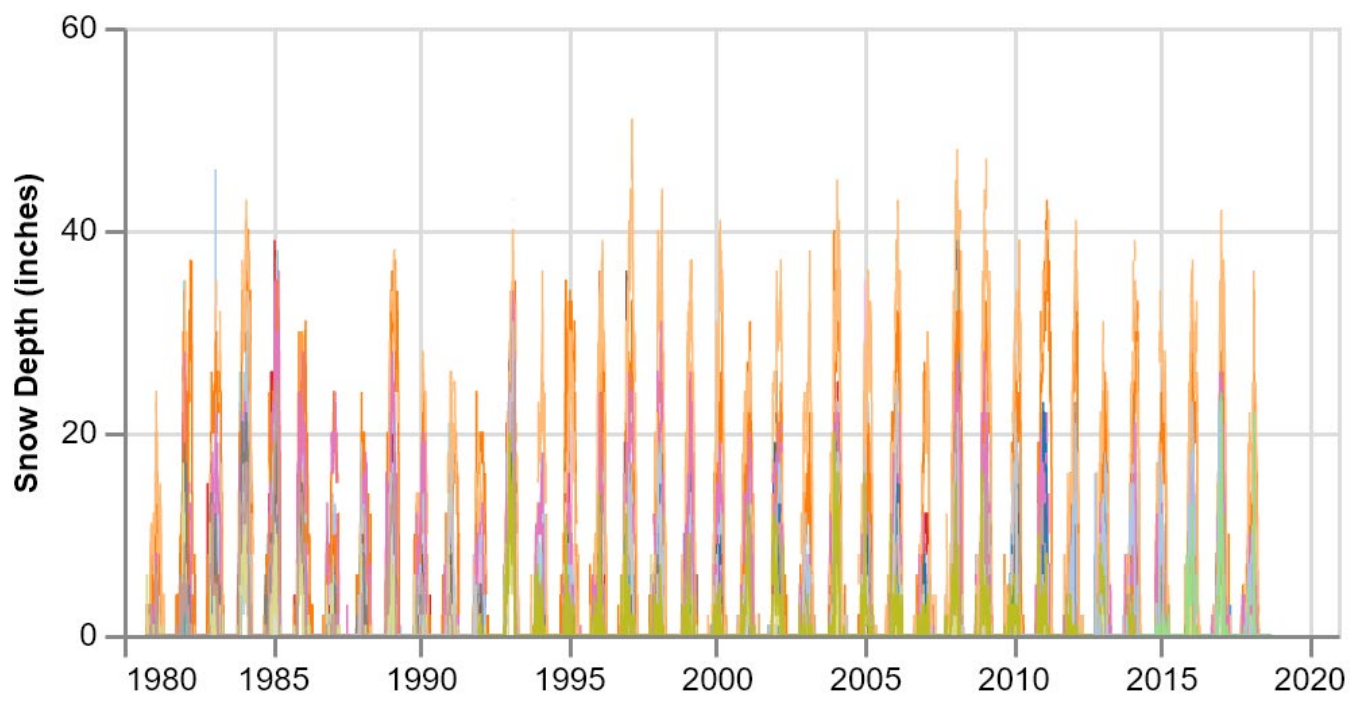


The SWE on day $i$ is, by definition,

$$
S W E_{\mathrm{i}}=\frac{\rho_{i}}{\rho_{w}} h_{i},
$$

where

$$
\begin{aligned}
S W E_{i} & =\text { the SWE on day } i \\
\rho_{i} & =\text { the average snow density on day } i \\
\rho_{w} & =\text { the density of water; and } \\
h_{i} & =\text { the snow depth on day } i .
\end{aligned}
$$

The density of water, $\rho_{w}$, is known; and the snow depth, $h_{i}$, is observed at the COOP and WBAN stations. $S W E_{i}$ can be estimated by first estimating the average snow density on day $i$. The average snow density on day $i, \rho$, is estimated using the Sturm et al. (2010) relationship:

$$
\rho_{i}=\left(\rho_{\max }-\rho_{0}\right)\left[1-e^{-k_{1} h_{i}-k_{2} \int \operatorname{DOY}_{i}}\right]+\rho_{0},
$$

where

$$
\begin{aligned}
\rho_{\max }= & \text { the maximum snow density of the prairie snow class } \\
& \left(0.594 \mathrm{~g} \mathrm{~cm}^{-3}\right), \\
\rho_{o}= & \text { the starting snow density of the prairie snow class } \\
& \left(0.2332 \mathrm{~g} \mathrm{~cm}^{-3}\right),
\end{aligned}
$$

$\mathrm{DOY}_{i}=$ the day of year on day $i$ (days before 1 January have negative DOY starting from 1 January and there is no day 0 ), and

$k_{1}$ and $k_{2}=$ constants for the prairie snow class (0.0016 and 0.0031, respectively).

We tested the applicability of this approach by calculating the snow density at the two SNOTEL stations located in the watershed, Sheep Mountain and Somsen Ranch. The observations at the SNOTEL stations included SWE and snow depth, which allowed the snow density to be determined. The snow densities match very well through most of each snow season. The largest error occurs at the very beginning and very end of the season when the snow depths are relatively small (Figure 50). Based on our results, the Sturm et al. (2010) approach to estimating SWE based on snow 
depth observations is fairly accurate. Figure 51 shows a time series of the computed SWE values.

There is a general trend for the average annual maximum SWE observed at the COOP and WBAN stations (Table 17) to increase with the elevation of the station as shown in Figure 52. This figure uses the average annual maximum SWE for the SNOTEL stations shown in Figure 48. The elevation of the COOP and WBAN stations ranges from $4400 \mathrm{ft}$ to $6400 \mathrm{ft}$. This can be compared to the elevation of the SNOTEL sites, which starts at $6500 \mathrm{ft}$ and ranges upward. The annual maximum SWE for the COOP and WBAN stations increases approximately $2.6 \mathrm{in}$. per $1000 \mathrm{ft}$ of elevation gain. This can be compared to the 8 in per $1000 \mathrm{ft}$ increase in SWE at the SNOTEL sites. This difference in SWE increase reflects the impact of elevation and the surrounding vegetation.

Figure 50. Calculated and observed snow density at the Sheep Mountain SNOTEL station.
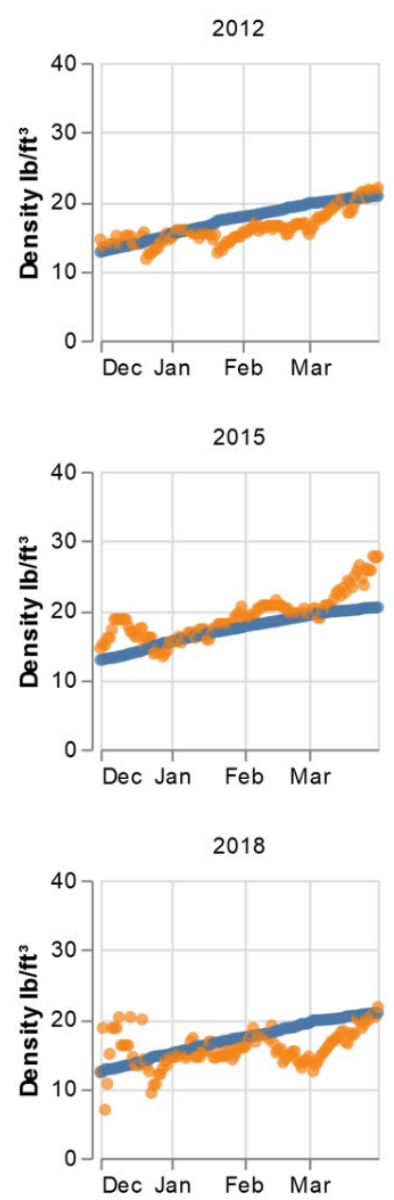

2013

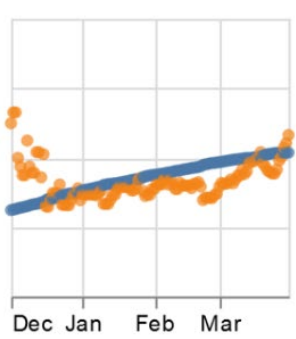

2016

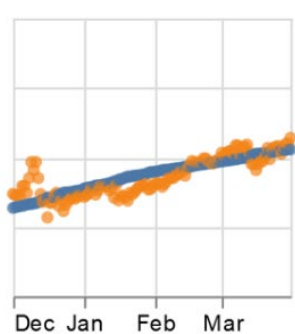

2019

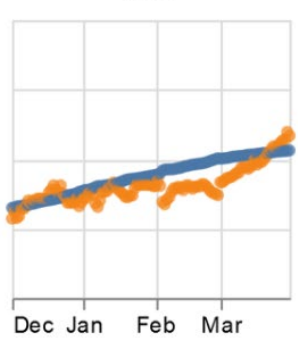

2014

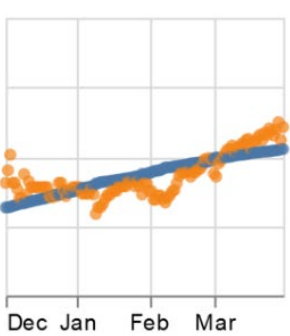

2017

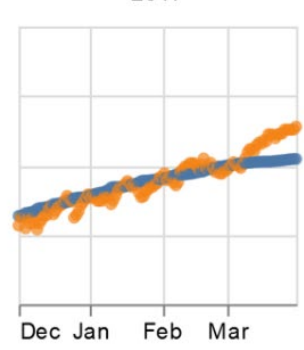

Calculated

Observed 
Figure 51. Calculated SWE at COOP and WBAN stations.

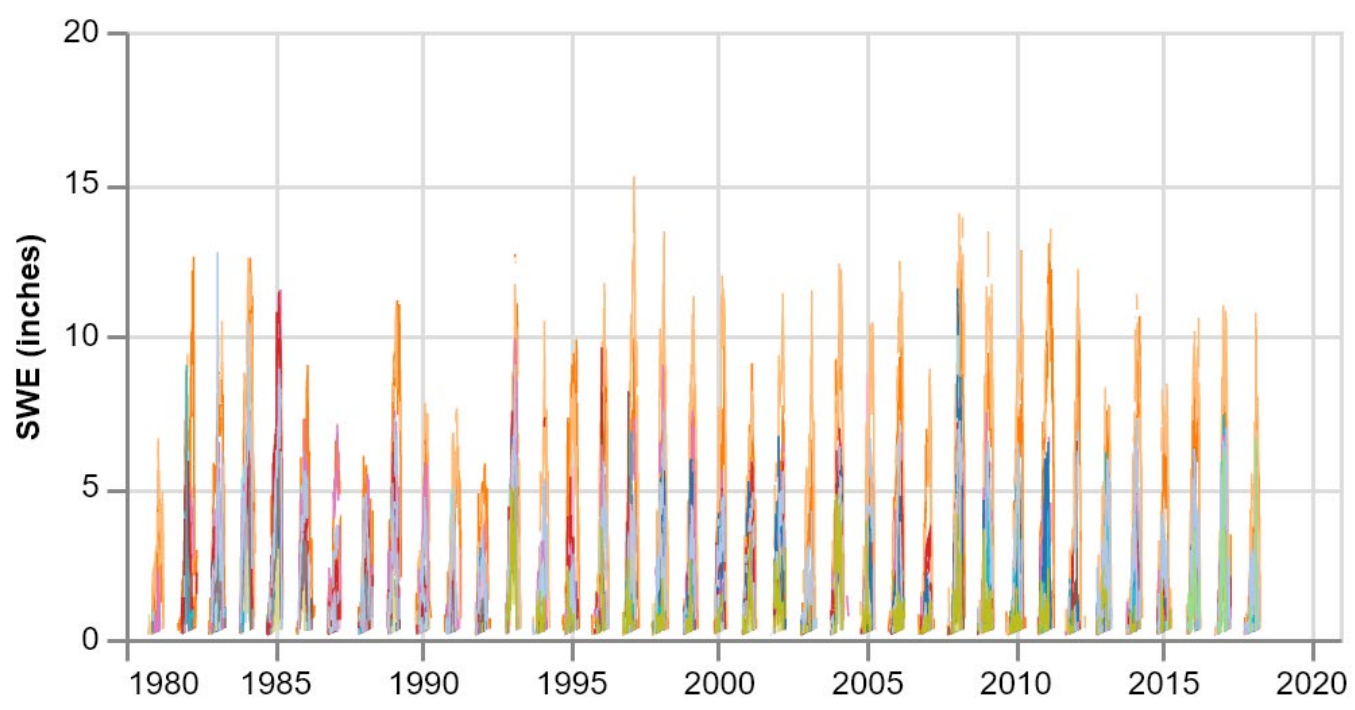

Table 17. COOP and WBAN annual maximum SWE data (inches).

\begin{tabular}{|l|c|c|c|c|}
\hline \multicolumn{1}{|c|}{ Location Name } & $\begin{array}{c}\text { Years Reporting Snow } \\
\text { 1981-Present }\end{array}$ & Average & Maximum & Minimum \\
\hline Aberdeen Exp Stn & $100.0 \%$ & 2.1 & 7.1 & 0.3 \\
\hline Blackfoot Fire Dept & $47.2 \%$ & 1.2 & 2.7 & 0.2 \\
\hline Downey & $11.1 \%$ & 4.3 & 6.6 & 0.7 \\
\hline Driggs & $100.0 \%$ & 5.4 & 11.4 & 1.8 \\
\hline Ft Hall 1 NNE & $100.0 \%$ & 2.5 & 6.4 & 0.5 \\
\hline Hammer 4 NW & $100.0 \%$ & 2.8 & 7.8 & 0.6 \\
\hline Idaho Falls-KIFI & $77.8 \%$ & 2.2 & 6.6 & 0.2 \\
\hline Idaho Falls 16 SE & $100.0 \%$ & 4.3 & 8.4 & 1.4 \\
\hline Lifton Pumping Stn & $100.0 \%$ & 3.7 & 8.7 & 0.9 \\
\hline McCammon & $77.8 \%$ & 3.5 & 9.0 & 0.4 \\
\hline Pocatello 2 NE & $72.2 \%$ & 2.6 & 6.0 & 0.5 \\
\hline Preston & $52.8 \%$ & 3.5 & 9.0 & 0.4 \\
\hline Rexburg BYU Idaho & $75.0 \%$ & 4.0 & 11.5 & 0.7 \\
\hline Saint Anthony & $75.0 \%$ & 4.2 & 11.5 & 0.4 \\
\hline Sugar City & $16.7 \%$ & 4.4 & 6.2 & 2.7 \\
\hline Swan Valley & $41.7 \%$ & 4.6 & 8.8 & 1.6 \\
\hline Afton & $94.4 \%$ & 5.8 & 12.7 & 0.3 \\
\hline Alta 1 NNW & $100.0 \%$ & 9.5 & 23.3 & 5.6 \\
\hline Bedford 3 SE & $100.0 \%$ & 10.0 & 15.2 & 0.5 \\
\hline Jackson & $100.0 \%$ & 5.9 & 11.5 & 2.2 \\
\hline Malad City & $58.3 \%$ & 3.0 & 6.6 & 0.8 \\
\hline Pocatello Rgnl AP & $100.0 \%$ & 2.0 & 4.2 & 0.6 \\
\hline Idaho Falls 46 W & $100.0 \%$ & 2.8 & 9.0 & 0.4 \\
\hline
\end{tabular}


Figure 52. Average annual maximum SWE and elevation for the COOP and WBAN stations and the SNOTEL stations.

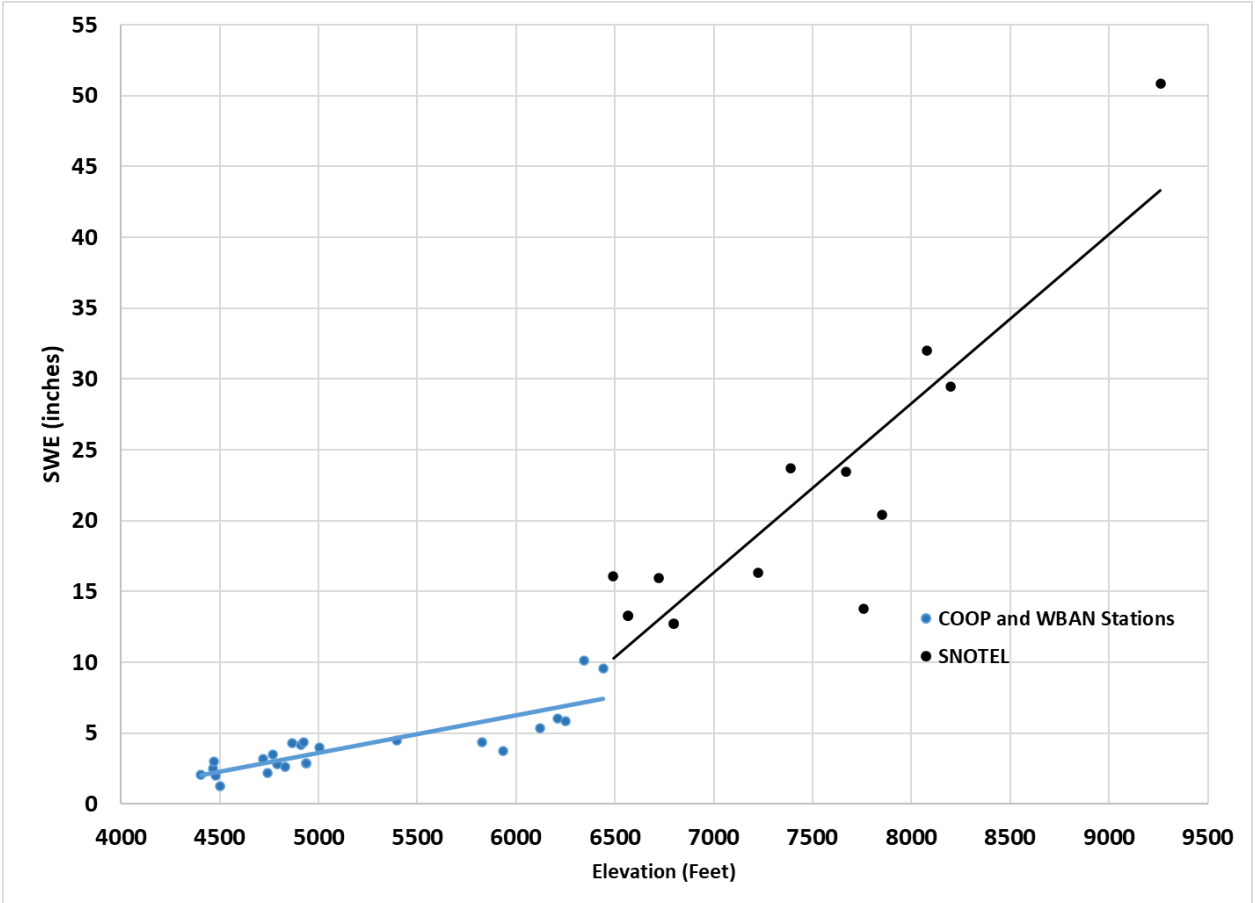

\subsubsection{Gridded SWE data}

\subsubsection{SNODAS}

The NWS National Operational Hydrologic Remote Sensing Center (NOHRSC) provides a near-real-time $1 \mathrm{~km}^{2}$ spatially distributed estimate of SWE and other snow properties across the continental United States through its SNODAS dataset. SNODAS data covers the time period from 2003 to the present (NOHRSC 2004). SNODAS integrates a combination of downscaled forcing data, an energy balance snow model, and assimilated observations in the SNODAS daily gridded SWE product to arrive at the best estimate of the snow characteristics over the United States and to minimize error associated with any individual method (Carroll et al. 2006). Though these data are also subject to errors, this product provides the only real-time spatially distributed estimate of snowpack conditions throughout the U.S. and is used for operational models and forecasting for several river basins (e.g., Lea and Reid 2006; Schneiderman et al. 2013). Studies have evaluated the snow model within SNODAS and have shown that it generally provides good results at a point scale (Rutter et al. 2008; Frankenstein et al. 2008), though over a larger scale, particularly where ground observations are sparse or biased, additional error is introduced in SNODAS products (Molotch and Bales 2005; Meromy et al. 2013). 


\subsubsection{University of Arizona SWE}

The University of Arizona (UA) developed a $4 \mathrm{~km}$ gridded daily SWE dataset covering 1982 to 2017 for the continental U.S. (Broxton et al. 2019; Zeng et al. 2018). This dataset was developed by interpolating SWE and snow depth from SNOTEL (Serreze et al. 1999), the NWS COOP network sites, and $4 \mathrm{~km}$ gridded PRISM precipitation and temperature data. Broxton et al. (2016) demonstrated the quality and reliability of the UA SWE data compared to reanalysis and land assimilation products. Dawson et al. (2018) reported that UA SWE agrees well with basin-averaged SWE determined through Airborne Snow Observatory products. Cho et al. (2019) compared UA SWE and the airborne gamma radiation SWE record collected by NOHRSC. The airborne gamma survey had collected areal mean SWE data over a network of 2400 flight lines covering 25 states and $7 \mathrm{Ca}-$ nadian provinces (Carroll et al. 2001). They found that UA SWE had better agreement with gamma SWE than two satellite-based SWE estimations, SSMI/S (Special Sensor Microwave/Imager) and GlobSnow-2, in all land cover types and snow classes.

\subsubsection{Satellite data}

MOD10A1 Cloud-Gap-Filled Snow-Covered Area (referred to as CGF-SCA) is a gridded snow product based on satellite imagery that provides cloudfree daily estimates of snow-covered area (SCA). In this study, we used the CGF-SCA for the Willow Creek Basin from 1 October 2000 through 11 November 2019.

CGF-SCA is based on the MODIS (Moderate Resolution Imaging Spectroradiometer) / Terra Snow Cover Daily L3 Global 500 m Grid (Hall et al. 2006), a global, gridded fractional snow-covered area (FSCA) product the National Snow and Ice Data Center produces daily. Terra is a National Aeronautics and Space Administration (NASA) satellite that carries a MODIS instrument. MODIS acquires imagery of the earth's surface in 36 spectral bands. SCA is estimated using the normalized difference snow index (NDSI), which leverages the contrasting reflectance of snow in the visible and shortwave infrared regions of the spectrum (Hall et al. 2002). FSCA is estimated using an empirical relationship between FSCA and NDSI (Salomonson and Appel 2004). Clouds prevent MODIS from imaging the ground surface and introduce time gaps into the remotely sensed data. CGF-SCA estimates the FSCA in a cloud-blocked pixel based on the FSCA of the most recent cloud-free images of the pixel. Pixels with FSCA 
less than 20\% are set as no snow. Morriss et al. (2018) evaluates the overall accuracy of CGF-SCA. In general, CGF-SCA compares favorably with other automated approaches for producing cloud-free estimates of SCA, and the SCA values compare favorably with manual estimates.

Figure 53 shows an example of the CFG-SCA time series. In this figure, the 500 m CFG-SCA pixels covering the entire Willow Creek Basin were summed to determine the total area of the watershed covered by snow. The results are presented in square miles.

Figure 53. Estimated SCA for the Willow Creek Basin.

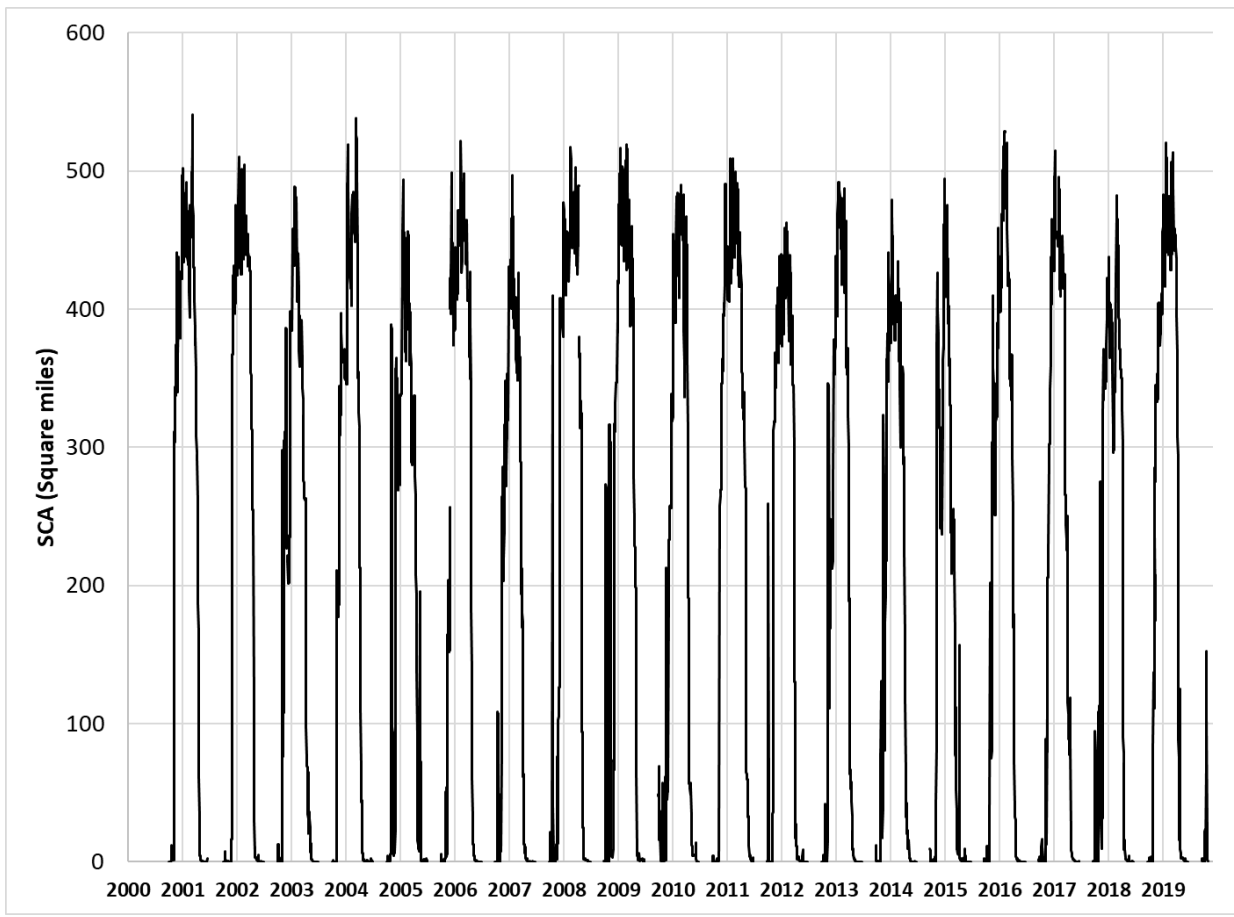

\subsection{Snow data analysis}

\subsubsection{Processing gridded SWE data}

The daily UA SWE and SNODAS gridded SWE datasets were processed at a daily time series of the SWE volume in the entire Willow Creek Basin and each of the three subbasins: Ririe, Ririe Upstream, and Grays Lake. First, the UA SWE and SNODAS gridded SWE datasets were reprojected to the Albers Equal Area projection using the open-source Geospatial Data Abstraction Library (GDAL/OGR Contributors 2020). Appendix B provides additional details about the GIS (geographic information system) metadata for the UA SWE, SNODAS, and spatial information developed in 
our project. We clipped the datasets to the Ririe Watershed boundaries using rasterstats (Perry 2019). We found the total watershed and subbasin SWE volumes by summing each SWE depth value of the clipped SWE raster at the native resolution of the original dataset ( $4 \mathrm{~km}$ for UA and $1 \mathrm{~km}$ for SNODAS). The resulting daily time series of SWE volume shows overall reasonable agreement between the datasets (Figure 54).

Figure 54. UA and SNODAS SWE volume of the Willow Creek Basin.

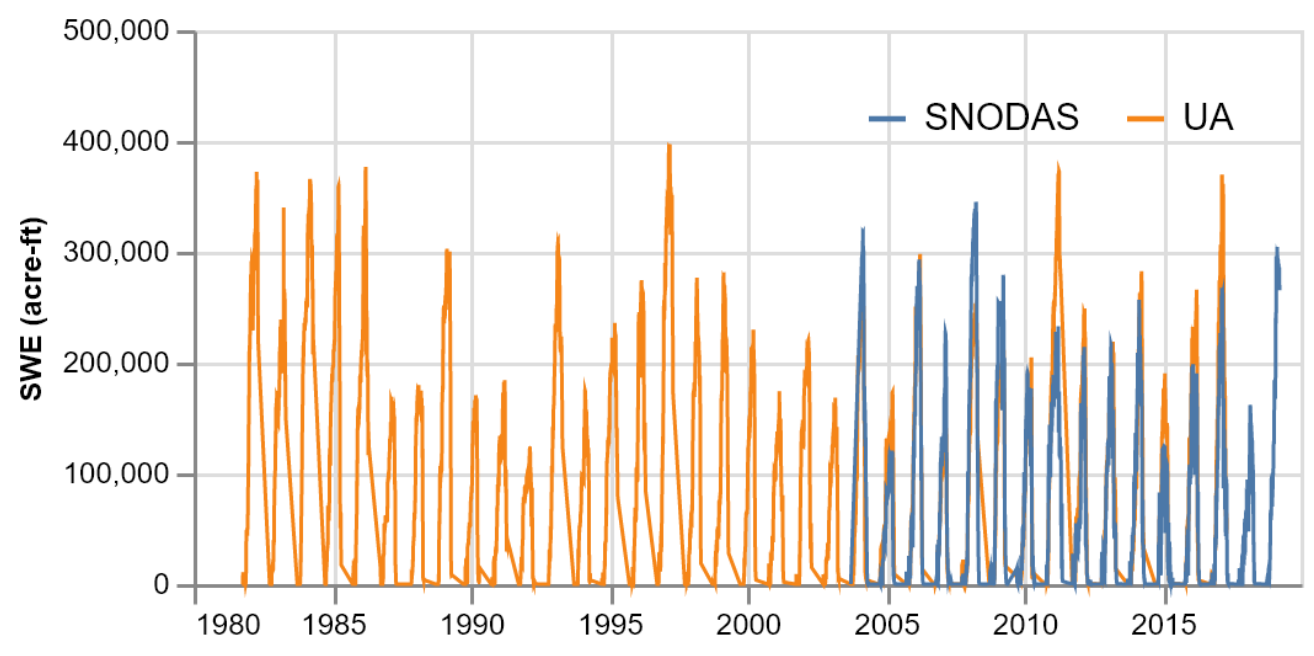

\subsubsection{Snow data discussion}

This section discusses the available snow data and selects a dataset for analysis. Information on SWE in the Willow Creek Basin is available from several sources, as described above. There are ground-based observations at the two SNOTEL sites located in or immediately next to the watershed, Sheep Mountain and Somsen Ranch, and at the NWS COOP station located in the watershed, Idaho Falls $16 \mathrm{SE}$. There are also two sources of gridded snow data, UA SWE and SNODAS, that cover the watershed. In general, water managers prefer ground-based observations of snow, such as the SNOTEL stations and the COOP stations, because they are measurements collected in the watershed of interest. However, in this study we determined that the gridded snow data provided a more accurate representation of the SWE distribution of the watershed than distributions developed based on the available ground-based observations.

Point measurements are useful if the observation location is representative of overall conditions and the trends in snow conditions throughout the watershed are known. Unfortunately, both SNOTEL sites are located in or on 
the edge of forested "tree islands," which are not representative of the general land cover found in the Willow Creek Watershed. Figure 55 is satellite images of the SNOTEL sites, showing that the SNOTEL sites are located in relatively small treed areas surrounded by shrub/scrub land. Open areas including shrub/scrub land, grassland, and cultivated crops compose $68 \%$ of the watershed (Figure 6). Deciduous and evergreen forests compose only $20 \%$ of the watershed. A number of reports have described the impact of trees and other vegetation on spatial snow distribution as compared to open areas in the western states (e.g., Hiemstra et al. 2002; Holtmeier and Broll 1992; Musselman et al. 2008; Pomeroy et al. 2001). Stands of trees in areas otherwise open serve as snow "traps" and create areas within the stand and immediately downwind with deeper snow depth and greater SWE amounts. In addition, stands of trees create areas with longer snow duration where the annual peak SWE is reached later in the winter season than the surrounding open area.

Figure 55. Satellite images of areas surrounding Sheep Mountain and Somsen Ranch SNOTEL sites showing tree islands.
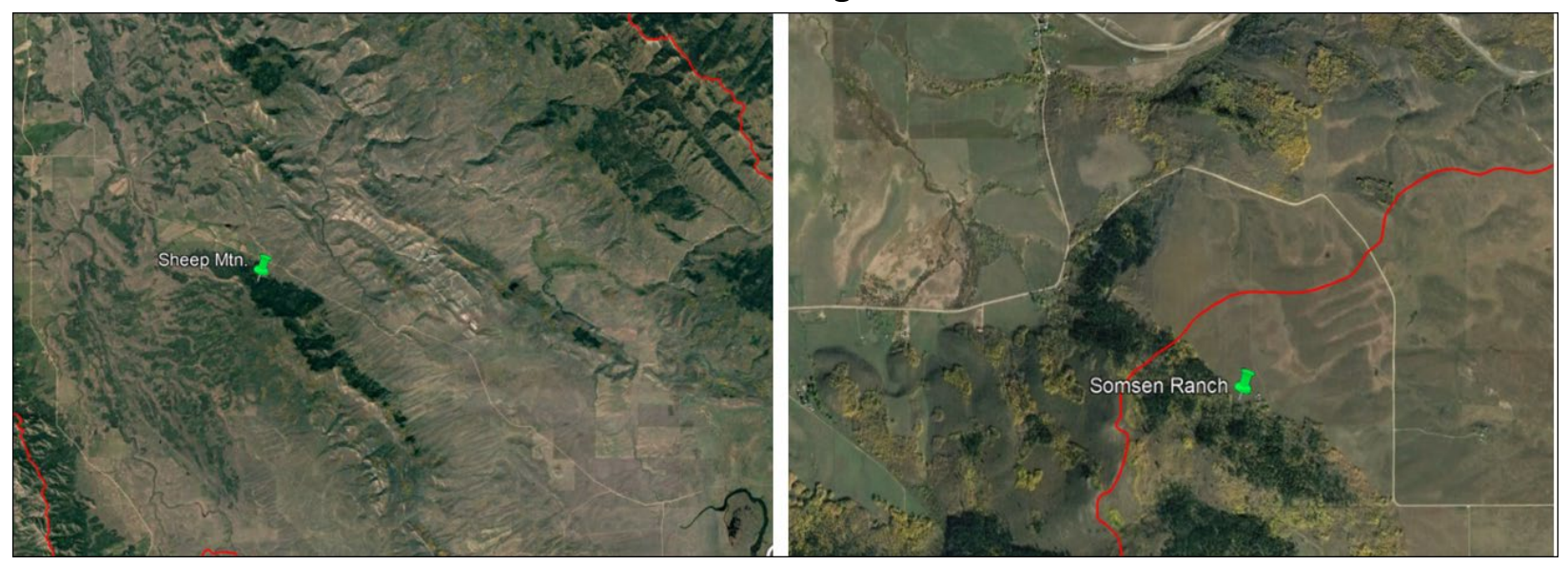

\subsubsection{Snow-cover duration and the timing of the annual SWE maximum}

We examined the snow-cover duration and the timing of the annual SWE maximum at the SNOTEL stations and the COOP station by using two approaches. Our first approach compared the duration and annual maximum timing observed at each station located in the watershed. Figure 56 shows the snow duration for each year for each station and indicates the date of the annual maximum SWE for each year. Table 18 lists the average duration of continuous snow cover, the average number of days with snow reported, and the average day of year on which the annual maximum SWE occurs. There is a significant difference between the COOP station and the 
SNOTEL stations values. Each winter season, the COOP station has an average of 85 days of continuous snow and an average of 108.6 days with snow reported. The average day of the year that the annual maximum SWE occurs is 15 January. While the average is mid-January, the maximum SWE date can range from November to March, depending on the water year. In contrast, the Sheep Mountain SNOTEL station has an average of 171.3 days of continuous snow and an average of 176.2 days with snow reported, and 22 March is the average day of the year on which the annual maximum SWE occurs. Similarly, the Somsen Ranch SNOTEL station has an average of $\mathbf{1 7 4 . 7}$ days of continuous snow and an average of 178.0 days with snow reported, and 25 March is the average day of the year on which the annual maximum SWE occurs. The maximum SWE date generally ranges from late February to mid-April.

Figure 56. Snow duration and timing of SWE annual maximum at SNOTEL and COOP stations. Circles represent the annual maximum for each station.

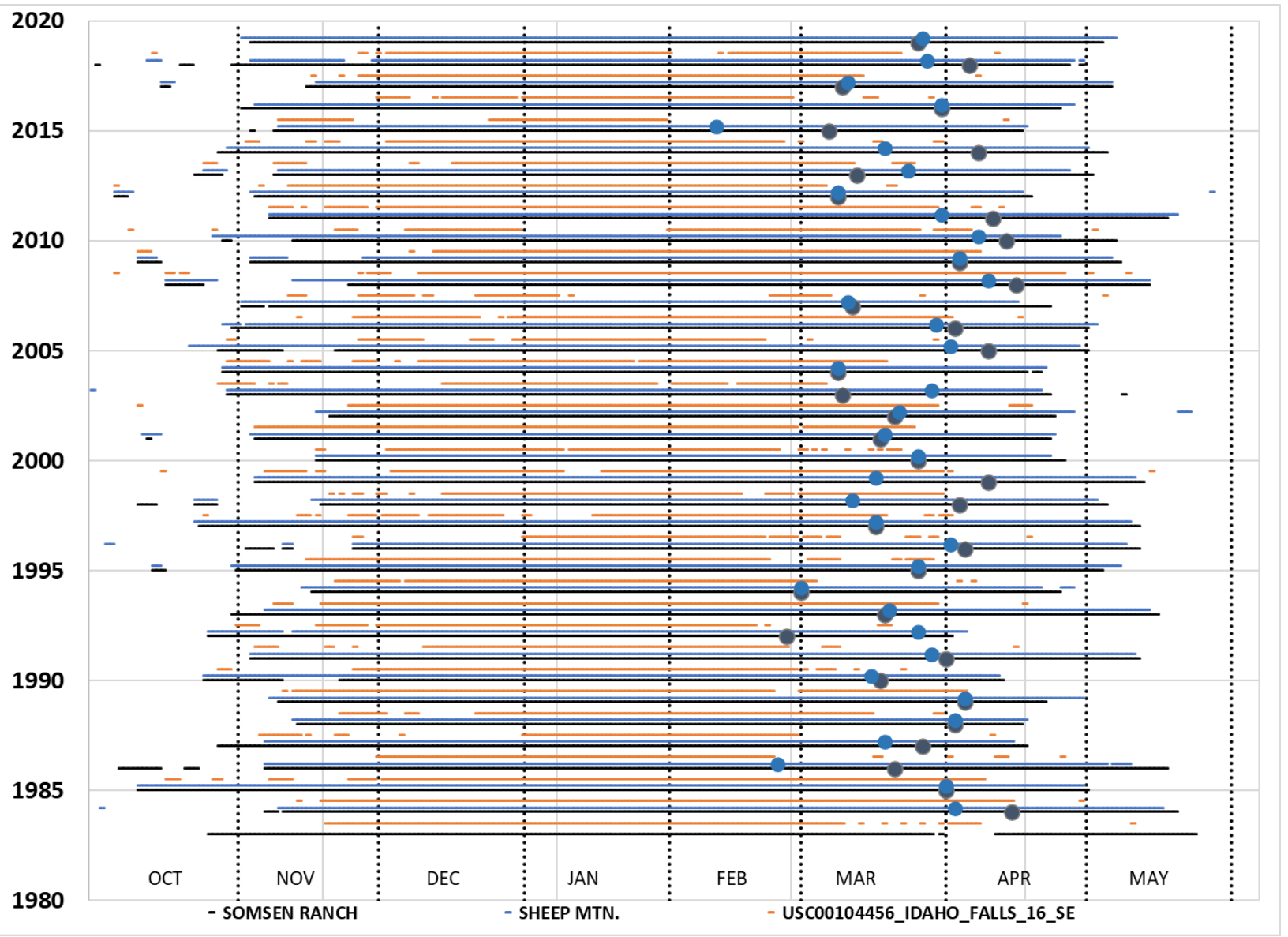


Table 18. SWE duration at ground-based stations.

\begin{tabular}{|l|c|c|c|c|c|c|}
\hline \multicolumn{1}{|c|}{ Station } & $\begin{array}{c}\text { Elevation } \\
\text { (ft) }\end{array}$ & $\begin{array}{c}\text { Data } \\
\text { Source }\end{array}$ & $\begin{array}{c}\text { Average Annual } \\
\text { Maximum SWE } \\
\text { (in.) }\end{array}$ & $\begin{array}{c}\text { Average Number } \\
\text { of Days of } \\
\text { Continuous Snow }\end{array}$ & $\begin{array}{c}\text { Average Number } \\
\text { of Days with } \\
\text { Reported Snow }\end{array}$ & $\begin{array}{c}\text { Average Date } \\
\text { of Max SWE }\end{array}$ \\
\hline Idaho Falls 16 SE & 5827 & COOP & 4.3 & 85.0 & 108.6 & 15 Jan \\
\hline Sheep Mountain & 6650 & SNOTEL & 13.4 & 171.3 & 176.2 & 22 Mar \\
\hline Somsen Ranch & 6800 & SNOTEL & 13.0 & 174.7 & 178.0 & 25 Mar \\
\hline
\end{tabular}

Our second approach compared the duration observed at each of the stations to the duration determined by the CGF-SCA data. The Willow Creek Basin was divided into approximately $100 \mathrm{~m}$ (330 ft) elevation bands, and the SCA fraction of each band was calculated for each day over the period of record. Then we determined the average days each winter for each elevation category of SCA. The categories of SCA were $\geq 10 \% \mathrm{SCA}, \geq 25 \% \mathrm{SCA}$, $\geq 50 \%$ SCA, and $\geq 75 \%$ SCA. Figure 57 shows the results along with the duration of snow at the SNOTEL station and the COOP station. The average number of days of continuous snow at the COOP station is very close to the snow-cover duration for $\geq 50 \%$ SCA for that elevation band based on CFGSCA. The average number of days of continuous snow at the SNOTEL stations, on the other hand, is relatively much longer. The elevation band corresponding to the Sheep Mountain SNOTEL site only had 4.5\% snow cover during the average number of days for that site. The average number of days for the Somsen Ranch SNOTEL was equal to the snow-cover duration for $\geq 2.7 \%$ SCA for its elevation band. This data suggests that the average SWE duration at Sheep Mountain and Somsen Ranch SNOTEL sites remains snow covered beyond the expected duration for each of the elevation bands in which they are located. While these two SNOTEL sites do not necessarily represent the mean of their respective snow elevation bands, water managers do find them helpful for tracking the remaining snow during the final stages of filling Ririe Reservoir storage. 
Figure 57. Average snow duration (days) by elevation and fraction based on CGF-SCA. The bottom circle for each station is the average number of days of continuous snow, and the top circle for each station is the average number of days with reported snow.

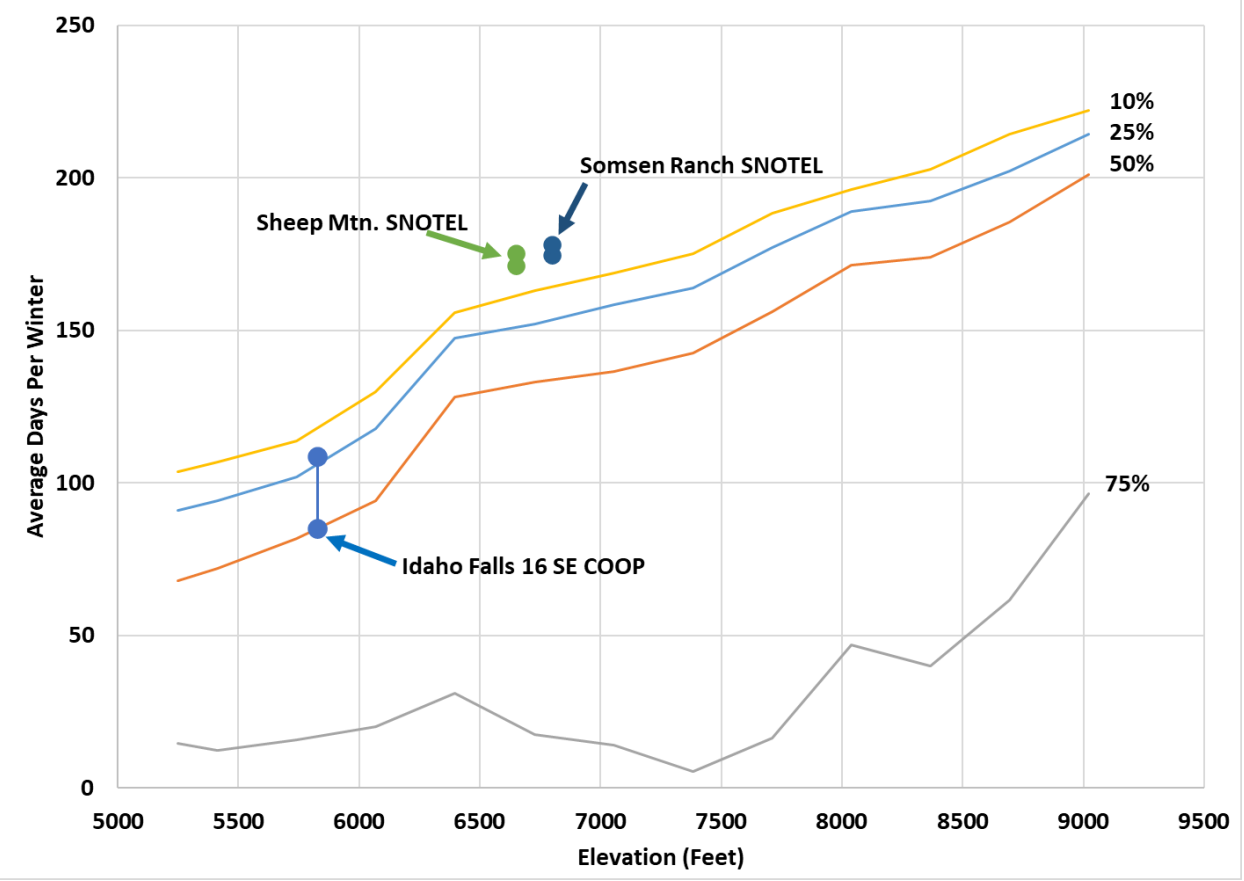

\subsubsection{SWE magnitude}

Based on Figure 56, the duration of snow presence at the SNOTEL sites is significantly longer than at the COOP station. This condition is one of the reasons that estimating SWE for the entire watershed is challenging when using only SNOTEL sites. Longer snow durations are associated with deeper snow (larger SWE) and reduced rate of snow melt. Both of these conditions could be true, given the treed areas in which the SNOTEL sites are located as described above. There is no remote, practical method available to determine the degree to which the SWE at the ground stations is representative of the overall SWE of the subbasin in which it is located. The average annual maximum SWE at the SNOTEL sites is significantly larger than the average annual maximum SWE at the COOP site (Figure 57). We used the PRISM gridded precipitation data (PRISM Climate Group 2019) and the UA SWE data to gain insight into this situation. Figure 58 plots the average annual maximum UA SWE for each of the three subbasins against the mean elevation of each subbasin. Figure 57 shows the mean annual total SWE versus elevation for all SNOTEL and COOP sites. Here, the average annual maximum SWE at the SNOTEL sites is greater than that indicated by the UA SWE. The figure also shows that the average annual maximum SWE at the COOP site is generally in line with UA SWE. 
We performed a check on the UA SWE results using the monthly PRISM precipitation for each of the subbasins. We summed the monthly PRISM precipitation for the months of December, January, February, and March of each water year. The majority of snowfall that contributes to the annual maximum SWE occurs in these months. We expect the sum of the precipitation for these months should roughly correspond with the annual maximum SWE. Figure 58 also shows the average maximum PRISM precipitation sum for December through March for each of the three subbasins. The PRISM results and the UA SWE track each other closely. The PRISM data and the UA SWE data being consistent is not totally unexpected as the PRISM data was used to estimate the UA SWE data. However, this further demonstrates that the SNOTEL data, which is most often used to describe SWE conditions in the Willow Creek Basin, is not representative of the entire watershed and could overestimate snowmelt runoff volume in hydrologic simulations.

Figure 58. Comparison of average annual maximum SWE for the SNOTEL and COOP sites compared to the spatially averaged UA SWE for each of the subbasins, and the average annual PRISM precipitation sum for the months of December through March for each of the subbasins.

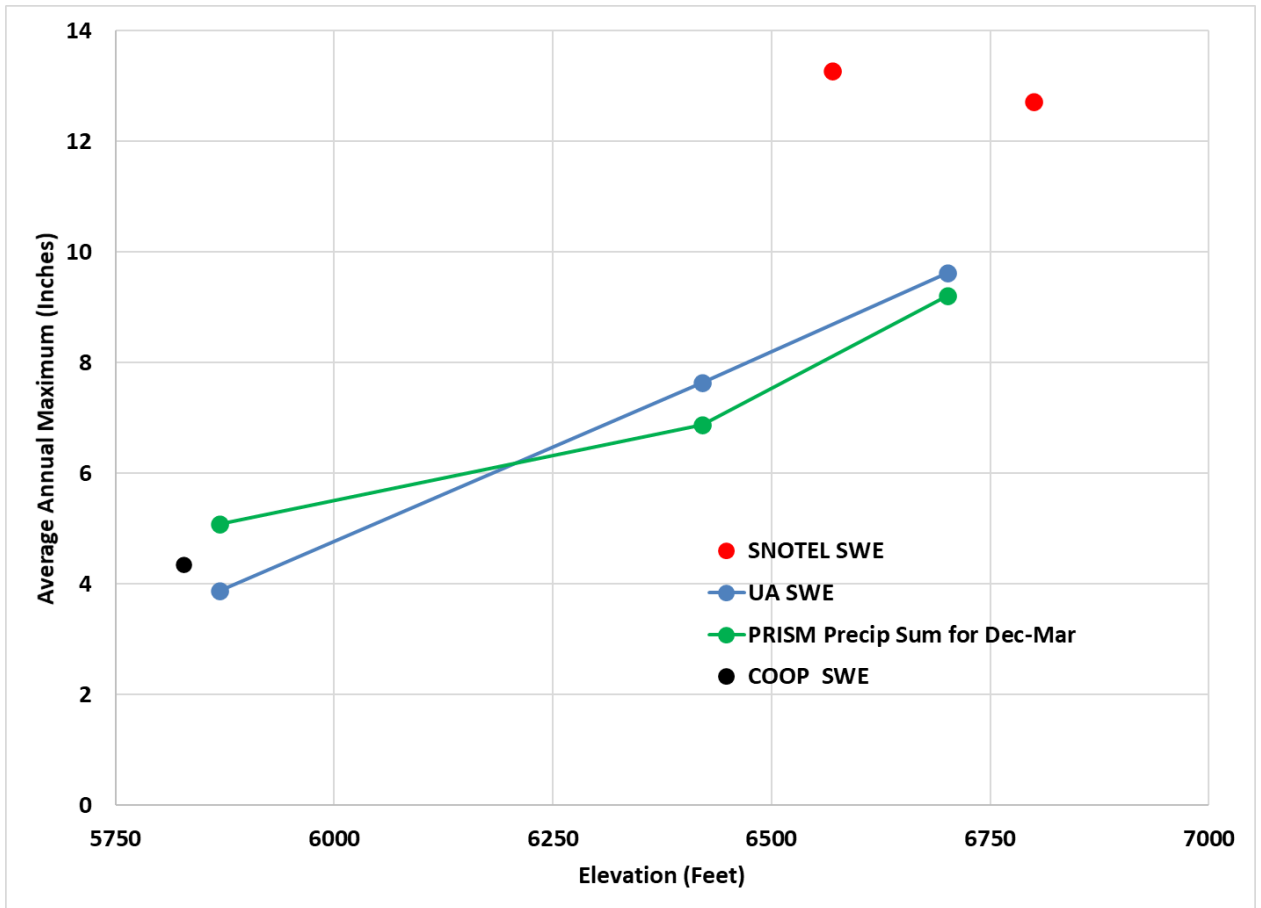




\subsubsection{Snow data summary}

The relatively large difference between the average annual maximum SWE at the two SNOTEL sites and the UA SWE results for each subbasin suggests that the SNOTEL SWE reflects the influence of the surrounding trees and that the SNOTEL results are not reflective of their subbasin's overall snow conditions. In addition, there is relatively close agreement between the UA SWE gridded data and the SNODAS gridded data as section 4.3 will show. Therefore, the UA SWE gridded data will serve as the basis for SWE information for the Willow Creek Basin.

\subsection{Estimating SWE exceedance probabilities}

There are many different statistical approaches for estimating the AEP of SWE based on an annual maximum series. We chose the log-normal probability distribution as adequate to describe AEP of SWE up to 1\% AEP. Ellingwood and Redfield (1983) found that the log-normal fit SWE data better than other distributions. The log-normal distribution is also used to estimate the return period of SWE for roof snow loads in Minimum Design Loads for Buildings and Other Structures (7-10) (ASCE 2010). Our report uses the log-normal probability distribution to estimate the AEP SWE depths based on a series of annual and monthly maximums. We determined the AEP for the annual maximum SWE for each subbasin based on the UA SWE and SNODAS gridded data (Table 19 and Figures 59-62). We found that the UA SWE data generally agreed with the SNODAS for most probabilities. This comparison proved that the UA SWE reasonably represented the Willow Creek Basin for a range of SWE conditions. The final quantiles were calculated using the UA SWE because it provided a long time series for parameter estimation. Figures 59-62 also demonstrate that the lognormal distribution does work for SWE data in this watershed.

We calculated the AEP of the maximum SWE depth for the months of October through March for each subbasin and the Willow Creek Basin (Table 20 and Figures 63-67). Figure 67 shows the AEP for the annual maximum SWE for the Willow Creek Basin. We calculated the 90\% confidence intervals using the noncentral-T distribution (Stedinger 1982), shown in Figures 63-68. The log-normal parameters and the monthly maximum SWE values for each subbasin are in Appendix D. We do not recommend using SWE values for any AEP of less than $1 \%$ when performing hydrologic load- 
ing estimates from snowmelt runoff with large precipitation events. Because the focus of our study is to evaluate flood risk operating criteria for Ririe, we have not included AEP values for probabilities less than $1 \%$.

Table 19. SWE depths (inches) for specific return periods for the Willow Creek Basin and subbasins.

\begin{tabular}{|l|c|c|c|c|c|c|c|c|}
\hline \multirow{2}{*}{ AEP } & \multicolumn{2}{|c|}{ Willow Creek Basin } & \multicolumn{2}{c|}{$\begin{array}{c}\text { Grays Lake } \\
\text { Subbasin }\end{array}$} & \multicolumn{2}{c|}{$\begin{array}{c}\text { Ririe Upstream } \\
\text { Subbasin }\end{array}$} & \multicolumn{2}{c|}{ Ririe Subbasin } \\
\cline { 2 - 9 } & UA & SNODAS & UA & SNODAS & UA & SNODAS & UA & SNODAS \\
\hline $5 \%$ & 11.39 & 10.99 & 14.90 & 12.19 & 12.31 & 11.92 & 7.19 & 7.57 \\
\hline $2 \%$ & 12.87 & 12.48 & 16.78 & 13.67 & 14.03 & 13.65 & 8.54 & 9.31 \\
\hline $1 \%$ & 13.96 & 13.59 & 18.17 & 14.77 & 15.31 & 14.95 & 9.58 & 10.69 \\
\hline
\end{tabular}

Figure 59. AEP of the annual maximum SWE for the Willow Creek Basin.

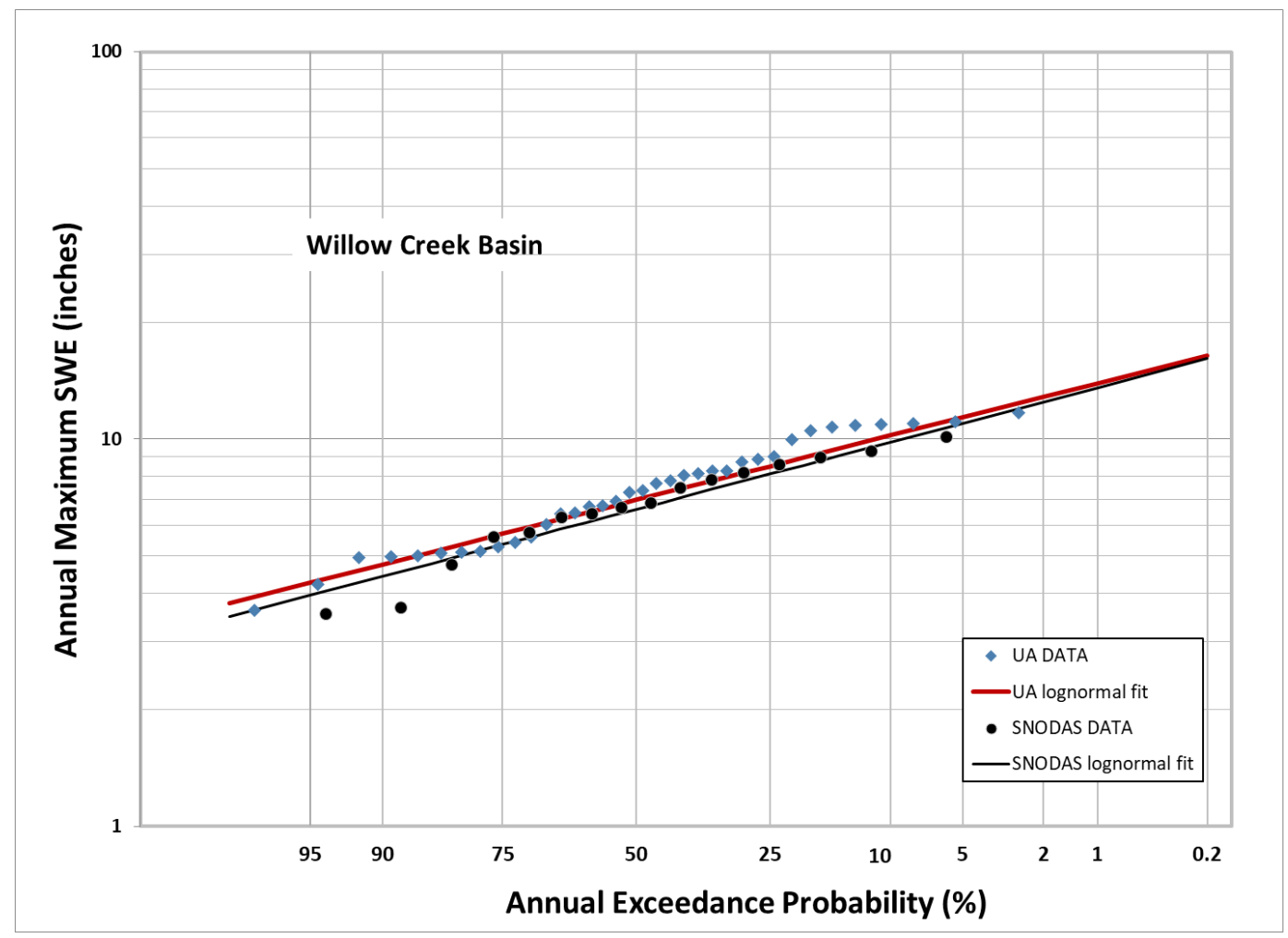


Figure 60. AEP of the annual maximum SWE for the Ririe Subbasin.

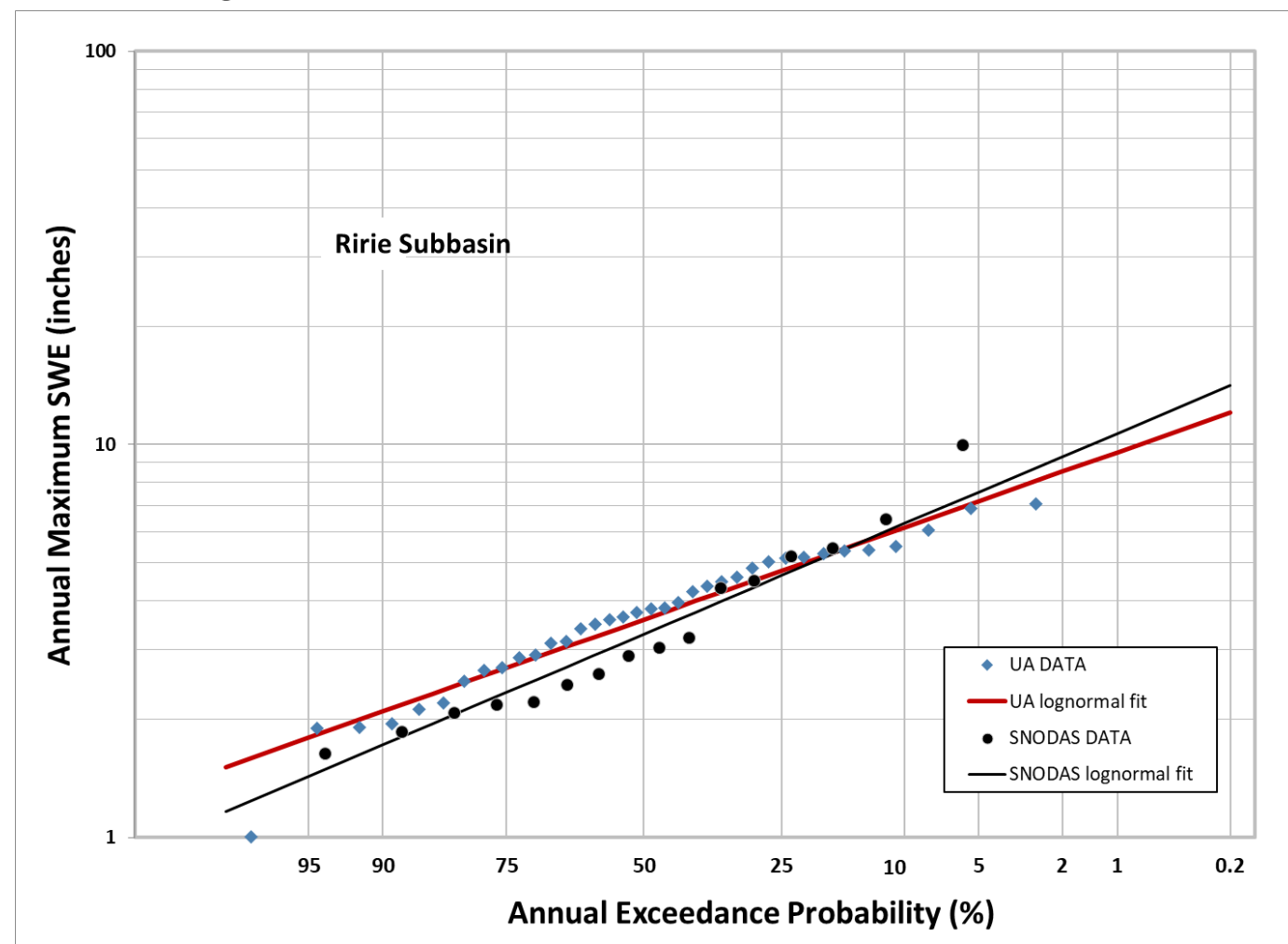

Figure 61. AEP of the annual maximum SWE for the Ririe Upstream Subbasin.

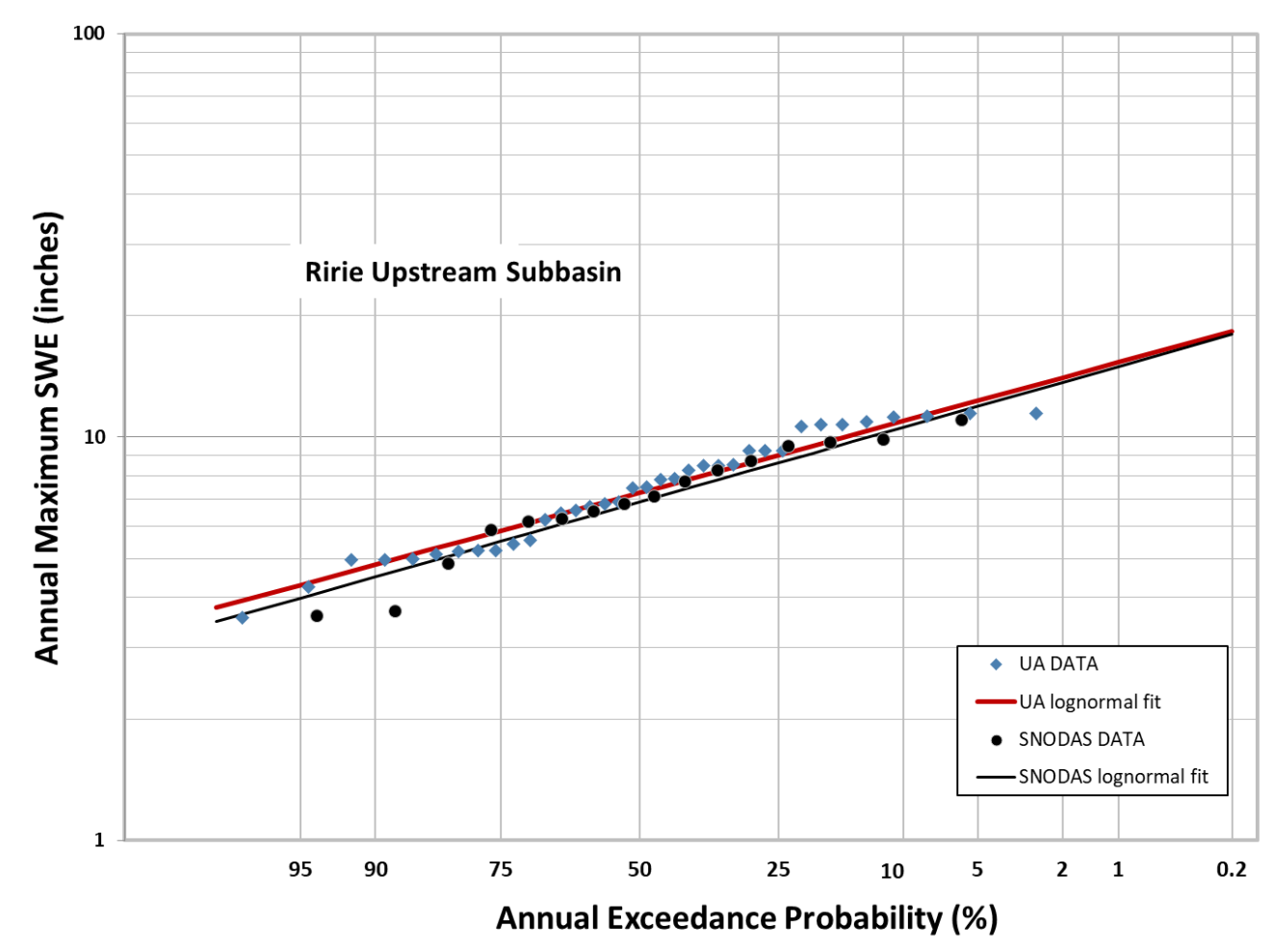


Figure 62. AEP of the annual maximum SWE for the Grays Lake Subbasin.

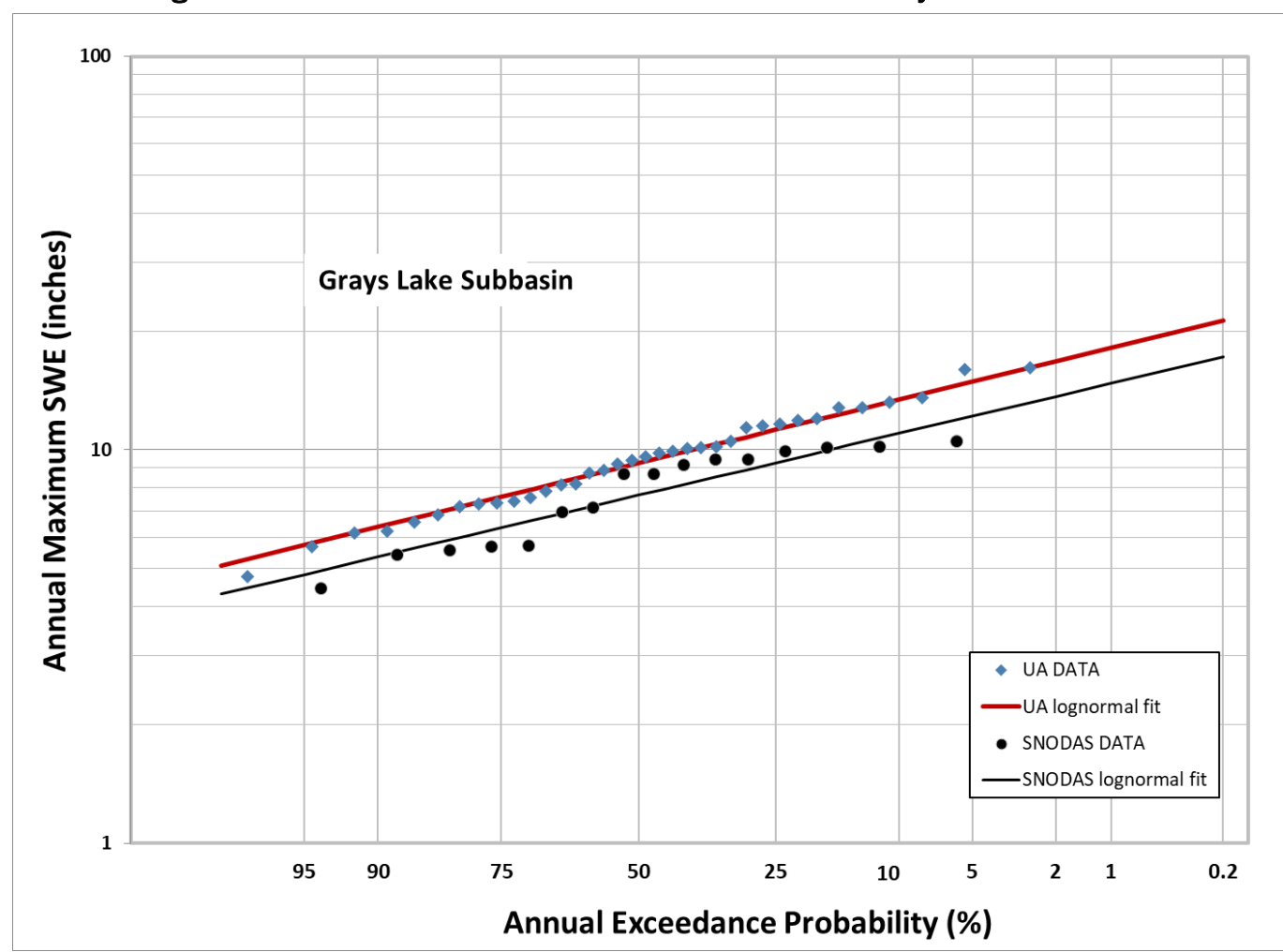

Table 20. SWE depths (inches) for specific annual exceedance probabilities by month.

\begin{tabular}{|l|c|c|c|c|c|}
\hline AEP (\%) & Nov & Dec & Jan & Feb & Mar \\
\hline \multicolumn{7}{|c|}{ Willow Creek Basin } \\
\hline 0.05 & 3.19 & 6.41 & 8.57 & 10.48 & 11.68 \\
\hline 0.02 & 4.13 & 7.71 & 9.75 & 11.86 & 13.33 \\
\hline 0.01 & 4.90 & 8.71 & 10.63 & 12.89 & 14.56 \\
\hline \multicolumn{7}{|c|}{ Ririe Subbasin } \\
\hline 0.05 & 1.99 & 4.45 & 5.77 & 6.91 & 7.54 \\
\hline 0.02 & 2.71 & 5.68 & 6.91 & 8.27 & 9.40 \\
\hline 0.01 & 3.32 & 6.70 & 7.78 & 9.32 & 10.89 \\
\hline \multicolumn{7}{|c|}{ Ririe Upstream Subbasin } \\
\hline 0.05 & 3.24 & 6.64 & 8.81 & 10.78 & 11.98 \\
\hline 0.02 & 4.19 & 8.02 & 10.05 & 12.23 & 13.74 \\
\hline 0.01 & 4.98 & 9.09 & 10.97 & 13.31 & 15.05 \\
\hline \multicolumn{7}{|c|}{ Grays Lake Subbasin } \\
\hline 0.05 & 3.85 & 7.05 & 9.90 & 12.34 & 14.59 \\
\hline 0.02 & 4.97 & 8.32 & 11.16 & 13.88 & 16.43 \\
\hline 0.01 & 5.89 & 9.30 & 12.09 & 15.00 & 17.79 \\
\hline
\end{tabular}


Figure 63. AEP of the annual maximum SWE for the Willow Creek Basin for November.

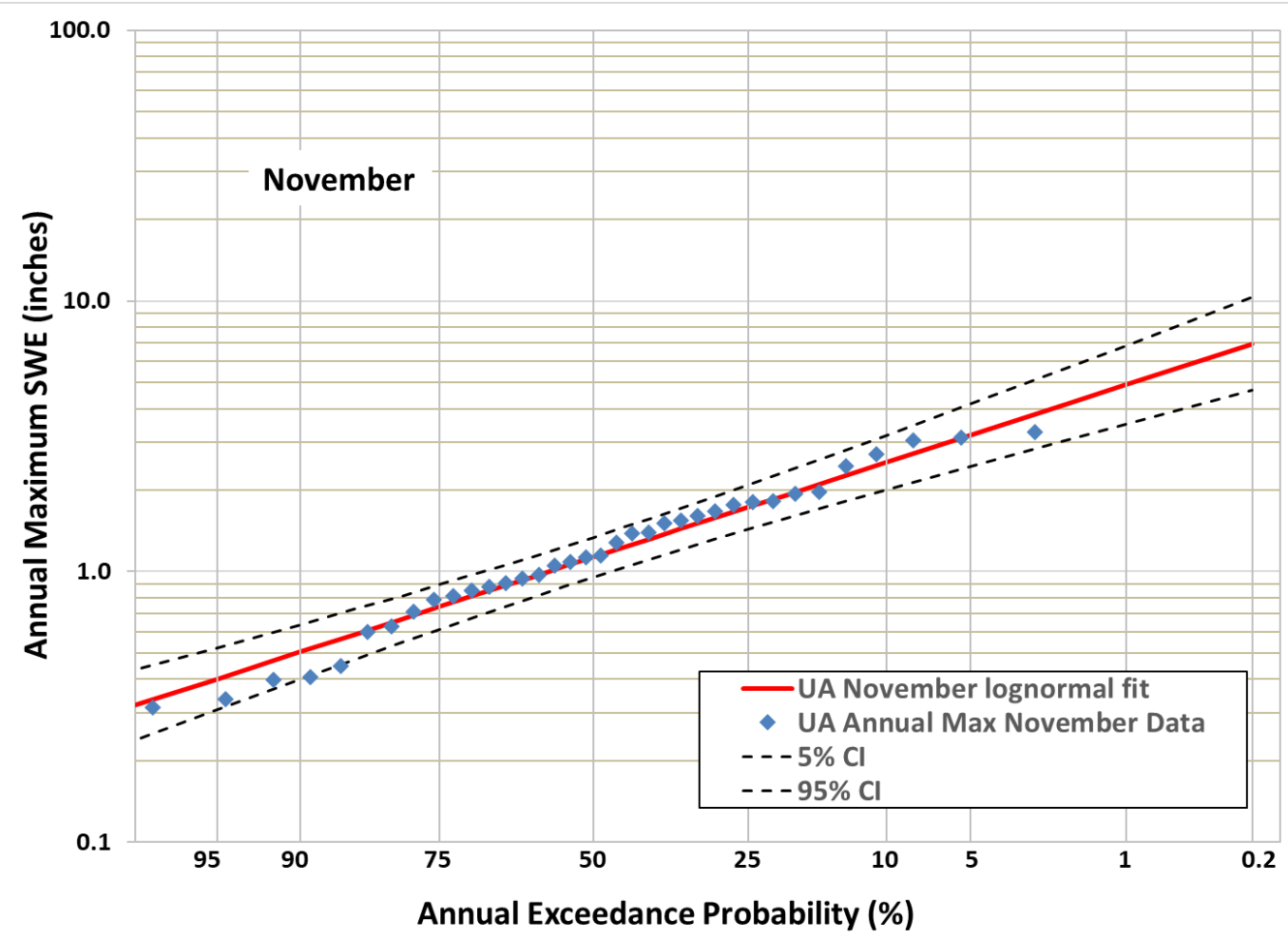

Figure 64. AEP of the annual maximum SWE for the Willow Creek Basin for December.

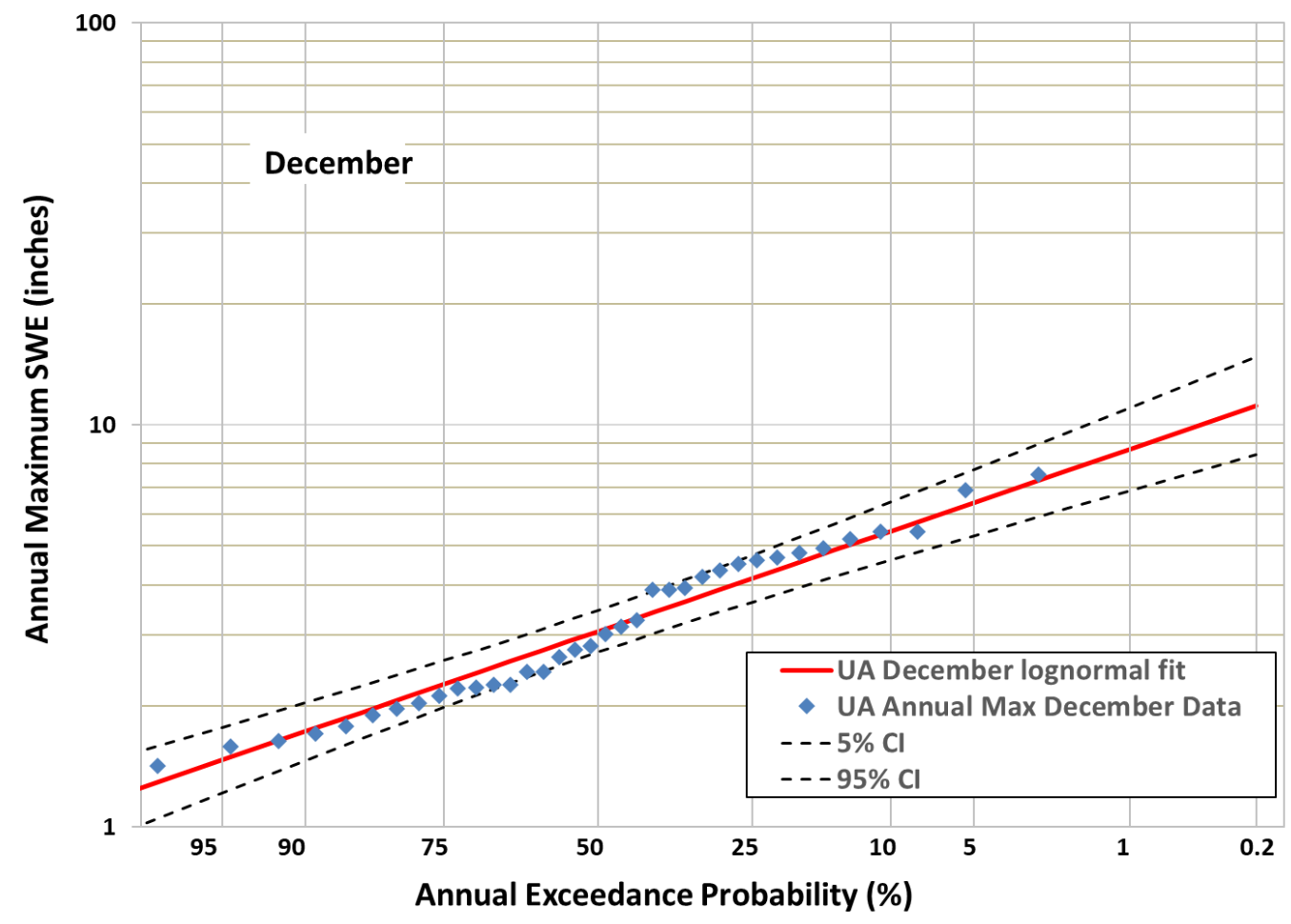


Figure 65. AEP of the annual maximum SWE for the Willow Creek Basin for January.

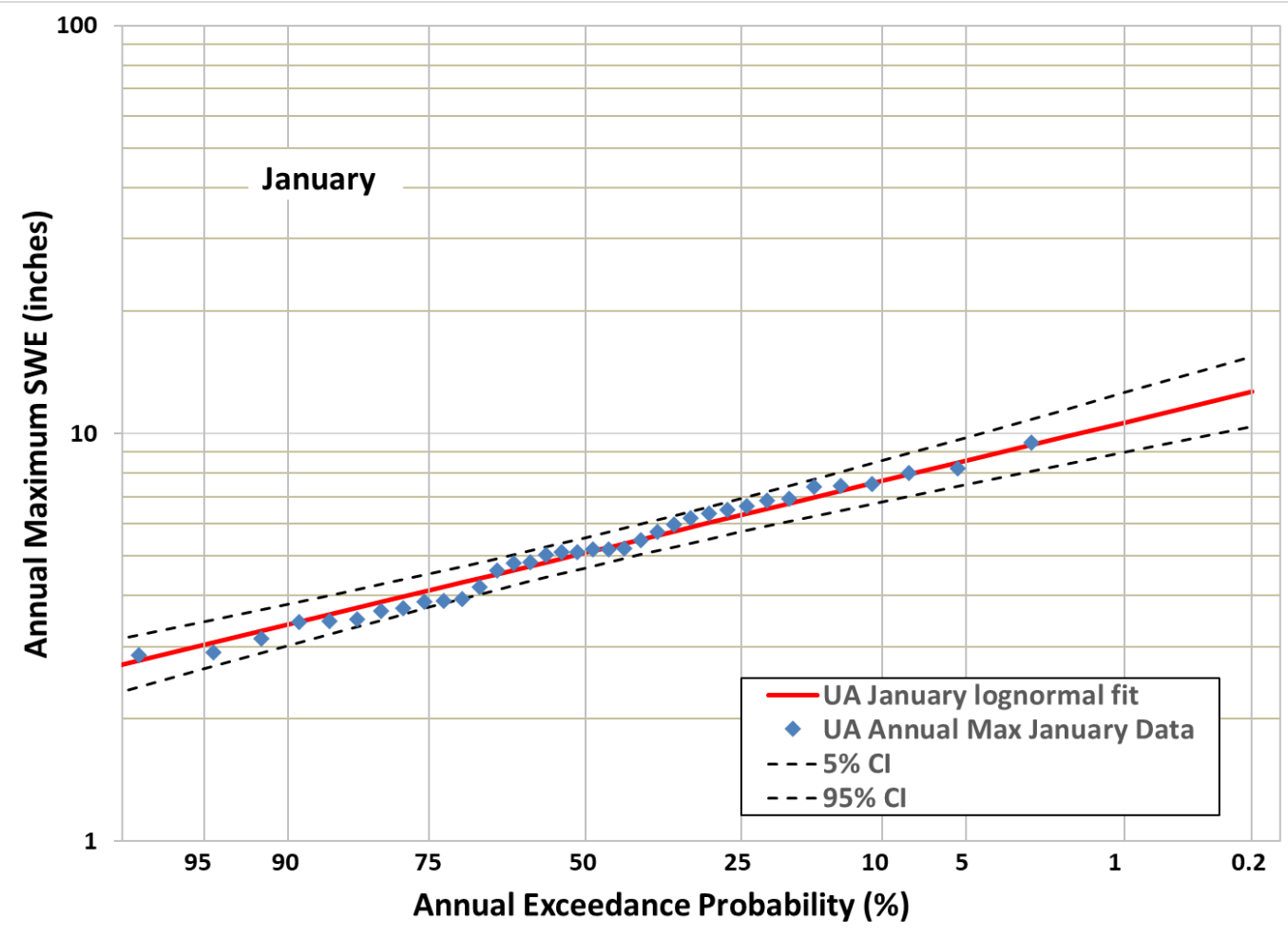

Figure 66. AEP of the annual maximum SWE for the Willow Creek Basin for February.

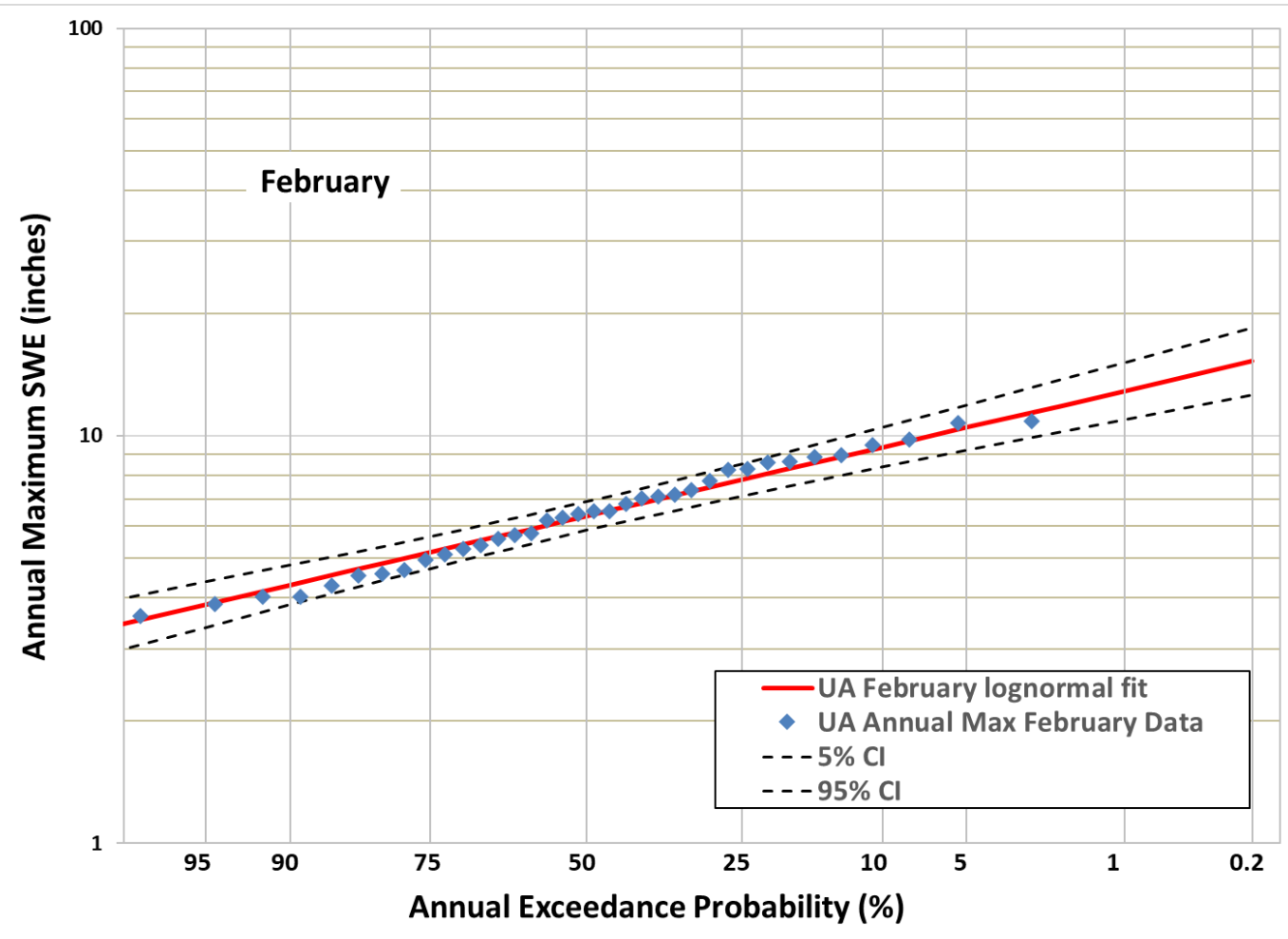


Figure 67. AEP of the annual maximum SWE for the Willow Creek Basin for March.

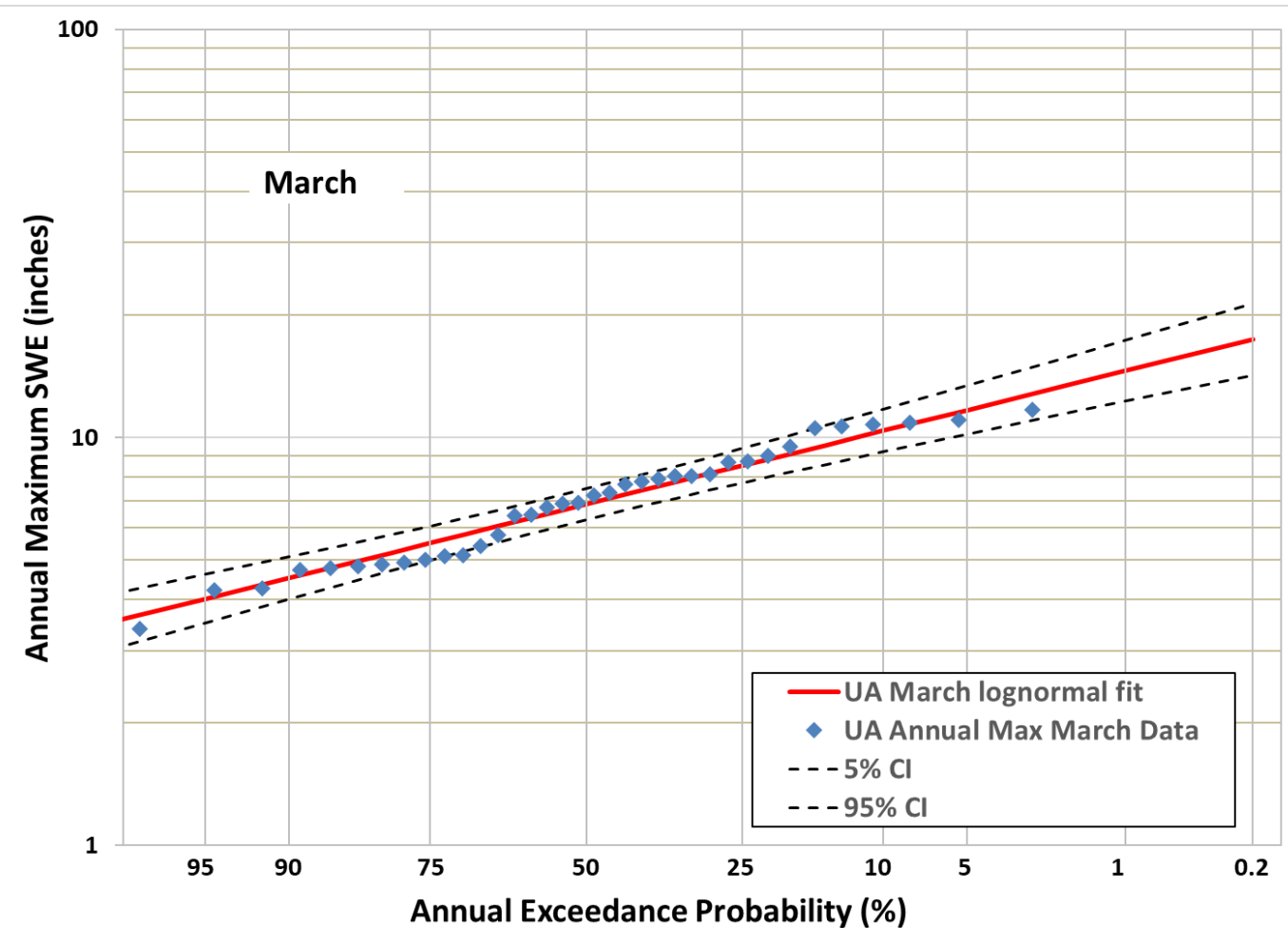

Figure 68. AEP of the annual maximum SWE for the Willow Creek Basin.

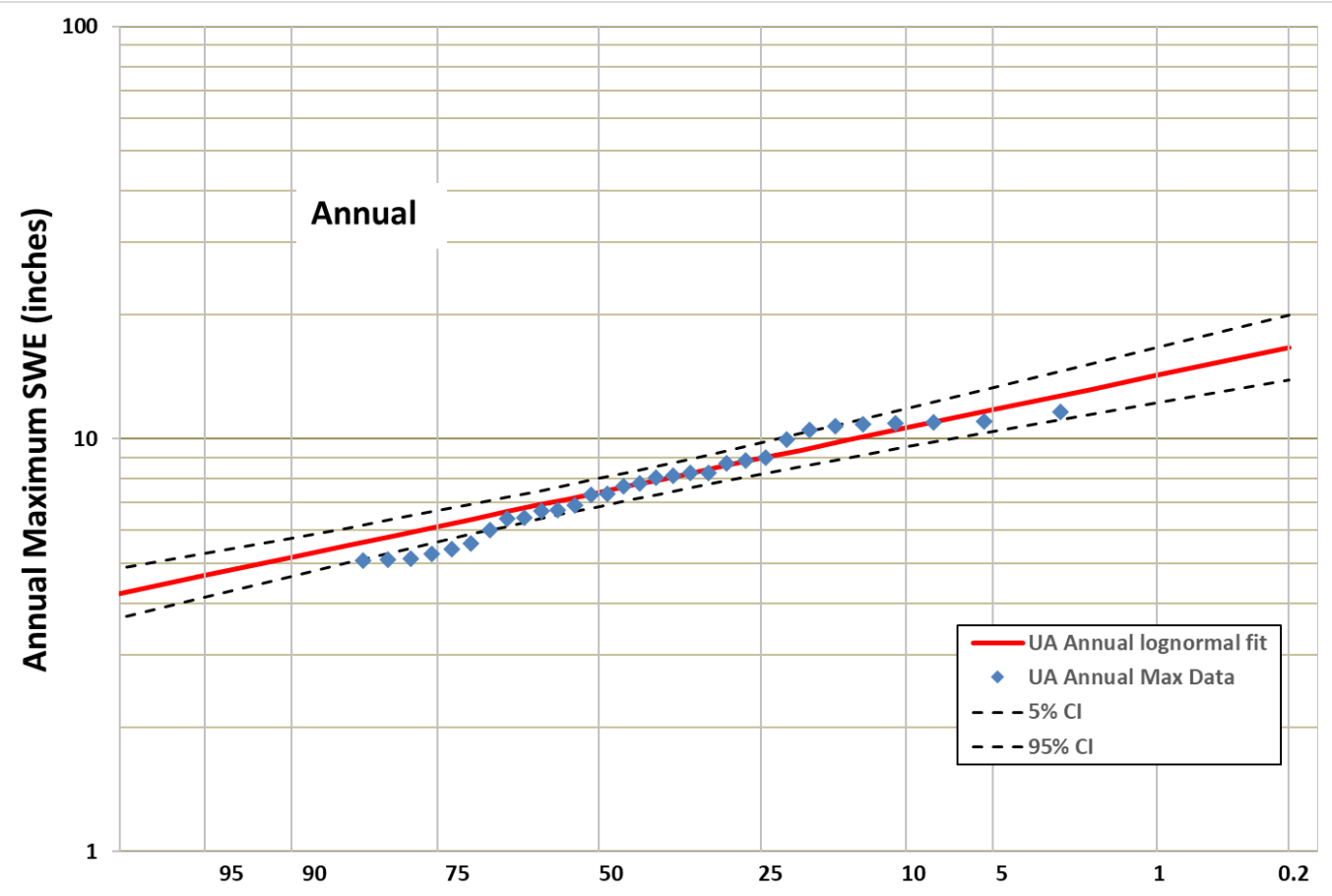

Annual Exceedance Probability (\%) 


\subsection{Probable maximum snow accumulation}

The probable maximum snow accumulation (PMSA) represents the upper limit to the maximum seasonal snow accumulation. The WMO report (WMO 1969) provides two methods for estimating the PMSA. The first, the "partial season method" estimates the upper limit of seasonal snow accumulation by combining the maximum monthly snowfall, described in terms of SWE in specific time periods regardless of the year of occurrence. For example, there, the upper limit was estimated by combining the greatest observed snowfall in any November with that in any December, etc., through all the months of the winter season. The report also describes the process for shorter periods, those less than 1 month, including 2 weeks, 1 week, and 4 days. WMO (1969) noted that "as the combination interval decreases, the estimated maximum snow accumulation increases." The proper limit to the combination interval used "would be the average interval between major winter storms in the basin in question in the seasons of greatest observed snowfall" (WMO 1969).

A second approach, the "snow storm maximization method" uses "determination of the ratio of the maximum moisture content possible at that time of year in the area under consideration, and the actual moisture content of the precipitation-producing air mass in the storm." The observed snowfall is then multiplied by this maximization ratio. Debs et al. (1999) used this method to determine the PMSA in the probable maximum flood study in northern Quebec. Further, in the probable maximum flood study for the proposed Susitna-Watana Hydroelectric Project (MWH Americas Inc. 2014) located in central Alaska, the PMSA was determined to be equal to 3.0 times the October through April cumulative average precipitation, based on a hydrometeorological report prepared for an adjacent watershed (U.S. Weather Bureau 1966).

We used the partial season method to estimate the PMSA. First, the daily snowfall, in inches of SWE, was estimated based on the UA SWE data. This provided daily snowfall estimates from 1982 to 2017 . We divided the winter period into a series of increasing intervals with specified durations. First, for example, the winter was divided into intervals of one day with a specific day of year assigned to each interval. Then the maximum snowfall that occurred on that day of year over the entire period of record was found. The result was a daily time series with length of one winter season. Each day of the time series was equal to the maximum snowfall that had occurred on that same day of year over the entire period of record. The 
time series was then summed to arrive at the PMSA with interval duration of one day. This process was then repeated for intervals with durations of 4, 7, 14, and 30 days. Figure 69 shows the PMSA of each interval duration. As noted in WMO (1969), as the interval duration decreases, the PMSA increases. Additionally, there is a strong power-law relationship between the interval duration and the PMSA of the form

$$
\operatorname{PMSA}(D)=a D^{b},
$$

where

$\operatorname{PMSA}(D)=$ the PMSA calculated for interval with duration $D$ in days and $a$ and $b=$ the fitted coefficients.

Figure 69 also shows the power-law curves, and Table 21 lists the fitted coefficients. Once the duration that corresponds to the average interval between major snowfall events during the winter season is selected, the power-law curve can be used to determine the proper PMSA for the watershed and each subbasin.

We computed the average interval between major storm events by first using the approach described by Restrepo-Posada and Eagleson (1982) to identify the minimum time between independent storms in the Willow Creek Basin during the winter. This analysis used the precipitation data from the GHCN station USCo0104456, Idaho Falls 16 SE, located in the Willow Creek Watershed. Data was available for 1955 to the present. We selected a precipitation amount of $0.15 \mathrm{in}$. as a minimum precipitation required to define a storm. With this, the minimum time between independent storms in the Willow Creek Watershed was 1.65 days; and the average time interval between storms was 12.0 days. Based on these results, we determined the PMSA for the Willow Creek Basin and its subbasins by using the relationships shown in Figure 69. Table 21 lists the estimated PMSAs. For relative comparison purposes, we have listed the 1\% AEP (100-year return period) and 0.2\% AEP (500-year return period) SWE along with the PMSA value. The PMSA is approximately 2.0 times the $1 \%$ AEP and 1.6 times the $0.2 \%$ AEP SWE. 
Figure 69. PMSA as a function of the accumulation time step for 12-day average storm interval.

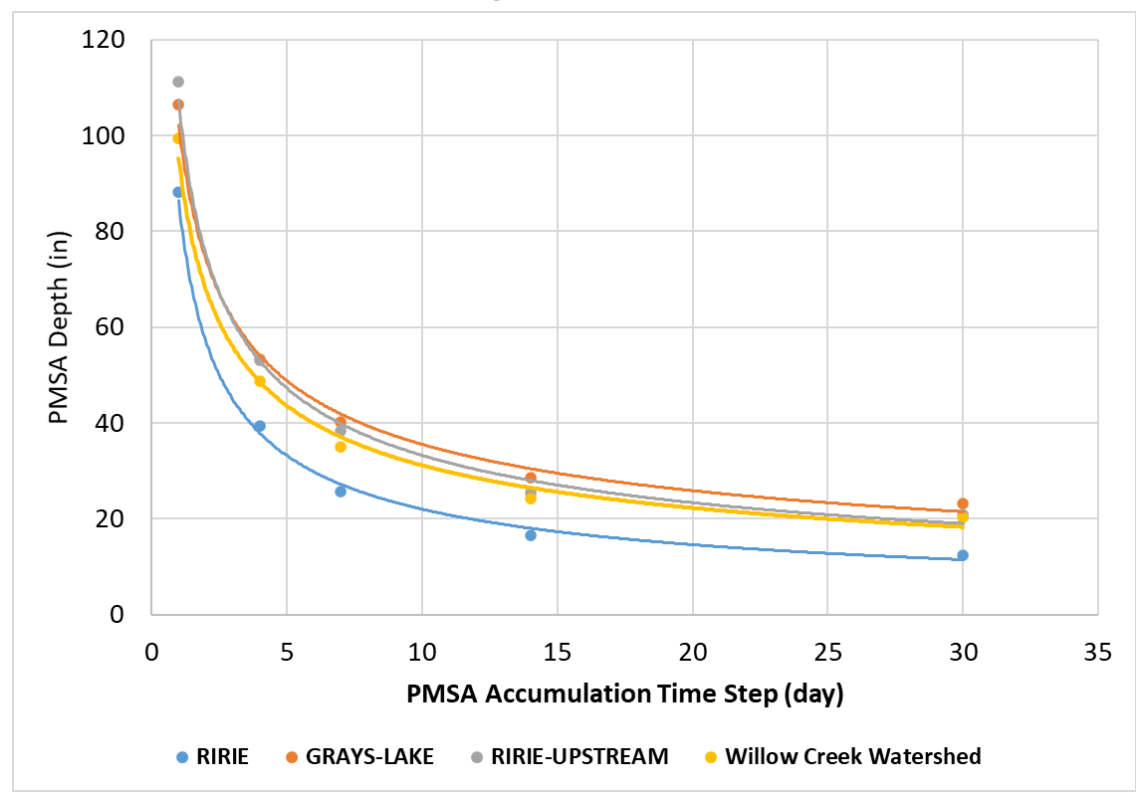

Table 21. PMSA, 0.2\% AEP, and 1\% AEP comparison for the Willow Creek Basin and subbasins (inches).

\begin{tabular}{|l|c|c|c|c|}
\hline \multicolumn{1}{|c|}{ SWE Method } & Ririe Subbasin & Ririe Upstream & Grays Lake & Total Watershed \\
\hline PMSA & 19.8 & 30.3 & 32.7 & 28.6 \\
\hline $0.2 \%$ AEP & 12.08 & 18.26 & 21.33 & 16.47 \\
\hline $1 \%$ AEP & 9.58 & 15.31 & 18.17 & 13.96 \\
\hline a coefficient & 86.348 & 107.34 & 102.28 & 95.333 \\
\hline$b$ coefficient & -0.593 & -0.509 & -0.459 & -0.485 \\
\hline
\end{tabular}




\section{Frozen Ground}

The frigid winter air temperatures in the Willow Creek Basin can cause the water in the upper layer of the soil to freeze. Ice forming in the soil matrix reduces the soil infiltration capacity-with the actual change in infiltration primarily dependent on the soil moisture content, the soil type, and the number and size of large flow passages through the soil (macropores). Frozen ground was reported to be an important factor in the record floods of 1962. Thomas and Lamke (1962) reported that "The rain plus the melted snow ran off rapidly, as the frozen ground prevented infiltration. This resulted in floods with unusually rapid rises of unusual magnitudes." The impact of frozen ground has long been recognized as a factor contributing to floods in the Northwest:

Many areas of the United States experience flooding in watersheds where infiltration is impaired because of frozen soil. In the Pacific Northwest this phenomenon is quite common in eastern Oregon, eastern Washington, and the arid Snake River drainages in southern Idaho. In forecasting floods it is very important to account for the effects of frozen ground, but it is often difficult to anticipate the magnitude of the effect (Molnau and Bissell 1983).

Both the anecdotal and observational evidence suggest that to accurately estimate the potential winter flood hydrograph, quantification of reduced infiltration due to frozen soil conditions is necessary.

There are a wide range of approaches for estimating the impact of frozen soil on infiltration and runoff. Physically based models calculate infiltration through frozen soil using detailed descriptions of the soil properties and the environmental conditions. These types of models include formulations of thermal conduction and convection, liquid flow (capillary and gravity flows), phase changes (freezing-thawing, evaporation-condensation, and sublimation-deposition), vapor diffusion, and other processes (see Tao and Gray 1994 for example). At the other extreme are relatively simple index approaches based on air temperature and snow depth (Molnau and Bissell 1983) that indicate when to expect enhanced runoff due to frozen soil. Gray and others have written extensively on infiltration into frozen soils (see for example Gray et al. 2001; Maulé and Gray, 1994). 
Gray proposed that frozen soils can be separated into three general groups in terms of their potential infiltration capacity:

1. Unlimited (predominately gravity flow): Soils are capable of infiltrating most or all available meltwater.

2. Restricted: Soils infiltrability is restricted by an impervious surface.

3. Limited (predominately capillary flow): Soil infiltrability is governed primarily by the soil moisture content (water + ice), soil temperature at the start of snow ablation, and infiltration opportunity time.

For the Willow Creek Basin, the majority of soils would be described by the "limited" classification. Infiltration into soils in the "limited" group is governed by two conditions: whether the soil is frozen and the moisture content of the frozen soil. The infiltration of the frozen soil is described by a nonlinear function of the soil moisture. As a result, it is necessary to determine the period of time each winter during which the soil is frozen and to determine the soil moisture content of the frozen soil. Section 5.2 describes the procedures for making these determinations .

In this chapter, we quantify the reduced infiltration by developing a Frozen-Soil-Infiltration Model (FSIM) for the Willow Creek Watershed. We applied FSIM results in HEC-HMS to demonstrate how frozen soils limited infiltration and enhanced runoff during the record flood of 1962. Our description in this chapter includes a brief review of the impact of frozen ground on infiltration and runoff, the model development, and results for the Willow Creek Basin.

For this analysis, we used data from a variety of sources, including groundbased observations of soil conditions, winter flood hydrographs, gridded model data of soil temperatures, and satellite data. This information was the primary input for two supporting components for FSIM: a ground temperature and ground freezing submodel and a soil moisture submodel. These submodels use observed air temperatures and precipitation along with the known soil properties of the Willow Creek Basin to produce output describing the ground state for each day of the winter season. Output from the two submodels is fed into FSIM, which produces an estimate of the soil infiltration capacity for each day. We then used the FSIM results in HEC-HMS to alter the base soil infiltration. 
The FSIM developed for this report is based on the approach of Maulé and Gray (1994) and bridges this gap between approaches by creating a physically based model of frozen-soil infiltration that uses readily available data (i.e., air temperature and precipitation) and can be used directly in a hydrologic model (e.g., HEC-HMS) for analysis.

\subsection{Data}

The air temperature and precipitation used for our frozen ground model development were based on the Idaho Falls 16 SE station (described in chapter 2). This chapter describes in detail other datasets used that were specific for this analysis.

\subsubsection{Ground temperature observations}

We used data from three soil observation networks: Agriculture Meteorology (AgriMet) operated by the Reclamation, the NRCS SNOTEL, and the National Oceanic Atmospheric and Administration's U.S. Climate Reference Network (USCRN). The field observation stations considered in this analysis are equipped with sensors that measure soil temperature at various depths. Figure 70 shows the locations of each observation station we used.

Figure 70. Locations of AgriMet, USCRN, and SNOTEL stations.

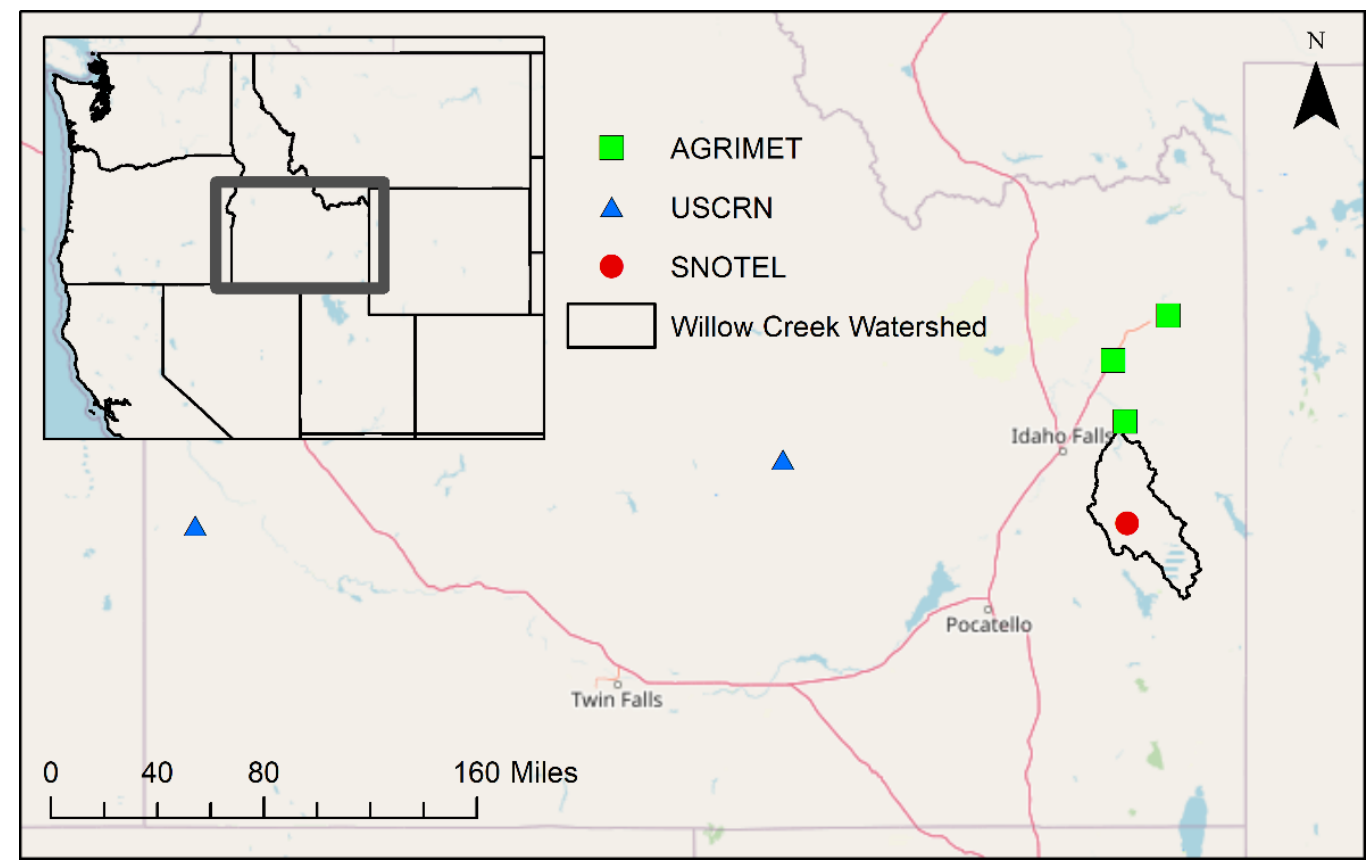




\subsubsection{AgriMet}

The AgriMet network consists of weather stations that are used to improve irrigation water management by measuring several metrological variables related to crop evapotranspiration (Reclamation 2020a). Some AgriMet stations also monitor soil temperature (Palmer 2011). Temperature probes are installed at various depths and report daily ground temperatures. There are three AgriMet stations equipped with soil temperature probes in the vicinity of Willow Creek Watershed (Table 22).

Table 22. AgriMet station soil temperature measurement depths.

\begin{tabular}{|l|c|c|c|c|c|c|c|}
\hline & & & & \multicolumn{3}{|c|}{$\begin{array}{c}\text { Soil Temperature } \\
\text { Probe Depth } \\
\text { (in.) }\end{array}$} & \\
\cline { 5 - 8 } & & & & \multicolumn{3}{|c|}{} \\
\cline { 5 - 8 } Station & Elevation & Lat & Long & $\mathbf{2}$ & $\mathbf{4}$ & $\mathbf{8}$ & Start Year \\
\hline Ashton & 5300 & $44.025^{\circ}$ & $-111.4667^{\circ}$ & & $\mathrm{X}$ & $\mathrm{X}$ & 1995 \\
\hline Rexburg & 4875 & $43.85^{\circ}$ & $-111.7667^{\circ}$ & & $\mathrm{X}$ & & 1995 \\
\hline Ririe & 5075 & $43.61035^{\circ}$ & $-111.7006^{\circ}$ & $\mathrm{X}$ & $\mathrm{X}$ & $\mathrm{X}$ & 2018 \\
\hline
\end{tabular}

The Ashton station had both the longest period of record and multiple sensor depths available. We used this information to evaluate timing, duration, and depth of soil temperatures below $32^{\circ} \mathrm{F}$. Figure 71 shows the timing and duration of soil temperatures below $32^{\circ} \mathrm{F}$ at the Ashton station. The soil temperature observations at this station indicate there can be multiple freezing and thawing cycles throughout the winter. In contrast, there were also several years that contained very few, if any, days the soil temperature reached freezing. The soil column at 4 and $8 \mathrm{in}$. had temperatures below $32^{\circ} \mathrm{F}$ for an average of 22 and 27 days, respectively.

The Ririe AgriMet Station is the closest ground observation station to the Willow Creek Basin and began recording soil temperature observations in WY 2018 (Figure 72). When the soil temperatures fell below $32^{\circ} \mathrm{F}$, the soil column remained frozen for an average duration of 17.3, 27.8, and 52.5 days for 2, 4, and 8 in. depths, respectively 
Figure 71. Ashton AgriMet station durations and timing of mean daily soil temperatures below $32^{\circ} \mathrm{F}$.

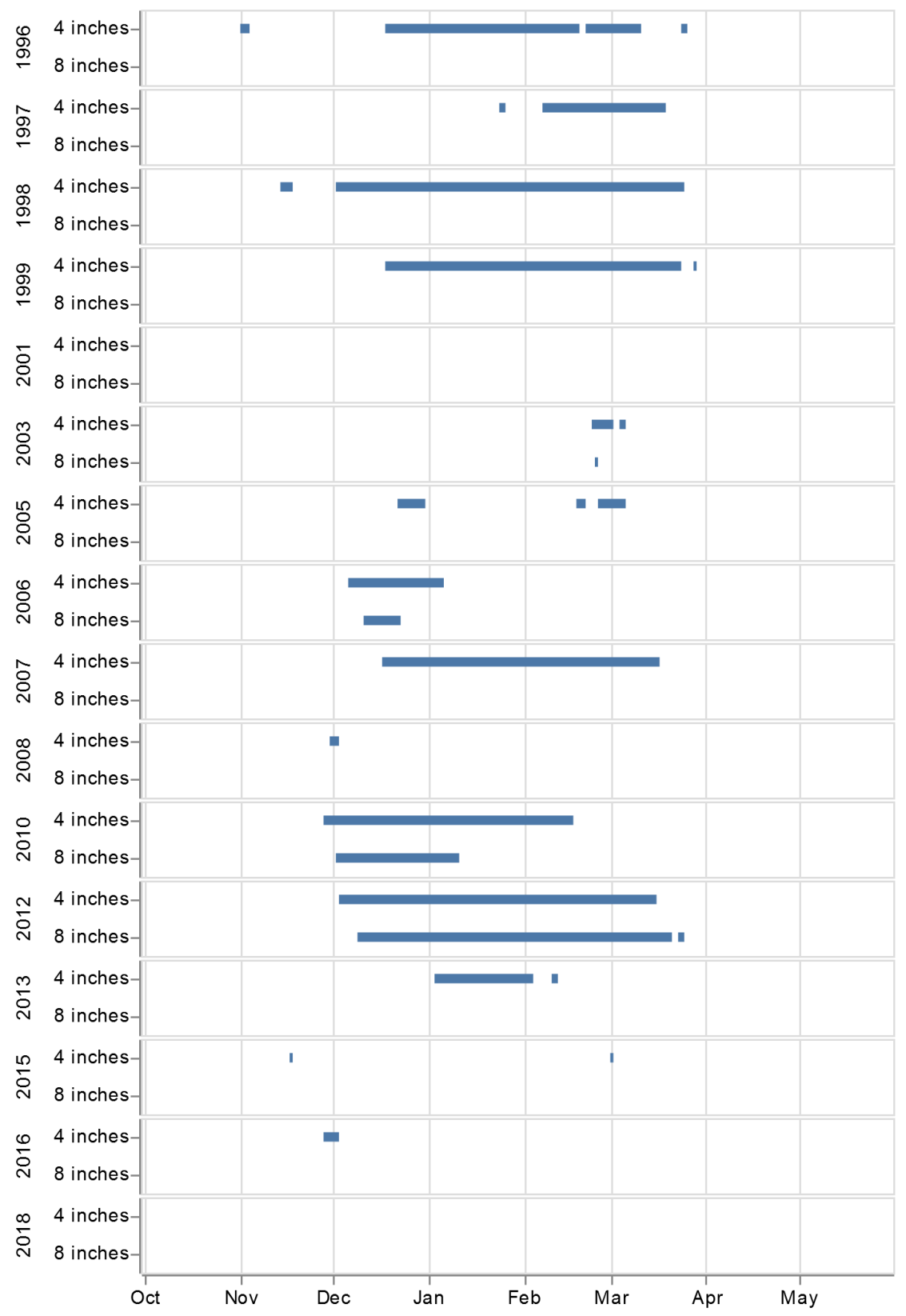

Figure 72. Ririe AgriMet station durations and timing of mean daily soil temperatures below $32^{\circ} \mathrm{F}$.

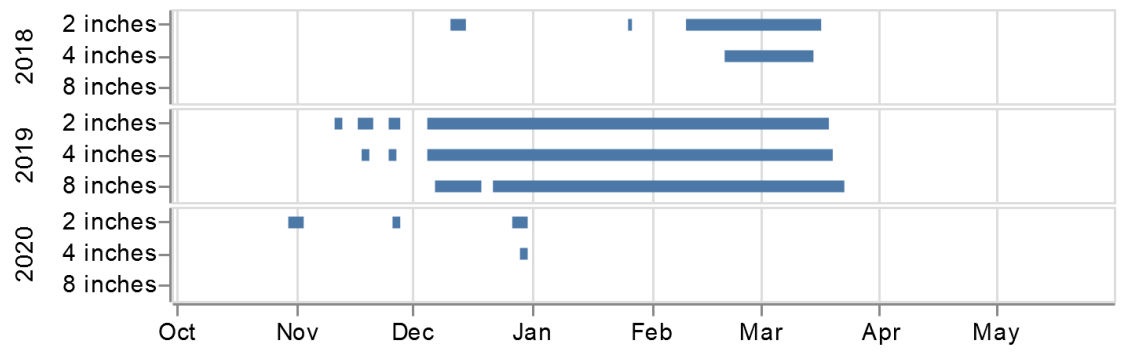




\subsubsection{SNOTEL}

In 2006, soil temperature probes were installed at the Sheep Mountain SNOTEL site at depths of 2, 8, and 20 in. Observations of soil temperature at 2 in. indicate the soil temperature dropped below $32^{\circ} \mathrm{F}$ for an average of 50.4 days per winter. Typically, the top 2 in. layer freezes in early November and can persist through the winter (Figure 73). At all measured depths, the soil column experiences multiple freezing-thawing cycles that indicate frozen ground conditions do not persist for extended periods. The lack of developing a $32^{\circ} \mathrm{F}$ isotherm below a 2 in. depth is because snow insulates the ground from heat exchanges with the atmosphere due to the relatively deep and persistent snowpack as shown in section 4.1.

Figure 73. Sheep Mountain SNOTEL durations and timing of mean daily soil temperatures below $32^{\circ} \mathrm{F}$.

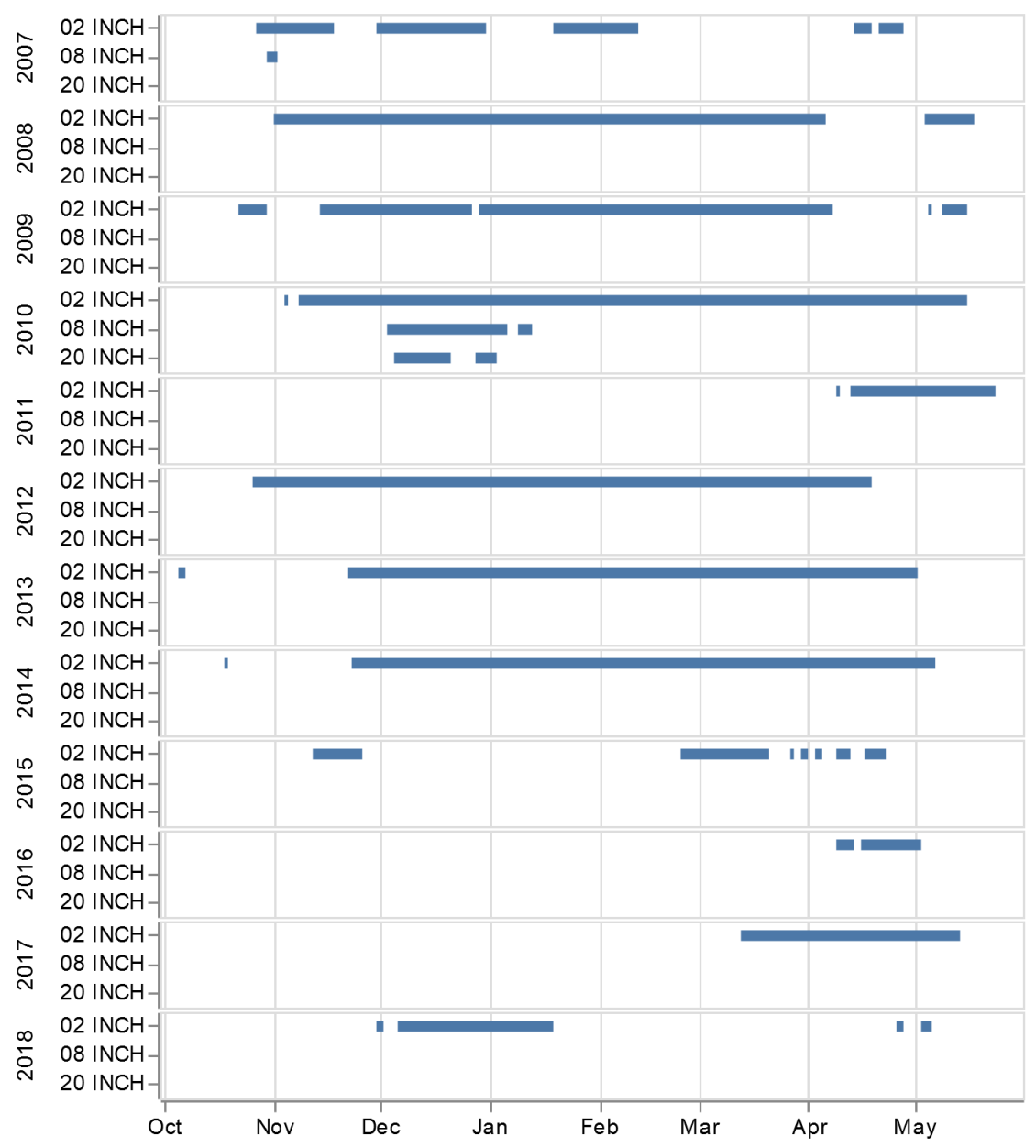




\subsubsection{USCRN}

NOAA established USCRN weather stations to monitor atmospheric and soil conditions in remote areas (Bell et al. 2013; Diamond et al. 2013). The USRCN sites collect high-quality measurements from multiple temperature probes at three locations surrounding the instrumentation tower. Soil temperature probes are installed in vertical profile depths ranging from 1.97 to 19.69 in., with the maximum probe depth determined by the soil conditions at individual sites. There are two USCRN sites in Idaho (Table 23), but they are not close to Willow Creek Watershed (Figure 70). Because of the geographical and climatological differences across southern Idaho, the soil temperature observations at the USCRN sites are not representative of Willow Creek Watershed.

Table 23. USCRN station soil temperature depths.

\begin{tabular}{|c|c|c|c|c|c|c|c|}
\hline \multirow[b]{2}{*}{ Station } & \multirow[b]{2}{*}{ Lat } & \multirow[b]{2}{*}{ Long } & \multicolumn{4}{|c|}{ Soil Temperature Probe Depth (in.) } & \multirow[b]{2}{*}{ Start Year } \\
\hline & & & 1.97 & 3.94 & 7.87 & 19.69 & \\
\hline Arco & 43.46 & -113.56 & $x$ & $x$ & & & 2012 \\
\hline Murphy & 43.2 & -116.75 & $x$ & $x$ & $x$ & $x$ & 2012 \\
\hline
\end{tabular}

\subsubsection{Reanalysis and remote-sensing data}

\subsubsection{Modern-Era Retrospective Analysis for Research and Applications,} Version 2 (MERRA-2)

The MERRA-2 dataset (Gelaro et al. 2017) is a reanalysis product derived from the NASA Goddard Earth Observing System Model, Version 5 (GEOS-5) data assimilation system. MERRA-2 uses a forecast model to combine disparate observations into a gridded product. The soil temperature in MERRA-2 has six layers with thicknesses of 0.10, 0.20, 0.39, 0.76, 1.51 , and $10.00 \mathrm{~m}$ and is provided on a grid with a resolution of $0.625^{\circ} \times 0.5^{\circ}$.

The Ririe and Ririe Upstream Subbasins are largely contained in one pixel of the MERRA-2 dataset (Figure 74). Data from pixel "2" was used to create a time series of ground temperatures (Figure 75). This analysis used the top layer, TSOIL1, representing the upper $10 \mathrm{~cm}$ ( 4 in.) of the soil column (Figure 75). Table 24 summarizes the basic statistics for the TSOIL1 layer between November and March. 
Figure 74. MERRA-2 pixels for the Willow Creek Basin.

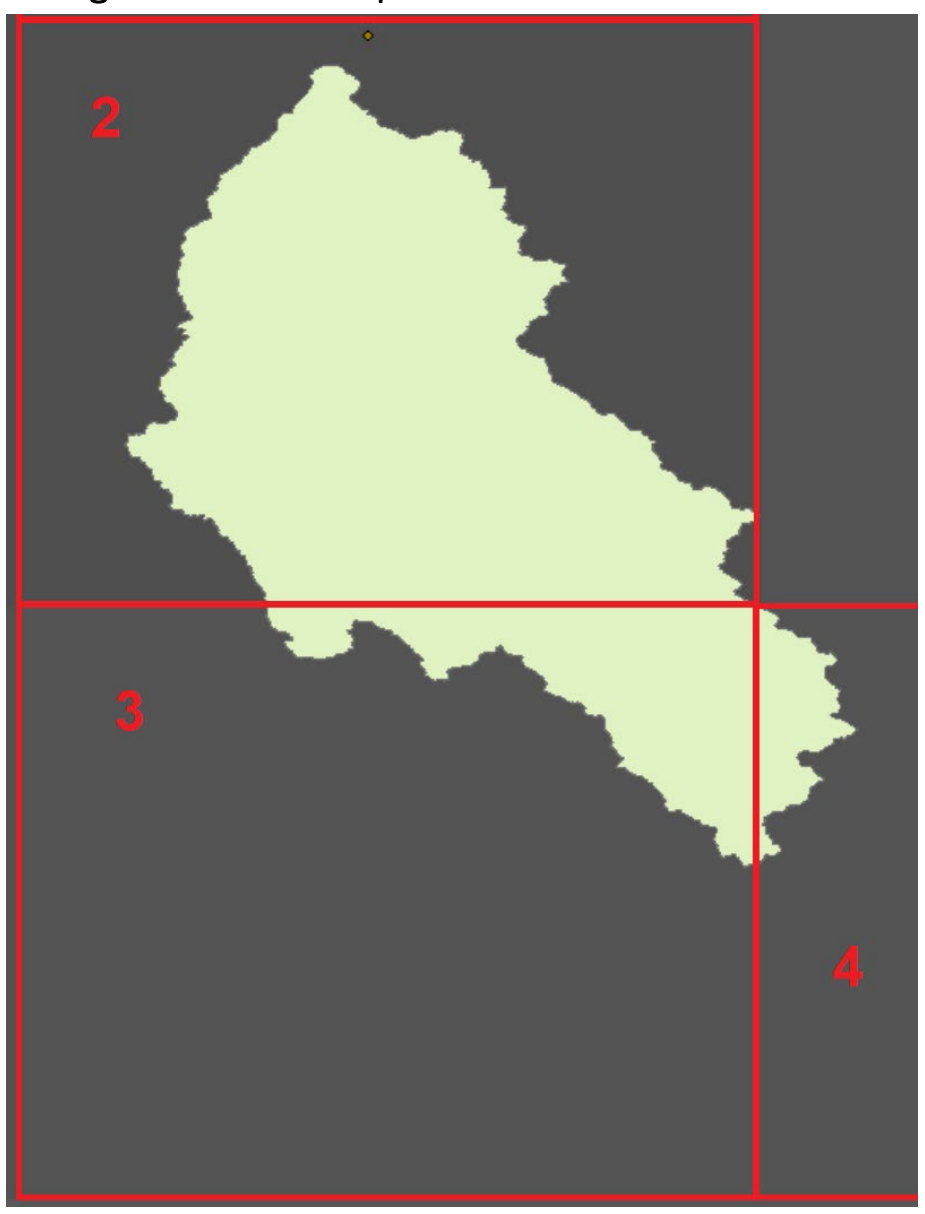

Table 24. Summary statistics of MERRA-2 winter ground temperatures (10 $\mathrm{cm}$ surface layer).

\begin{tabular}{|l|r|r|r|r|r|}
\hline Summary Statistic & Nov & Dec & Jan & Feb & Mar \\
\hline Mean & 0.4 & -2.4 & -2.1 & -2.1 & 0.7 \\
\hline Median & 0.1 & -1.7 & -1.8 & -1.8 & 0.5 \\
\hline Standard Deviation & 2.6 & 2.5 & 1.6 & 1.8 & 2.4 \\
\hline Min & -9.5 & -16.6 & -10.7 & -10.0 & -6.5 \\
\hline Max & 9.9 & 4.1 & 0.3 & 2.4 & 8.9 \\
\hline
\end{tabular}


Figure 75. MERRA-2 soil temperature: TSOIL1 layer representing the top $10 \mathrm{~cm}$ of the soil column averaged over the Willow Creek Watershed.

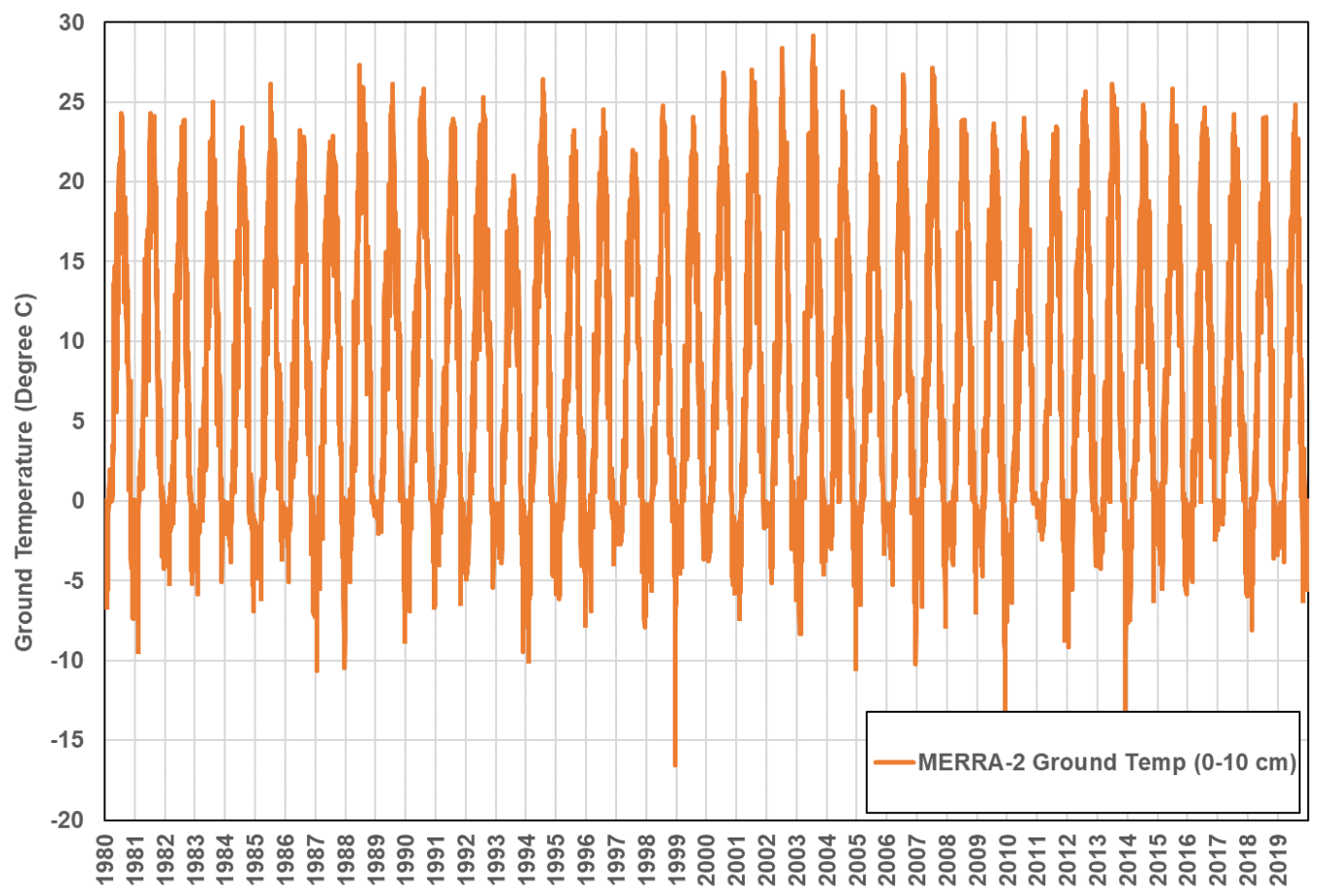

\subsubsection{Soil Moisture Active Passive (SMAP) Mission}

SMAP is a NASA satellite mission that currently utilizes a passive L-band radiometer to measure soil moisture. The specific dataset used in our study is the SMAP Level 3 Radiometer Global Daily 9 km EASE-Grid (Equal-Area Scalable Earth Grids) enhanced passive soil moisture product L3_SM_P_E (O'Neill et al. 2019). As described by the product specification document (Chan and Dunbar 2020),

The SMAP products represent four levels of data processing. Level 1 products contain instrument related data. Level 1 products appear in granules that are based on half orbits of the SMAP satellite. The northernmost and southernmost orbit locations demarcate half orbit boundaries. Level 2 products contain output from geophysical retrievals that are based on instrument data. Level 2 products also appear in half orbit granules. Level 3 products contain global output of the Level 2 geophysical retrievals for an entire day (24-hour period). Level 4 products contain output from geophysical models that employ SMAP data.... 
The enhanced SMAP L3_SM_P_E product is a daily global composite of the enhanced SMAP L2_SM_P_E product, which contains gridded data of 6:00 am (descending) and 6:00 pm (ascending) SMAP radiometerbased soil moisture retrieval, ancillary data, and qualityassessment flags on the global 9-km Equal-Area Scalable Earth (EASE) Grid 2.o designed by the National Snow and Ice Data Center (NSIDC). To generate the enhanced SMAP L3_SM_P_E product the processing software ingests one day's worth of L2_SM_P_E granules and creates individual global composites as two-dimensional arrays for each output parameter defined in the L2_SM_P_E product. Descending (6:00 am) and ascending (6:00 pm) data are stored in separate arrays. Wherever data overlap occurs (typically at high latitudes due to overlapping orbits), the data point whose acquisition time is closest to the 6:00 am local solar time (for descending passes) or 6:00 pm local solar time (for ascending passes) is chosen.

Figure 76 shows the time series of SMAP data used in our study.

Figure 76. Time series of SMAP Level 3 Radiometer Global Daily $9 \mathrm{~km}$ EASE-Grid enhanced passive soil moisture product (L3_SM_P_E).

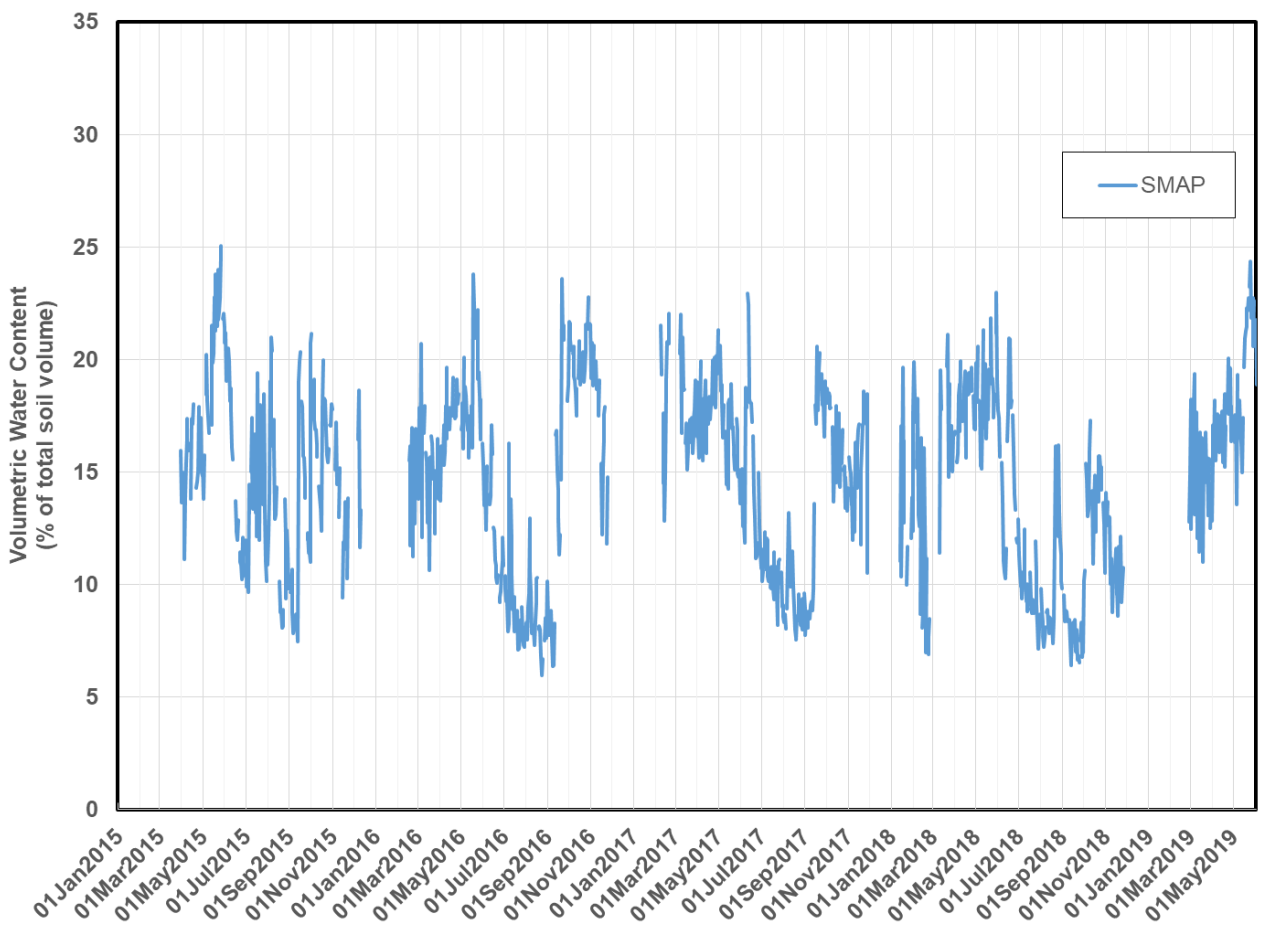




\subsection{Frozen-Soil-Infiltration Model}

Frozen ground conditions are known to enhance runoff from snowmelt and direct precipitation. Our study developed the FSIM to determine the infiltration capacity of the soil when the ground is frozen. The model has a modular framework and includes two integrated submodels (Figure 77):

- Ground Temperature Model (FSIM-GTM)-Physically based heat-flow model with empirical treatment of snow-cover effects for determining periods of frozen ground

- Soil Moisture Model (FSIM-SMM)-An antecedent precipitation index (API) model for estimating soil moisture

FSIM used weather observations (Wx Obs) as input. These inputs include air temperature, snow depth, and precipitation data from the Idaho Falls 16 SE COOP station. We selected this station because it is in the basin and includes observations during the February 1962 flood event of record.

The FSIM components were calibrated using available data:

- FSIM-GTM was calibrated to NASA MERRA-2 reanalysis soil temperature data.

- FSIM-SMM was calibrated to NASA SMAP satellite-based soil moisture measurements.

- FSIM was calibrated to the February 1962 runoff event by using HEC-HMS.

FSIM was ultimately used to calculate a time series of infiltration capacity reduction factors (ICRF) and daily infiltration rates. We used this time series to create probability distributions of ICRF for each month of the winter, which can be used to directly sample for use in HEC-HMS simulations in a Monte Carlo framework. 
Figure 77. Schematic of the CRREL FSIM model framework.

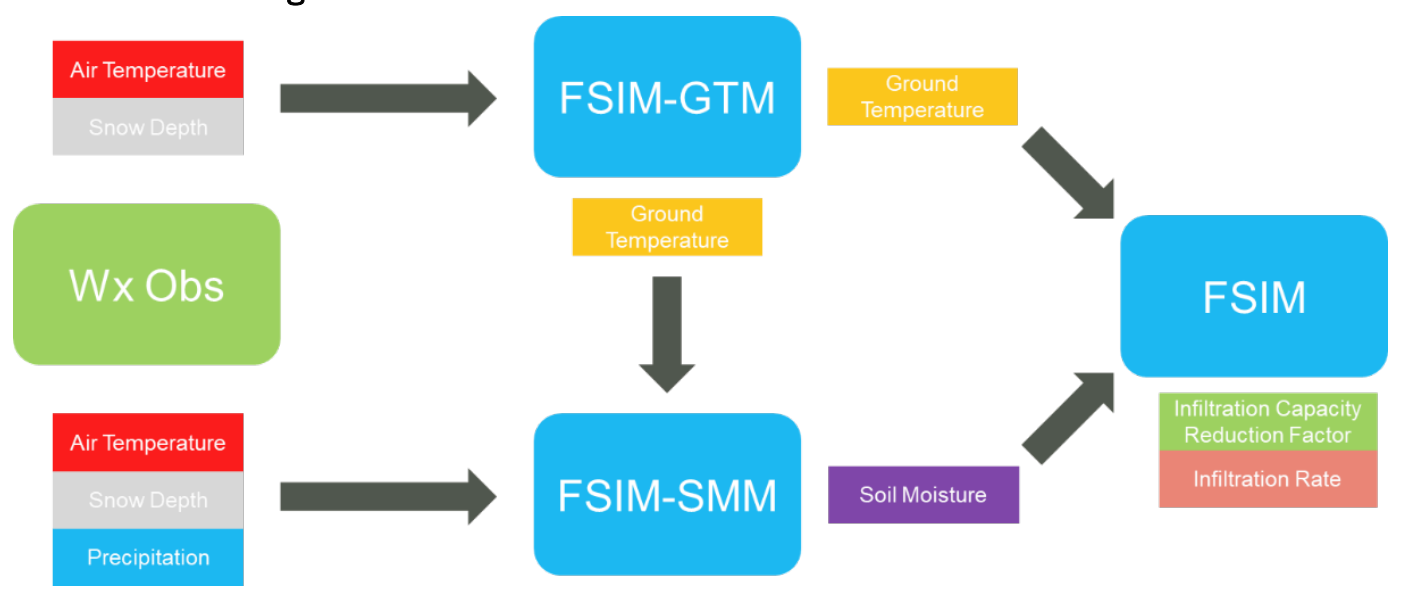

\subsubsection{Description of watershed soil properties}

\subsubsection{Overview}

Infiltration rates of precipitation and meltwater into soil are tied to the soil's physical structure. Soils with coarse grain sizes, such as sands and gravels, or soils with cracks, fissures, or preferential flow paths more freely accept infiltrating water than finer-grained soils, such as silts or clays. Soil texture properties can be used to estimate infiltration rates for unfrozen soils.

Infiltration into frozen soils is sensitive to the amount of water in the soil matrix when the ground freezes. Water in pore spaces freezes and obstructs the movement of water. Soil moisture is commonly measured in terms of volumetric water content (VWC), which is a ratio of the volume of water to the total volume of soil, where the volume of soil includes the sum of volume of water, air-filled pore spaces, and soil solids. Identical VWCs can mean starkly different things in different soil types upon freezing. A porous sand with well-connected flow paths will see less influence on infiltration upon freezing than a silt with poorly connected pores, even if they have the same initial VWC. The silt has fewer effective flow paths through the soil matrix, and ice formation in those scarce routes will retard infiltration more than in the sand, even if the same volume of ice forms in both soils.

We characterized the soil texture in the watershed using U.S. Department of Agriculture (USDA) NRCS soil texture ratings and hydrologic soils group ratings. This is used to estimate the unfrozen infiltration rate of the soil in the watershed. Next, we characterize the physical meaning of VWC for soils in the basin by estimating the permanent wilting point (PWP), field capacity (FC), and satiated water contents. These are values used for 
agricultural purposes but are useful for describing the physical range of water contents in a soil. Water is tightly held by the soil matrix at the PWP (able to withstand -15 bars of matric suction), FC represents the VWC when free draining has ceased, and satiated conditions approximate saturated condition when the VWC is maximized (NRCS, n.d.).

\subsubsection{Methods}

We obtained soil property data from the USDA-NRCS Soil Survey Geographic Database (SSURGO) (NRCS, n.d.) and processed them using ArcMap. We used USDA soil texture and hydrologic soils group ratings to characterize the typical infiltration environment in the basin. We also used basin-averaged water content ratings at a range of suction pressure ratings to estimate the permanent wilting point, field capacity, and satiated water content, which are used directly in the FSIM.

\subsubsection{Soil texture}

The spatial distribution of the USDA soil texture rating is shown in Figure 78 and summarized in Table 25. The dominant soil surface texture in the Willow Creek Basin is silt loam, with some smaller areas of silty clay loam and slightly decomposed plant material.

Table 25. USDA surface soil texture rating of Willow Creek Watershed.

\begin{tabular}{|l|c|}
\hline \multicolumn{1}{|c|}{ NRCS Surface Texture } & Percentage of Watershed Area \\
\hline Silt loam & $55 \%$ \\
\hline Silty clay loam & $10 \%$ \\
\hline Slightly decomposed plant material & $9 \%$ \\
\hline Very cobbly loam & $6 \%$ \\
\hline Loam & $4 \%$ \\
\hline Stratified silt loam to stony clay & $4 \%$ \\
\hline Very stony loam & $2 \%$ \\
\hline Gravelly loam & $1 \%$ \\
\hline Stony loam & $1 \%$ \\
\hline Moderately decomposed plant material & $1 \%$ \\
\hline Bedrock & $1 \%$ \\
\hline Sandy loam & $<1 \%$ \\
\hline Ashy silt loam & $<1 \%$ \\
\hline Clay loam & $<1 \%$ \\
\hline Gravel, cobbles & $<1 \%$ \\
\hline Very gravelly loam & $<1 \%$ \\
\hline Unclassified & $5 \%$ \\
\hline
\end{tabular}


Figure 78. USDA soil texture ratings for Willow Creek Watershed.

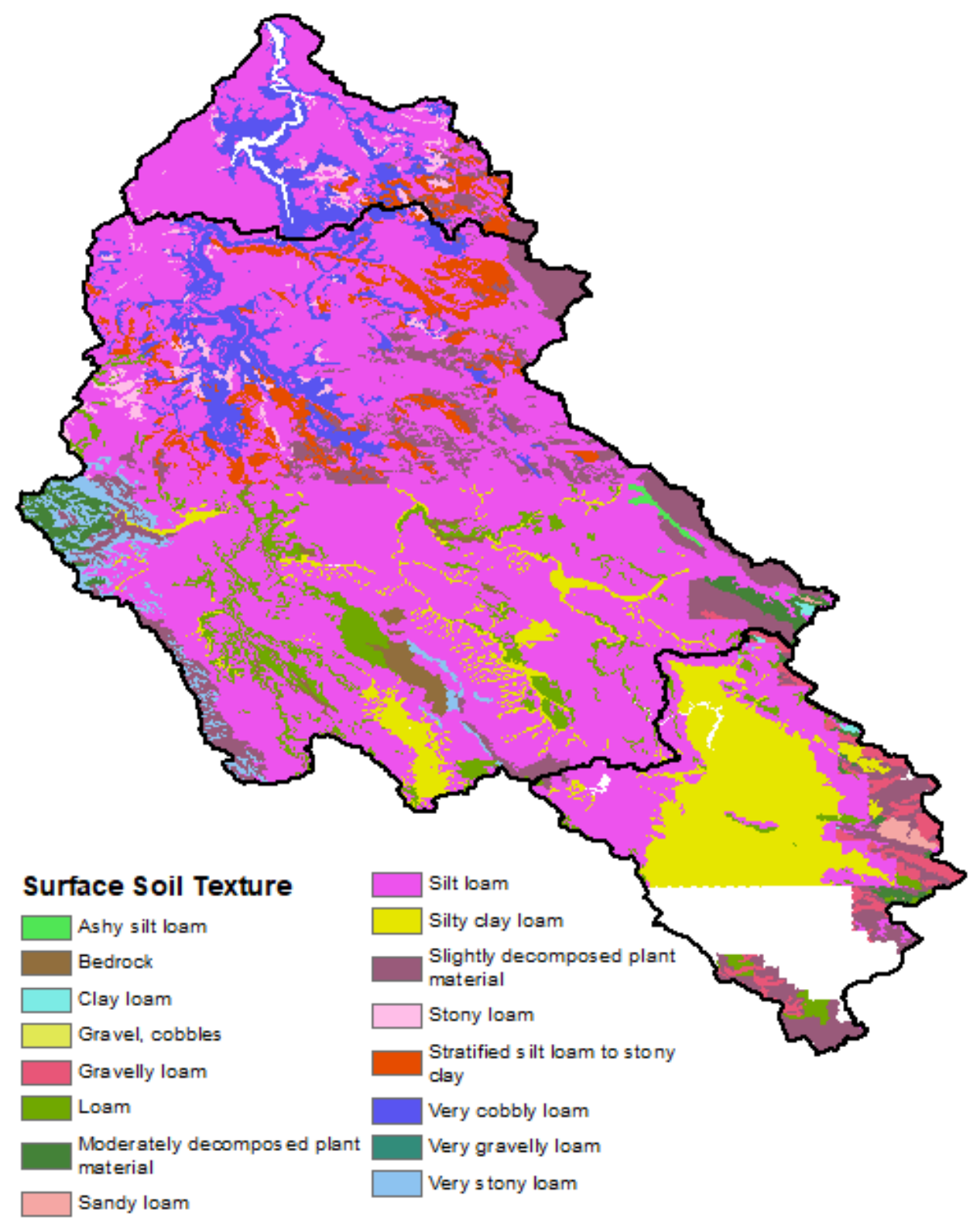

\subsubsection{Hydrologic Soils Group classification of soils}

Within the SSURGO database, mapped soils are assigned a Hydrologic Soils Group (HSG) rating, which categorizes soils with similar runoff characteristics. The soils groups as defined by NRCS (2020) are as follows:

Group A. Soils having a high infiltration rate (low runoff potential) when thoroughly wet. These consist mainly of deep, well drained to excessively drained 
sands or gravelly sands. These soils have a high rate of water transmission.

Group B. Soils having a moderate infiltration rate when thoroughly wet. These consist chiefly of moderately deep or deep, moderately well drained or well drained soils that have moderately fine texture to moderately coarse texture. These soils have a moderate rate of water transmission.

Group C. Soils having a slow infiltration rate when thoroughly wet. These consist chiefly of soils having a layer that impedes the downward movement of water or soils of moderately fine texture or fine texture. These soils have a slow rate of water transmission.

Group D. Soils having a very slow infiltration rate (high runoff potential) when thoroughly wet. These consist chiefly of clays that have a high shrink-swell potential, soils that have a high water table, soils that have a claypan or clay layer at or near the surface, and soils that are shallow over nearly impervious material. These soils have a very slow rate of water transmission.

If a soil is assigned to a dual hydrologic group (A/D, $\mathrm{B} / \mathrm{D}$, or $\mathrm{C} / \mathrm{D}$ ), the first letter is for drained areas and the second is for undrained areas. Only the soils that in their natural condition are in group D are assigned to dual classes.

Spatial distribution of HSGs for the watershed are shown in Figure 79 and are summarized in Table 26. The watershed is dominated by $\mathrm{C}$ and $\mathrm{B}$ soils with a smaller fraction of $\mathrm{D}$ soils and a very small area with an A rating. Based on this information, the watershed is expected to have a slow to moderate rate of infiltration under unfrozen conditions. Figure 80 shows suggested hourly infiltration rates based on soil texture and USDA-NRCS hydrologic soils groups from the HEC-HMS technical reference manual (Feldman 2000). Based on this information, hourly unfrozen infiltration 
rates in the basin are expected to fall between 0.05 and 0.15 in./hour. Calculation of infiltration rates for the watershed is achieved through direct calibration from observed events as discussed in section 5.3.

Figure 79. USDA-NRCS hydrologic soil group ratings for Willow Creek Watershed.

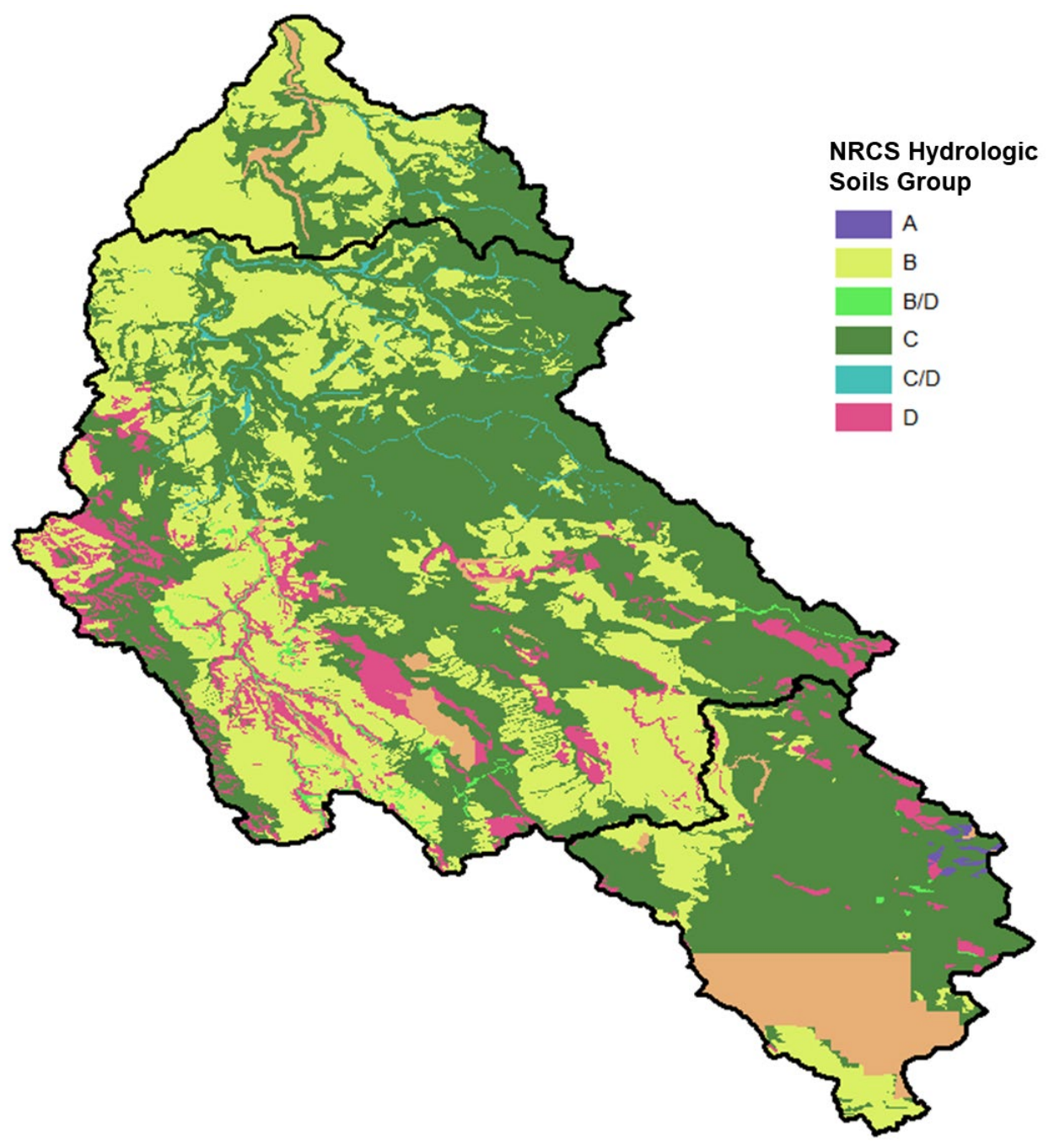

Table 26. USDA-NRCS hydrologic soils group ratings for the Willow Creek Basin.

\begin{tabular}{|l|c|}
\hline $\begin{array}{c}\text { NRCS Hydrologic } \\
\text { Soils Group }\end{array}$ & $\begin{array}{c}\text { Percentage of } \\
\text { Watershed Area }\end{array}$ \\
\hline C & $52 \%$ \\
\hline B & $34 \%$ \\
\hline D & $7 \%$ \\
\hline C/D & $1 \%$ \\
\hline B/D & $1 \%$ \\
\hline A & $<1 \%$ \\
\hline Unclassified & $6 \%$ \\
\hline
\end{tabular}


Figure 80. Infiltration rates based on soil texture and hydrologic soil group (reprinted from Feldman 2000).

\begin{tabular}{|c|l|c|}
\hline Soil Group & \multicolumn{1}{|c|}{ Description } & $\begin{array}{c}\text { Range of Loss Rates } \\
\text { (in./hr) }\end{array}$ \\
\hline A & Deep sand, deep loess, aggregated silts & $0.30-0.45$ \\
\hline B & Shallow loess, sandy loam & $0.15-0.30$ \\
\hline C & $\begin{array}{l}\text { Clay loams, shallow sandy loam, soils low in organic } \\
\text { content, and soils usually high in clay }\end{array}$ & $0.05-0.15$ \\
\hline D & $\begin{array}{l}\text { Soils that swell significantly when wet, heavy plastic } \\
\text { clays, and certain saline soils }\end{array}$ & $0.00-0.05$ \\
\hline
\end{tabular}

\subsubsection{Permanent wilting point, field capacity, and satiated water contents}

The NRCS SSURGO database includes water content ratings for mapped soils. The relevant values used in our study are water content under 15, $1 / 3$, and o bar suction pressure. These values represent the permanent wilting point, field capacity, and satiated water content conditions and are expressed as percentages of a total soil volume. The values were retrieved from the database for the top $25 \mathrm{~cm}$ of the soil column. The spatial distribution of the field capacity and permanent wilting point are shown in Figure 81 and summarized in Table 27.

Figure 81. Field capacity and permanent wilting point in Willow Creek Watershed.
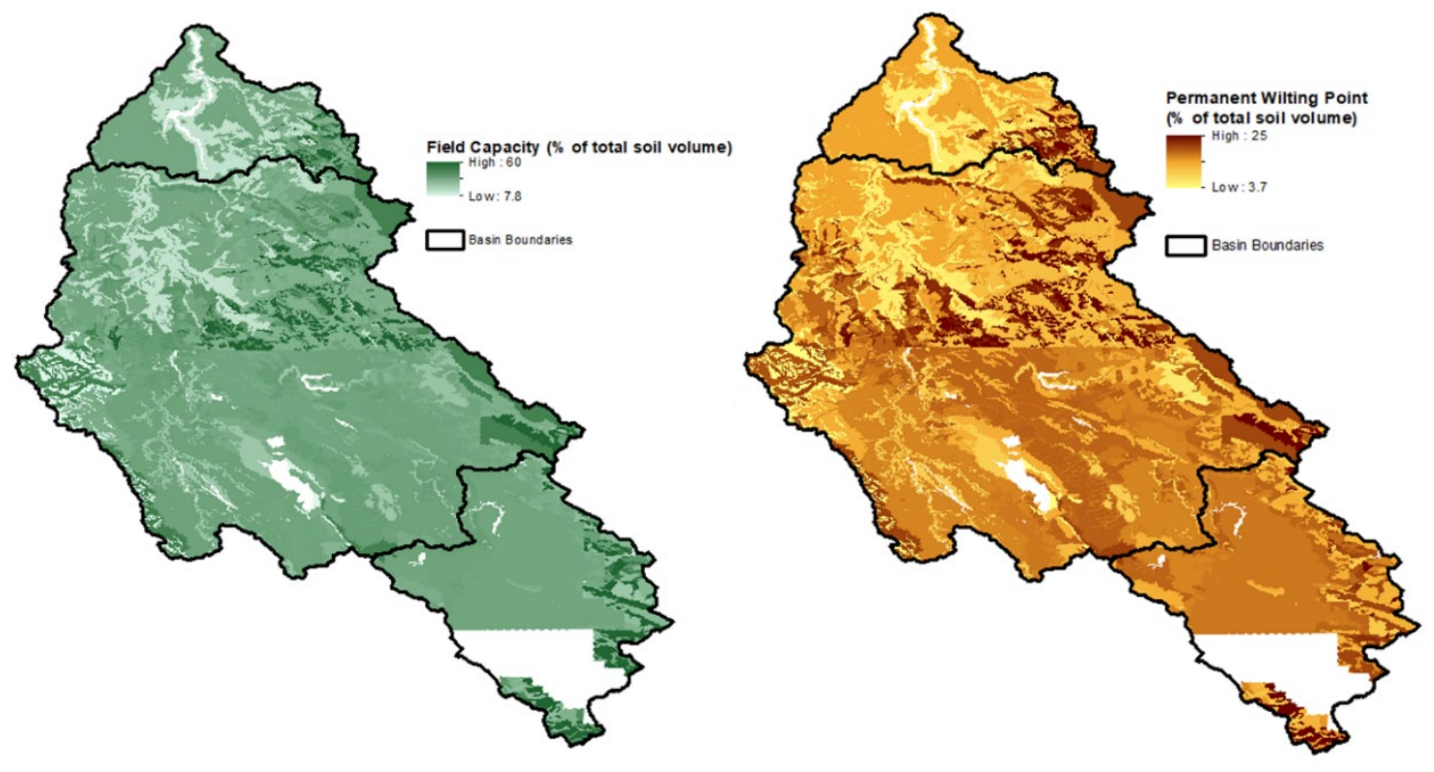
Table 27. Water content parameters for Willow Creek Watershed.

\begin{tabular}{|l|c|c|c|}
\hline SSURGO Field & Description & Interpretation & $\begin{array}{c}\text { Volumetric Water } \\
\text { Content (\%) }\end{array}$ \\
\hline wfifteenbar_r & Water Content, 15 bar & Permanent Wilting Point & 14.8 \\
\hline wthirdbar_I & Water Content, 1/3 bar & Field Capacity & 27.4 \\
\hline wsatiated_r & Water Content, 0 bar & Satiated & 37.6 \\
\hline
\end{tabular}

\subsubsection{Estimating Ground Temperature / Ground Freezing}

Ground temperature conditions are an important input to the FSIM. While there is one measured ground temperature record within the basin (Sheep Mountain SNOTEL) and one near the basin (Ririe AgriMet), these stations do not provide insight about soil temperatures beyond their short periods of record (less than 15 years in the case of SNOTEL and 3 years in the case of the AgriMet station). In addition, the SNOTEL station is located in a forested area, which would likely introduce bias if used to describe the soil temperature of the basin on average, which is predominantly open, unforested land. Since the FSIM is intended to be used to develop probability distributions of infiltration conditions applicable to the entire watershed, it was necessary to develop a method to estimate ground temperatures that are representative of the entire watershed and not based solely on a specific point of observation that may not represent spatial differences in the watershed.

To address the lack of directly measured ground temperatures representative of the watershed average, we developed a simple ground temperature model (FSIM-GTM). The modeling approach follows Rankinen et al. (2004) with some modifications to improve performance at the study location. The time-dependent inputs to the model include air temperature and snow depth. These values are readily available for a long period of record at the study site (Idaho Falls $16 \mathrm{SE}$ records start before 1960), which allows application of the model as far back as input data are available. This approach also enables water managers to use the model in near real time to estimate soil temperatures based only on air temperature and snow depth measurements from the COOP station. The model may also be useful in a forecast mode if the input parameters can be adequately predicted; however, investigation of this use is outside the scope of this study. 


\subsubsection{Soil temperature model formulation}

The FSIM-GTM is based on simplified versions of the coupled heat and water flow equations. To simplify the solution to these equations, or analysis assumed that the total soil water content does not change with time. This assumption implies that variations in water content at the study site will not have major impacts on heat transfer in the soil. After applying these assumptions and some algebraic rearrangement, the coupled equations reduce to

$$
C_{A} \frac{\partial T}{\partial t}=\frac{\partial}{\partial z}\left[K_{T} \frac{\partial T}{\partial z}\right]
$$

where

$$
\begin{aligned}
C_{A} & =\text { the apparent heat capacity, } \\
Z & =\text { a space coordinate }(\mathrm{m}), \\
t & =\text { time (days), } \\
T & =\text { temperature }\left({ }^{\circ} \mathrm{C}\right), \text { and } \\
K_{T} & =\text { soil thermal conductivity }\left(\mathrm{Wm}^{-}{ }^{\circ} \mathrm{C}^{-1}\right) .
\end{aligned}
$$

$C_{A}$ is approximated as the sum of specific heat of the soil and a parameter $C_{I C E}$, which accounts for the energy released or consumed when water in the soil freezes or thaws $\left(\mathrm{J} \mathrm{m}^{-3}{ }^{\circ} \mathrm{C}^{-1}\right)$ :

$$
C_{A}=\left(C_{S}+C_{I C E}\right)
$$

Equation (7) is solved with an explicit finite difference approximation. We assumed that the air temperature is equal to the surface temperature and that there is no heat flux at the bottom of the soil layer under consideration. The practical form of the equation is as follows:

$$
T_{*}^{t+1}=T_{Z}^{t}+\frac{\Delta t K_{T}}{C_{A}\left(2 Z_{S}\right)^{2}}\left[T_{A I R}^{t}-T_{Z}^{t}\right]
$$

where

$T_{*}^{t+1}=$ the unknown temperature at depth $Z_{s}$ at time $t+1$,

$T_{z}^{t}=$ the computed soil temperature from the previous time step,

$T_{A I R}^{t}=$ the air temperature at the current time step,

$\Delta t=$ the time-step length, and

$K_{T}=$ the soil thermal conductivity. 
We determined during initial testing of the model that the model was extremely sensitive to rapid changes in air temperature when using daily data. To address this issue, an additional term was added to Equation (9) to represent the limited heat transfer that can physically be transferred from the air to the soil. The revised form of the ground temperature equation is as follows:

$$
T_{*}^{t+1}=T_{Z}^{t}+\frac{\Delta t}{2 Z_{s} C_{A}} \frac{\left[T_{A I R}^{t}-T_{Z}^{t}\right]}{\left(\frac{2 Z_{S}}{K_{T}}+\frac{1}{H_{A}}\right)},
$$

where $H_{A}$ is a heat transfer coefficient between the air and the soil $\left(\mathrm{Wm}^{-2}\right.$ ${ }^{\circ} \mathrm{C}^{-1}$ ).

The equations thus far have ignored the effects of snow cover. To address the effects of snow cover on heat transfer, an empirical function is applied to the calculated soil temperature at each time step, following Rankinen et al. (2004). The function limits the heat transfer between the air and soil when snow is present and effectively decays the frozen soil temperature towards the thawing point:

$$
T_{Z}^{t+1}=T_{*}^{t+1} e^{-f_{s} D_{s},}
$$

where

$$
\begin{aligned}
T_{Z}^{t+1}= & \text { the soil temperature adjusted for the presence of snow at time } \\
& t+1, \\
f_{s}= & \text { an empirical parameter }\left(\mathrm{m}^{-1}\right), \text { and } \\
D_{s}= & \text { the snow depth }(\mathrm{m}) .
\end{aligned}
$$

\subsubsection{Ground Temperature Model calibration}

The FSIM-GTM was run using average daily air temperature and snow depth from the Idaho Falls 16 SE COOP site.

Soil temperatures from MERRA-2 were compared to average daily temperatures measured at a depth of 2 in. at the Ririe AgriMet station (which began recording ground temperatures in November 2017) and the Sheep Mountain SNOTEL site (Table 28). The MERRA-2 soil temperatures, which represent average conditions in the basin, are colder than observations at the two point locations. While the observational time series were 
considered for use in calibration, the Ririe AgriMet station is not in the basin and has a very short period of record. The SNOTEL site is in the basin, but the temperature time series exhibits very little variation in the winter, suggesting it is strongly influenced by the snow depth at that station, which is likely not representative of the basin. While not directly measured, the MERRA-2 reanalysis data, which is a combination of modeled and assimilated observational data, has been shown to reasonably estimate winter soil temperatures when compared to ground observations (Yang and Zang 2018). Absent the availability of directly measured ground temperatures representative of the basin, we calibrated FSIM-GTM to the MERRA-2 reanalysis soil temperature data field TSOIL1, which represents the average temperature of the surface soil layer with a thickness of approximately $10 \mathrm{~cm}$ (4 in.).

Table 28. Ririe AgriMet 2 in. ground temperatures compared with MERRA-2 TSOIL1 soil temperatures between November 2017 and December 2019.

\begin{tabular}{|l|l|r|r|r|r|r|}
\hline \multirow{4}{*}{ Mean } & & Nov & Dec & Jan & Feb & Mar \\
\hline \multirow{4}{*}{ Median } & Ririe AgriMet & 1.6 & -0.1 & -0.5 & -0.1 & 1.1 \\
\cline { 2 - 7 } & Sheep Mtn & -0.1 & -0.1 & 0.0 & 0.1 & 0.1 \\
\cline { 2 - 7 } & MERRA & -1.5 & -1.7 & -2.2 & -0.7 & 4.9 \\
\hline \multirow{3}{*}{ Deviatandard } & Ririe AgriMet & 1.0 & 0.2 & 0.0 & -0.1 & -0.1 \\
\cline { 2 - 7 } & Sheep Mtn & -0.2 & -0.2 & 0.0 & 0.1 & 0.1 \\
\cline { 2 - 7 } & MERRA & -1.3 & -1.6 & -1.6 & -0.5 & 4.1 \\
\hline \multirow{4}{*}{ Min } & Ririe AgriMet & 2.0 & 0.9 & 1.0 & 0.5 & 2.0 \\
\cline { 2 - 7 } & Sheep Mtn & 0.7 & 0.2 & 0.1 & 0.1 & 0.0 \\
\cline { 2 - 7 } & MERRA & 1.0 & 0.9 & 2.0 & 2.0 & 2.9 \\
\hline \multirow{3}{*}{ Max } & Ririe AgriMet & -1.3 & -2.6 & -3.5 & -0.7 & -1.7 \\
\cline { 2 - 7 } & Sheep Mtn & -1.8 & -0.4 & -0.2 & 0.0 & 0.0 \\
\cline { 2 - 7 } & MERRA & -5.5 & -4.7 & -8.1 & -4.3 & 0.2 \\
\hline & Ririe AgriMet & 7.7 & 1.6 & 0.3 & 1.8 & 6.3 \\
\cline { 2 - 7 } & Sheep Mtn & 2.6 & 0.4 & 0.3 & 0.2 & 0.1 \\
\cline { 2 - 7 } & MERRA & 0.0 & -0.3 & 0.1 & 3.1 & 11.6 \\
\hline
\end{tabular}

The FSIM-GTM was computed at a depth $Z_{s}$ of $5.1 \mathrm{~cm}$ ( $2 \mathrm{in}$.) for comparison with the reanalysis data. The model was calibrated to minimize the sum of squares error (SSE) in January, February, and March between 1980 and 2018. Table 29 presents calibrated model parameters. 
Table 29. Calibrated parameters for the FSIM-GTM.

\begin{tabular}{|c|c|c|}
\hline Parameters & Units & Parameter Value \\
\hline$C_{s}$ & $\mathrm{~J} \mathrm{~m}^{-3}{ }^{\circ} \mathrm{C}^{-1}$ & $1.3 \times 10^{6}$ \\
\hline$K_{T}$ & $\mathrm{Wm}^{-3}{ }^{\circ} \mathrm{C}^{-1}$ & 0.5 \\
\hline$C_{\text {ICE }}$ & $\mathrm{J} \mathrm{m}^{-3}{ }^{\circ} \mathrm{C}^{-1}$ & $1.6 \times 10^{6}$ \\
\hline$H_{A}$ & $\mathrm{Wm}^{-2}{ }^{\circ} \mathrm{C}^{-1}$ & 0.55 \\
\hline$f_{s}$ & $\mathrm{~m}^{-1}$ & -1.3 \\
\hline
\end{tabular}

The modeled ground temperature was converted to a binary series where ground temperatures below $0^{\circ} \mathrm{C}$ were classified as "potentially frozen" and those equal to or greater than $0^{\circ} \mathrm{C}$ were classified as "unfrozen."

$$
\text { class }=\left\{\frac{0 \text { if Soil Temp } \geq 0^{\circ} \mathrm{C}}{1 \text { if Soil Temp }<0^{\circ} \mathrm{C}}\right.
$$

The MERRA-2 soil temperature time series was converted to a binary series in a similar manner. We evaluated the FSIM-GTM's ability to correctly classify potentially frozen conditions following a similar approach to Derksen (2017) and Kraatz et al. (2018):

$$
\begin{aligned}
\text { Frozen accuracy } & =N_{\mathrm{CRREL}=1, \mathrm{MERRA}=1} / N_{\text {MERRA }=1} \\
\text { Unfrozen accuracy } & =N_{\mathrm{CRREL}=0, \mathrm{MERRA}=\mathrm{o}} / N_{\text {MERRA }=0} \\
\text { Overall accuracy } & =\left(N_{\mathrm{CRREL}=1, \mathrm{MERRA}=1}+N_{\mathrm{CRREL}=0, \mathrm{MERRA}=0}\right) / N_{\text {TOTAL }}
\end{aligned}
$$

where $N$ is the count of each model results with the stated criteria and $N_{\text {TOTAL }}$ is the total number of events. Table 30 presents the model classification results.

In addition, $F_{1}$ scores were computed, which is a measure of the model's precision and recall. Precision is a measure of how much the model generates false positives (overestimates frozen ground condition relative to MERRA) while recall measures the tendency to generate false negatives (underestimates frozen ground condition relative to MERRA):

$$
\begin{aligned}
\text { Precision } & =N_{\text {CRREL }=1, \mathrm{MERRA}=1} /\left(N_{\mathrm{CRREL}=1, \mathrm{MERRA}=1}+N_{\mathrm{CRREL}=1, \mathrm{MERRA}=\mathrm{0}}\right) \\
\text { Recall } & =N_{\mathrm{CRREL}=1, \mathrm{MERRA}=1} /\left(N_{\mathrm{CRRL}=1, \mathrm{MERRA}=1}+N_{\mathrm{CRREL}=0, \mathrm{MERRA}=1}\right)
\end{aligned}
$$

$F_{1}$ is the harmonic mean of precision and recall:

$$
F_{1}=2 \times(\text { Precision } \times \text { Recall }) /(\text { Precision }+ \text { Recall })
$$


In general, these statistics suggest that the model is skilled at matching ground temperatures from the MERRA dataset that indicate frozen conditions, particularly in December and January, with a slight drop in performance in February. Scores in November and March are the lowest, primarily because these are periods of freeze up and thaw. The apparent heat capacity concept, which simplifies the complex latent and sensible heat exchange of soil moisture as it freezes and thaws, may introduce some timing error during these periods.

Table 30. Performance of potentially frozen ground classification based on FSIM-GTM soil temperatures compared with MERRA-2 soil temperatures between 1981 and 2018. A positive result indicates a potentially frozen condition. Model accuracy better than $80 \%$ is highlighted in green.

\begin{tabular}{|l|c|c|c|c|c|c|}
\hline & All Season & Nov & Dec & Jan & Feb & Mar \\
\hline Number of Comparisons & $\mathbf{1 4 6 0 2}$ & $\mathbf{1 1 4 0}$ & $\mathbf{1 1 7 7}$ & $\mathbf{1 2 1 2}$ & $\mathbf{1 1 0 2}$ & $\mathbf{1 2 0 9}$ \\
\hline MERRA Frozen & 4242 & 411 & 1078 & 1202 & 995 & 359 \\
\hline FSIM Frozen & 4777 & 586 & 1101 & 1179 & 963 & 625 \\
\hline True Positives (\%) & 27.4 & 33.4 & 89.4 & 96.9 & 82.3 & 27.1 \\
\hline True Negatives (\%) & 65.6 & 46.0 & 4.2 & 0.4 & 4.6 & 45.7 \\
\hline False Positives (\%) & 5.3 & 18.0 & 4.2 & 0.4 & 5.1 & 24.6 \\
\hline False Negatives (\%) & 1.6 & 2.6 & 2.2 & 2.3 & 8.0 & 2.6 \\
\hline Frozen Accuracy (\%) & 94.3 & 92.7 & 97.6 & 97.7 & 91.2 & 91.4 \\
\hline Unfrozen Accuracy (\%) & 92.5 & 71.9 & 50.5 & 50.0 & 47.7 & 65.1 \\
\hline Overall Accuracy (\%) & 93.0 & 79.4 & 93.6 & 97.3 & 86.9 & 72.9 \\
\hline F1 Score & 0.89 & 0.76 & 0.97 & 0.99 & 0.93 & 0.67 \\
\hline
\end{tabular}

\subsubsection{Ground Temperature Model results}

The FSIM-GTM includes several simplifying assumptions that aid in the numerical solution of the model and importantly its practical implementation in data-sparse locations. The model assumes that total soil moisture does not vary over the period of the simulation, that there is not a significant heat flux from the bottom of the soil layer, and that variations in snow-cover density do not significantly impact the heat transfer through the snowpack.

The model uses the common approach of assuming an apparent heat capacity, which accounts for the highly nonlinear energy balance that occurs during the exchange of sensible and latent heat at the phase transition point (Vogel et al. 2019). This implementation assumes that the apparent heat capacity is constant below $0^{\circ} \mathrm{C}$. Attempts to vary the apparent heat capacity as a function of ground temperature as in Hansson et al. (2004) 
did not improve model results. In fact, the calibrated apparent heat capacity during freezing conditions is less than an order of magnitude larger than during unfrozen conditions. This is likely because the soil moisture content is typically relatively low (i.e., less than field capacity).

Despite its simplicity, the model performs well relative to MERRA-2 in most cases. Figures 82 and 83 present an example of a well-correlated time series during a relatively cold winter.

The FSIM-GTM is driven by daily average air temperature and snow depth from a single NOAA COOP station located in the basin of interest. Despite a number of simplifying assumptions, the FSIM-GTM reasonably approximates daily time series of the MERRA-2 reanalysis surface layer $(10 \mathrm{~cm}$ total depth) soil temperature time series over the period between 1981 and 2018. The model also performs well at classifying days as "potentially frozen" or "unfrozen" relative to the MERRA-2 dataset.

Figure 82. Example of CRREL's FSIM-GTM compared to MERRA-2 $10 \mathrm{~cm}$ layer soil temperature during a cold winter with moderate snow cover.

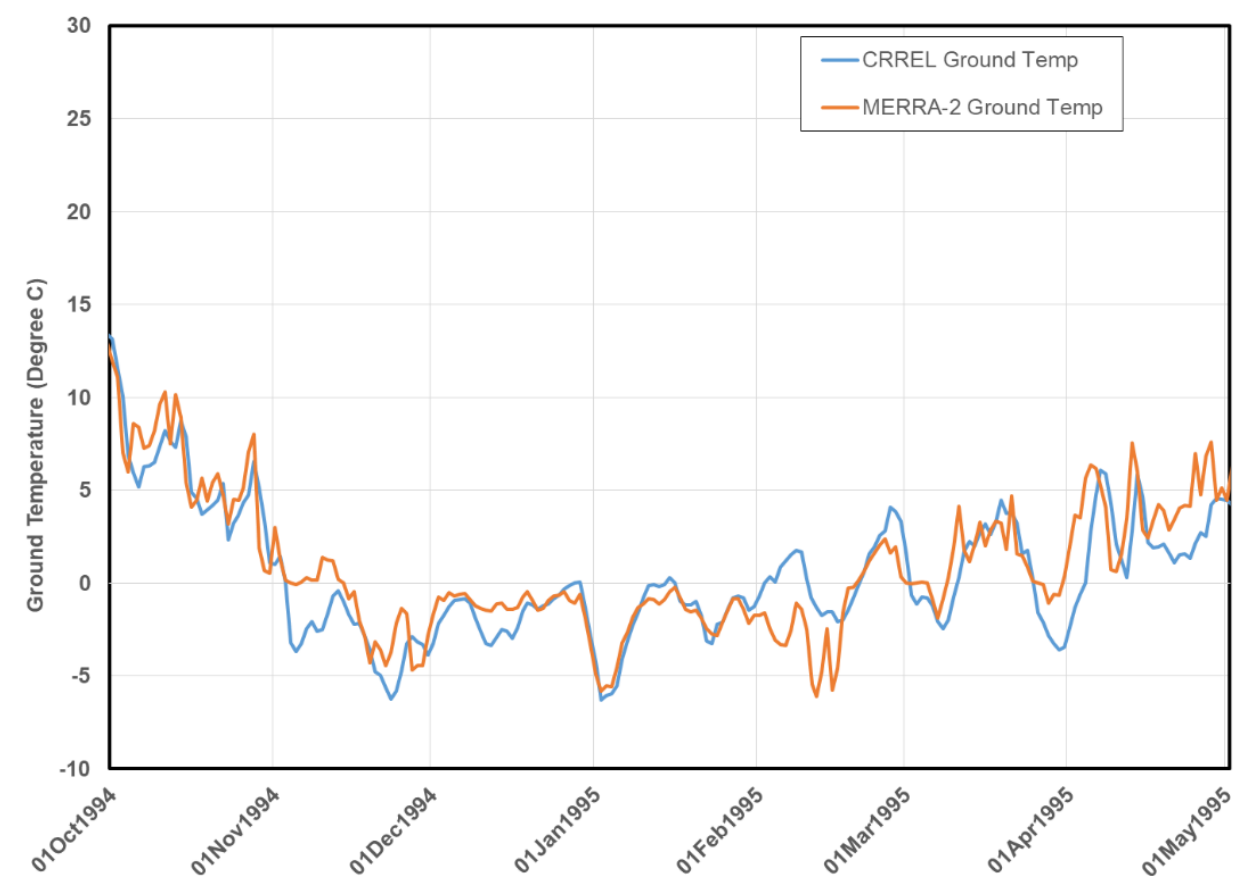


Figure 83. Example of CRREL's FSIM-GTM compared to MERRA-2 $10 \mathrm{~cm}$ layer soil temperature during a cold winter with higher snow cover.

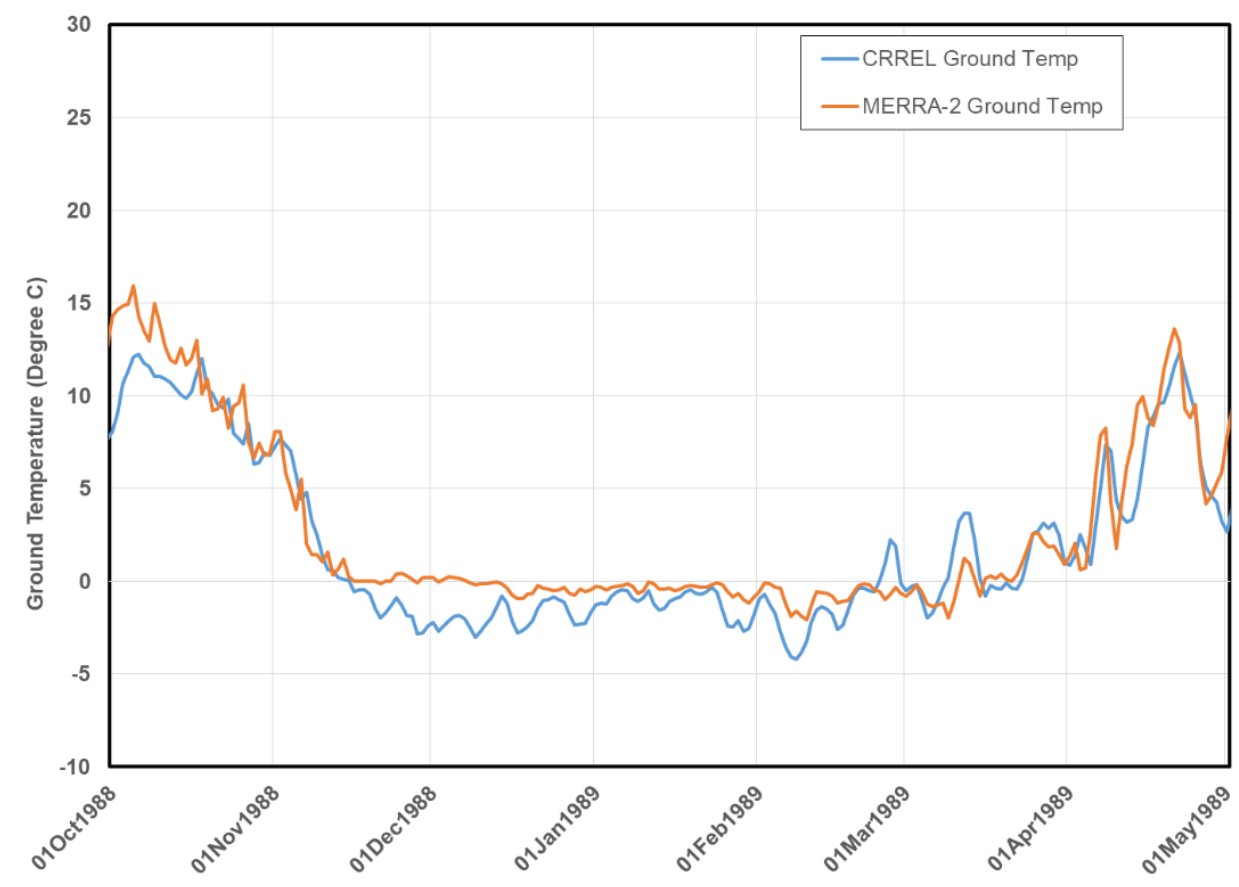

These results indicate that a simple model can be applied to the historic time series of air temperature and snow depth at Idaho Falls 16 SE to create an extended modeled time series of ground temperatures from 1960 to the present. This effectively increases the length of modeled ground temperatures by 20 years and allows for estimation of ground temperature conditions preceding the February 1962 runoff event.

\subsubsection{Estimating Soil Moisture}

In addition to soil temperature and potentially frozen or unfrozen classification, the other important input to FSIM is soil moisture. Soil moisture measurements in the basin are available at the Sheep Mountain SNOTEL site beginning in 2006. However, for similar reasons as discussed in the ground temperature section, we wanted a longer time series representative of average basin conditions.

We constructed a soil moisture model (FSIM-SMM) to extend soil moisture measurements as far back as practical. The model uses the same input data as the FSIM-GTM with the addition of precipitation data, also from the Idaho Falls 16 SE COOP station. 


\subsubsection{Soil Moisture Model formulation}

The model is based on the API concept of soil moisture modeling. The form used in this study is a modification of a basic API equation described by Crow et al. (2005):

$$
\mathrm{API}_{i}=\gamma \mathrm{API}_{i-1}+P_{i},
$$

where

$$
\begin{aligned}
P_{\mathrm{i}} & =\text { the daily precipitation and } \\
\gamma & =\text { a loss coefficient. }
\end{aligned}
$$

The API framework was adopted and modified for direct incorporation in FSIM. The primary modifications include directly computing the soil moisture level, implementing basic temperature dependence of the loss coefficient, and including snowmelt as an input. The modified form of the soil moisture equation used in the FSIM-SMM is as follows:

$$
S M_{i}=\gamma(T) S M_{i-1}+A_{p} P_{i}+A_{M} M_{i},
$$

where

$$
\begin{aligned}
S M= & \text { the soil moisture, in terms of volumetric water content } \\
& \left(\mathrm{m}^{3} \mathrm{~m}^{-3}\right), \\
\gamma= & \text { a loss coefficient that is a function of temperature } T, \\
M_{i}= & \text { daily snow melt, and } \\
A_{p} \text { and } A_{m}= & \text { constants that convert precipitation depth and snow melt, } \\
& \text { respectively, to change in soil volumetric water content } \\
& \left(\mathrm{m}^{3} \mathrm{~m}^{-4}\right) .
\end{aligned}
$$

The loss parameter assumes a value of 1 when the ground is classified as potentially frozen $\left(<0^{\circ} \mathrm{C}\right.$ in this case) and is a constant at other temperatures. This effectively prevents soil moisture content from decreasing from the level immediately before the ground enters a potentially frozen state. This captures the reduction in losses due to evaporation and drainage once liquid water in pore spaces turn into ice. In the potentially frozen state, the model still accumulates soil moisture from snowmelt and direct precipitation. This accounts for the process described by Gray and Norum (1967) and observed by others (Appels et al. 2018; Roy et al. 2020; Mohammed et al. 2019) where melt water or precipitation refreezes in the soil matrix. 


\subsubsection{Soil Moisture Model calibration}

FSIM-SMM is run using the same time series input as the FSIM-GTM-average daily air temperature and snow depth from Idaho Falls 16 SE. In addition, the model uses the daily precipitation record from the same station. The snow depth from the station is converted into snow SWE using the method described in the chapter 4 of this report. We used this record to calculate a time series of snow melt. The model uses ground temperature calculated with the FSIM-GTM to adjust the loss coefficient, using a threshold of $0^{\circ} \mathrm{C}$ to switch the value from a constant calibrated value for unfrozen conditions to 1 for frozen conditions.

We calibrated the model against the SMAP time series averaged over the Ririe Upstream Subbasin, which consists of $229 \mathrm{~km}$ (5.6 mile) pixels. The calibration period ranged from 30 March 2015 to 30 September 2018. The SMAP L3_SM_P_E soil moisture data used in this calibration are not available when the ground is frozen. While we compared the model results over the entire period when the SMAP was available, the model was specifically calibrated to minimize the SSE for November and March. November soil moistures represent the antecedent soil moisture condition prior to freeze up and are the most important values to accurately model. The March values were used to calibrate the snowmelt parameter in the model.

A temperature threshold of $1^{\circ} \mathrm{C}\left(33.8^{\circ} \mathrm{F}\right)$ was used to discriminate between frozen precipitation, which was not added directly to the model, and liquid precipitation, which was added to the accumulated soil moisture. Bounds of 0.240 and $0.080 \mathrm{~m}^{3} \mathrm{~m}^{-3}$ were placed on the model as part of the calibration process. The upper bound of the model is less than the assumed field capacity and satiated water contents ( 0.274 and $0.376 \mathrm{~m}^{3} \mathrm{~m}^{-3}$ ); therefore, model results at the upper bound should be interpreted to be potentially higher.

The model was run over the record at Idaho Falls 16 SE from 1960 to 2019. We calibrated the decay coefficient $(\gamma)$ and precipitation and snow melt accumulation parameters $\left(A_{\mathrm{p}}\right.$ and $\left.A_{\mathrm{M}}\right)$ to minimize the SSE between SMAP and the model for November and March in WYs 2016, 2017, and 2018. Table 31 presents calibrated parameters. 
Table 31. FSIM-SMM calibrated parameters.

\begin{tabular}{|c|c|}
\hline Parameter & Value \\
\hline$\gamma$ & 0.974 \\
\hline$A_{\mathrm{p}}\left(\mathrm{m}^{3} \mathrm{~m}^{-4}\right)$ & $0.25 \times 10^{-3}$ \\
\hline$A_{\mathrm{M}}\left(\mathrm{m}^{3} \mathrm{~m}^{-4}\right)$ & $0.10 \times 10^{-3}$ \\
\hline
\end{tabular}

\subsubsection{Soil Moisture Model results}

Despite the simplicity of the FSIM-SMM model, it is able to reasonably estimate the SMAP soil moisture, particularly in November prior to the freeze up (Figure 84). Table 32 presents error statistics. Eliminating soil moisture losses during frozen conditions and accumulating soil moisture from liquid precipitation inputs and snowmelt over the winter reduced error in soil moisture estimates for March relative to the basic form of the API model.

March errors are higher than those in November, partially because the physical processes of water infiltrating a thawing soil matrix and then refreezing are more difficult to capture versus the evaporation- and drainage-driven processes that dictate the soil moisture condition in November. Figure 85 presents the complete results over the calibration period.

Figure 84. FSIM-GTM and SMM model results for winter of WY 2017.

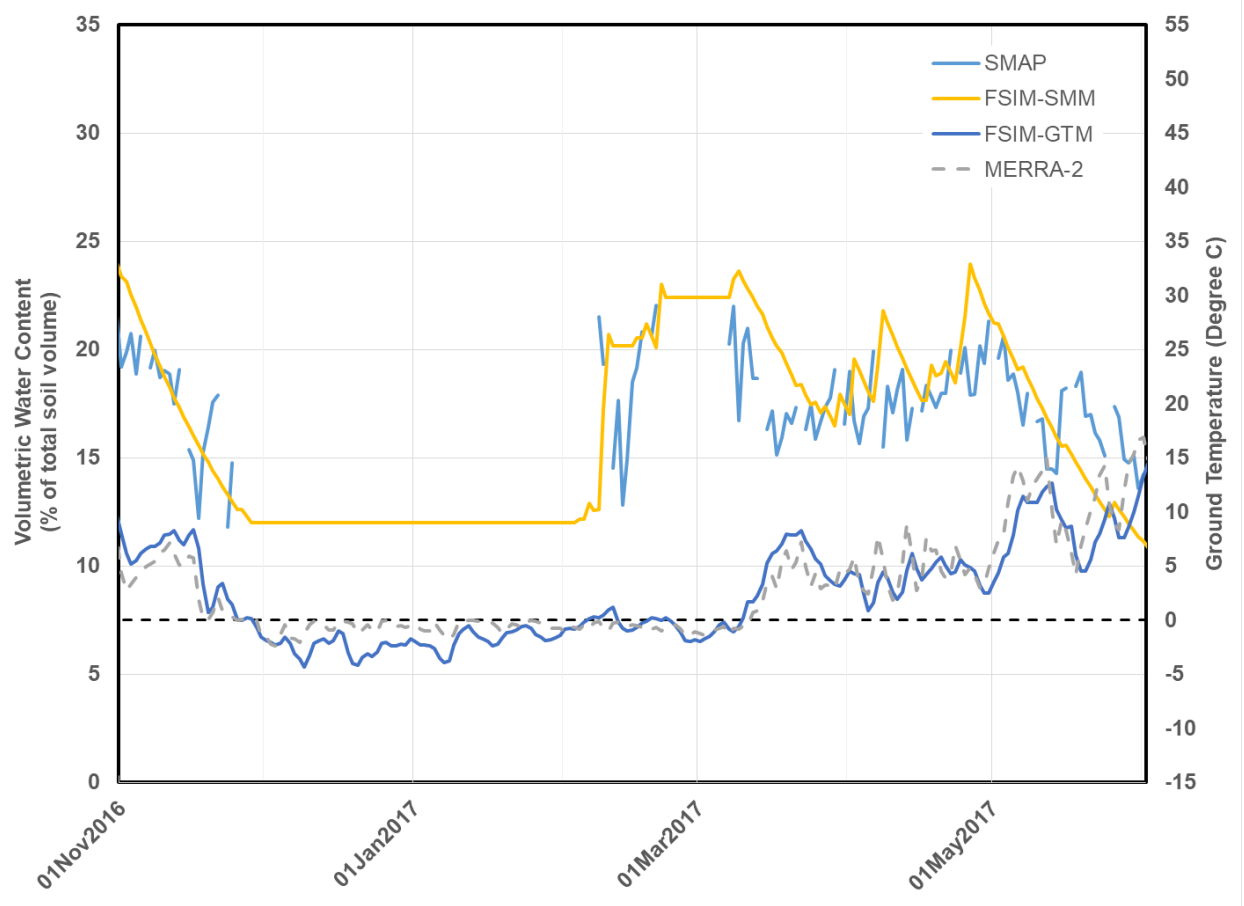


Table 32. FSIM-SMM model error statistics. Bold numbers are the error statistics reported as soil volumetric water content.

\begin{tabular}{|l|c|c|c|}
\hline \multicolumn{1}{|c|}{ Error Statistic } & $\begin{array}{c}\text { All Season } \\
\text { WY 2016-2018 }\end{array}$ & $\begin{array}{c}\text { November } \\
\text { WY 2016-2018 }\end{array}$ & $\begin{array}{c}\text { March } \\
\text { WY 2016-2018 }\end{array}$ \\
\hline RMSE $\left(\mathrm{m}^{3} \mathrm{~m}^{-3}\right)$ & 0.0335 & 0.0239 & 0.0340 \\
(VWC \%) & $\mathbf{( 3 . 3 5 \% )}$ & $\mathbf{( 2 . 3 9 \% )}$ & $\mathbf{( 3 . 4 0 \% )}$ \\
\hline MAE $\left(\mathrm{m}^{3} \mathrm{~m}^{-3}\right)$ & 0.0255 & 0.0190 & 0.0286 \\
(VWC \%) & $\mathbf{( 2 . 5 5 \% )}$ & $\mathbf{( 1 . 9 0 \% )}$ & $\mathbf{( 2 . 8 6 \% )}$ \\
\hline
\end{tabular}

Figure 85. FSIM-SMM soil moisture compared with SMAP (L3_SM_P_E) averaged over Ririe Upstream Subbasin of Willow Creek Watershed. Percentage volumes equal 100 times the volumetric water content $\left(\mathrm{m}^{3} \mathrm{~m}^{-3}\right)$.

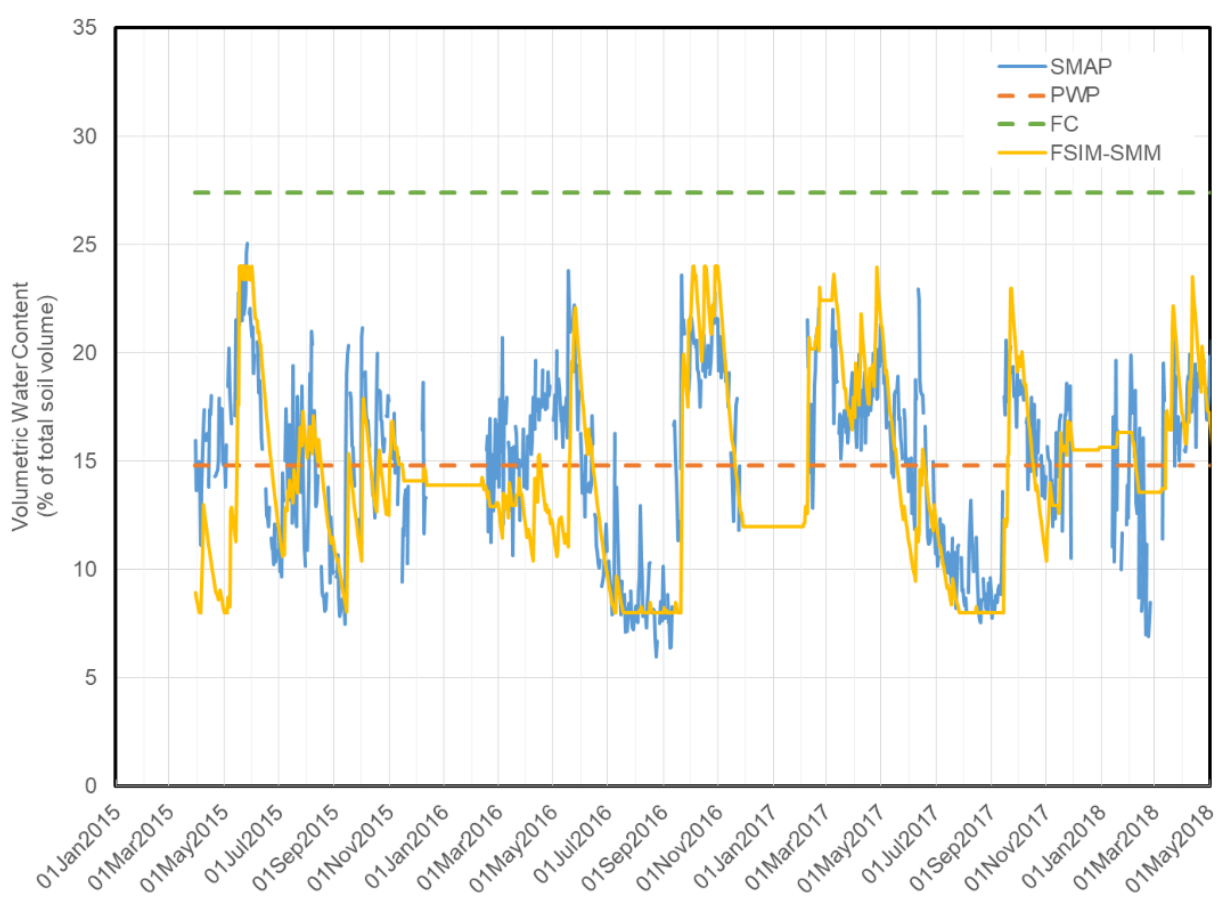

\subsubsection{Application of FSIM-SMM and FSIM-GTM to the Willow Creek Watershed}

We used FSIM-SMM (using ground temperature inputs from FSIM-GTM) to generate a time series of daily soil moisture values based on data from the Idaho Falls 16 SE COOP station. Initial inspection of the November soil water contents (Figure 86) shows a variation in pre-freeze-up conditions, which may indicate which years had potential for reduced infiltration conditions. While November conditions set the stage for the winter season, rainfall or snowmelt and midwinter thaw events can likely change the moisture content over the course of the winter. Table 33 summarizes the winter (January-March) moisture conditions as estimated by FSIM-SMM. 
Figure 86. November soil moistures by year from FSIM-SMM.

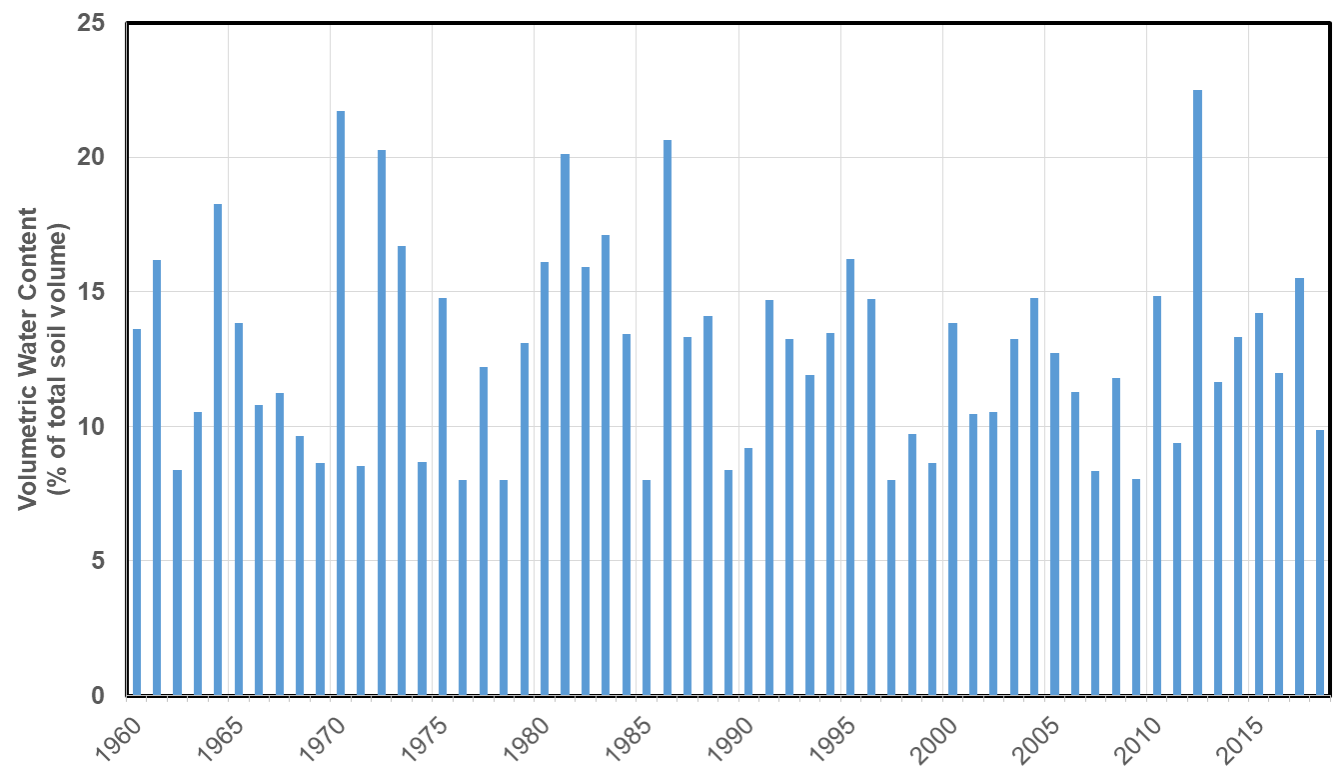

Table 33. Average soil moisture (volumetric water content \%) for WYs 1961 to 2018 estimated by FSIM-SMM. Soil moisture averages equal to or greater than $20 \%$ are highlighted in red.

\begin{tabular}{|c|c|c|c|c|c|c|c|c|c|}
\hline Date & Jan & Feb & Mar & Jan-Mar & Date & Jan & Feb & Mar & Jan-Mar \\
\hline 1961 & 13.6 & 14.1 & 14.8 & 14.2 & 1990 & 8.9 & 9.1 & 9.8 & 9.2 \\
\hline 1962 & 17.0 & 20.7 & 21.5 & 19.7 & 1991 & 9.6 & 10.0 & 17.9 & 12.6 \\
\hline 1963 & 8.2 & 17.0 & 17.2 & 14.0 & 1992 & 14.8 & 16.2 & 13.9 & 14.9 \\
\hline 1964 & 10.6 & 10.6 & 10.6 & 10.6 & 1993 & 13.2 & 13.7 & 15.9 & 14.3 \\
\hline 1965 & 24.0 & 23.0 & 24.0 & 23.7 & 1994 & 12.6 & 13.1 & 11.0 & 12.2 \\
\hline 1966 & 14.2 & 14.2 & 14.3 & 14.3 & 1995 & 14.6 & 14.0 & 17.6 & 15.4 \\
\hline 1967 & 12.1 & 14.3 & 14.3 & 13.5 & 1996 & 18.8 & 20.6 & 20.7 & 20.1 \\
\hline 1968 & 11.2 & 13.5 & 14.1 & 13.0 & 1997 & 22.9 & 24.0 & 22.8 & 23.2 \\
\hline 1969 & 17.3 & 23.8 & 23.7 & 21.5 & 1998 & 10.8 & 11.5 & 12.3 & 11.6 \\
\hline 1970 & 11.8 & 14.9 & 17.8 & 14.8 & 1999 & 9.7 & 10.3 & 10.5 & 10.2 \\
\hline 1971 & 22.3 & 19.4 & 22.2 & 21.4 & 2000 & 8.7 & 9.2 & 8.8 & 8.9 \\
\hline 1972 & 10.2 & 12.6 & 13.3 & 12.0 & 2001 & 13.6 & 13.6 & 13.4 & 13.5 \\
\hline 1973 & 22.9 & 23.9 & 22.8 & 23.2 & 2002 & 10.8 & 10.9 & 12.7 & 11.5 \\
\hline 1974 & 17.7 & 20.9 & 21.3 & 20.0 & 2003 & 17.8 & 21.7 & 18.9 & 19.4 \\
\hline 1975 & 8.8 & 8.8 & 9.3 & 8.9 & 2004 & 14.2 & 14.7 & 13.5 & 14.1 \\
\hline 1976 & 14.8 & 14.8 & 15.6 & 15.1 & 2005 & 14.5 & 14.0 & 13.5 & 14.0 \\
\hline 1977 & 8.0 & 8.4 & 11.2 & 9.2 & 2006 & 22.6 & 22.7 & 22.9 & 22.7 \\
\hline 1978 & 12.5 & 14.2 & 14.7 & 13.8 & 2007 & 11.6 & 13.0 & 12.5 & 12.3 \\
\hline 1979 & 8.2 & 8.4 & 8.9 & $\mathbf{8 . 5}$ & 2008 & 8.0 & 8.2 & 8.5 & 8.2 \\
\hline 1980 & 15.1 & 17.8 & 17.5 & 16.8 & 2009 & 12.0 & 13.1 & 14.6 & 13.2 \\
\hline 1981 & 12.7 & 12.8 & 11.7 & 12.4 & 2010 & 8.1 & 8.1 & 8.6 & 8.3 \\
\hline 1982 & 23.8 & 23.3 & 23.4 & 23.5 & 2011 & 17.3 & 19.2 & 21.2 & 19.2 \\
\hline
\end{tabular}




\begin{tabular}{|c|c|c|c|c|c|c|c|c|c|}
\hline Date & Jan & Feb & Mar & Jan-Mar & Date & Jan & Feb & Mar & Jan-Mar \\
\hline 1983 & 18.7 & 19.4 & 18.4 & 18.8 & 2012 & 13.1 & 13.1 & 14.2 & 13.5 \\
\hline 1984 & 17.5 & 17.5 & 18.4 & 17.8 & 2013 & 22.5 & 22.8 & 22.0 & 22.4 \\
\hline 1985 & 13.6 & 13.6 & 13.3 & 13.5 & 2014 & 11.7 & 12.8 & 17.3 & 14.0 \\
\hline 1986 & 8.0 & 14.4 & 16.9 & 13.1 & 2015 & 14.1 & 16.4 & 12.3 & 14.2 \\
\hline 1987 & 21.7 & 22.5 & 21.1 & $\mathbf{2 1 . 7}$ & $\mathbf{2 0 1 6}$ & 13.9 & 13.5 & 13.0 & 13.5 \\
\hline 1988 & 13.6 & 13.6 & 13.7 & 13.6 & $\mathbf{2 0 1 7}$ & 12.0 & 18.6 & 20.3 & 16.9 \\
\hline 1989 & 14.1 & 14.7 & 17.1 & 15.3 & $\mathbf{2 0 1 8}$ & 15.9 & 14.2 & 16.6 & 15.6 \\
\hline
\end{tabular}

Since FSIM-SMM incorporates winter rainfall and snowmelt events, the soil moisture can change significantly over the course of a winter as water enters the ground and refreezes. Typically, March soil moistures are higher than in November. Figure 87 clearly shows the effect of large rain or snowmelt effects. Of note is the February 1962 event, which saw a modest increase in moisture from an already elevated initial level in November. The effects of the large warming, precipitation, and snowmelt event in WY 1965, which triggered the so-called Christmas floods of 1964, are also evident in the results.

Figure 87. Example of monthly average soil moisture estimates from FSIMSMM for WYs 1961-1970.

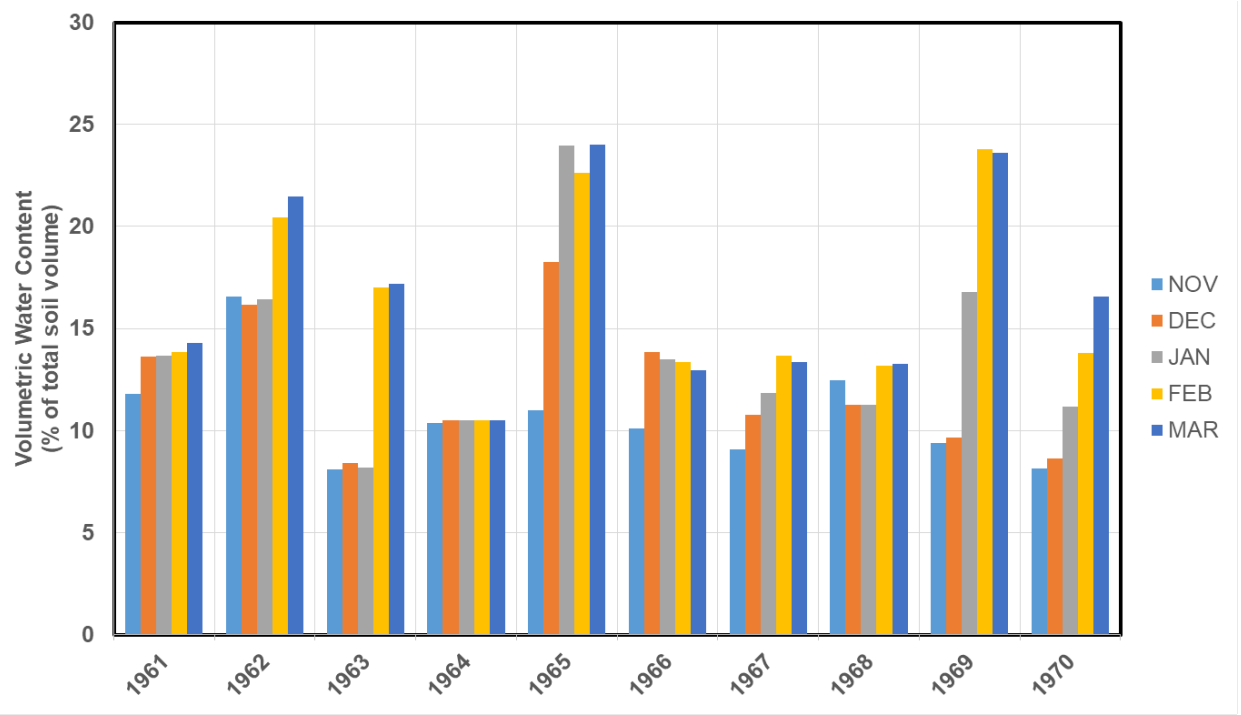

The February 1962 event is of particular interest due to the high amount of runoff that was attributed, in part, to effects of frozen ground conditions. The FSIM-GTM and SMM model results provide some insight on that event (Figure 88). The soil moisture levels were relatively high entering the winter (see also Figure 86); and the ground was frozen from early December on, which extended the high soil moisture condition into February. 
The high soil moisture content combined with frozen conditions would likely have limited the infiltration capacity when the precipitation event initiated.

Figure 88. Soil moisture and ground temperature conditions from FSIM-GTM and SMM during WY 1962, which saw a significant winter runoff event in early February.

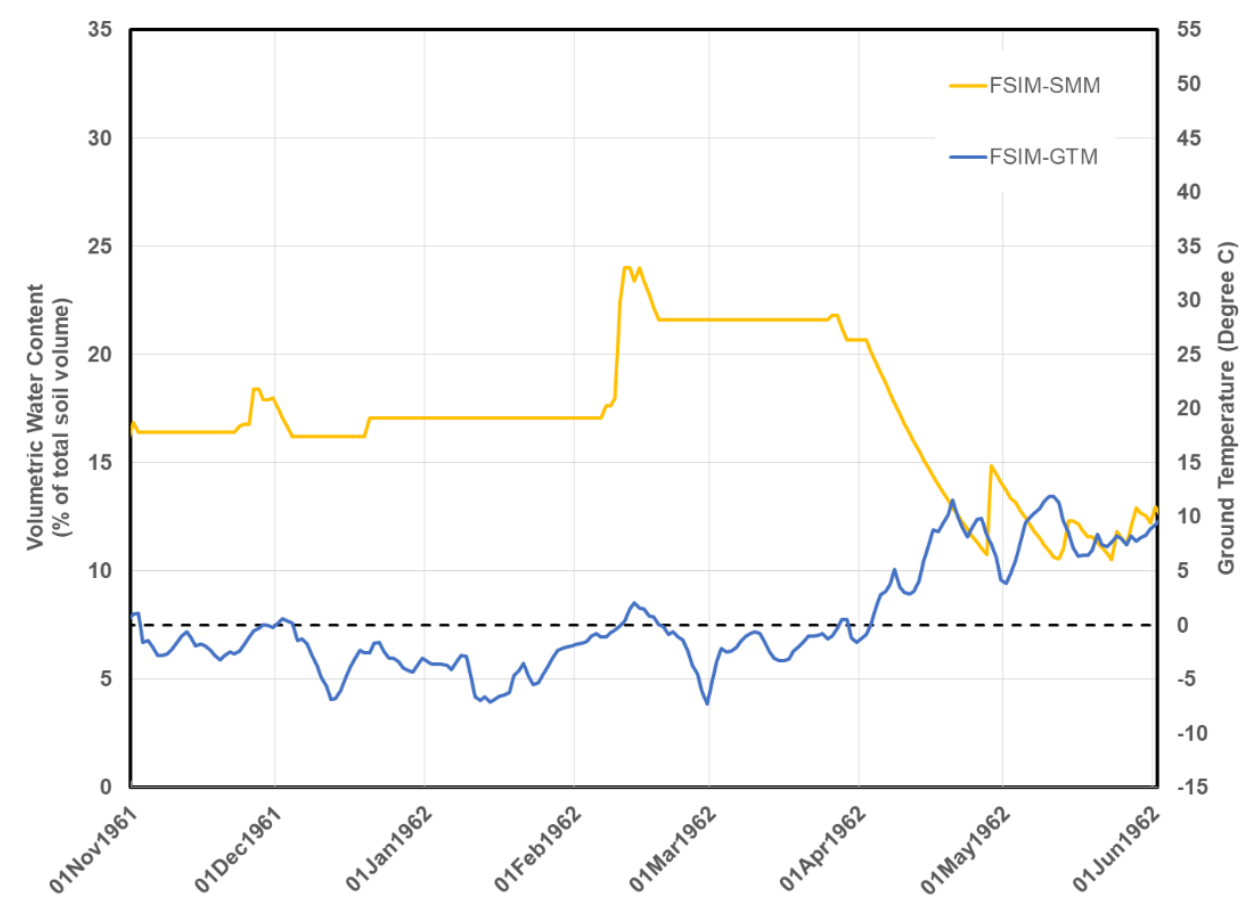

The FSIM-SMM is a simple soil moisture model that relies on limited input data (average air temperature, precipitation, and SWE along with ground temperature) to produce a time series of soil moisture. The soil moisture results generally agree with soil moistures derived from measurements made by the satellite based SMAP radiometer. Similar to the utility of the FSIM-GTM, the model can be easily applied to the Idaho Falls 16 SE COOP station time series to generate an extended estimated daily time series of soil moisture equal to that of the COOP record.

\subsubsection{Modeling Frozen Ground Infiltration}

Gray et al. (2001) proposed that frozen soils can be separated into three general groups in terms of their potential infiltration capacity:

4. Unlimited (predominately gravity flow): Soils are capable of infiltrating most or all available meltwater. This group includes the following: 
a. Dry, severely cracked colloidal soils-usually fine-textured mineral soils under vegetation during the summer months

b. Dry, coarse-textured and gravelly soils-deep, relatively uniform profiles and sand, sandy loam, or other permeable material underlying well-drained peat and organic deposits (e.g., forest soils)

c. Sloping, shallow, highly permeable deposits underlain by a relatively impermeable subsurface material (e.g., forest litter and moss on bedrock, tundra peat on permafrost)

5. Restricted: Soils' infiltrability is restricted by an impervious surface. This group includes the following:

a. Mineral and other soils frozen in a wet condition (e.g., $>70-80 \%$ pore saturation)

b. Soils in which an impeding layer develops at or near the ground surface (e.g., a basal ice lens that forms at the soil surface due to rain that occurs near freeze-up or the freezing of percolating or infiltrating meltwater)

6. Limited (predominately capillary flow): Soil infiltrability is governed primarily by the soil moisture content (water + ice) and soil temperature at the start of snow ablation and the infiltration-opportunity time.

The infiltration state can be dynamic during an event as meltwater (or precipitation) enters the soil matrix and freezes in the pore structures, restricting infiltration, or conversely delivers heat to the frozen soil, thawing frozen water in the pores and increasing infiltration. Gray and Norum (1967) identified three general categories of infiltration rate progression for frozen soils:

1. A constant, low infiltration rate if the soil matrix was frozen with a high soil moisture content or if an impervious layer of refrozen meltwater formed at the surface.

2. An infiltration rate that rapidly decreases, which can occur if the soil moisture is low and meltwater entering the pores freezes in place and restricts flow.

3. An infiltration rate that increases over time, which can occur when the ground is frozen at with a high moisture content $(70 \%-80 \%$ of field capacity). In this case, melt water enters the pores, transferring heat, which is used to melt ice-filled pores. 
Examples of each of these three cases can be found in the literature. Shanley and Chalmers (1999) observed significantly reduced infiltration rates in a watershed in northern Vermont over the course of an event where rain fell on so-called "concrete frost" that formed when the finegrained surface soil froze with a high moisture content. Unsaturated frozen soils subjected to simulated snow melt in laboratory experiments have exhibited initially high infiltration rates, which decrease asymptotically to a lower steady infiltration rate due to refreezing of meltwater (Appels et al. 2018; Roy et al. 2020). In an experiment simulating rain on frozen ground, ponded water forming on the surface of a frozen soil column suddenly infiltrated when the soil matrix thawed due to the heat input from the water (Holten et al. 2018).

It is difficult to anticipate and model these potential conditions using daily data on a basin-scale model; however, some key assumptions can be made based on knowledge of the site. The SMAP soil moisture data suggests that the basin does not see excessively high moisture contents and especially not in the lead up to freezing conditions, at least between 2015 and 2018. This suggests that the soils in Willow Creek Watershed are rarely if ever in a "restricted" condition as defined by Gray and Norum (1967) and are unlikely to form an impermeable "concrete frost" layer as observed by Shanley and Chalmers (1999).

In some cases, direct precipitation may fall on frozen soil and thaw the soil with heat introduced by the precipitation; however, it seems more likely that rain will fall on a snowpack and that heat from the precipitation will contribute to melting snow rather than directly warming the ground. In cases where precipitation is falling on frozen ground, the ambient air temperature is typically above freezing; and while heat from the precipitation process may expedite thawing, the effect is likely to occur on a timescale much smaller than the daily time step of the FSIM model. Therefore, direct treatment of the effect of heat transfer from precipitation on infiltration is not warranted for this practical model.

This leaves the assumption that, when frozen, the soil in the Willow Creek Basin has reduced infiltration capacity and that the infiltration rate may increase or decrease when the soil is exposed to liquid water. In addition, changes to the infiltration rate are driven by ambient air temperature. 


\subsubsection{FSIM formulation}

Ireson (2013) categorized methods to estimate effects of frozen ground on infiltration as simple parametric models, ground thawing- and freezingdepth models, and fully coupled mass and heat transport models. The third approach requires complex numerical solutions outside the scope of a study of this nature. Ground thawing- and freezing-depth models have proven adept at predicting frost depth (e.g., Follum et al. 2018); however, linking these model results to infiltration or runoff effects is not straightforward.

Several studies, including Zhao and Gray (1997) and Maulé and Gray (1994), have proposed parametric models for estimating infiltration of frozen soils. While the two above studies provided acceptable results, both require site-specific calibration. Maulé and Gray's model is easier to implement and requires only two time series: frozen/unfrozen state and soil moisture.

FSIM is based on the infiltration-reduction model proposed by Maulé and Gray (1994). While the original equation directly solved for a daily infiltration rate, we rearranged the equation to produce a ratio of the limited infiltration rate to the maximum infiltration rate:

$$
\xi_{a}=\frac{\mathrm{INF}_{a}}{\mathrm{INF}}=\beta\left[1-\left(\frac{\left(\theta_{a}-\theta_{\mathrm{PWP}}\right)}{\left(\theta_{S}-\theta_{\mathrm{PWP}}\right)}\right)^{0.5}\right],
$$

where

$$
\begin{aligned}
\xi_{a} & =\text { the ICRF, } \\
\mathrm{INF}_{a} & =\text { the infiltration rate on the current day }\left(\mathrm{m} \mathrm{s}^{-1}\right), \\
\mathrm{INF} & =\text { the infiltration rate }\left(\mathrm{m} \mathrm{s}^{-1}\right), \\
\beta & =\text { the dry frozen ground infiltration-reduction coefficient } \\
\theta & =\text { the soil moisture content }\left(\mathrm{m}^{3} \mathrm{~m}^{-3}\right) \\
a & =\text { water contents for the current day, } \\
\mathrm{PWP} & =\text { the permanent wilting point, and } \\
S & =\text { saturated conditions. }
\end{aligned}
$$

FSIM combines the two submodels, GTM and SMM, to estimate infiltration reduction based on ground temperature and soil moisture conditions. FSIM generates a time series of ICRF that can provide insights about the 
infiltration state or can be used to directly estimate adjustments to infiltration rates in a hydrologic model to capture the effect of frozen ground.

\subsubsection{FSIM calibration}

FSIM was calibrated to the Willow Creek Basin using the winter flood event of record, which occurred in February 1962. The calibration entailed using HEC-HMS to calculate a daily infiltration rate during the 1962 event and during unfrozen periods. The infiltration rate and associated soil moisture calculated with FSIM-SMM along with the unfrozen infiltration rate are then used to solve for $\beta$ in Equation (14), which is an ICRF for frozen soils with soil moisture less than the permanent wilting point.

With a calibrated value of $\beta$, Equation (14) can be used to develop a time series of ICRF as a function of ground temperature and soil moisture. These inputs are the outputs of the FSIM-GTM and FSIM-SMM models, respectively.

\subsection{HEC-HMS model setup}

We used the modified HEC-HMS model provided by USACE-NWW as the basis of this analysis (Figure 89). The model includes the Grays Lake Reservoir Subbasin, but that portion of the model is diverted out of the basin and does not contribute to the Ririe Reservoir. CRREL further simplified the basin model to include only the deficit and constant loss parameters. Table 34 summarizes the basin methods used in the model.

The model was first calibrated to match the estimated peak of the February 1962 event. The HMS meteorological model provided by USACENWW entitled "1962_Validation_Met" was used with the only modification being that the precipitation inputs were changed to daily observations from Idaho Falls $16 \mathrm{SE}$, as the simulation was run with a daily time step.

We developed the initial SWE based on the observed snow depth at Idaho Falls 16 SE COOP converted to SWE (see chapter 4 regarding the method) and then adjusted for elevation using the observed SWE and elevation relationship described in chapter 4. Ultimately, the selected SWE did not limit melt, and total melt over the event approximately matched the estimated value of 2 in. from the Ririe Project Design Memorandum (USACE 1966). Table 35 summarizes the meteorological model input parameters. 
Figure 89. Diagram of the HEC-HMS model of the Willow Creek Watershed.

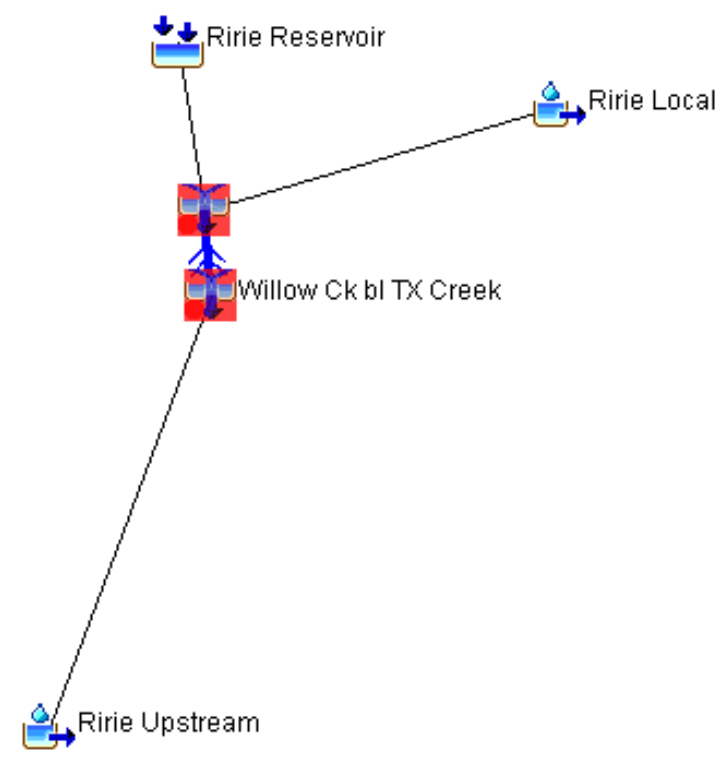

Table 34. Basin methods used for HEC-HMS model calibration.

\begin{tabular}{|l|l|l|l|l|l|}
\hline \multicolumn{7}{|c|}{ Subbasin } & Canopy & Surface & \multicolumn{1}{c|}{ Loss } & \multicolumn{1}{c|}{ Transform } & Baseflow \\
\hline Ririe Upstream & None & None & Deficit and Constant & Clark Unit Hydrograph & Constant Monthly \\
\hline Ririe Local & None & None & Deficit and Constant & Clark Unit Hydrograph & None \\
\hline
\end{tabular}

Table 35. Meteorological model for the February 1962 calibration.

\begin{tabular}{|l|c|}
\hline \multicolumn{2}{|c|}{ Met Model Summary } \\
\hline Hyetograph & Daily 16 SE COOP \\
\hline Snow ATIa Parameter & Value \\
\hline PX $^{\mathrm{b}}$ Temp $\left({ }^{\circ} \mathrm{F}\right)$ & 32.8 \\
\hline Base Temp $\left({ }^{\circ} \mathrm{F}\right)$ & 32 \\
\hline ATI Coefficient & 0.98 \\
\hline Wet Melt Rate (in./deg-day) & 0.0788 \\
\hline Rain Limit (in./day) & 0.2 \\
\hline ATI Melt Rate Function & Based on Sheep Mtn SNOTEL \\
\hline Cold Limit (in./day) & 0.22 \\
\hline Cold Rate Coefficient & 0.34 \\
\hline Water Capacity (\%) & 3 \\
\hline Groundmelt (in./day) & 0 \\
\hline Initial SWE & SWE (in.) \\
\hline Ririe Local & 1.12 \\
\hline Ririe Upstream & 4.06 \\
\hline
\end{tabular}




\subsection{February 1962 model run}

We ran the model for the February 1962 event with a daily time step and compared it to an estimated runoff hydrograph contributing to the reservoir, which USACE-NWW provided (Figure 90). The calibration aimed to match the estimated peak flow rate of $5080 \mathrm{cfs}$ that occurred during the February 1962 flood event (USACE 1966). Table 36 summarizes the basin parameters used for the calibration.

As the model was run with a daily time step, with daily average precipitation intensity, the calibrated infiltration rates are valid only as estimates of the daily infiltration rate. For the February 1962 event, the calibrated daily infiltration rate was $0.9 \mathrm{in} . /$ day.

Figure 90. Runoff hydrograph at the Ririe Dam site. The solid blue line is the combined inflow from Ririe Local and Ririe Upstream. The solid black line is the daily averaged estimated hydrograph from USACE-NWW.

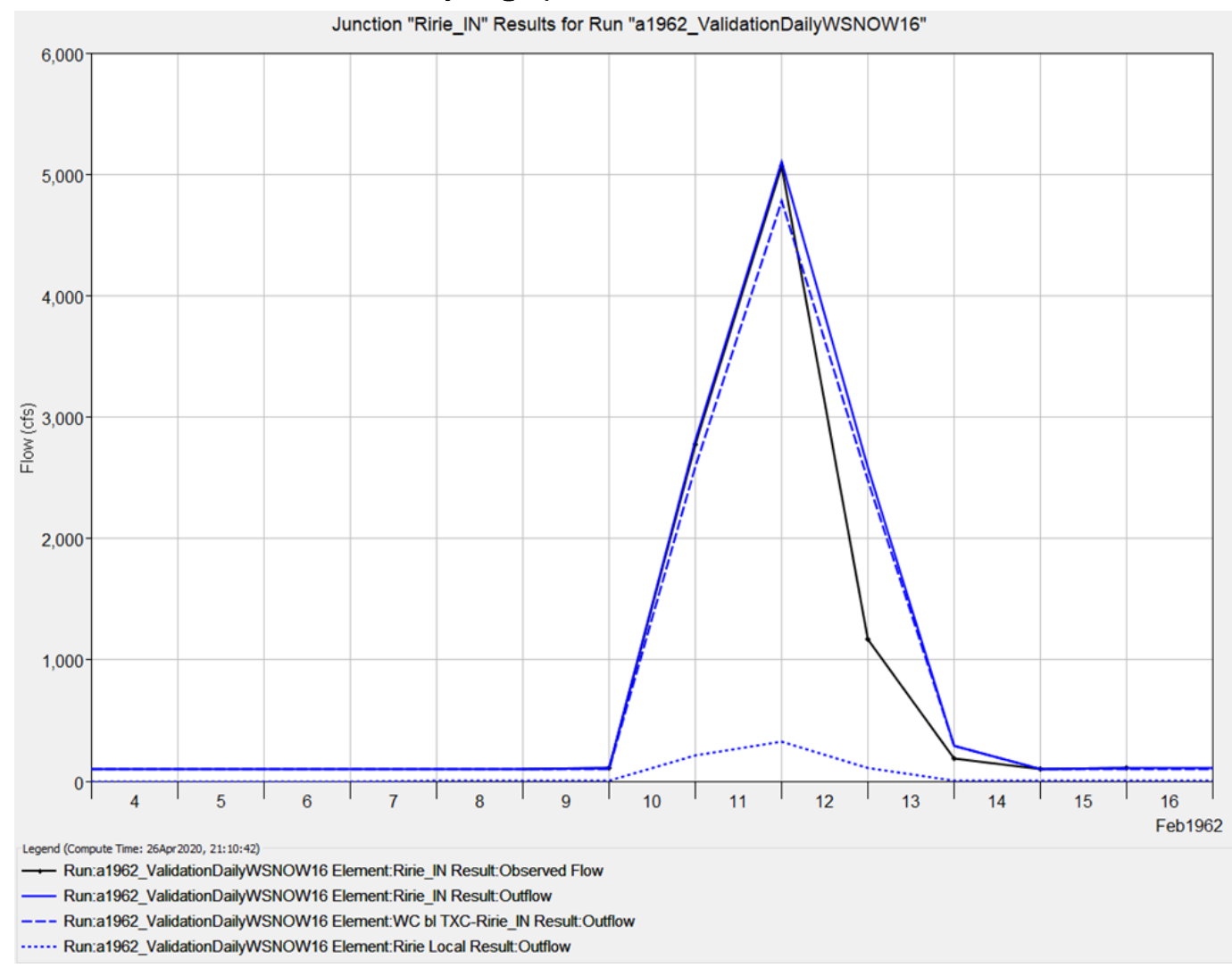


Table 36. Basin parameters used to calibrate the infiltration rate during the February 1962 flood event.

\begin{tabular}{|c|c|c|c|c|c|c|c|c|}
\hline \multirow[b]{2}{*}{ Subbasin } & \multirow[b]{2}{*}{$\begin{array}{l}\text { Time } \\
\text { Step }\end{array}$} & \multicolumn{2}{|c|}{ Loss } & \multirow[b]{2}{*}{$\begin{array}{c}\text { Constant } \\
\text { Rate } \\
\text { (in./day) }\end{array}$} & \multirow[b]{2}{*}{$\begin{array}{l}\text { Impervious } \\
\text { (\%) }\end{array}$} & \multicolumn{2}{|c|}{ Clark Unit Hydrograph } & \multirow{2}{*}{$\begin{array}{c}\text { Baseflow } \\
\begin{array}{c}\text { Flow } \\
\text { (cfs) }\end{array}\end{array}$} \\
\hline & & $\begin{array}{l}\text { Initial } \\
\text { Deficit } \\
\text { (in.) }\end{array}$ & $\begin{array}{l}\text { Constant } \\
\text { Rate } \\
\text { (in./hour) }\end{array}$ & & & $\begin{array}{c}\text { Time of } \\
\text { Concentration } \\
\text { (hour) }\end{array}$ & $\begin{array}{c}\text { Storage } \\
\text { Coefficient } \\
\text { (hour) }\end{array}$ & \\
\hline $\begin{array}{l}\text { Ririe } \\
\text { Local }\end{array}$ & 1 day & 0 & 0.038 & 0.9 & 2.21 & 4.61 & 4.61 & 0 \\
\hline $\begin{array}{l}\text { Ririe } \\
\text { Upstream }\end{array}$ & 1 day & 0 & 0.038 & 0.9 & 0.11 & 14.3 & 14.3 & 100 \\
\hline
\end{tabular}

\subsection{Discussion of February 1962 event calibration}

The February 1962 flood event was the result of a large precipitation event combined with the availability of a significant amount of SWE all over probably frozen ground in the Ririe and Ririe Upstream basins. Figure 91 shows the breakdown of sources of liquid water at the soil surface (LWASS) in the HEC-HMS model, which demonstrates the significant impact of snowmelt during the event.

Figure 91. Breakdown of direct precipitation and snow melt contributions to liquid water at the soil surface (LWASS) for the Ririe Upstream Subbasin during the February 1962 event.

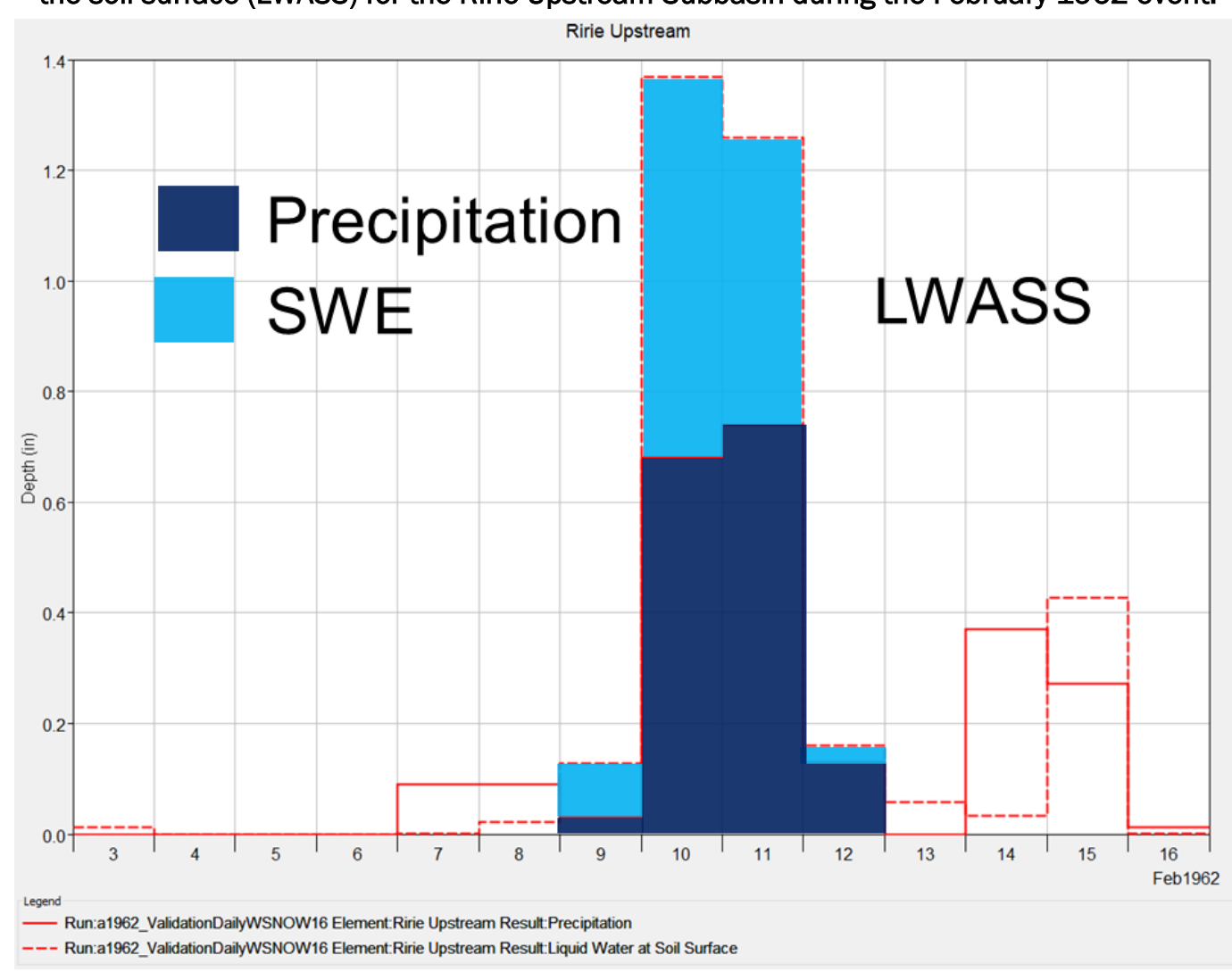


Figure 92 shows the calibrated partitioning of runoff and infiltration during the event, clearly showing that while there was a significant amount of runoff, a majority of LWASS still infiltrated the frozen soil. High levels of infiltration during an extreme event supports the assumption that the infiltration rate of frozen soil in the Willow Creek Watershed is typically "limited" as defined by Gray et al. (2001) and that significant infiltration can still occur despite the soil being in a frozen state.

Figure 92. Partitioning of the LWASS into runoff and infiltration losses during the February 1962 event.

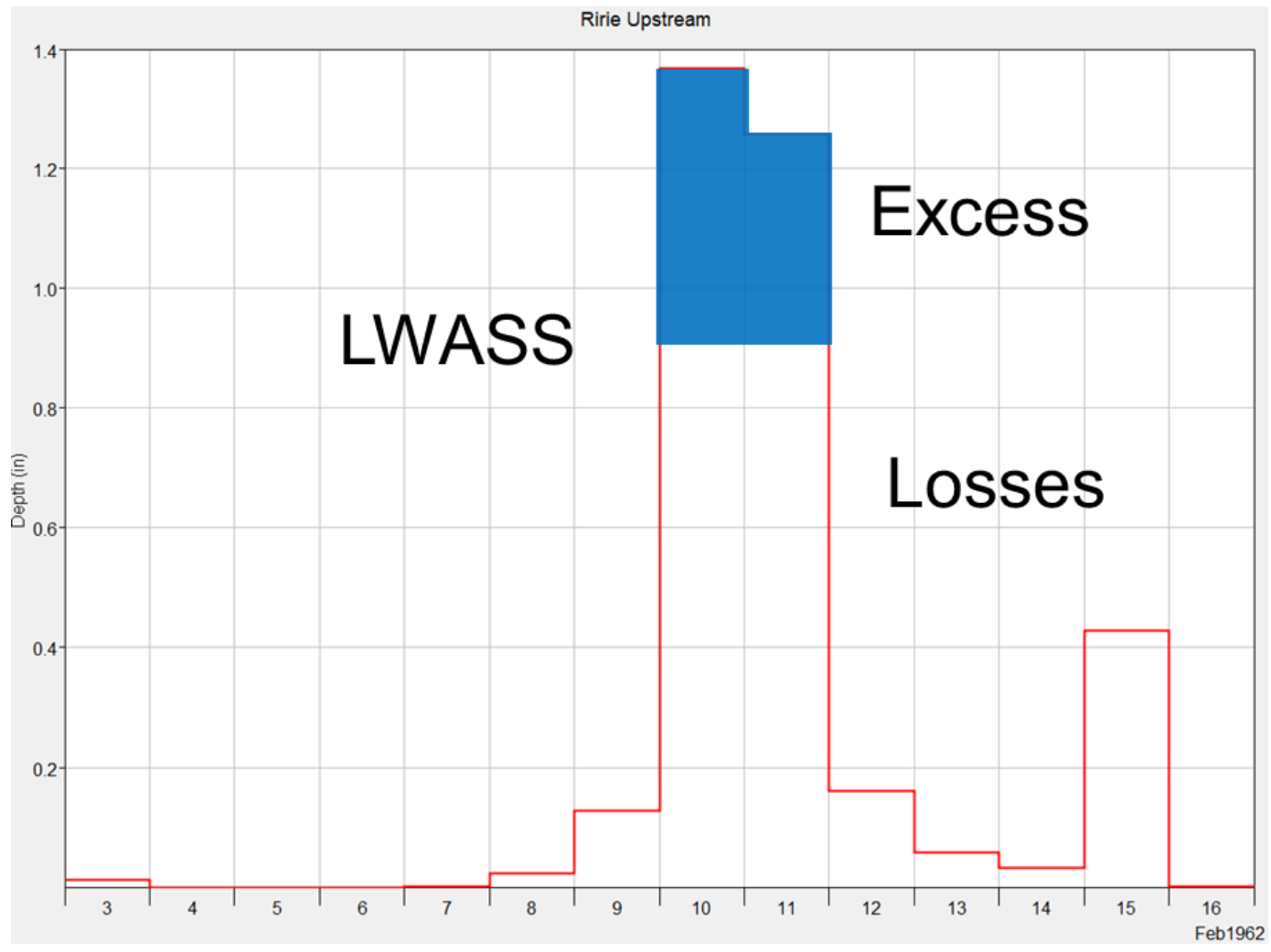

\subsection{FSIM calibration during unfrozen period}

The model presented by Maulé and Gray (1994), which FSIM is based on, requires definition of the unlimited infiltration rate (Equation [14]). This is the value that the ICRF is applied to in order to define the frozen ground infiltration rate at a given time as a function of soil moisture. We calculated the unlimited infiltration rate by identifying isolated large rainfall events in the Idaho Falls 16 SE COOP record and by calibrating HEC-HMS models to calculate runoff from these events. Model runoff was calibrated to the volumes from the Reclamation-calculated inflow record to the Ririe Reservoir (Reclamation 2020b). The basin model used for the 1962 event was also used for the unfrozen events. The unfrozen event occurred when 
snow was not present; therefore, the meteorological model included only the daily precipitation from the Idaho Falls 16 SE COOP station.

In general, calibration of three of the four events was possible by simply using an infiltration rate in excess of the daily precipitation availability (Table 37). During these events, runoff was relatively low, and the impervious areas in the model (unchanged from those presented in Table 36) provided enough runoff to match the Reclamation-calculated inflow volumes. An exception was the June 2004 event, which did result in slightly elevated runoff in response to a 24-hour precipitation amount of 1.53 in. A daily infiltration rate of $1.48 \mathrm{in} /$ day provided $0.05 \mathrm{in}$. of runoff to match the observed runoff volume. From this we can assume that the unlimited daily infiltration rate is approximately $1.5 \mathrm{in}$./day.

Table 37. Calibrated infiltration rates for modeled events.

\begin{tabular}{|l|c|c|c|c|}
\hline \multirow{2}{*}{ Event Start } & \multicolumn{3}{|c|}{ Max Precipitation/LWASS (in.) } & Infiltration Rate \\
\cline { 2 - 5 } & 24-hour & 48-hour & 72-hour & in./day \\
\hline $9 / 5 / 2002$ & 0.65 & 1.00 & 1.02 & $>0.65$ \\
\hline $6 / 11 / 2004$ & 1.53 & 1.62 & 1.90 & 1.48 \\
\hline $10 / 3 / 2015$ & 0.98 & 1.21 & 1.21 & $>0.98$ \\
\hline $9 / 21 / 2016$ & 1.10 & 1.70 & 2.00 & $>1.10$ \\
\hline $2 / 11 / 1962$ & 1.37 & 2.63 & 2.76 & 0.9 \\
\hline
\end{tabular}

A daily infiltration rate of $1.5 \mathrm{in}$./day is equal to an hourly infiltration rate of $0.0625 \mathrm{in}$./hour, which is on the lower end of the recommended range for C soils in Feldman (2000) (Figure 80). It is important to recognize that the calibrated infiltration rates were derived using daily precipitation values. It is well known that infiltration processes operate on a timescale much smaller than one day, likely on the order of minutes or less (Kandel et al. 2004). Using daily precipitation increments can be challenging because precipitation intensity is averaged to a uniform intensity for 24 hours. This effectively depresses in HEC-HMS the hourly infiltration rate parameter necessary to generate rainfall excess matching observed runoff. Disaggregating daily precipitation to increments closer to the process scale using statistical approaches may improve estimates of true hourly infiltration rates during periods without snow cover (Kandel et al. 2004). However, the effects of snow cover, precipitation interception, and snow melt introduce complex processes that are difficult to resolve for small increments of time at basin scale. The model was therefore calibrated using a 
daily time step. Since the model was calibrated to daily precipitation values, caution should be used when comparing with hourly infiltration rates.

\subsection{Calibration of the FSIM $\beta$ parameter}

The FSIM $\beta$ parameter is a site-specific value that represents the infiltration-reduction capacity of a soil with a soil moisture below the permanent wilting point as a result of the soil freezing. Using the February 1962 event as the calibration point, $\beta$ can be estimated with the FSIM-SMM-calculated soil moisture antecedent to the event, the calibrated infiltration rate during the event $\left(\mathrm{INF}_{\mathrm{a}}\right)$, and the calibrated infiltration rate during the unfrozen event in 2004 (INF), see Equation (14). In this case, $\beta$ is estimated to be 0.96. This implies that when the soil is dry (below the permanent wilting point of approximately $0.0148 \mathrm{~m}^{3} \mathrm{~m}^{-3}$ ), the transition from unfrozen to frozen ground state does not have a significant effect on infiltration. When soil moisture is higher than the permanent wilt point, water present in macropores freezes, physically obstructing infiltration. Calculated moisture content prior to a potential runoff event is an essential piece of information needed to estimate the infiltration rate when the ground is frozen.

\subsection{Application of the FSIM model to Willow Creek Watershed}

We used output from the FSIM-GTM and FSIM-SMM submodels to calibrate the FSIM model. The FSIM-GTM produced ground temperature and the FSIM-SMM produced soil moisture from the Idaho Falls 16 SE COOP station from 1960 to 2018 climatology data. FSIM produced a time series of ICRF over this period. Figure 93 presents histograms of that output. While there is typically little or no infiltration capacity reduction in the basin in winter, the likelihood of major infiltration reduction is not insignificant. Additions of liquid precipitation and snowmelt over the course of the winter contribute to increasing soil moisture contents, causing the lowest ICRF to occur in January and February. While early March soil moisture contents are typically the highest during the winter, thawing soils allow drainage processes to resume, which reduces soil moisture content and reduces the potential for runoff events that are significantly affected by frozen ground conditions. 
Figure 93. Frequency of average monthly infiltration capacity reduction factors.

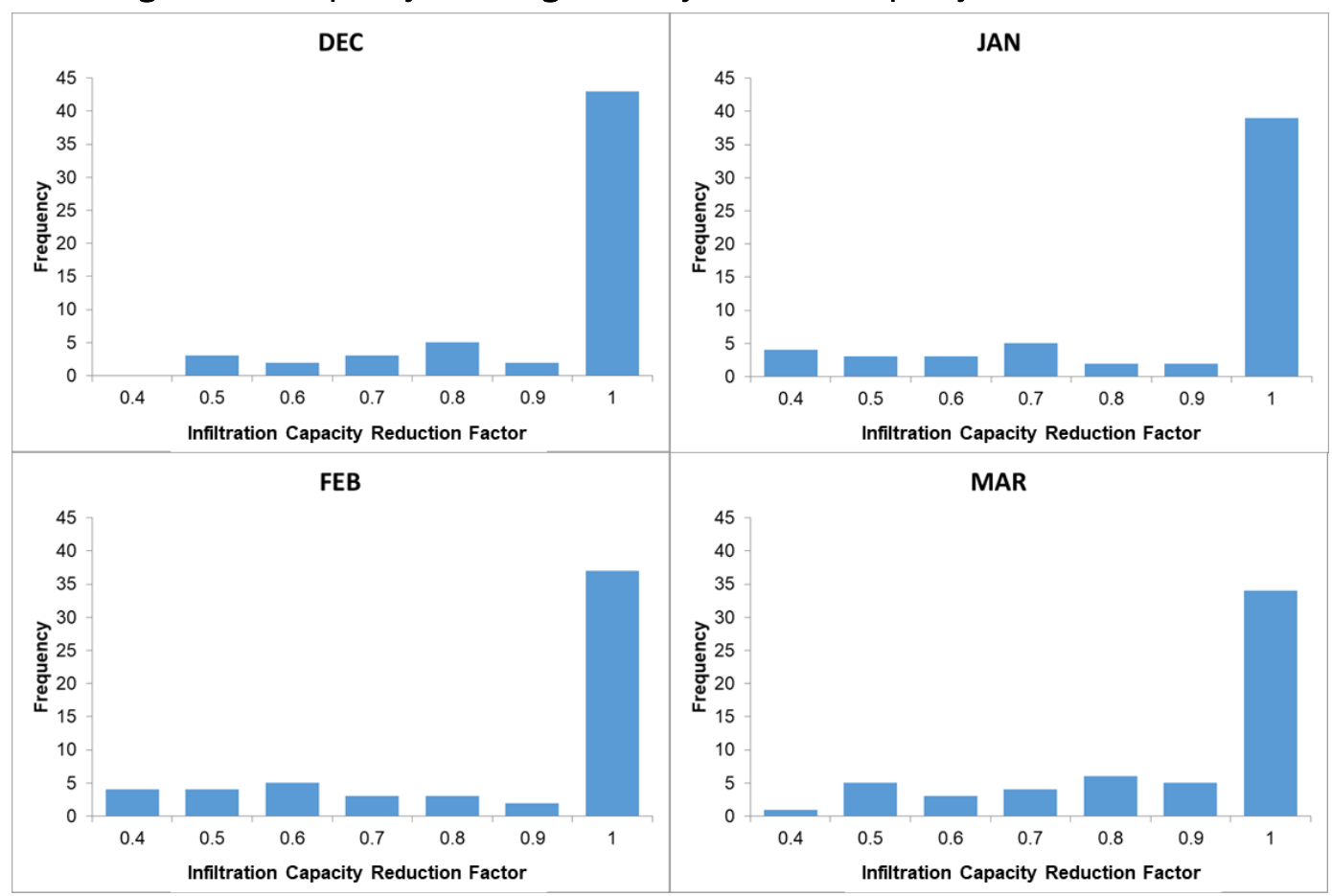

The FSIM model is calibrated to the February 1962 flood event. Ideally, the model would be validated with several similar events; however, a review of the Reclamation-calculated inflow record, which begins in 1976, revealed no additional winter flow events on the order of the 1962 event. We identified several above-average winter flow events; however, the peak flow rates of most of these events did not exceed 500 cfs. The HEC-HMS basin model was calibrated to two of the largest midwinter events observed, occurring on 20 February 1980 and 11 February 2017. The ICRF for the calibrated events was calculated and compared to the FSIM-modeled ICRF (Table 38).

Table 38. Infiltration capacity reduction factors for large winter flow events.

\begin{tabular}{|l|c|c|c|}
\hline Date & Peak Flow (cfs) & FSIM ICRF & Calibrated ICRF \\
\hline $20-F e b-80$ & 718 & 0.49 & 0.30 \\
\hline $11-F e b-17$ & 453 & 1.00 & 1.00 \\
\hline
\end{tabular}

For the 1980 event, the FSIM model results show a relatively dry fall preceding a mid-January thaw accompanied by rain, which elevated moisture content before refreezing. A second thaw in mid-February with precipitation and snowmelt caused soil moistures to rise again while the soil was still frozen, resulting in the calculated ICRF of 0.49 . This directly preceded 3 days with rainfall amounts ranging between 0.2 and $0.3 \mathrm{in} . /$ day falling 
on bare ground at Idaho Falls $16 \mathrm{SE}$. The calibrated value of 0.30 from HEC-HMS is lower than the FSIM value but is reasonably similar.

For the 2017 event, the FSIM model results show a very dry fall with frozen ground through the winter. There was essentially no soil moisture increase over the winter leading up to the February event. Bitter cold air temperatures in late January did not significantly depress the ground temperature due to the presence of a significant snowpack. A warm-up in early February accompanied by light rain thawed the slightly frozen ground before rainfall of approximately $0.7 \mathrm{in}$./day fell for 2 days, producing significant snow melt. Despite the large amount of LWASS (0.9-1.5 in./day) over the 2 days of rain, the observed runoff was relatively modest. Using the unlimited infiltration capacity of $1.5 \mathrm{in}$./day (calculated during the calibration phase) produced a runoff volume that was nearly identical to the Reclamation-calculated Ririe Reservoir inflow volume.

Attempts to calibrate the HMS model to smaller winter flow events did not yield conclusive results, primarily because the excess LWASS needed to match the Reclamation flow values was extremely small, on the order of $0.04 \mathrm{in}$./day or less. At these small volumes, the model results become very sensitive to minor variations in calculated snowmelt. This demonstrates that this approach should probably not be used to estimate the effects of frozen ground on infiltration during very small events without high confidence in the accuracy of the LWASS values.

\subsubsection{FSIM results for Willow Creek Watershed}

Table 39 presents the basic summary statistics of the ICRF calculated with FSIM. Ultimately the ICRF and associated infiltration rate will be sampled from a probability distribution and used in a realization of a HEC-HMS run within a Monte Carlo framework. This intended application necessitates the development of a probability distribution for ICRF.

Table 39. Summary statistics of the infiltration capacity reduction factor.

\begin{tabular}{|l|c|c|c|c|c|c|}
\hline \multicolumn{1}{|c|}{ Summary Statistics } & Oct & Nov & Dec & Jan & Feb & Mar \\
\hline Average & 1.00 & 0.96 & 0.89 & 0.83 & 0.82 & 0.84 \\
\hline Median & 1.00 & 0.98 & 0.96 & 0.96 & 0.96 & 0.96 \\
\hline Standard Deviation & 0.01 & 0.06 & 0.15 & 0.20 & 0.21 & 0.19 \\
\hline Minimum & 0.93 & 0.67 & 0.44 & 0.36 & 0.35 & 0.35 \\
\hline Maximum & 1.00 & 1.00 & 0.98 & 0.98 & 0.97 & 1.00 \\
\hline Coefficient of Variation & 0.01 & 0.06 & 0.16 & 0.24 & 0.26 & 0.22 \\
\hline
\end{tabular}


Figure 94 shows the exceedance probabilities of the ICRF by month. These curves were fit using local regression (LOESS) to create continuous functions describing the probabilities of ICRF by month (Table 40).

Figure 94. Percent exceedance plot for infiltration capacity reduction factors.

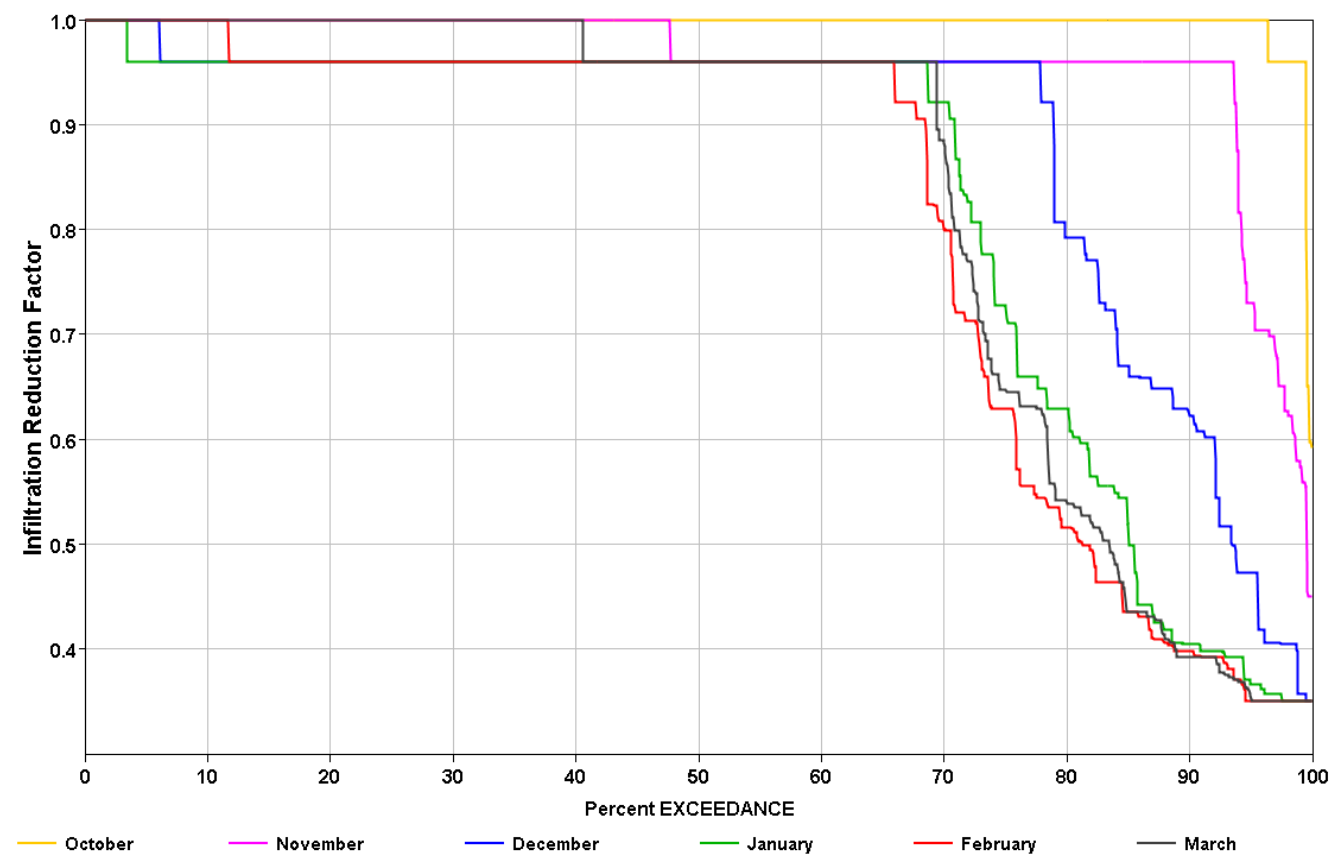

Table 40. Infiltration capacity reduction factor probabilities by month.

\begin{tabular}{|l|c|c|c|c|c|c|c|c|c|}
\hline & \multicolumn{8}{|c|}{ Percent Exceedance } \\
\cline { 2 - 10 } Month & $\mathbf{1 0}$ & $\mathbf{2 0}$ & $\mathbf{3 0}$ & $\mathbf{4 0}$ & $\mathbf{5 0}$ & $\mathbf{6 0}$ & $\mathbf{7 0}$ & $\mathbf{8 0}$ & $\mathbf{9 0}$ \\
\hline Oct & 1.000 & 1.000 & 1.000 & 1.000 & 1.000 & 1.000 & 1.000 & 1.000 & 1.000 \\
\hline Nov & 1.000 & 1.000 & 1.000 & 1.000 & 0.959 & 0.960 & 0.960 & 0.960 & 0.968 \\
\hline Dec & 0.958 & 0.960 & 0.960 & 0.960 & 0.960 & 0.960 & 0.960 & 0.822 & 0.624 \\
\hline Jan & 0.960 & 0.960 & 0.960 & 0.960 & 0.960 & 0.960 & 0.910 & 0.617 & 0.403 \\
\hline Feb & 0.998 & 0.960 & 0.960 & 0.960 & 0.960 & 0.960 & 0.796 & 0.518 & 0.397 \\
\hline Mar & 1.000 & 1.000 & 1.000 & 0.987 & 0.960 & 0.960 & 0.878 & 0.547 & 0.395 \\
\hline
\end{tabular}

When sampling for Monte Carlo simulations, the coupling of input parameters must be considered and conditional probabilities used if the sampled population is coupled with other populations being sampled. In the case of ICRF, the frozen ground state and soil moisture content are functions of the air temperature, precipitation, snow depth, and SWE time series leading up to the event. With the understanding that the ICRF will be used in simulations with a look-back window of only 10 days, it is reasonable to assume very little coupling with SWE. This assumption is supported by the 
series of events that preceded the February 1962 event, as detailed in the Ririe Project Design Memorandum (USACE 1966):

Flood causes were: (1) a period of several days of cold weather in January which caused frozen ground to depths of 2 to 3 feet; (2) snowstorms in early February that left several inches of snow on the ground; and (3) more or less continuous rainfall on 9-12 February, totaling 1.8 inches depth of water.

While significant SWE was present prior to the event, this was completely independent of the ground temperature state, which froze during a period when snow depths were much lower.

ICRF will have some potential coupling with the simulated temperature and precipitation time series; however, accounting for this would require inclusion of FSIM in the Monte Carlo framework, which is not practical at this time. In this case, it is necessary to assume that the sampled ICRF is applicable over the duration of the event.

There is a strong seasonality component evident in the ICRF probability distributions when broken down by month. With the understanding that the Monte Carlo simulation realizations will have dates associated with them, it would be more accurate to sample from monthly probability distributions rather than a seasonal average distribution.

We therefore recommend that the ICRF probability distributions be sampled independently of other sampled values, except for seasonality.

\subsection{Frozen ground summary}

We conducted this analysis to provide tools to quantify the effect of frozen ground on runoff in operational models. This is a challenging problem to address on a basin-wide scale where available forcing, calibration, and validation data are limited. Guidance for conducting this type of study is essentially nonexistent. Therefore, the CRREL FSIM aims to address this current gap in hydrologic modeling.

When selecting the methods used in FSIM, we sought models that captured physical processes while acknowledging the limitations set by having 
sparse input data. Output from FSIM was geared towards ease of integration for implementation in HEC-HMS.

FSIM was ultimately used to calculate a time series of ICRF and daily infiltration rates. This time series was used to create probability distributions of ICRF for each month of the winter, which can be used to directly sample for use in HEC-HMS simulations in a Monte Carlo framework. 


\section{Large-Precipitation-Event Characterization}

Extreme precipitation is the primary driver of high river flows and flooding during winter months in the Pacific Northwest. The main mechanism for producing precipitation extremes in this region is atmospheric rivers (ARs). ARs are corridors of intense water-vapor flux that are narrow in nature, on the order of approximately $100 \mathrm{~km}$ (62 miles) wide, but extend thousands of miles into the tropics or subtropics, tapping warmer temperatures and much higher water-vapor values. Water vapor is the important ingredient here. ARs are responsible for the vast majority of poleward moisture transport in relatively few filamentary bands around the globe (Zhu and Newell 1998). When this nearly saturated air impacts complex coastal terrain such as the Cascades Mountains or the Sierras of California, that air is forced upward and cooled, and water vapor is condensed into clouds and precipitation (Ralph et al. 2006; Stohl et al. 2008; Viale and Nuñez 2011; Neiman et al. 2011). Higher values of water vapor produce higher-intensity precipitation, so ARs are very efficient at producing extreme precipitation along the U.S. West Coast and in the Pacific Northwest, generally over the course of 18-72 hours (Warner et al. 2012).

ARs are an active area of ongoing research, and much has been learned about the climatology and dynamics of ARs along the U.S. West Coast and the Pacific Ocean Basin. It is well known, for instance, that ARs occur year-round (Neiman et al. 2008) but generally relate to flooding only when the moisture plume of an AR is associated with elevated horizontal wind (Ralph et al. 2011), happening in conjunction with a strong winter jet stream (Ralph et al. 2011; Warner et al. 2012; Cordeira et al. 2013). So, primary flooding season along the coastal United States is October through March. While there are good examples of flood-inducing storms during October and March, the peak of the season is from November to February (Warner et al. 2012). ARs that penetrate inland in the Pacific Northwest are largely beneficial in terms of water supply, rather than flood inducing (Ralph et al. 2019).

The dynamics of ARs are also fairly well understood at both regional (Neiman et al. 2008; Ralph et al. 2011; Warner et al. 2012) and local scales (Dettinger 2011; Neiman et al. 2011; Ralph et al. 2013). ARs are warm and moist sources of tropical water vapor that develop with storm systems (also 
referred to synonymously as frontal systems) able to tap the available moisture source and pull air into midlatitudes. Often, the combination of warm, moist air and strong temperature gradients associated with the frontal system can create a strong low-level jet stream (area of elevated horizontal wind speed) ahead of the cold front in neutrally buoyant air, producing the necessary water-vapor flux to cause intense precipitation (Ralph et al. 2004, 2005). The winter precipitation along the Pacific Northwest coast is evidence of the impact of ARs on the climatology of the coast and areas farther inland. During an AR event, elevated values of integrated water-vapor flux intersect the coast and come into contact with the terrain of the coastal mountain ranges. With very little resistance to upward motion (approximately neutral buoyancy), the mountains deflect the incoming air upward, cooling it as it rises. Since warmer air can hold more water vapor (Held and Soden 2006; O'Gorman and Muller 2010), this cooling causes the saturated air column to become supersaturated; and condensation occurs readily, creating clouds and precipitation. Even higher-precipitation efficiency occurs if the mountain barrier is oriented perpendicular to the incoming flux (Neiman et al. 2011). As the air column continues over the mountain crests, it warms and dries as it descends, and the relatively arid climate of Eastern Washington and Eastern Oregon results.

In some cases, an AR can be vertically deep enough, sufficiently intense, and oriented in just the right direction that elevated values of water vapor can make it farther inland and create extreme precipitation in places that are normally dry during the winter (Rutz et al. 2014, 2015). Although, integrated water-vapor values and precipitation are generally lower compared to those where an AR intersects the coast, the water-vapor and precipitation values are still anomalously high at locations downstream of coastal influence (Rutz et al. 2014). Rutz et al. $(2014,2015)$ also show that there are preferred locations along the coast and directions of approach of ARs that allow that elevated moisture content to areas inland, setting up ideal paths for ARs to channel the moisture into areas that would otherwise not receive values so high.

Finally, much has been made of a flooding event that occurred in February of 1962. This event was the flood of record in the Willow Creek Basin; and immediately after the event, USGS wrote a complete report detailing the conditions of this event. While the precipitation during this event was related to AR conditions in the prior couple of days, heavy precipitation was not the only important factor. While the basin above Ririe received $1.5 \mathrm{in}$. 
of rain over 3 days, the existing winter snow cover and frozen ground were essential factors contributing to flooding (Thomas and Lamke 1962).

Although some of the above work has shown broadly the impacts of winter ARs in the inland Pacific Northwest, previous studies have not conducted specific extreme precipitation analysis in southeast Idaho. The following analysis is meant to explore the source of some of the more extreme precipitation totals over Southeast Idaho and the Willow Creek Basin above Ririe Dam near Idaho Falls, Idaho. Our analysis examines typical largescale patterns that lead to extreme precipitation, including mean water-vapor availability, upper level winds, surface pressure, and midlevel temperatures. We established a thorough climatology from the historical record and identified the types of events that cause extreme precipitation in the basin. The following analysis is crucial to understanding the potential impacts of ARs and when those impacts are possible in Southeast Idaho.

\subsection{Large-precipitation-event data}

Our analysis started by examining over 40 observing stations discussed in chapters 3 and 4. Again, our discussion of large events relies on the Idaho Falls 16 SE weather station because of its location and precipitation representation to the Willow Creek Basin above Ririe Dam. As discuss previously, this station is located inside the Willow Creek Watershed (Figure 6), has a period of record spanning from November 1955 through the present, and has a nearly complete record with $98 \%$ coverage. For the purpose of this study and consistency with other datasets used, 62 complete years of record were utilized from January 1956 through December 2017. Furthermore, only "winter" months were examined, chosen here as the wet season from October 1 to March 31, since that is the season of interest based on current operations at Ririe Dam.

Climatological winter precipitation along the Pacific Coast is known to be greater in magnitude than precipitation farther inland, east of any Coastal Mountains, the Cascade Mountain Range in Washington and Oregon, and the Sierra Mountain Range in California (PRISM Climate Group 2020). Extreme winter events in the Willow Creek Basin were identified using the 72-hour total precipitation at the Idaho Falls 16 SE station. This storm duration was chosen due to low daily precipitation amounts in the relatively arid inland Northwest (e.g., southeast Idaho), the duration of precipitation extremes during winter months (Warner et al. 2012; Rutz et al. 2014), the correlation between precipitation durations and stream flow volumes 
(Warner et al. 2012), and the response time of Willow Creek hydrology to falling precipitation (roughly 19 hours). The 72-hour precipitation to identify extreme precipitation events in the Pacific Northwest is well documented in the literature related to ARs and Pacific Northwest hydrology (e.g., Warner et al. 2012).

The NOAA Physical Sciences Laboratory (PSL) provides an online tool to examine historical mean daily synoptic conditions or multiday composite conditions using the NCAR/NCEP (National Center for Atmospheric Research / National Centers for Environmental Prediction) Reanalysis Dataset available from 1948 to the present (Physical Sciences Laboratory 2020; Kalnay et al. 1996), covering our complete observed record at Idaho Falls $16 \mathrm{SE}$. The resolution of this global dataset is approximately $208 \mathrm{~km}$ (129 mile) with 28 vertical levels. Pressure and surface-level analyses are archived on a $2.5^{\circ} \times 2.5^{\circ}$ latitude-longitude grid. We used several variables in the Willow Creek Basin study, including mean sea-level pressure, $700 \mathrm{hPa}$ geopotential height, $500 \mathrm{hPa}$ geopotential height, $850 \mathrm{hPa}$ temperature, $700 \mathrm{hPa} u$ and $v$ winds, column-integrated water vapor, and all associated anomalies from climate normals from 1981 to 2010. We used the top 50 extreme 3-day precipitation events at the Idaho Falls 16 SE climate station for daily synoptic conditions and composites. Each event was identified by the middle day of the 72-hour period, and dates were eliminated if they were recognized to be temporally adjacent to days occurring higher in the list, specifically, within 5 days of another date previously identified. This ensured that all dates in the list were synoptically independent and the composites were not unduly influenced by a particular storm (set of synoptic conditions). Additionally, the dates composited were the ones that exhibited the greatest values of integrated water vapor at the coast, often occurring $0-3$ days prior to the middle day of the extreme precipitation period, and were located by visual inspection.

Due to limited NCAR/NCEP reanalysis product availability, a final variable, integrated water-vapor transport (IVT), was plotted using a similar online tool available through PSL. The North American Regional Reanalysis (NARR) product is a higher-resolution reanalysis dataset covering only North America and surrounding areas (including the eastern North Pacific Ocean) at about $0.5^{\circ}$ resolution at Pacific Northwest latitudes and is archived on 29 vertical pressure levels for 1979-present (Mesinger et al. 2006). The shorter temporal period prevented the use of this reanalysis 
exclusively, and composites of this variable include only a subset of the top fifty 72 -hour precipitation events.

\subsection{Large-precipitation-event results}

Table 41 lists the top 50 events in 72-hour precipitation at Idaho Falls 16 $\mathrm{SE}$, spanning the examined period winter months (October-March) from 1955 to 2017. (Use of the 72-hour event dates is based on the middle date, with precipitation totals by day and full period). Figure 95 breaks down these extreme precipitation dates by month and decade of occurrence. The highest number of storms (12) occurs in January with the months of October, November, and December roughly equally split (8-9). February and March have relatively fewer events and are equal in number (6). Splitting the top 50 events up by decade reveals a roughly equal number of storms per decade, save for the 1970 s (only 3) and, although our record starts in 1955 , latter half of the 1950 (no storms).

Similar results are found in Warner et al. (2012), but there are some differences. The peak number of events during the winter months is similar in both studies and of little surprise. The differences occur in the shoulder seasons. While the next most frequent months are November and December, there is a steep decline in October in the Warner et al. study. Similarly, on the decadal scale, the decline in the 1970s of extreme events identified in the present study is not surprising and matches previous literature (Chang et al. 2002; Chang and Fu 2002), primarily due to weaker storm tracks during those decades. However, we do not note a decline in the 1960 s when the storm track was also determined in previous analysis to be weaker and no events in the 1950 s despite a more active storm track during that decade (Chang et al. 2002; Chang and Fu 2002). There are likely a number of reasons for the differences between the present work and other studies, but the primary ones are that the current study is reviewing climate statistics at one location (rather than many) that is in interior southeast Idaho (rather than on the Pacific Coast). Additionally, Rutz et al. (2014) previously completed climatological frequency and duration analyses on the Western U.S. as a whole by with mixed results. Rutz et al. (2014) found similar monthly climatologies to Warner et al. (2012) and noted shorter-duration storms for the interior overall; however, those results varied depending on location throughout the west, and the location of interest here is not directly studied in the Rutz et al. (2014) analysis. 
Table 41. Top 50 dates for 72-hour precipitation totals (inches) at Idaho Falls SE 16 weather station in winter months (October-March). The date identified is Day 2 of the 72-hour period. The offset is given as the date used in the spatial composites. Dates noted by an asteriskare identified as non-AR days and are excluded from spatial composites.

\begin{tabular}{|c|c|c|c|c|c|}
\hline $\begin{array}{l}\text { Offset } \\
\text { (Days) }\end{array}$ & $\begin{array}{l}\text { Date } \\
\text { (Day 2) }\end{array}$ & $\begin{array}{l}\text { Day } 1 \\
\text { (in.) }\end{array}$ & $\begin{array}{c}\text { Day } 2 \\
\text { (in.) }\end{array}$ & $\begin{array}{c}\text { Day } 3 \\
\text { (in.) }\end{array}$ & $\begin{array}{l}\text { Total 3-Day Rain } \\
\text { (in.) }\end{array}$ \\
\hline-2 & 20-Jan-69 & 0.58 & 0.45 & 1.40 & 2.43 \\
\hline-2 & 23-Feb-98 & 2.00 & 0.00 & 0.25 & 2.25 \\
\hline 0 & 20-Nov-86 & 0.02 & 0.00 & 2.10 & 2.12 \\
\hline 0 & 3-Nov-08 & 0.72 & 0.04 & 1.26 & 2.02 \\
\hline-1 & 23-Dec-64 & 0.73 & 0.98 & 0.30 & 2.01 \\
\hline-3 & 14-Jan-03 & 0.80 & 0.90 & 0.17 & 1.87 \\
\hline-2 & 10-Jan-17 & 0.95 & 0.46 & 0.34 & 1.75 \\
\hline-2 & 26-Dec-08 & 1.53 & 0.08 & 0.12 & 1.73 \\
\hline-1 & 4-Mar-91 & 0.23 & 1.12 & 0.26 & 1.61 \\
\hline 0 & 31-Jan-63 & 0.11 & 0.96 & 0.53 & 1.60 \\
\hline-2 & 11-Feb-62 & 0.68 & 0.74 & 0.13 & 1.55 \\
\hline 1 & 16-Feb-86 & 0.75 & 0.49 & 0.29 & 1.53 \\
\hline 0 & 27-Dec-96 & 0.55 & 0.47 & 0.47 & 1.49 \\
\hline 0 & 11-Jan-80 & 1.10 & 0.00 & 0.37 & 1.47 \\
\hline-2 & 1-Jan-06 & 0.95 & 0.03 & 0.46 & 1.44 \\
\hline-1 & 20-Jan-12 & 0.02 & 1.09 & 0.32 & 1.43 \\
\hline-3 & 16-Oct-16 & 0.16 & 0.71 & 0.56 & 1.43 \\
\hline-1 & 25-Oct-10 & 0.72 & 0.64 & 0.05 & 1.41 \\
\hline-1 & 1-Dec-12 & 0.46 & 0.00 & 0.90 & 1.36 \\
\hline-1 & 2-Jan-97 & 0.09 & 1.15 & 0.11 & 1.35 \\
\hline 0 & 5-Oct-1994* & 0.18 & 0.92 & 0.22 & 1.32 \\
\hline-2 & 9-Feb-17 & 0.00 & 0.70 & 0.62 & 1.32 \\
\hline-2 & 21-Dec-81 & 0.74 & 0.04 & 0.52 & 1.30 \\
\hline-1 & 2-Oct-15 & 0.00 & 0.98 & 0.31 & 1.29 \\
\hline-1 & 13-Jan-69 & 0.73 & 0.14 & 0.41 & 1.28 \\
\hline-2 & 26-Nov-64 & 0.37 & 0.80 & 0.08 & 1.25 \\
\hline 0 & 1-Oct-1971* & 0.46 & 0.72 & 0.06 & 1.24 \\
\hline 0 & 28-Dec-10 & 0.04 & 0.00 & 1.20 & 1.24 \\
\hline-1 & 21-Mar-95 & 0.00 & 1.21 & 0.01 & 1.22 \\
\hline-2 & 31-Mar-10 & 1.19 & 0.00 & 0.03 & 1.22 \\
\hline-2 & 4-Oct-67 & 0.38 & 0.00 & 0.83 & 1.21 \\
\hline-2 & 11-Mar-95 & 0.16 & 0.26 & 0.79 & 1.21 \\
\hline-2 & 3-Jan-96 & 0.01 & 0.00 & 1.20 & 1.21 \\
\hline-1 & 13-Nov-88 & 0.40 & 0.50 & 0.30 & 1.20 \\
\hline-1 & 23-Nov-81 & 0.35 & 0.09 & 0.75 & 1.19 \\
\hline 0 & 26-Mar-71 & 0.02 & 0.95 & 0.22 & 1.19 \\
\hline
\end{tabular}




\begin{tabular}{|c|c|c|c|c|c|}
\hline $\begin{array}{c}\text { Offset } \\
\text { (Days) }\end{array}$ & $\begin{array}{c}\text { Date } \\
\text { (Day 2) }\end{array}$ & $\begin{array}{c}\text { Day 1 } \\
\text { (in.) }\end{array}$ & $\begin{array}{c}\text { Day 2 } \\
\text { (in.) }\end{array}$ & $\begin{array}{c}\text { Day 3 } \\
\text { (in.) }\end{array}$ & $\begin{array}{c}\text { Total 3-Day Rain } \\
\text { (in.) }\end{array}$ \\
\hline-1 & $25-$ Nov-89 & 0.45 & 0.01 & 0.72 & 1.18 \\
\hline 0 & $29-J a n-06$ & 0.31 & 0.00 & 0.86 & 1.17 \\
\hline 0 & $21-$ Nov-98 & 0.00 & 0.32 & 0.84 & 1.16 \\
\hline 0 & $19-$ Oct-07 & 0.00 & 0.20 & 0.95 & 1.15 \\
\hline-1 & $25-$ Nov-70 & 0.48 & 0.51 & 0.14 & 1.13 \\
\hline 0 & 12-Dec-95 & 0.03 & 0.70 & 0.40 & 1.13 \\
\hline 0 & 6-Oct-2006* & 0.25 & 0.53 & 0.33 & 1.11 \\
\hline 0 & 1-Mar-2014* & 0.53 & 0.34 & 0.24 & 1.11 \\
\hline 0 & 21-Jan-67 & 0.12 & 0.46 & 0.53 & 1.11 \\
\hline 0 & 15-Feb-82 & 0.40 & 0.20 & 0.50 & 1.10 \\
\hline-2 & 22-Oct-61 & 0.87 & 0.11 & 0.11 & 1.09 \\
\hline 0 & 29-Dec-03 & 0.37 & 0.40 & 0.32 & 1.09 \\
\hline-1 & 23-Nov-88 & 0.13 & 0.89 & 0.04 & 1.06 \\
\hline-1 & 20-Feb-68 & 0.26 & 0.47 & 0.33 & 1.06 \\
\hline
\end{tabular}

Figure 95. Top 50 3-day precipitation events at Idaho Falls 16 SE by month (left) and decade (right).

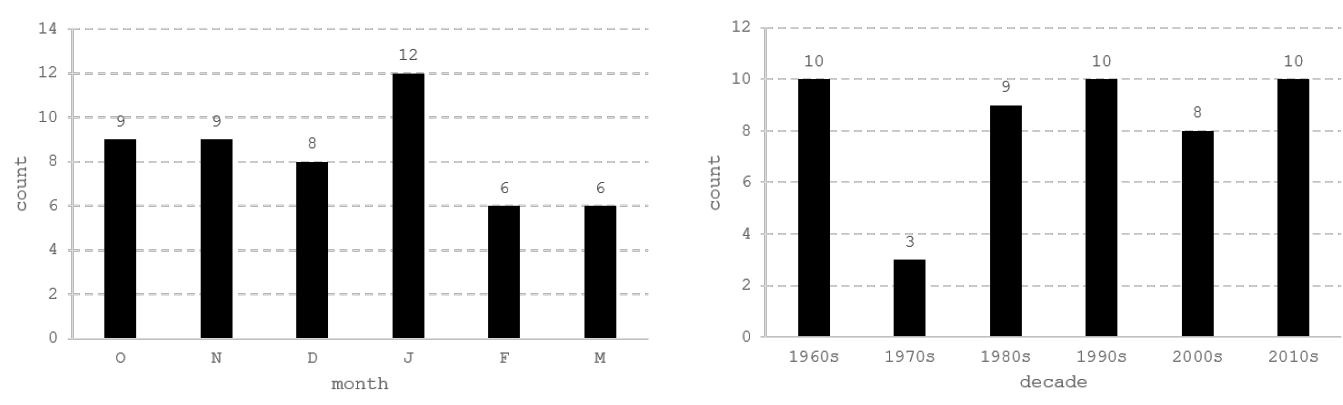

We examined the spatial distribution of several variables for days surrounding the top fifty 72 -hour precipitation totals. In 46 of these events, there was an AR event apparent in the integrated water-vapor field in the Pacific Ocean off the coast of California within a three-day window surrounding the middle day of the period. For a sample of these individual days, see Figure 96. Examining integrated water-vapor fields during days prior to maximum precipitation ensured that any water vapor present in Southern Idaho was related to ARs originating from the Pacific Ocean. This observation is also verified in other variables that exhibit classic AR traits, discussed in more detail below. The four non-AR events occurred during the shoulder seasons in the first week of October or the last week of March and were related to relatively strong spring or autumn convection, which is fairly common during those months. For these reasons, we did not include those events in the analysis and do not discuss them further. 
Figure 96. Integrated water vapor $\left(\mathrm{kg} / \mathrm{m}^{2}\right)$ for the top four dates for 72 -hour precipitation at Idaho Falls 16 SE using the NCAR/NCEP Reanalysis tool.

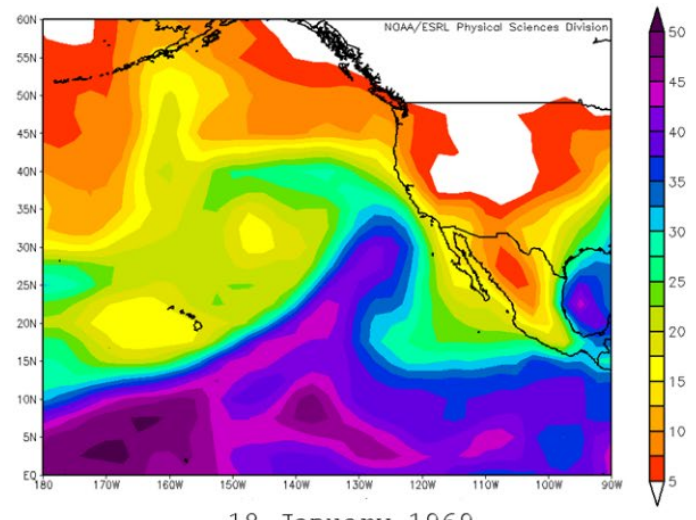

18 January 1969

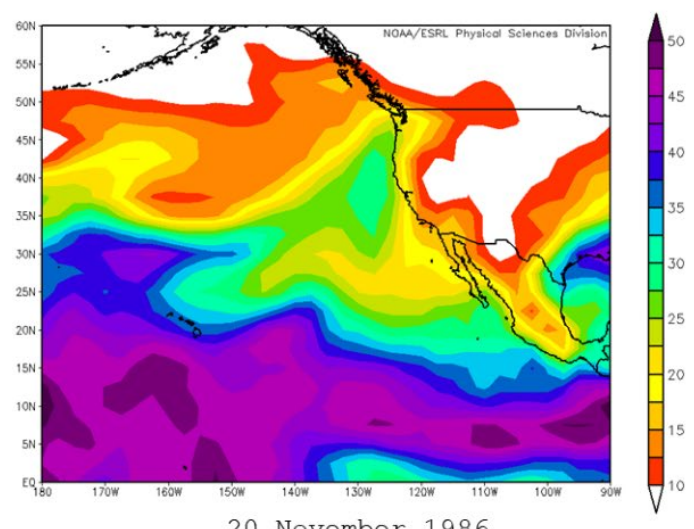

20 November 1986
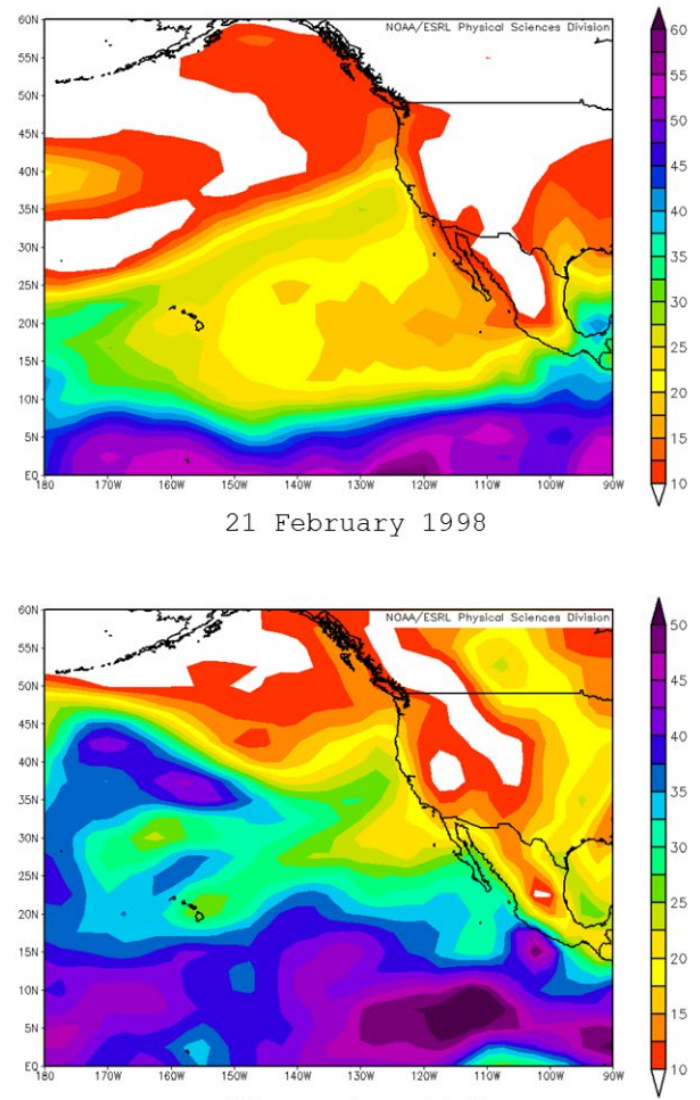

03 November 2008

Composites of integrated water vapor for $46 \mathrm{AR}$ events show a clear AR signature extending from the California coast into the Pacific Ocean towards the Hawaiian Islands. The plume intersects the coast at roughly central California off the coast of San Francisco and extends into the Pacific to the southwest (Figure 97), with the highest integrated water-vapor values just offshore. The majority of individual AR days also exhibit similar synoptic patterns. While the values appear to be highest offshore of the coast, many hundreds of miles away from southeast Idaho, the composite integrated water-vapor anomalies extend well into the area of interest (Figure 98). As previously stated, the water vapor from that direction intersects the coast south of the main Oregon Coast Range and largely squeezes through a narrow pathway to the north of the High Sierras located a bit farther inland. This water vapor tends to end up in southeast Idaho $0-3$ days after the peak intensity of the AR off the California coast (Table 41). 
Figure 97. Integrated water-vapor $\left(\mathrm{kg} / \mathrm{m}^{2}\right)$ composite of the top 46 dates in 3day precipitation at Idaho Falls 16 SE using the NCAR/NCEP Reanalysis tool.

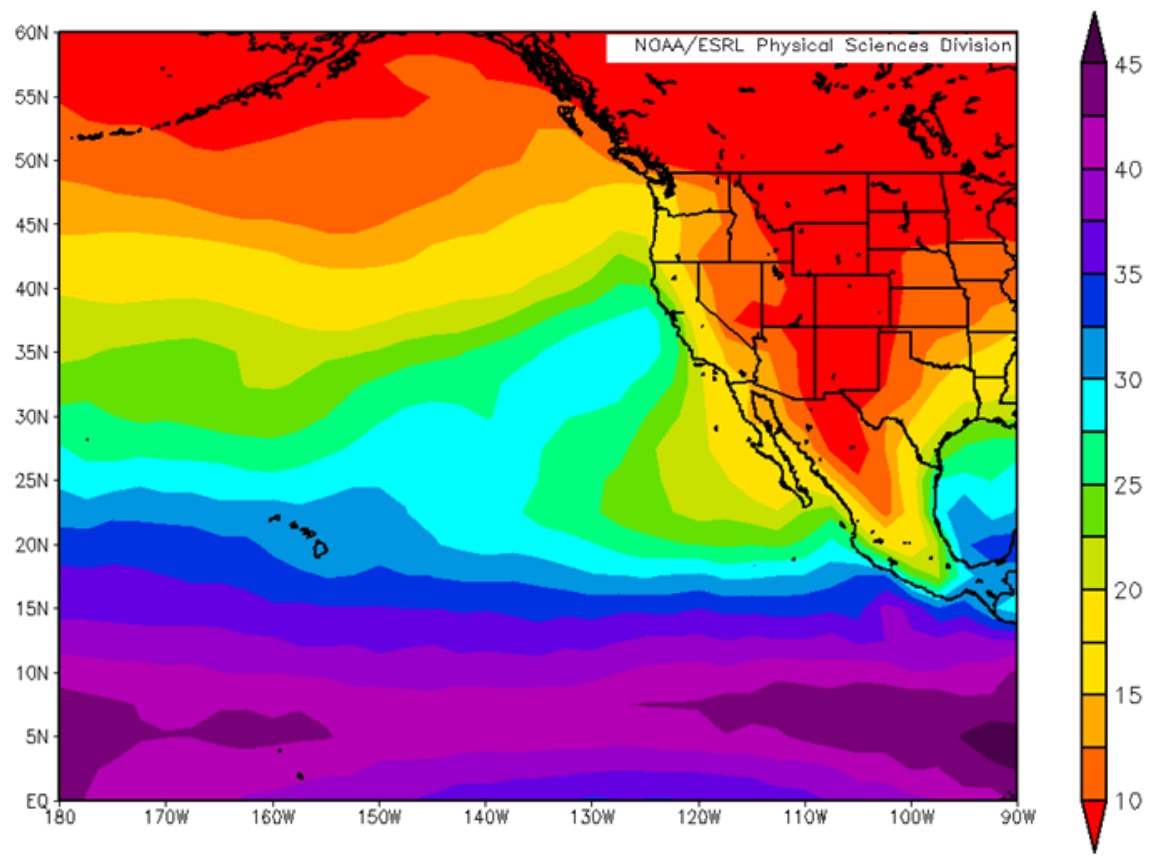

Figure 98 . Integrated water-vapor $\left(\mathrm{kg} / \mathrm{m}^{2}\right)$ anomaly composite (1981-2010 climatology) of the top 46 dates in 3-day precipitation at Idaho Falls $16 \mathrm{SE}$ using the NCAR/NCEP Reanalysis tool.

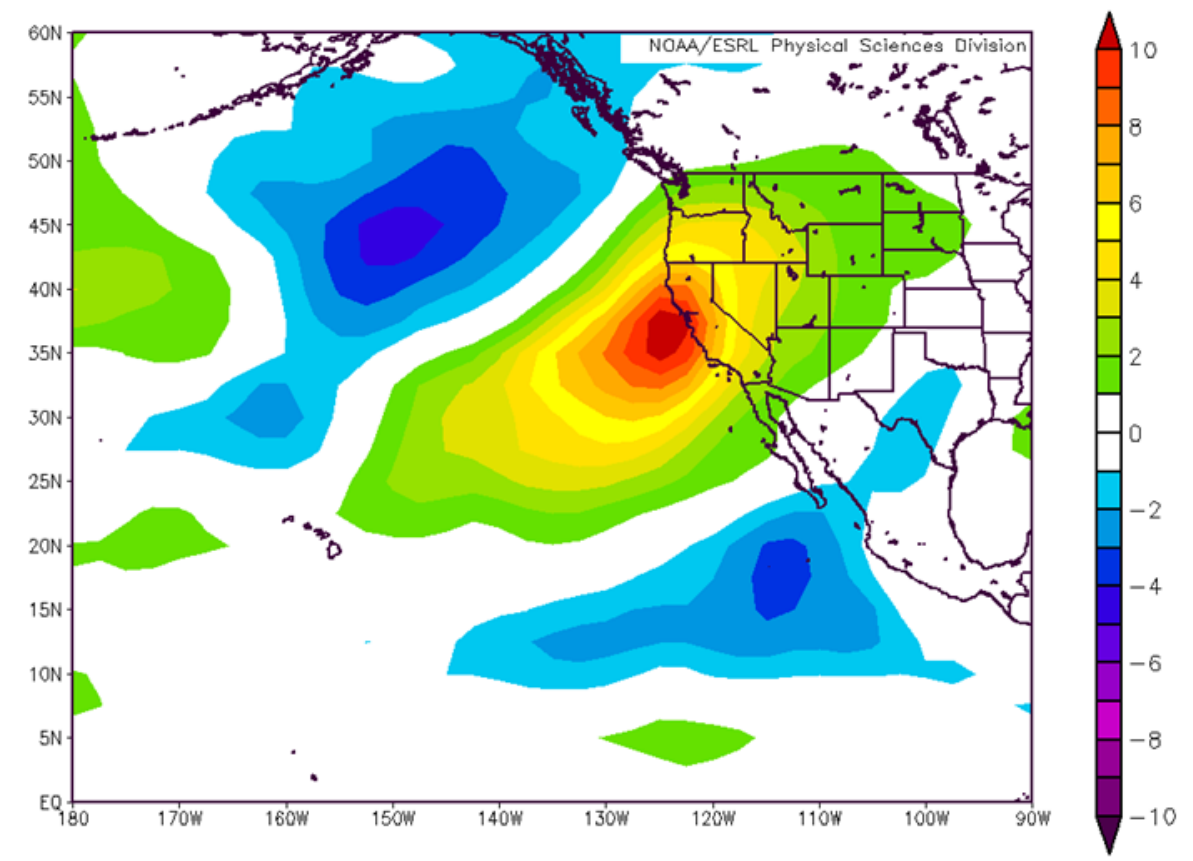

While integrated water vapor is a useful variable and a good proxy for heavy precipitation (Ralph et al. 2004), it is only part of the story. The other necessary component is a strong wind that can direct water vapor 
into complex terrain and force rising motion. The $700 \mathrm{hPa}$ geopotential height composites (roughly $3 \mathrm{~km}$ (1.86 mile) above the surface and just above the highest terrain) of the top 46 events indicate a trough axis offshore between longitudes $135^{\circ} \mathrm{W}$ and $140^{\circ} \mathrm{W}$ and downstream ridging between $115^{\circ} \mathrm{W}$ and $120^{\circ} \mathrm{W}$ (Figure 99). This places southeast Idaho in the ideal position for extreme rainfall associated with ARs (Rutz et al. 2014; Neiman et al. 2008). At the $700 \mathrm{hPa}$ level, the winds roughly parallel the geopotential height contours (isopleths), providing a southwesterly wind along the core of the jet stream above it and ample upper-level dynamical support for heavy precipitation nearer the surface (Figure 100). The combined effects of wind and precipitable water throughout the atmospheric column are known as IVT and are the primary variable for AR identification (Neiman et al. 2002, 2008; Ralph et al. 2006, 2013; Viale and Nuñez 2011). IVT for the available extreme events at Idaho $16 \mathrm{SE}$ indicates strong water-vapor-flux anomalies $\left(75^{-120 ~} \mathrm{~W} \mathrm{~s}^{-3}\right.$ or $\left.\mathrm{kg} \mathrm{m}^{-1} \mathrm{~s}^{-1}\right)$ into the intermountain west and southeast Idaho (Figure 101), consistent with AR conditions and the other variables.

Figure 99. A $700 \mathrm{hPa}$ geopotential height $(\mathrm{m})$ composite of the top 46 dates in 3-day precipitation at Idaho Falls 16 SE using the NCAR/NCEP Reanalysis tool.

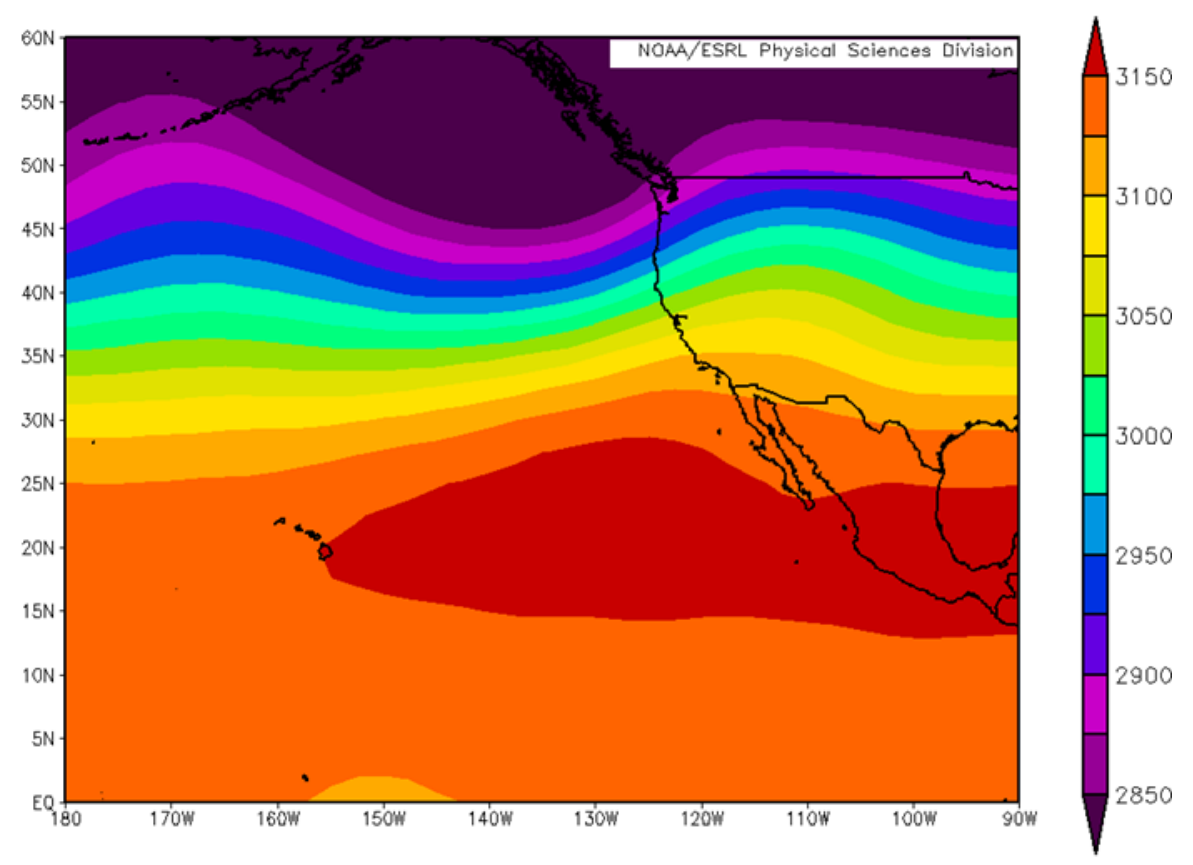


Figure 100. A $700 \mathrm{hPa}$ vector wind and wind speed $(\mathrm{m} / \mathrm{s})$ composite of the top 46 dates in 3-day precipitation at Idaho Falls 16 SE using the NCAR/NCEP Reanalysis tool.

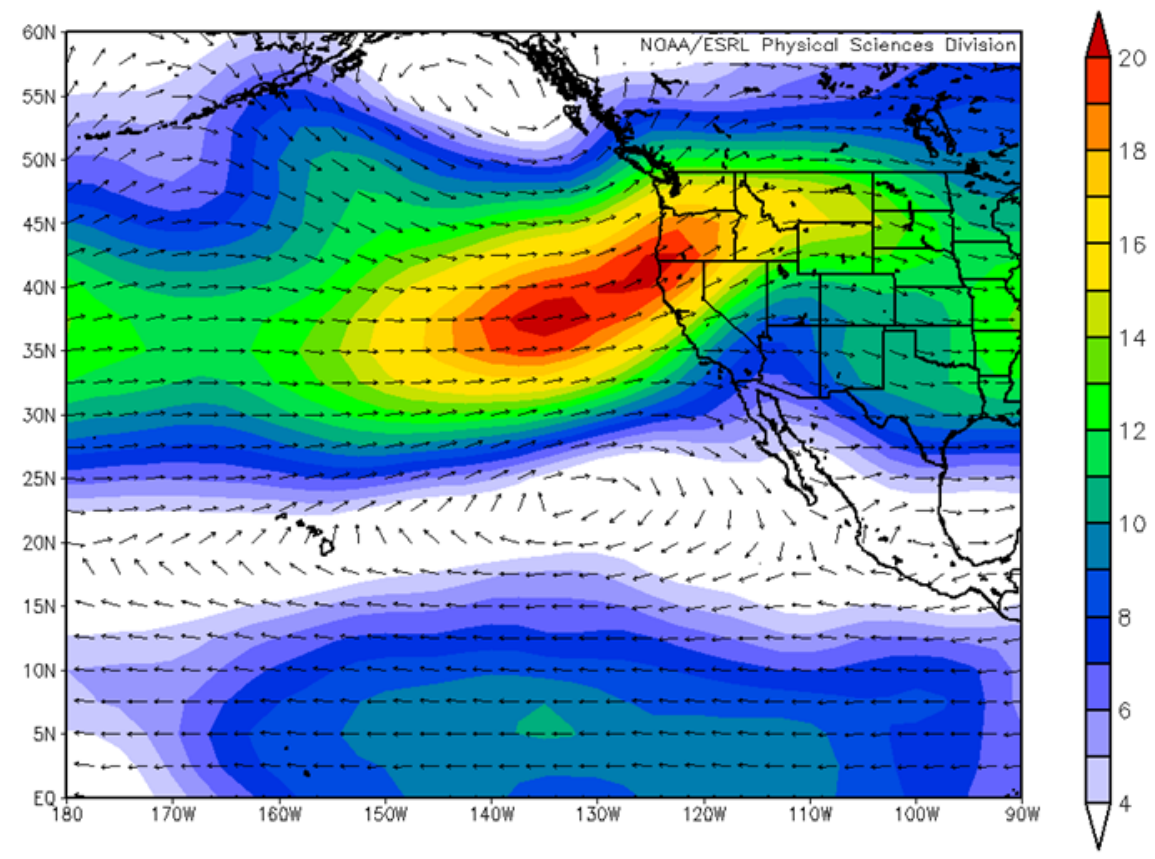

Figure 101. Vector wind and IVT $\left(\mathrm{kg} \mathrm{m}^{-1} \mathrm{~s}^{-1}\right)$ composite of the top 34 available dates in 3-day precipitation at Idaho Falls 16 SE during 19792017 using the NCAR/NCEP Reanalysis tool.
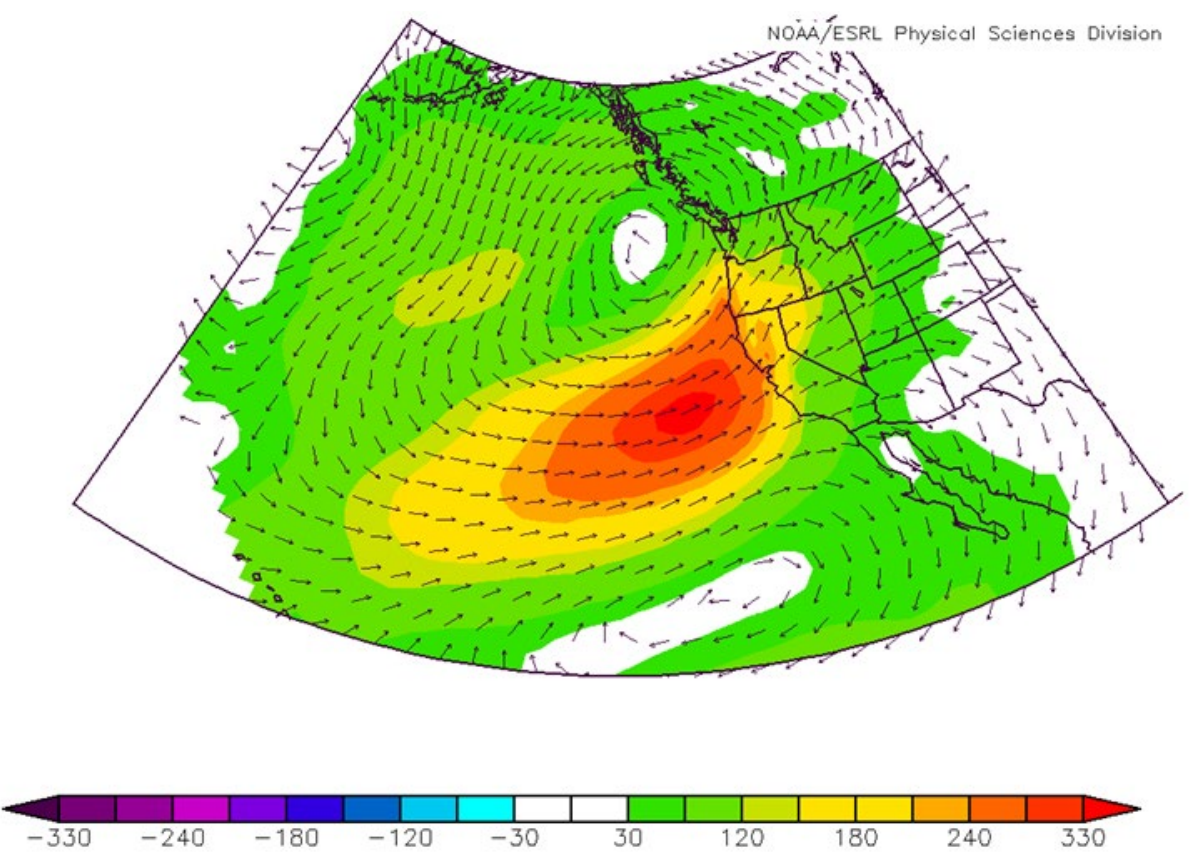
The final key ingredient to AR-related heavy precipitation is anomalously high temperatures. Water-vapor holding capacity in the atmosphere increases as temperature increases, so above-normal temperature is necessary for above-normal winter moisture availability and resultant heavy precipitation. The $850 \mathrm{hPa}$ temperature anomalies for the 46 extreme precipitation events at Idaho Falls $16 \mathrm{SE}$ indicate a clear positive temperature anomaly bullseye over southeast Idaho (Figure 102) of over 4 Celsius, a complimentary indication of AR conditions. On average, this is an increased temperature above normal of greater than $7^{\circ} \mathrm{F}$, in most cases making the temperature during individual cases well above freezing so that all of the associated precipitation falls as rain rather than snow. Positive temperature anomalies associated with AR conditions are well documented aspects of extreme precipitation events (Ralph et al. 2004, 2005; Neiman et al. 2008) and were associated with the February 1962 event as well. Our analysis showed increases in temperatures for the 46 events over time as the AR approaches (Figure 103). This summary temperature time series reveals the complex nature of the atmosphere as it evolves with the passage of the AR. As water-vapor content in the atmosphere increases with the approach of the AR in days ahead of the maximum 72-hour precipitation, overnight temperatures (minimum temperature) cannot as effectively decrease as more of Earth's outgoing radiation is "trapped" in the atmosphere, keeping the minimum temperatures higher and the temperature range smaller. As the AR and trailing cold front pass through the area, minimum and maximum temperatures cool, and the atmosphere dries out, expanding the overall temperature range. This behavior can also be seen in the variance boxplot for all 50 extreme events (Figure 103). In the days before the event, the variance is high since each individual event has a different synoptic signature. At the time of the event, the synoptic structure is similar for each event, and the AR is in its ideal location for maximum precipitation. In the days following the event, the individual storms evolve differently, and the variance increases again. 
Figure 102. An $850 \mathrm{hPa}$ temperature $\left({ }^{\circ} \mathrm{C}\right)$ anomaly composite (1981-2010 climatology) of the top 46 dates in 3-day precipitation at Idaho Falls $16 \mathrm{SE}$ using the NCAR/NCEP Reanalysis tool.

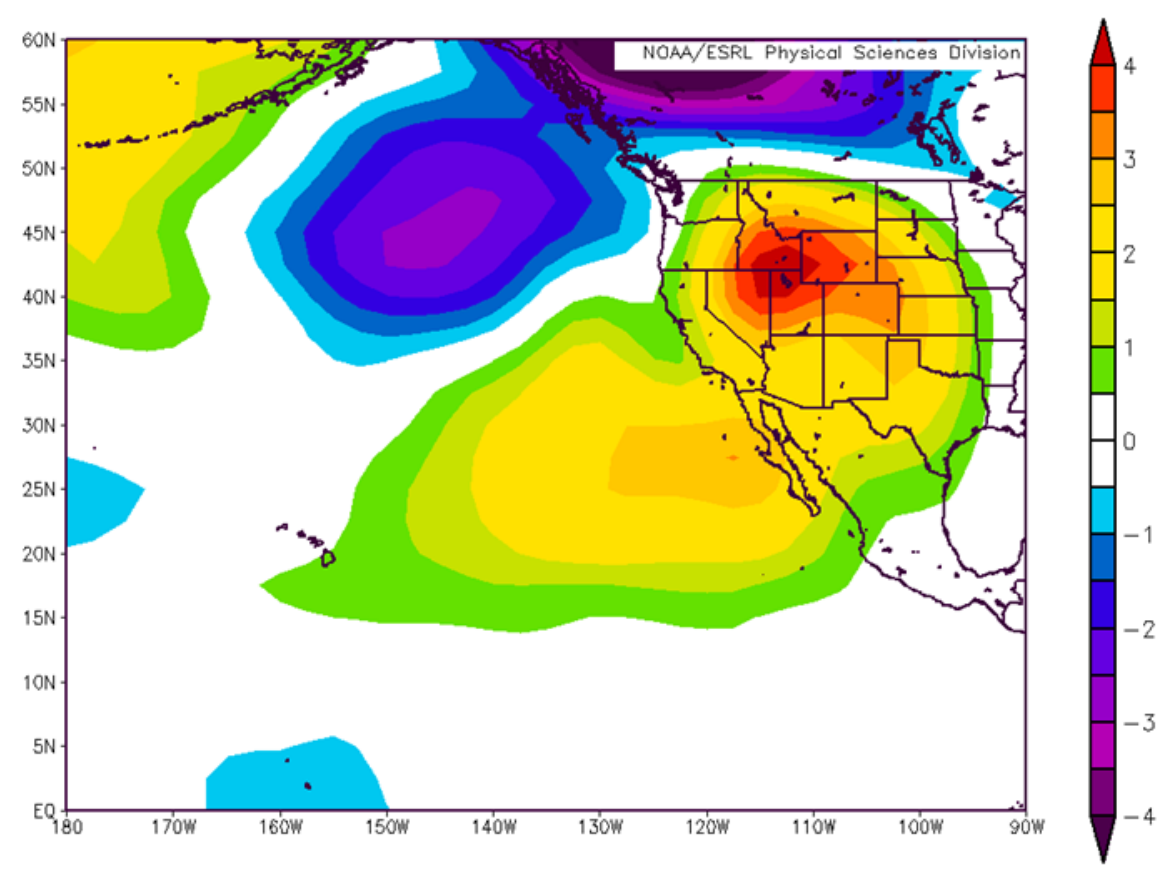

Figure 103. Observed maximum (red) and minimum (b/ue) temperature evolution (left) for \pm 5 days surrounding the center day of 3-day precipitation for the top 50 events at Idaho Falls $16 \mathrm{SE}$, and maximum (red) and minimum (b/ue) temperature evolution boxplots (right) for \pm 5 days surrounding the center day of 72-hour precipitation for the top 50 events at Idaho Falls 16 SE.
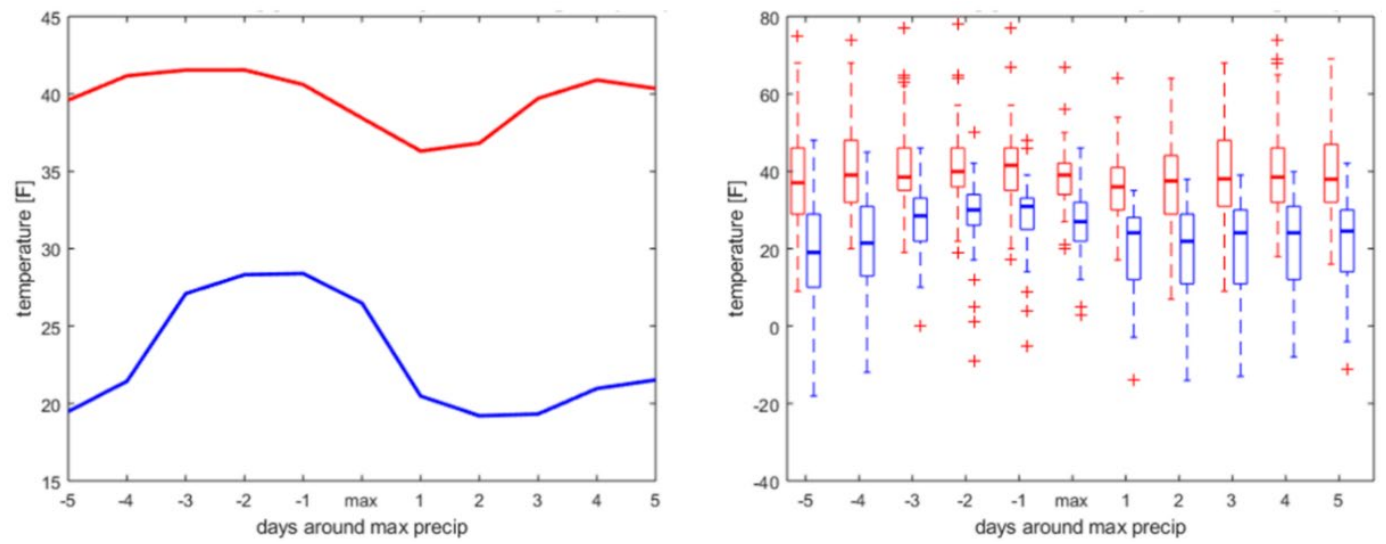

\subsection{Large-precipitation-event summary}

From this analysis, it is clear that the main threat for winter extreme rain events in eastern Idaho and the Willow Creek Basin are ARs. Of the top 50 precipitation events at a climate station inside the Willow Creek Watershed, precipitation related to ARs was responsible for the vast majority (46 events). Of the events that were not associated with ARs, those events were 
convective in nature and in either early October or late March. Extreme precipitation-related AR events can occur throughout the winter season, occurring most frequently in January but significantly apparent in all other winter months.

The February 1962 flooding event on Willow Creek was due to AR-related heavy rain falling on frozen ground, indicating that ARs, while generally anomalously warm for the winter season, can occur quickly enough that the associated precipitation cannot readily infiltrate as the ground does not have time to sufficiently thaw. The magnitude and severity of runoff that occurs is likely more a function of how frozen the ground is and the existing snow cover, rather than the magnitude of the precipitation. However, the combination of all three of those factors (extreme precipitation, frozen ground to some depth, and snow cover-enough to melt and add to the runoff but not too much so that it mainly absorbs much of the falling precipitation) is a recipe for the greatest runoff, which is what the Willow Creek Basin experienced in February 1962. There are examples of these types of events at various magnitudes throughout the winter months. On average, 1-2 heavy precipitation events associated with ARs occur each year (Rutz et al. 2014) and there is no reason that these events cannot occur in association with frozen ground in any given year (average high temperatures in Idaho Falls, the nearest large city, are generally below zero for much of December through early February), causing a flood with magnitudes equal or greater than the 1962 flooding event. The fact that it has not happened in recent years is not an indication that it will not happen in the future or that it is so rare as to not warrant heightened concern.

Finally, the synoptic situations capable of producing water-vapor plumes that have the potential to enter the Willow Creek Basin are conditions that occur on a fairly regular basis along the California coast. With a peak in January, during a time when interior high temperatures are climatologically below freezing, the Central California coast regularly receives ARs oriented from the southwest to the northeast. This flux of water vapor likely makes it through a narrow gap to the south of the Oregon coastal range and around the north end of the High Sierra, allowing it to penetrate into the deep Interior West and southeast Idaho. However, wind direction is not the only important factor. Wind intensities of significant magnitude contribute to more-intense integrated water-vapor flux, likely deep enough to get over or through the complex terrain and into the intermountain region of Idaho. This dynamic situation coupled with positively anomalous 
temperatures and elevated water vapor can create ideal AR conditions and heavy precipitation.

Extreme precipitation is one of the main contributing factors for flooding in the Willow Creek Basin above Ririe, but there are others. Certainly, the soil conditions and snow cover are two important ones. The analysis contained in this section is meant to cover only the precipitation aspect, and additional analysis and modeling is necessary for conclusions regarding final runoff. The main conclusion should be that AR conditions are what cause heavy precipitation, primarily falling as rain, and the precipitation can easily fall on frozen ground at any time during the winter months. 


\section{Summary}

Ririe Dam and Reservoir in eastern Idaho is an important project for both flood risk management and water supply in the Upper Snake River Basin. The project was designed and constructed following the 1962 flood event that devastated communities in eastern Idaho and northern Nevada. The current reservoir operating criteria requires a fixed amount of reservoir storage be evacuated going into the winter to reduce the chances of winter floods. However, the fixed storage requirement affords limited flexibility for water managers to balance flood risk management and refill for water supply. Within this context, our study objectives were to provide input data necessary to perform hydrologic model simulations within a Monte Carlo framework for USACE-NWW. These inputs include subbasin-averaged precipitation and SWE quantiles for a range of probabilities, estimates of flow enhancement probability due to frozen soils, and a description of the overall meteorological conditions that result in large winter precipitation events for Willow Creek.

We performed a precipitation frequency analysis by using a regional frequency framework that used ground-based stations. The zonally averaged values were derived using subbasin boundaries concurrent with the hydrologic model that will be used within the Monte Carlo framework. The precipitation quantiles were estimated using the GEV distribution, which we found to be the best overall fit for the ground-based datasets. The quantile estimates were then reduced using an ARF, which accounts for spatial heterogeneity within storm events. The zonally averaged data compare well with the NOAA-published values in the area.

There are limited choices for SWE datasets that can be used to represent spatially averaged SWE depths. For our analysis, we selected a daily spatially continuous dataset developed by researchers at the UA. This dataset has a $4 \mathrm{~km}$ spatial resolution similar to PRISM and has values dating back to 1982. The ground-based stations and SNODAS were both used to ensure that the UA dataset reasonably represented snowpack conditions within the Willow Creek Basin. The SWE quantiles were estimated using a lognormal distribution. The resulting quantile comparisons between UA and SNODAS were very similar for low and midelevation subbasins upstream of Ririe Reservoir, especially at the lower AEPs. For the highest elevation subbasin in the watershed, there was some deviation between the SNODAS and UA quantiles, which was likely due to the process by which 
SNODAS estimates SWE on open water. We used the PMSA method to develop the largest SWE depth reasonably possible for each of the subbasins considered in our study. Estimation of this value followed the WMO (1969) process. We anticipate that the lognormal quantiles will be used within the Monte Carlo framework; however, we have also included our PMSA results for all subbasins.

Frozen soil limited infiltration and was one of the documented causes of the 1962 flood in eastern Idaho. Although reduced infiltration during a precipitation event is qualitatively understood and supported by observational information, the quantification of how much flow enhancement will occur for specific frozen soil conditions is still a topic of continued research. Because frozen soil is critical for flood generation in the Willow Creek Basin, we developed a Frozen Soil Infiltration Model (FSIM) to help quantify changes in infiltration capacity depending on the ground temperature and soil moisture. This model is based on previous research, but the current formulation is novel and will be the first to be used within a Monte Carlo framework for hydrologic simulations. The model results indicate that infiltration-reduction capacity can be reduced by up to $70 \%$ in the Willow Creek Basin given specific temperature and precipitation conditions. Based on the model results, the likelihood of increased runoff due to frozen soils is highest in January through February each year.

Our study also characterized large precipitation events that reach the Willow Creek Basin. In general, most of the large precipitation events in October through March are due to inland penetration of ARs. These AR events form in the Pacific Ocean and usually make landfall on the California coast, moving from southwest to northeast. The peak precipitation intensity in the Willow Creek Basin is usually within 3 days of the storm reaching California. Although AR events are still an active area of research, changes in intensity or frequency of these storms will likely have an impact on winter precipitation for areas of eastern Idaho and the Willow Creek Basin.

As water resources, specifically water supply, become more valuable in the western U.S., USACE will need to evaluate flood risk for future requests for operational changes. Our study provides an example of how to do this, and our results provide the necessary inputs for hydrologic models to better define current flood risk for the Ririe Dam and Reservoir Watershed. Once the current flood risk is quantified, opportunities to develop a more effective and accurate water management plan are possible. 
While we reference USACE software during our development of precipitation, SWE, and soil-infiltration reduction factors due to frozen soils, these results can be used in most hydrologic modeling tools that requires similar inputs. Further, our results presented here focus on the Willow Creek Basin in eastern Idaho, but the methods can be used in other watersheds provided similar ground-based and gridded datasets are available. Even with climate change occurring, large regions of the U.S. will still experience freezing conditions in the winter months. The ability to better understand and quantify flooding potential due to snow and frozen ground is critical to ensure the safety of communities across the country. 


\section{References}

Appels, Willemijn M., Anna E. Coles, and Jeffrey J. McDonnell. 2018. "Infiltration into Frozen Soil: From Core-Scale Dynamics to Hillslope-Scale Connectivity.”

Hydrological Processes 32, no. 1 (November): 66-79. https://doi.org/10.1002/hyp.11399.

ASCE (American Society of Civil Engineers). 2010. Minimum Design Loads for Buildings and Other Structures (7-10). Prepared by the Committee on Minimum Design Loads for Buildings and Other Structures. ASCE/SEI 7-10. Reston, VA: American Society of Civil Engineers. https://ascelibrary.org/doi/book/10.1061/9780784412916\#.

Asquith, W. H., and J. S. Famiglietti. 2000. "Precipitation Areal-Reduction Factor Estimation Using an Annual-Maxima Centered Approach.” Journal of Hydrology 230, no. 1-2 (April): 55-69. https://doi.org/10.1016/S0022-1694(00)00170-0.

Bartles, Michael, Gary Brunner, Matthew Fleming, Beth Faber, Greg Karlovits, and Julia Slaughter. 2019. HEC-SSP Statistical Software Package User's Manual. Version 2.2. Davis, CA: U.S. Army Corps of Engineers, Hydrologic Engineering Center. https://www.hec.usace.army.mil/software/hec-ssp/documentation/HECSSP_22_Users_Manual.pdf.

Bell, Jesse E., Michael A. Palecki, C. Bruce Baker, William G. Collins, Jay H. Lawrimore, Ronald D. Leeper, Mark E Hall, et al. 2013. "U.S. Climate Reference Network Soil Moisture and Temperature Observations." Journal of Hydrometeorology 14, no. 3 (June): 977-88.https://doi.org/10.1175/JHM-D-12-0146.1.

Bonnin, G. M., D. Martin, B. Lin, T. Parzybok, M. Yekta, and D. Riley. 2011. NOAA Atlas 14, Precipitation-Frequency Atlas of the United States, Volume 1. Version 5.0. Silver Spring, Maryland: National Oceanic and Atmospheric Administration, and National Weather Service.

Broxton, Patrick, Nicholas Dawson, and Xubin Zeng. 2016. "Linking Snowfall and Snow Accumulation to Generate Spatial Maps of SWE and Snow Depth." Earth and Space Science 3, no. 6 (April): 246-56. https://doi.org/10.1002/2016EA000174.

Broxton, Patrick, Xubin Zeng, and Nicholas Dawson. 2019. Daily $4 \mathrm{Km}$ Gridded SWE and Snow Depth from Assimilated In-Situ and Modeled Data Over the Conterminous US. Version 1. Boulder, CO: NASA National Snow and Ice Data Center Distributed Active Archive Center. https://doi.org/10.5067/0GGPB220EX6A.

Carroll, Tom, Don Cline, Carrie Olheiser, Andy Rost, Anders Nilsson, Greg Fall, and Long Li. 2006. "NOAA's National Snow Analyses." Paper presented at the 74th Annual Meeting of the Western Snow Conference, Las Cruces, NM, 17-20 April 2006. https://www.nohrsc2.noaa.gov/technology/pdf/WSC_2006.pdf.

Carroll, Tom, Don Cline, Greg Fall, Anders Nilsson, Long Li, and Andy Rost. 2001. "NOHRSC Operations and the Simulation of Snow Cover Properties for the Coterminous U.S. Paper presented at the 69th Annual Meeting of the Western Snow Conference, Sun Valley, Idaho, 16-19 April 2001. https://www.nohrsc2.noaa.gov/technology/pdf/wsc2001.pdf. 
Chan, Steven, and R. Scott Dunbar. 2020. Enhanced Level 3 Passive Soil Moisture Product Specification Document. JPL D-56292. Pasadena, CA: National Aeronautics and Space Administration, Jet Propulsion Laboratory. https://nsidc.org/sites/nsidc.org/files/technical-references/PSD_SPL3SMP_E_V4.pdf.

Chang, Edmund K. M, Sukyoung Lee, and Kyle L. Swanson. 2002. "Storm Track Dynamics." Journal of Climate 15, no. 16 (August): 2163-83. https://doi.org/10.1175/1520-0442(2002)015<02163:STD>2.0.C0;2.

Chang, Edmund K. M., and Yunfei Fu. 2002. "Interdecadal Variations in Northern Hemisphere Winter Storm Track Intensity.” Journal of Climate 15, no. 6 (March):642-58. https://doi.org/10.1175/1520-0442(2002)015<0642:IVINHW>2.0.C0;2.

Cho, Eunsang, Jennifer M. Jacobs, and Carrie M. Vuyovich. (2019). "The Value of LongTerm (40 Years) Airborne Gamma Radiation SWE Record for Evaluating Three Observation-Based Gridded SWE Data Sets by Seasonal Snow and Land Cover Classifications." Water Resources Research 56, no. 1 (December): 1-23. https://doi.org/10.1029/2019WR025813.

Cordeira, Jason M., F. Martin Ralph, and Benjamin J.Moore. 2013. “The Development and Evolution of Two Atmospheric Rivers in Proximity to Western North Pacific Tropical Cyclones in October 2010.” Monthly Weather Review 141, no. 12 (December): 4234-55. https://doi.org/10.1175/MWR-D-13-00019.1.

Crow, W. T., R. Bindlish, and T. J. Jackson. 2005. "The Added Value of Spaceborne Passive Microwave Soil Moisture Retrievals for Forecasting Rainfall-Runoff Partitioning: Value of Spaceborne Soil Moisture.” Geophysical Research Letters 32, no. 18 (September): 1-5. https://doi.org/10.1029/2005GL023543.

Dawson, Nicholas, Patrick Broxton, and Xubin Zeng. 2018. "Evaluation of Remotely Sensed Snow Water Equivalent and Snow Cover Extent over the Contiguous United States." Journal of Hydrometeorology 19, no. 11 (November): 1777-91. https://doi.org/10.1175/JHM-D-18-0007.1.

Debs, I., D. Sparks, J. Rousselle, and S. Birikundavyi. 1999. "Évaluation des méthodes utilisées pour l'estimation de la crue maximale probable en régions nordiques [Evaluation of the Methods Used for the Estimation of the Probable Maximum Flood in Northern Regions].” Canadian Journal of Civil Engineering 26, no. 3 (June): 355-367. https://doi.org/10.1139/198-071.

Derksen, Chris, Xiaolan Xu, R. Scott Dunbar, Andreas Colliander, Youngwook Kim, John S. Kimball, T. Andrew Black, et al. 2017. "Retrieving Landscape Freeze/Thaw State from Soil Moisture Active Passive (SMAP) Radar and Radiometer Measurements." Remote Sensing of Environment 194, no. 1 (June): 48-62. https://doi.org/10.1016/j.rse.2017.03.007.

Dettinger, Michael. 2011. "Climate Change, Atmospheric Rivers, and Floods in California-A Multimodel Analysis of Storm Frequency and Magnitude Changes." Journal of the American Water Resources Association 47, no. 3 (June): 514-23. https://doi.org/10.1111/i.1752-1688.2011.00546.x. 
Diamond, Howard J., Thomas R. Karl, Michael A. Palecki, C. Bruce Baker, Jesse E. Bell, Ronald D. Leeper, David R. Easterling, et al. 2013. "U.S. Climate Reference Network after One Decade of Operations: Status and Assessment." Bulletin of the American Meteorological Society 94, no. 4 (April): 485-98. https://doi.org/10.1175/BAMS-D-12-00170.1.

Ellingwood, Bruce, and Robert Redfield. 1983. "Ground Snow Loads Structural Design.” Journal of Structural Engineering 109, no. 4 (April): 950-64. https://doi.org/10.1061/(ASCE)0733-9445(1983)109:4(950).

Feldman, Arlen D., ed. 2000.Hydrologic Modeling System HEC-HMS: Technical Reference Manual. CPD-74B. Davis, CA: U.S. Army Corps of Engineers, Hydrologic Engineering Center. https://www.hec.usace.army.mil/software/hec-hms $\angle$ documentation/HEC-HMS_Technical\%20Reference\%20Manual_(CPD-74B).pdf.

Follum, Michael L., Jeffrey D. Niemann, Julie T. Parno, and Charles W. Downer. 2018. “A simple Temperature-Based Method to Estimate Heterogeneous Frozen Ground within a Distributed Watershed Model." Hydrology and Earth System Sciences 22, no. 5 (May): 2669-88. https://doi.org/10.5194/hess-22-2669-2018.

Frankenstein, Susan, Anne Sawyer, and Julie Koeberle. 2008. "Comparison of FASST and SNTHERM in Three Snow Accumulation Regimes." Journal of Hydrometeorology 9, no. 6 (December): 1443-63. https://doi.org/10.1175/2008JHM865.1.

GDAL/OGR Contributors. 2020. GDAL/OGR Geospatial Data Abstraction Software Library. Open Source Geospatial Foundation. https://gdal.org.

Gelaro, Ronald, Will McCarty, Max J. Suárez, Ricardo Todling, Andrea Molod, Lawrence Takacs, Cynthia A. Randles, et al. 2017. "The Modern-Era Retrospective Analysis for Research and Applications, Version 2 (MERRA-2)." Journal of Climate 30, no. 14 (July): 5419-54. https://doi.org/10.1175/JCLI-D-16-0758.1.

Gray, D. M., and D. I. Norum. 1967. "The Effect of Soil Moisture on Infiltration as Related to Runoff and Recharge." In Proceedings of Hydrology Symposium No. 6: Soil Moisture, 133-53. Ottawa, ON: National Research Council Canada. http://citeseerx.ist.psu.edu/viewdoc/download?doi=10.1.1.724.7976\&rep=rep1\&type=pdf.

Gray, D. M., Brenda Toth, Litong Zhao, J. W. Pomeroy, and R. J. Granger. 2001. "Estimating Areal Snowmelt Infiltration into Frozen Soils." Hydrological Processes 15, no. 6 (November):3095-111. https://doi.org/10.1002/hyp.320.

Hall, D. K., G. A. Riggs, and V. V. Solomonson. 2006. "MODIS Snow and Sea Ice Products.” In Earth Science Satellite Remote Sensing, ed. J. J. Qu, W. Gao, M. Kafatos, R. E. Murphy, and V. V. Salomonson, 154-81. New York: Springer Berlin Heidelberg. https://doi.org/10.1007/978-3-540-37293-6_9.

Hall, Dorothy K., George A. Riggs, Vincent V. Salomonson, Nicolo E. DiGirolamo, and Klaus J.Bayr. 2002. "MODIS Snow-Cover Products." Remote Sensing of Environment 83, no. 1-2 (November): 181-94.

Hansen, E. M., D. D. Fenn, P. Corrigan, and J. L. Vogel. 1994. Probable Maximum Precipitation-Pacific Northwest States: Columbia River (Including Portions of Canada), Snake River and Pacific Coastal Drainages. Hydrometeorological Report No. 57. Silver Spring, MD: National Weather Service. 
Hansson, Klas, Jirka Šimůnek, Masaru Mizoguchi, Lars-Christer Lundin, and Martinus Th. Van Genuchten. 2004. "Water Flow and Heat Transport in Frozen Soil: Numerical Solution and Freeze-Thaw Applications. Vadose Zone Journal 3, no. 2 (May): 693-704. https://doi.org/10.2136/vzj2004.0693.

Held, Isaac M., and Brian J. Soden. 2006. "Robust Responses of the Hydrological Cycle to Global Warming." Journal of Climate 19, no. 16 (November): 5686-99. https://doi.org/10.1175/JCLI3990.1.

Hennig, Christian. 2020. Flexible Procedures for Clustering. Version 2.2-9. R package. https://cran.r-project.org/web/packages/fpc/fpc.pdf.

Hiemstra, Christopher A., Glen E. Liston and William A. Reiners. 2002. "Snow Redistribution by Wind and Interactions with Vegetation at Upper Treeline in the Medicine Bow Mountains, Wyoming, U.S.A.” Arctic, Antarctic, and Alpine Research 34 (3): 262-73. https://doi.org/10.1080/15230430.2002.12003493.

Holten, Roger, Frederik Norheim Bøe, Marit Almvik, Sheela Katuwal, Marianne Stenrød, Mats Larsbo, Nicholas Jarvis, and Ole Martin Eklo. 2018. "The Effect of Freezing and Thawing on Water Flow and MCPA Leaching in Partially Frozen Soil." Journal of Contaminant Hydrology 219 (December): 72-85. https://doi.org/10.1016/i.jconhyd.2018.11.003.

Holtmeier, Friedrich-Karl, and Gabriele Broll. 1992. "The Influence of Tree Islands and Microtopography on Pedoecological Conditions in the Forest-Alpine Tundra Ecotone on Niwot Ridge, Colorado Front Range, U.S.A." Arctic and Alpine Research 24 (3): 216-28. https://doi.org/10.1080/00040851.1992.12002949.

Hosking, J. R. M. 1990. "L-Moments: Analysis and Estimation of Distributions Using Linear Combinations of Order Statistics.” Journal of the Royal Statistical Society. Series B (Methodological) 52 (1): 105-24. http://www.jstor.org/stable/2345653.

Hosking, J. R. M. 2019. Regional Frequency Analysis Using L-Moments. Version 3.3. R package. https://cran.r-project.org/web/packages/ImomRFA/ImomRFA.pdf.

Hosking, J. R. M., and J. R. Wallis. 1993. "Some Statistics Useful in Regional Frequency Analysis.” Water Resources Research, 29, no. 2 (February): 271-81. https://agupubs.onlinelibrary.wiley.com/doi/pdf/10.1029/92WR01980.

Hosking, J., and J. Wallis. 1997. Regional Frequency Analysis: An Approach Based on L-Moments. Cambridge: Cambridge University Press. https://doi.org/10.1017/CB09780511529443.

Ireson, A. M., G. van der Kamp, G. Ferguson, U. Nachshon, U., and H. S. Wheater. 2013. "Hydrogeological Processes in Seasonally Frozen Northern Latitudes: Understanding, Gaps, and Challenges.” Hydrogeology Journal 21 (October): 5366. https://doi.org/10.1007/s10040-012-0916-5.

Jenkins, Gwilym M., and Donald G. Watts. 1968. Spectral Analysis and Its Applications. San Francisco: Holden Day. 
Kalnay, E., M. Kanamitsu, R. Kistler, W. Collins, D. Deaven, L. Gandin, M. Iredell, et al. 1996: “The NCEP/NCAR 40-Year Reanalysis Project." Bulletin of the American Meteoroligcal Society 77, no. 3 (March): 437-71. https://doi.org/10.1175/15200477(1996)077<0437:TNYRP>2.0.C0;2.

Kandel, D. D., A. W. Western, R. B. Grayson, and H. N. Turral. 2004. "Process Parameterization and Temporal Scaling in Surface Runoff and Erosion Modelling." Hydrological Processes 18, no. 8 (May): 1423-46. https://doi.org/10.1002/hyp.1421.

Karlovits, Gregory S., William Otero, and Wesley A. Brown. 2017. Willamette Basin Regional 72-Hour Wintertime Precipitation Frequency Analysis. RMC-TR-201705. Lakewood, CO: U.S. Army Corps of Engineers, Institute for Water Resources, Risk Management Center. https://www.iwrlibrary.us/\#/document/1ab0a6a6-9c48-41c8d984-f57ce9bdb209.

Khan, Said Arab, Ijaz Hussain, Tajammal Hussain, Muhammad Faisal, Yousaf Shad Muhammad, and Alaa Mohamd Shoukry. 2017. "Regional Frequency Analysis of Extremes Precipitation Using L-Moments and Partial L-Moments.” Advances in Meteorology Special Issue, Extreme Precipitation and Floods: Monitoring, Modelling, and Forecasting 2017 (March): 1-20. https://doi.org/10.1155/2017/6954902.

Kotz, Samuel, and Saralees Nadarajah. 200o. "Generalized Extreme Value Distributions." In Extreme Value Distributions: Theory and Applications, 61-93. Tuck Link, Singapore: World Scientific Publishing. https://doi.org/10.1142/9781860944024_0002.

Kraatz, Simon, Jennifer M. Jacobs, Ronny Schröder, Eunsang Cho, Michael Cosh, Mark Seyfried, John Prueger, and Stan Livingston. 2018. "Evaluation of SMAP Freeze/Thaw Retrieval Accuracy at Core Validation Sites in the Contiguous United States." Remote Sensing 10, no. 9 (September): 1-22. https://doi.org/10.3390/rs10091483.

Lea, Jolyne, and Ian Reid. 2006. "An Evaluation of SNODAS for Determining Snow Water Equivalent on Mount St. Helens, Washington.” Paper presented at the 74th Annual Meeting of the Western Snow Conference Western Snow Conference, Las Cruces, NM, 17-20 April 2006. https://westernsnowconference.org/sites/westernsnowconference.org/PDFs/2006LeaA.pdf.

Maidment, David R., ed. 1993. Handbook of Hydrology. New York: McGraw-Hill.

Maulé, C. P. and D. M. Gray. 1994. "Estimated Snowmelt Infiltration and Runoff for The Prairie Provinces.” Canadian Water Resources Journal 19 (3): 253-65. https://doi.org/10.4296/cwrj1903253.

Meromy, Leah, Noah P. Molotch, Timothy E. Link, Steven R. Fassnacht, and Robert Rice. 2013. "Subgrid Variability of Snow Water Equivalent at Operational Snow Stations in the Western USA." Hydrological Processes 27, no. 17 (August): 2383400. https://doi.org/10.1002/hyp.9355. 
Mesinger, Fedor, Geoff DiMego, Eugenia Kalnay, Kenneth Mitchell, Perry C. Shafran, Wesley Ebisuzaki, Dušan Jović, et al. 2006. "A Long-Term, Consistent, HighResolution Climate Dataset for the North American Domain, as a Major Improvement upon the Earlier Global Reanalysis Datasets in Both Resolution and Accuracy." Bulletin of the American Meteorological Society 87, no. 3 (March): 343-60. https://doi.org/10.1175/BAMS-87-3-343.

Miller, J. F., R. H. Frederick, and R. J. Tracey. 1973. NOAA Atlas 2 PrecipitationFrequency Atlas of the Western United States, Volume 5, Idaho. Silver Spring, MD: U.S Department of Commerce, National Oceanic and Atmospheric Administration, and National Weather Service. https://www.nws.noaa.gov/oh/hdsc/PF_documents/Atlas2_Volume5.pdf.

Miller, John F. 1964. Two- to Ten-Day Precipitation for Return Periods of 2 to 100 Years in the Contiguous United States. Technical Paper No. 49. Washington, DC: U.S. Department of Commerce, Weather Bureau. https://www.weather.gov/media/owp/hdsc_documents/TechnicalPaper_No49.pdf.

Mohammed, Aaron A., Igor Pavlovskii, Edwin E. Cey, and Masaki Hayashi. 2019. "Effects of Preferential Flow on Snowmelt Partitioning and Groundwater Recharge in Frozen Soils.” Hydrology and Earth System Sciences 23, no. 12 (December): 5017-31. https://doi.org/10.5194/hess-23-5017-2019.

Molnau, Myron, and Vernon C. Bissell. 1983. "A Continuous Frozen Ground Index for Flood Forecasting." Paper presented at the 51st Annual Western Snow Conference, Vancouver, WA, 19-21 April 1983. https://westernsnowconference.org/sites/westernsnowconference.org/PDFs/1983Molnau.pdf.

Molotch, Noah P., and Roger C. Bales. 2005. "Scaling Snow Observations from the Point to the Grid Element: Implications for Observation Network Design.” Water Resources Research 41, no. 11 (November): W11421. https://doi.org/10.1029/2005WR004229.

Morriss, B. F., E. Ochs, E. J.Deeb, S. D. Newman, S. F.Daly, and J. J.Gagnon. 2016. "Persistence-Based Temporal Filtering for MODIS Snow Products." Remote Sensing of Environment 175 (March): 130-7. https://doi.org/10.1016/i.rse.2015.12.030.

Murphy, Benjamin, Sebastian Müller, and Roman Yurchak. 2020. GeoStatFramework/PyKrige. Version 1.5.o. Python package. https://doi.org/10.5281/zenodo.3739879.

Musselman, K. N., N. P. Molotch, and P. D. Brooks. 2008. "Effects of Vegetation on Snow Accumulation and Ablation in a Mid-Latitude Sub-Alpine Forest." Hydrological Processes Special Issue: Eastern Snow Conference/Canadian Geophysical Union-Hydrology Section 22, no. 15 (July): 2767-76 (2008). https://doi.org/10.1002/hyp.7050.

MWH Americas Inc. 2014. Susitna-Watana Hydroelectric Project, Engineering Feasibility Report, Appendix B4, Probable Maximum Flood Study. 14-21-REP vo.o AEA11-022. Anchorage, Alaska: Alaska Energy Authority. https://www.arlis.org/docs/vol1/Susitna2/2/SuWa280/SuWa280title.pdf. 
Neiman, Paul F., F. Martin Ralph, A. B. White, D. E. Kingsmill, and P. O. G. Persson. 2002. "The Statistical Relationship Between Upslope Flow and Rainfall in California's Coastal Mountains: Observations During CALJET.” Monthly Weather Review 130, no. 6 (June): 1468-92. https://doi.org/10.1175/15200493(2002)130<1468:TSRBUF>2.0.C0;2.

Neiman, Paul J., F. Martin Ralph, Gary A. Wick, Jessica D. Lundquist, and Michael D. Dettinger. 2008. "Meteorological Characteristics and Overland Precipitation Impacts of Atmospheric Rivers Affecting the West Coast of North America Based on Eight Years of SSM/I Satellite Observations.” Journal of Hydrometeorology 9, no. 1 (February): 22-47. https://doi.org/10.1175/2007JHM855.1.

Neiman, Paul J., Lawrence J. Schick, F. Martin Ralph, Mimi Hughes, and Gary A. Wick. 2011. "Flooding in Western Washington: The Connection to Atmospheric Rivers." Journal of Hydrometeorology 12, no. 6 (December): 1337-58. https://doi.org/10.1175/2011jhm1358.1.

NOHRSC (National Operational Hydrologic Remote Sensing Center). 2004. Snow Data Assimilation System (SNODAS) Data Products at NSIDC, Version 1. Boulder, Colorado: National Snow and Ice Data Center. https://doi.org/10.7265/N5TB14TC.

NRCS (Natural Resources Conservation Service). 2016. Snow Survey \& Water Supply Forecasting Program. Brochure. Portland, OR: National Water and Climate Center, Natural Resources Conservation Service. https://www.wcc.nrcs.usda.gov/snotel/program_brochure.pdf.

NRCS (Natural Resources Conservation Service). n.d. "Web Soil Survey.” Natural Resources Conservation Service, U.S. Department of Agriculture. Accessed March 2020. https://websoilsurvey.nrcs.usda.gov/.

O'Gorman, P. A., and C. J. Muller. 2010. "How Closely Do Changes in Surface and Column Water Vapor Follow Clausius-Clapeyron Scaling in Climate Change Simulations?” Environmental Research Letters 5, no. 2 (April): 1-7. https://doi.org/10.1088/1748-9326/5/2/025207.

O'Neill, P. E., S. Chan, E. G. Njoku, T. Jackson, and R. Bindlish. 2019. SMAP Enhanced L3 Radiometer Global Daily $9 \mathrm{~km}$ EASE-Grid Soil Moisture. Version 3. HDF5 data set. Boulder, CO: NASA National Snow and Ice Data Center Distributed Active Archive Center. https://doi.org/10.5067/T90W6VRLCBHI.

Osborn, T. J., and Hulme, M. 1997. "Development of a Relationship between Station and Grid-Box Rainday Frequencies for Climate Model Evaluation.” American Meteorological Society 10, no. 8 (August): 1885-908. https://doi.org/10.1175/1520-0442(1997)010<1885:DOARBS>2.0.C0;2.

Palmer, Peter L. 2011. "AgriMet: A Reclamation Tool for Irrigation Water Management.” In World Environmental and Water Resources Congress 2011: Bearing Knowledge for Sustainability, 2682-91. Reston, VA: American Society of Civil Engineers. https://doi.org/doi:10.1061/41173(414)279.

Parida, Bhagabat P., and Ditiro B. Moalafhi. 2008. "Regional Rainfall Frequency Analysis for Botswana Using L-Moments and Radial Basis Function Network.” Physics and Chemistry of the Earth, Parts $A / B / C 33$ (8): 614-20.

https://doi.org/10.1016/j.pce.2008.06.011. 
Perry, Matthew T. 2019. Summary Statistics of Geospatial Raster Datasets Based on Vector Geometries. Version 0.14.0. Python package. https://github.com/perrygeo/python-rasterstats.

Physical Sciences Laboratory. 2020. NCEP/NCAR Reanalysis Data. Accessed 16 January 2020. https://psl.noaa.gov/data/composites/day/.

Pilon, Paul J., K. Adamowski, and Y. Alila. 1991. "Regional Analysis of Annual Maxima Precipitation Using L-Moments." Atmospheric Research 27, nos. 1-3 (December): 81-92. https://doi.org/10.1016/0169-8095(91)90009-L.

Pomeroy, J. W., and E. Brun E. 2001. "Physical Properties of Snow." In Snow Ecology: An Interdisciplinary Examination of Snow-Covered Ecosystems, ed. H. G. Jones, J. W. Pomeroy, D. A. Walker, and R.W. Hoham, 45-126. New York: Cambridge University Press.

PRISM Climate Group. 2019. Descriptions of PRISM Spatial Climate Datasets for the Conterminous United States. Corvallis, OR: Oregon State University. http://www.prism.oregonstate.edu/documents/PRISM_datasets.pdf.

PRISM Climate Group. 2020. PRISM 3O-Year Normals. Accessed 4 April 2020. Corvallis, OR: Oregon State University. https://prism.oregonstate.edu/normals/.

R Core Team. 2019. R: A Language and Environment for Statistical Computing. Vienna, Austria: R Foundation for Statistical Computing. https://www.r-project.org/.

Ralph, F. M., T. Coleman, P. J. Neiman, R. J. Zamora, and M. D. Dettinger. 2013. "Observed Impacts of Duration and Seasonality of Atmospheric-River Landfalls on Soil Moisture and Runoff in Coastal Northern California." Journal of Hydrometeorology 14, no. 2 (April): 443-59. https://doi.org/10.1175/JHM-D-12-076.1.

Ralph, F. Martin, Jonathan J. Rutz, Jason M. Cordeira, Michael Dettinger, Michael Anderson, David Reynolds, Lawrence J. Schick, and Chris Smallcomb. 2019. "A Scale to Characterize the Strength and Impacts of Atmospheric Rivers." Bulletin of the American Meteorological Society 100, no. 2 (February): 269-289. https://doi.org/10.1175/BAMS-D-18-0023.1.

Ralph, F. Martin, Paul J. Neiman, and Gary A. Wick. 2004. "Satellite and CALJET Aircraft Observations of Atmospheric Rivers over the Eastern North Pacific Ocean During the Winter of 1997/98." Monthly Weather Review 132, no, 7 (July): 1721-45. https://doi.org/10.1175/1520-0493(2004)132<1721:SACA00>2.0.C0;2.

Ralph, F. Martin, Paul J. Neiman, and Richard Rotunno. 2005. "Dropsonde Observations in Low-Level Jets over the Northeastern Pacific Ocean from CALJET-1998 and PACJET-2001: Mean Vertical-Profile and Atmospheric-River Characteristics.” Monthly Weather Review 133, no. 4 (April): 889-910. https://doi.org/10.1175/MWR2896.1.

Ralph, F. Martin, Paul J. Neiman, Gary A. Wick, Seth I. Gutman, Michael D. Dettinger, Daniel R. Cayan, Allen B. White. 2006. "Flooding on California's Russian River: Role of Atmospheric Rivers." Geophysical Research Letters 33, no. 13 (July): 1-5. https://doi.org/10.1029/2006GL026689. 
Ralph, F. Martin, Paul J. Neiman, George N. Kiladis, Klaus Weickmann, and David W. Reynolds. 2011. "A Multiscale Observational Case Study of a Pacific Atmospheric River Exhibiting Tropical-Extratropical Connections and a Mesoscale Frontal Wave." Monthly Weather Review 139, no. 4 (April): 1169-89. https://doi.org/10.1175/2010MWR3596.1.

Rankinen, K., T. Karvonen, and D. Butterfield. 2004. "A Simple Model for Predicting Soil Temperature in Snow-Covered and Seasonally Frozen Soil: Model Description and Testing." Hydrology and Earth System Sciences 8, no. 4 (August): 706-16. https://doi.org/10.5194/hess-8-706-2004.

Rantz, S. E., and others. 1982. Measurement and Computation of Streamflow: Volume 2. Computation of Discharge. Geological Survey Water-Supply Paper 2175. Washington, DC: U.S. Government Printing Office. https://pubs.usgs.gov/wsp/wsp2175/wsp2175_vol2.pdf.

Reclamation (U.S. Bureau of Reclamation). 2010. Ririe Dam Flood Frequency Study, Bonneville County, Idaho. Denver, CO: U.S. Bureau of Reclamation.

Reclamation (U.S. Bureau of Reclamation). 2020a. "AgriMet Historical Archive Weather Data Access.” Columbia-Pacific Northwest Region. https://www.usbr.gov/pn/agrimet/webarcread.html.

Reclamation (U.S. Bureau of Reclamation). 2020b. "Hydromet Historical Data Access: Site Selection." Columbia-Pacific Northwest Region. https://www.usbr.gov/pn/hydromet/arcread.html.

Reclamation (U.S. Bureau of Reclamation). n.d. "Ririe Dam.” Projects \& Facilities. Accessed 9 April 2021. https://www.usbr.gov/projects/index.php?id=199.

Restrepo-Posada, Pedro J., and Peter S. Eagleson. 1982. "Identification of Independent Rainstorms." Journal of Hydrology 55, nos. 1-4 (February): 303-19. https://doi.org/10.1016/0022-1694(82)90136-6.

Rosenberg, Eric A., Patrick W. Keys, Derek B. Booth, David Hartley, Jeff Burkey, Anne C. Steinemann, and Dennis P. Lettenmaier. 2010. "Precipitation Extremes and the Impacts of Climate Change on Stormwater Infrastructure in Washington State." Climate Research 102 (April): 319-49. https://doi.org/10.1007/s10584-010-9847-0.

Roy, Debjit, Xinhua Jia, Dean D. Steele, Xuefeng Chu, and Zhulu Lin. 2020. "Infiltration into Frozen Silty Clay Loam Soil with Different Soil Water Contents in the Red River of the North Basin in the USA." Water 12, no. 2 (January): 1-21. https://doi.org/10.3390/w12020321.

Rutter, Nick, Don Cline, and Long Li. 2008. "Evaluation of the NOHRSC Snow Model (NSM) in a One-Dimensional Mode." Journal of Hydrometeorology 9, no. 4 (August): 695-711. https://doi.org/10.1175/2008JHM861.1.

Rutz, Jonathan J., William J. Steenburgh, and F. Martin Ralph. 2014. "Climatological Characteristics of Atmospheric Rivers and Their Inland Penetration over the Western United States.” Monthly Weather Review 142, no. 2 (February): 905-21. https://doi.org/10.1175/MWR-D-13-00168.1. 
Rutz, Jonathan J., William J. Steenburgh, and F. Martin Ralph. 2015. “The Inland Penetration of Atmospheric Rivers over Western North America: A Lagrangian Analysis." Monthly Weather Review 143, no. 5 (May): 1924-44. https://doi.org/10.1175/MWR-D-14-00288.1.

Salomonson, V. V., and I. Appel. 2004. "Estimating Fractional Snow Cover from MODIS Using the Normalized Difference Snow Index." Remote Sensing of Environment 89 (3): 351-60. https://doi.org/10.1016/i.rse.2003.10.016.

Schneiderman, Elliot M., Adao H. Matonse, Mark S. Zion, David G. Lounsbury, Rajith Mukundan, Soni M. Pradhanang, Donald C. Pierson. 2013. "Comparison of Approaches for Snowpack Estimation in New York City Watersheds.” Hydrological Processes Special Issue: Eastern Snow Conference 27, no. 21 (October): 3050-60. https://doi.org/10.1002/hyp.9868.

Serreze, Mark C., Martyn P. Clark, Richard L. Armstrong, David A. McGinnis, and Roger S. Pulwarty. 1999. Characteristics of the Western United States Snowpack from Snowpack Telemetry (SNOTEL) Data. Water Resources Research 35, no. 7 (July): 2145-60. https://doi.org/10.1029/1999WR900090.

Shanley, James B., and Ann Chalmers. 1999. "The Effect of Frozen Soil on Snowmelt Runoff at Sleepers River, Vermont.” Hydrological Processes Special Issue:

Snow Hydrology 13, nos. 12-13 (September): 1843-57. https://doi.org/10.1002/(SICI)1099-1085(199909)13:12/13\%3C1843::AIDHYP879\%3E3.0.C0;2-G.

Singh, V. P. 1998. “Generalized Extreme Value Distribution.” In Entropy-Based Parameter Estimation in Hydrology, ed. V. P. Singh, 169-83. Springer Science+Business Media Dordrecht. https://doi.org/10.1007/978-94-017-1431-0_11.

Stedinger, Jery R. 1983. “Confidence Intervals for Design Events.” Journal of Hydraulic Engineering 109, no. 1 (January): 13-27. https://doi.org/10.1061/(ASCE)07339429(1983)109:1(13).

Stohl, A., C. Forster, and H. Sodemann. 2008. "Remote Sources of Water Vapor Forming Precipitation on the Norwegian West Coast at $60^{\circ} \mathrm{N}-\mathrm{A}$ Tale of Hurricanes and an Atmospheric River.” Journal of Geophysical Research 113, no. D5 (March): 1-13. https://doi.org/10.1029/2007JD009006.

Sturm, Matthew, Brian Taras, Glen E Liston, Chris Derksen, Tobias Jonas, and Jon Lea. 2010. "Estimating Snow Water Equivalent Using Snow Depth Data and Climate Classes.” Journal of Hydrometeorology 11, no. 6 (December): 1380-94. https://doi.org/10.1175/2010JHM1202.1.

Sveinsson, Oli G. B., Jose D. Salas, and Duane C. Boes. 2002. "Regional Frequency Analysis of Extreme Precpitation in Northeastern Colorado and Fort Collins Flood of 1997." Journal of Hydrologic Engineering 7, no. 1 (January): 49-63. https://doi.org/10.1061/(ASCE)1084-0699(2002)7:1(49).

Svensson, C., and D. A. Jones. 2010. "Review of Methods for Deriving Areal Reduction Factors." Journal of Flood Risk Management 3, no. 3 (September): 232-45. https://doi.org/10.1111/i.1753-318X.2010.01075.x. 
Tao, Y.-X., and D. M. Gray. 1994. "Prediction of Snowmelt Infiltration Into Frozen Soils." Numerical Heat Transfer, Part A: Applications 26 (6): 643-65. https://doi.org/10.1080/10407789408956015.

Thomas, Cecil A., and Robert D. Lamke. 1962. Floods of February 1962 in Southern Idaho and Northern Nevada. Geological Survey Circular 467. Washington, DC: U.S. Department of the Interior. https://pubs.usgs.gov/circ/1962/0467/report.pdf.

U.S. Fish and Wildlife Service. 2020. "Grays Lake: Historical Perspective." https://www.fws.gov/nwrs/threecolumn.aspx?id=2147522791.

U.S. Weather Bureau. 1966. Meteorological Conditions for the Probable Maximum Flood on the Yukon River Above Rampart, Alaska. Hydrometeorological Report No. 42. Washington, DC: U.S. Department of Commerce.

https://www.weather.gov/media/owp/oh/hdsc/docs/HMR42.pdf.

USACE (U.S. Army Corps of Engineers). 1965. Standard Project Flood Determination. EM 1110-2-1411. Washington, DC: U.S. Army Corps of Engineers. https://www.publications.usace.army.mil/Portals/76/Publications/EngineerManuals/EM_1110 -2-1411.pdf?ver=CbyTAMj06FrYx3EaaU1dhQ\%3d\%3d.

USACE (U.S. Army Corps of Engineers). 1966. Design Memorandum No. 1, Hydrology, Ririe Project, Willow Creek, Idaho. Walla Walla, WA: U.S. Army Corps of Engineers-Walla Walla District.

USACE (U.S. Army Corps of Engineers). 1978. Standing Operating Procedures for Ririe Dam, Willow Creek, Idaho. Walla Walla, WA: U.S. Army Corps of EngineersWalla Walla District.

USACE (U.S. Army Corps of Engineers). 2010. Winter Flood Frequency Analysis for Willow Creek at Ririe Dam. Walla Walla, WA: U.S. Army Corps of Engineers.

USGS (U.S. Geological Survey). 2020. "National Water Information System: Web Interface.” USGS 13057940 Willow Creek BL Tex Creek NR Ririe ID. https://waterdata.usgs.gov/id/nwis/uv?site_no $=13057940$.

Viale, Maximiliano, and Mario N. Nuñez. 2011. "Climatology of Winter Orographic Precipitation over the Subtropical Central Andes and Associated Synoptic and Regional Characteristics.” Journal of Hydrometeorology 12, no. 4 (August): 481507. https://doi.org/10.1175/2010JHM1284.1.

Viglione, A., F. Laio, and P. Claps. 2007. "A Comparison of Homogeneity Tests for Regional Frequency Analysis.” Water Resources Research 43, no. 3 (March): 110. https://doi.org/10.1029/2006WR005095.

Vogel, Tomas, Michal Dohnal, Jana Votrubova, Jaromir Dusek. 2019. "Soil Water Freezing Model with Non-Iterative Energy Balance Accounting.” Journal of Hydrology 578 (November): 1-8. https://doi.org/10.1016/j.jhydrol.2019.124071.

Wallis, J. R., M. G. Schaefer, B. L. Barker, and G. H. Taylor. 2007. "Regional Precipitation-Frequency Analysis and Spatial Mapping for 24-Hour and 2-Hour Durations for Washington State." Hydrology and Earth System Sciences Special Issue: A View from the Watershed Revisited 11, no. 1 (January): 415-42. https://doi.org/10.5194/hess-11-415-2007. 
Warner, Michael D., Clifford F. Mass, and Eric P. Salathé Jr. 2012. "Wintertime Extreme Precipitation Events along the Pacific Northwest Coast: Climatology and Synoptic Evolution." Monthly Weather Review 140, no. 7 (July): 2021-43. https://doi.org/10.1175/MWR-D-11-00197.1.

Wilks, S. S. 1963. "Multivariate Statistical Outliers.” Sankhyā: The Indian Journal of Statistics, Series A (1961-2002) 25, no. 4 (December): 407-26. http://www.jstor.org/stable/25049292.

WMO (World Meteorological Organization). 1969. Estimation of Maximum Floods: Report of a Working Group of the Commission for Hydrometeorology. WMONo.233.TP.126. Geneva, Switzerland: Secretariat of the World Meteorological Organization. https://library.wmo.int/doc_num.php?explnum_id=3444.

Yang, Kai, and Jingyong Zhang. 2018. "Evaluation of Reanalysis Datasets Against Observational Soil Temperature Data over China." Climate Dynamics 50 (March): 317-37. https://doi.org/10.1007/s00382-017-3610-4.

Yang, Limin, Suming Jin, Patrick Danielson, Collin Homer, Leila Gass, Stacie M. Bender, et al. 2018. "A New Generation of the United States National Land Cover Database: Requirements, Research Priorities, Design, and Implementation Strategies.” ISPRS Journal of Photogrammetry and Remote Sensing 146 (December): 108-23. https://doi.org/10.1016/i.isprsjprs.2018.09.006.

Zeng, Xubin, Patrick Broxton, and Nicholas Dawson. 2018. "Snowpack Change from 1982 to 2016 Over Conterminous United States.” Geophysical Research Letters 45, no. 23 (December): 12940-47. https://doi.org/10.1029/2018GL079621.

Zhao, Litong, and D. M. Gray. 1997. "A Parametric Expression for Estimating Infiltration into Frozen Soils.” Hydrological Processes 11, no. 13 (October): 1761-75. https://doi.org/10.1002/(SICI)1099-1085(19971030)11:13<1761::AID-HYP604>3.0.C0;2-0.

Zhu, Yong, and Reginald E. Newell. 1998. "A Proposed Algorithm for Moisture Fluxes from Atmospheric Rivers." Monthly Weather Review 126, no. 3 (March): 725-73. https://doi.org/10.1175/1520-0493(1998)126\%3C0725:APAFMF\%3E2.0.C0;2. 


\section{Appendix A: Willow Creek (Ririe Dam and Reservoir) Regional Frequency Analysis}

\section{A.1 Selection of regional frequency distribution}

The L-skew and L-kurtosis values for each station were spatially interpolated using kriging over the domain of our precipitation frequency analysis. The plots below show the results for the 24-hour, 48-hour, 72-hour and 96-hour durations, respectively.

Figure A-1. Spatially interpolated 24-hour L-skew and L-kurtosis for area near the Willow Creek Basin.

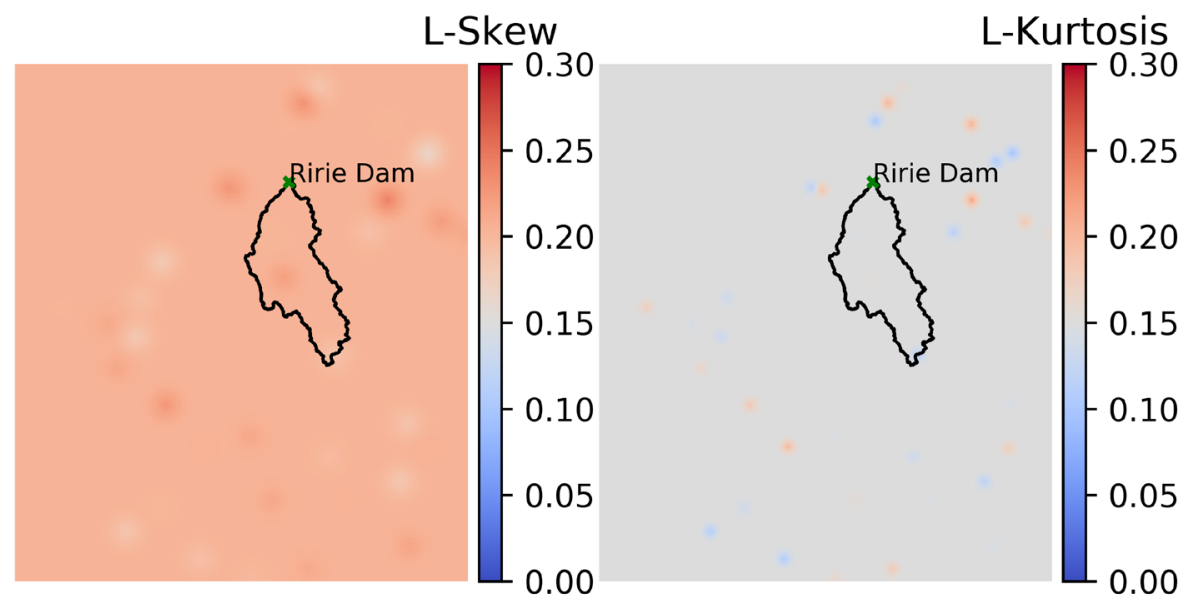

Figure A-2. Spatially interpolated 48-hour L-skew and L-kurtosis for area near the Willow Creek Basin.

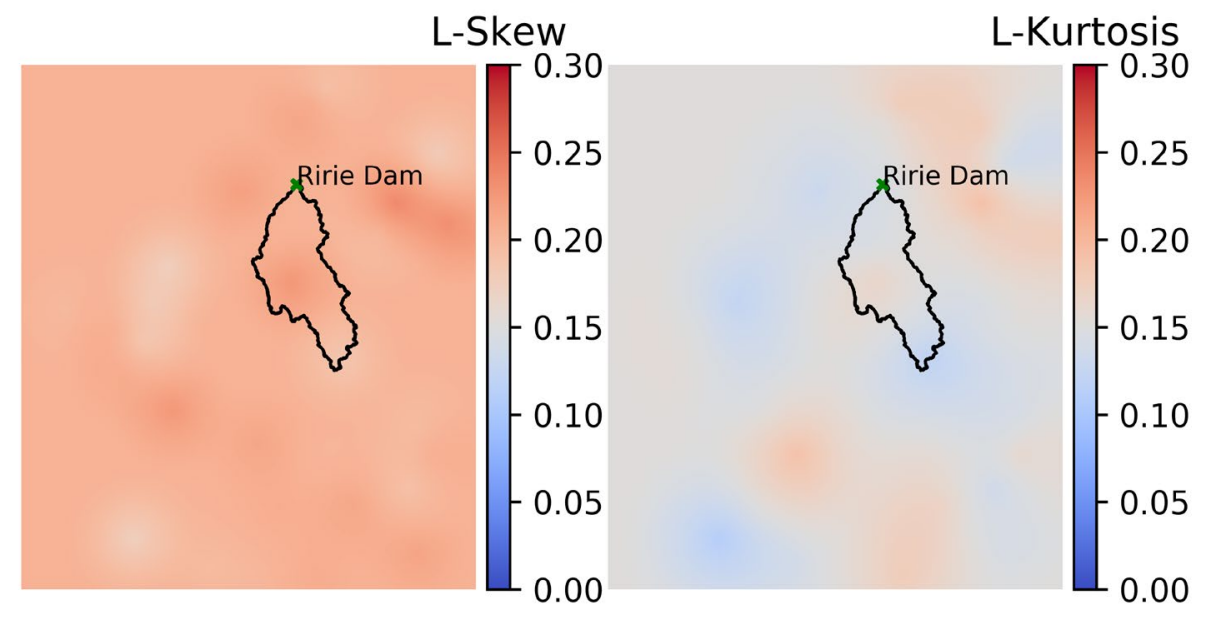


Figure A-3. Spatially interpolated 72-hour L-skew and L-kurtosis for area near the Willow Creek Basin.

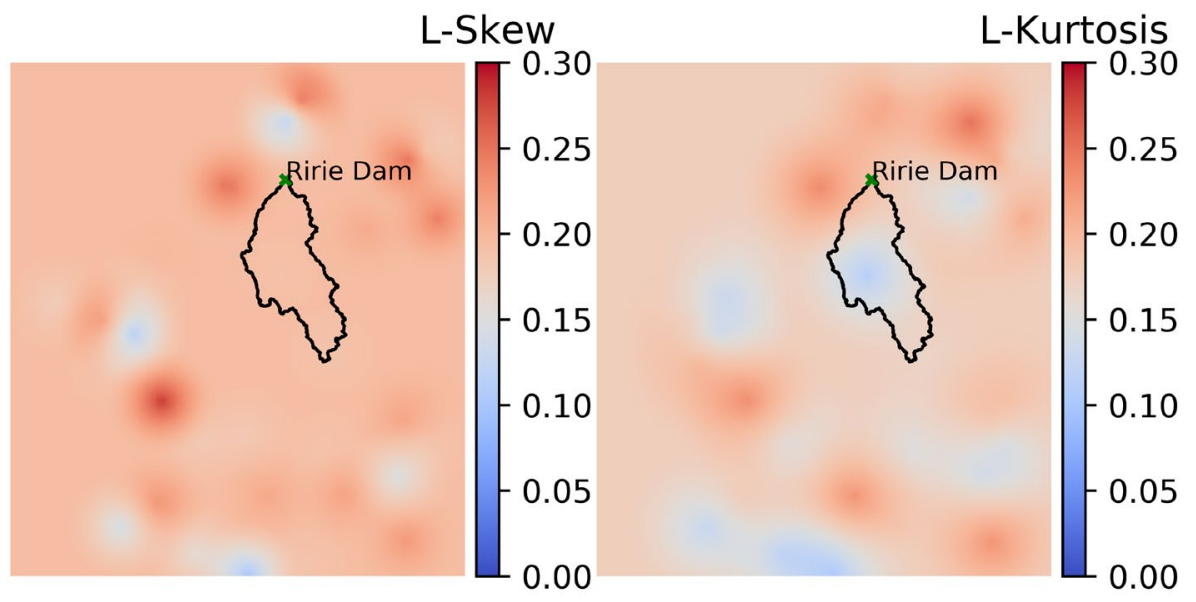

Figure A-4. Spatially interpolated 96-hour L-skew and L-kurtosis for area near the Willow Creek Basin.

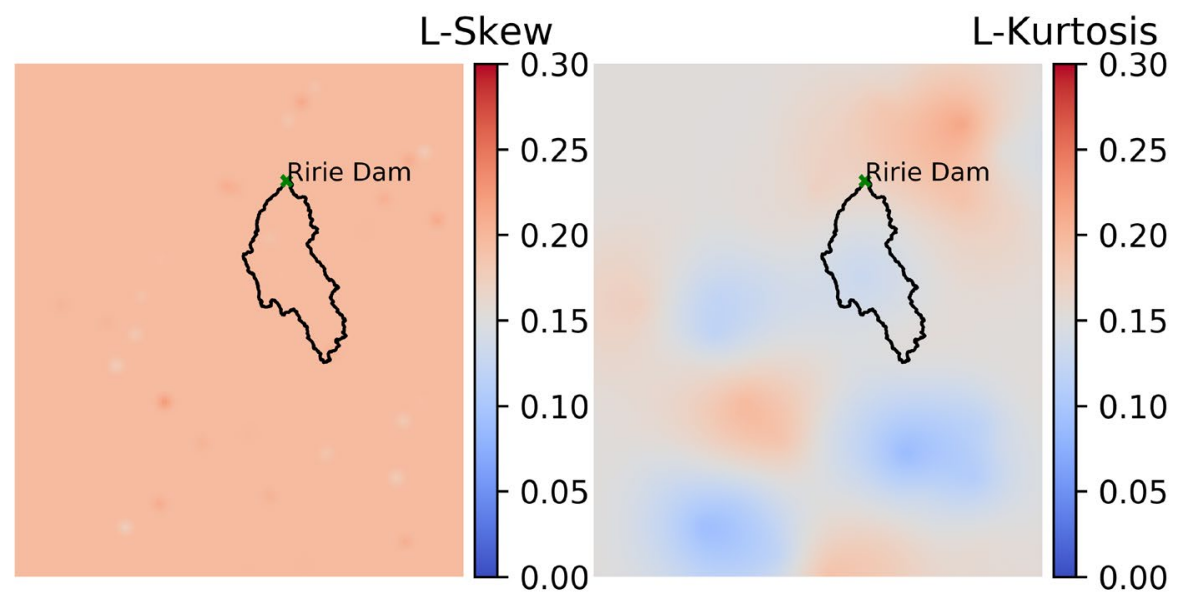

\section{A.2 Regional quantiles by subbasin}

Figures A-5 to A-7 show the results of the regionally factor quantiles for each subbasin. These quantiles have the ARF values applied, which are defined by duration in Table 8 of our report. A summary table of all values is also included (Table A-1). 
Figure A-5. Ririe Subbasin precipitation probabilities for 24-, 48-, 72-, and 96-hour storms using the 2-year ARF value.

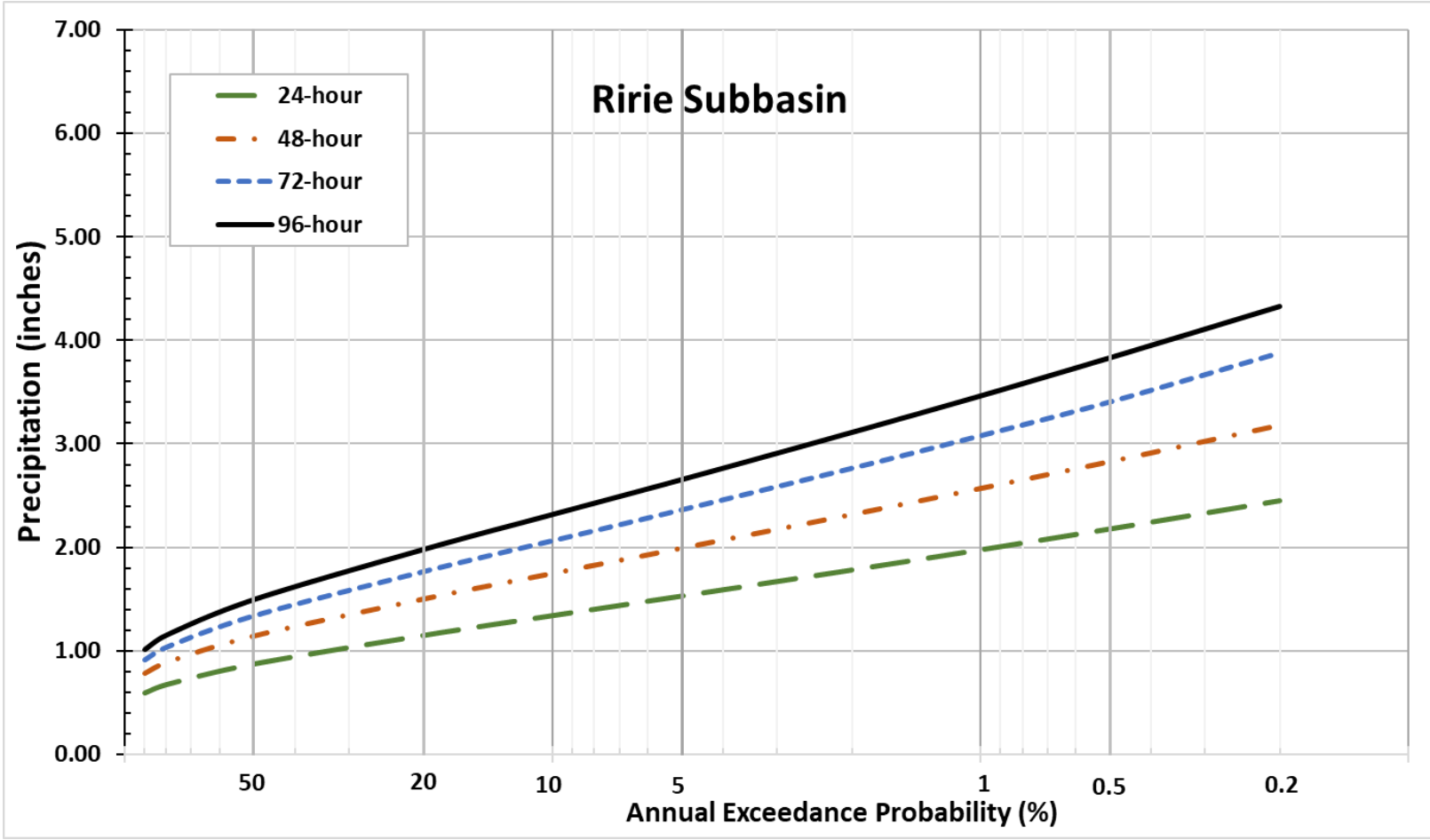

Figure A-6. Ririe Upstream Subbasin precipitation probabilities for 24-, 48-, 72-, and 96-hour storms using the 2-year ARF value.

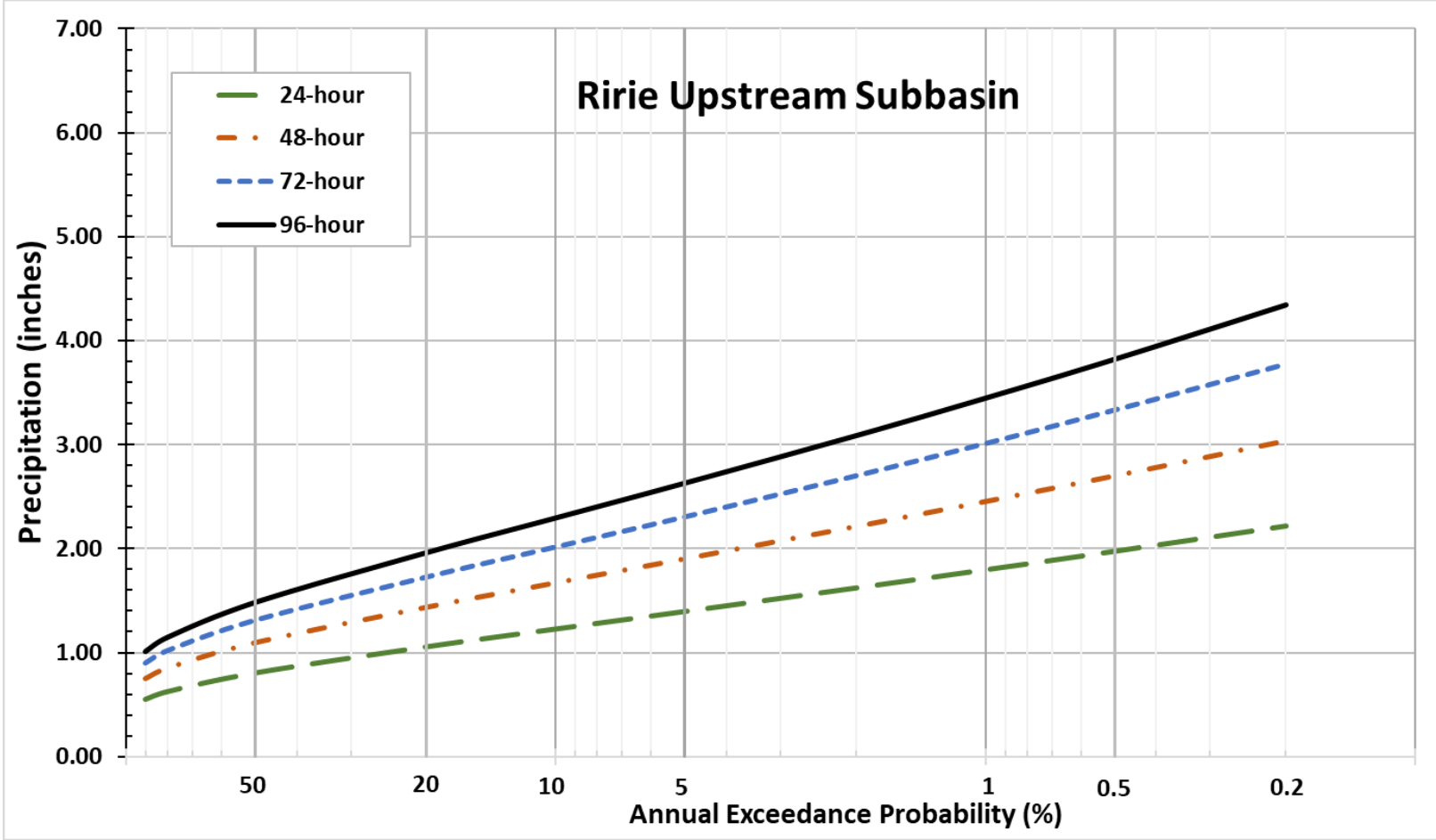


Figure A-7. Grays Lake Subbasin precipitation probabilities for 24-, 48-, 72-, and 96-hour storms using the 2-year ARF value.

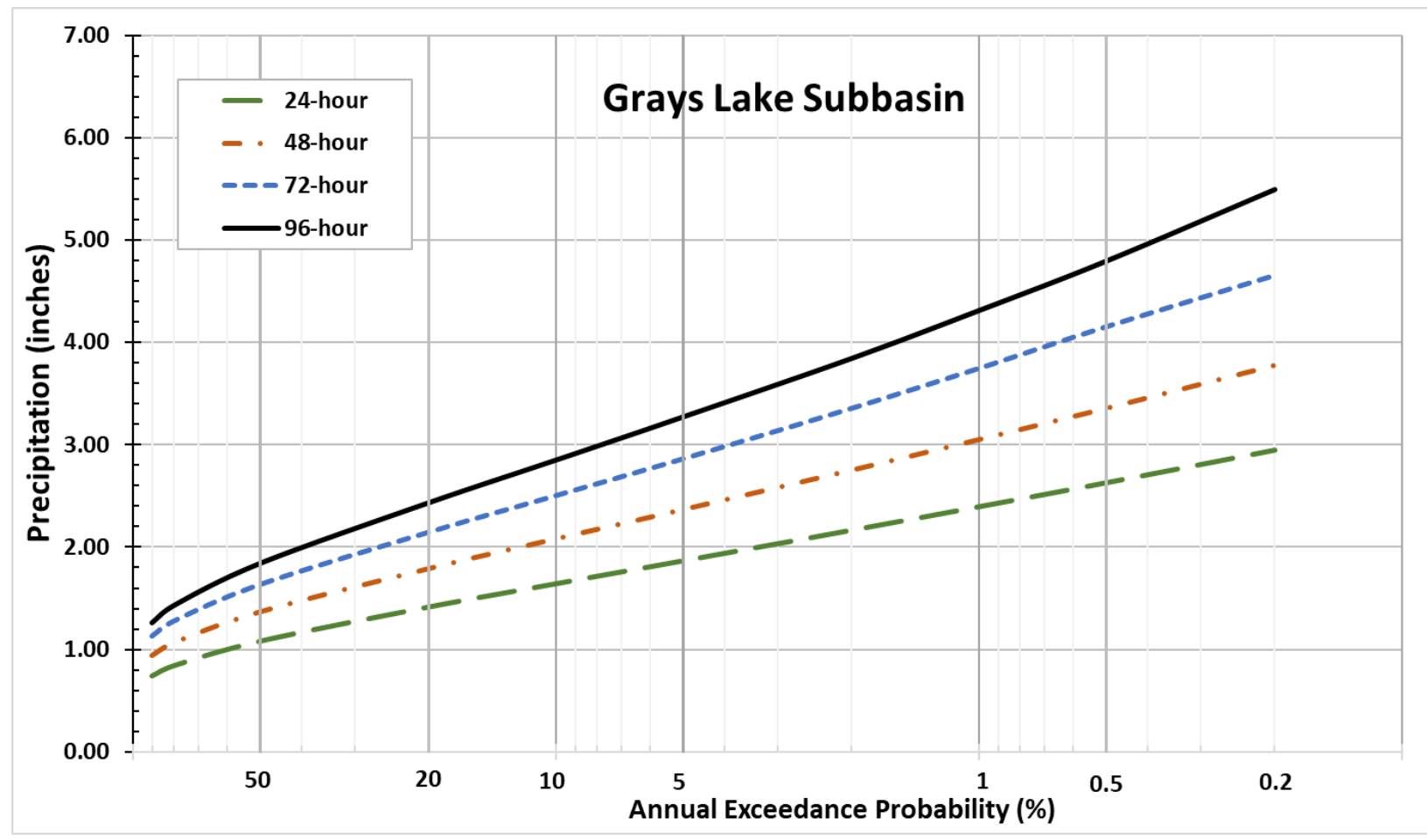


Table A-1. The Willow Creek Basin and subbasins spatially averaged precipitation amount using the 2-year ARF value.

\begin{tabular}{|c|c|c|c|c|c|c|c|c|c|c|c|c|c|c|c|c|}
\hline \multirow[b]{2}{*}{$\begin{array}{c}\text { AEP } \\
(\%)\end{array}$} & \multicolumn{4}{|c|}{ 24-hour } & \multicolumn{4}{|c|}{ 48-hour } & \multicolumn{4}{|c|}{ 72-hour } & \multicolumn{4}{|c|}{ 96-hour } \\
\hline & $\begin{array}{c}\text { Total } \\
\text { Watershed }\end{array}$ & $\begin{array}{c}\text { Ririe } \\
\text { Subbasin }\end{array}$ & $\begin{array}{c}\text { Ririe } \\
\text { Upstream } \\
\text { Subbasin }\end{array}$ & $\begin{array}{c}\text { Grays } \\
\text { Lake } \\
\text { Subbasin }\end{array}$ & $\begin{array}{c}\text { Total } \\
\text { Watershed }\end{array}$ & $\begin{array}{c}\text { Ririe } \\
\text { Subbasin }\end{array}$ & $\begin{array}{c}\text { Ririe } \\
\text { Upstream } \\
\text { Subbasin }\end{array}$ & $\begin{array}{c}\text { Grays } \\
\text { Lake } \\
\text { Subbasin }\end{array}$ & $\begin{array}{c}\text { Total } \\
\text { Watershed }\end{array}$ & $\begin{array}{c}\text { Ririe } \\
\text { Subbasin }\end{array}$ & \begin{tabular}{|c|} 
Ririe \\
Upstream \\
Subbasin
\end{tabular} & $\begin{array}{c}\text { Grays } \\
\text { Lake } \\
\text { Subbasin }\end{array}$ & $\begin{array}{c}\text { Total } \\
\text { Watershed }\end{array}$ & $\begin{array}{c}\text { Ririe } \\
\text { Subbasin }\end{array}$ & $\begin{array}{c}\text { Ririe } \\
\text { Upstream } \\
\text { Subbasin }\end{array}$ & $\begin{array}{c}\text { Grays } \\
\text { Lake } \\
\text { Subbasin }\end{array}$ \\
\hline 90 & 0.54 & 0.59 & 0.55 & 0.74 & 0.75 & 0.78 & 0.75 & 0.95 & 0.90 & 0.92 & 0.90 & 1.13 & 1.01 & 1.01 & 1.01 & 1.26 \\
\hline 80 & 0.61 & 0.67 & 0.62 & 0.84 & 0.85 & 0.89 & 0.85 & 1.07 & 1.02 & 1.04 & 1.02 & 1.28 & 1.15 & 1.16 & 1.15 & 1.43 \\
\hline 50 & 0.79 & 0.87 & 0.80 & 1.08 & 1.09 & 1.14 & 1.10 & 1.37 & 1.31 & 1.34 & 1.31 & 1.64 & 1.49 & 1.50 & 1.48 & 1.84 \\
\hline 20 & 1.04 & 1.15 & 1.05 & 1.41 & 1.43 & 1.50 & 1.44 & 1.79 & 1.72 & 1.77 & 1.73 & 2.15 & 1.97 & 1.98 & 1.96 & 2.44 \\
\hline 10 & 1.21 & 1.34 & 1.22 & 1.64 & 1.66 & 1.75 & 1.67 & 2.08 & 2.01 & 2.07 & 2.02 & 2.51 & 2.30 & 2.32 & 2.30 & 2.85 \\
\hline 5 & 1.37 & 1.53 & 1.39 & 1.87 & 1.89 & 1.99 & 1.90 & 2.37 & 2.30 & 2.37 & 2.31 & 2.87 & 2.64 & 2.66 & 2.63 & 3.27 \\
\hline 2 & 1.60 & 1.78 & 1.62 & 2.17 & 2.19 & 2.32 & 2.21 & 2.75 & 2.70 & 2.77 & 2.70 & 3.36 & 3.10 & 3.11 & 3.09 & 3.85 \\
\hline 1 & 1.77 & 1.98 & 1.79 & 2.40 & 2.43 & 2.57 & 2.45 & 3.05 & 3.01 & 3.08 & 3.01 & 3.75 & 3.46 & 3.46 & 3.45 & 4.31 \\
\hline 0.5 & 1.94 & 2.18 & 1.97 & 2.63 & 2.67 & 2.83 & 2.70 & 3.36 & 3.33 & 3.41 & 3.33 & 4.16 & 3.84 & 3.83 & 3.82 & 4.80 \\
\hline 0.2 & 2.18 & 2.45 & 2.21 & 2.95 & 3.01 & 3.18 & 3.03 & 3.78 & 3.76 & 3.88 & 3.77 & 4.66 & 4.37 & 4.33 & 4.34 & 5.49 \\
\hline
\end{tabular}




\section{A.3 Regional quantiles for ground-based stations}

We applied the regional growth factors developed in the regional frequency analysis to individual stations in the two homogeneous regions (Cluster 1 and 2). This allows us to use station quantiles with additional confidence because the depths for each probability have included the inherent spatial variability of precipitation. In this appendix, we include sets of three tables for each duration and region. For example, Tables A-2 through A-4 are the 24-hour median quantiles, 95\% confidence interval, and $5 \%$ confidence interval, respectively. The subsequent sets of tables follow this pattern for the 48-hour, 72-hour, and 96-hour durations (Tables A-5 through A-25). We would also note the results shown in Table A-17 for the Oxford Spring and Wildhorse Divide stations appear to be erroneous because the quantiles are nearly identical. We found after investigation of the datasets and L-moment estimates that the first and second L-moments are very close, which would result in the quantiles being nearly equal. 


\section{A.3.1 Region 1 regionally factored quantiles (24-hour)}

Table A-2. Region 1 regionally factored quantiles (24-hour).

\begin{tabular}{|c|c|c|c|c|c|c|c|c|c|c|c|}
\hline & & & & & & xceeda & babilit & & & & \\
\hline 24-H & lour Total (inches) & 0.90 & 0.80 & 0.50 & 0.20 & 0.10 & 0.05 & 0.02 & 0.01 & 0.005 & 0.002 \\
\hline & & & & & & Return & (years) & & & & \\
\hline ID & Station Name & 1.11 & 1.25 & 2 & 5 & 10 & 20 & 50 & 100 & 200 & 500 \\
\hline USC00100010 & ABERDEEN EXP STN & 0.40 & 0.46 & 0.62 & 0.84 & 1.00 & 1.15 & 1.36 & 1.52 & 1.68 & 1.91 \\
\hline USC00100915 & BLACKFOOT FIRE DEPT & 0.45 & 0.52 & 0.70 & 0.95 & 1.12 & 1.30 & 1.53 & 1.71 & 1.89 & 2.15 \\
\hline USC00102676 & DRIGGS & 0.48 & 0.56 & 0.75 & 1.01 & 1.20 & 1.38 & 1.63 & 1.82 & 2.02 & 2.29 \\
\hline USC00103297 & FT HALL 1 NNE & 0.40 & 0.47 & 0.63 & 0.85 & 1.01 & 1.16 & 1.37 & 1.53 & 1.70 & 1.93 \\
\hline USC00103732 & GRACE & 0.45 & 0.52 & 0.69 & 0.94 & 1.11 & 1.28 & 1.51 & 1.69 & 1.88 & 2.13 \\
\hline USC00104455 & IDAHO FALLS - KIFI & 0.45 & 0.52 & 0.70 & 0.95 & 1.12 & 1.29 & 1.53 & 1.71 & 1.89 & 2.15 \\
\hline USC00104456 & IDAHO FALLS 16 SE & 0.54 & 0.63 & 0.85 & 1.15 & 1.36 & 1.57 & 1.85 & 2.07 & 2.29 & 2.60 \\
\hline USC00105275 & LIFTON PUMPING STN & 0.41 & 0.48 & 0.64 & 0.87 & 1.02 & 1.18 & 1.39 & 1.56 & 1.73 & 1.96 \\
\hline USC00105716 & MCCAMMON & 0.59 & 0.69 & 0.93 & 1.26 & 1.49 & 1.71 & 2.02 & 2.26 & 2.50 & 2.84 \\
\hline USC00107208 & POCATELLO 2 NE & 0.46 & 0.54 & 0.72 & 0.97 & 1.15 & 1.33 & 1.56 & 1.75 & 1.94 & 2.20 \\
\hline USC00107346 & PRESTON & 0.61 & 0.71 & 0.96 & 1.30 & 1.53 & 1.77 & 2.09 & 2.33 & 2.59 & 2.94 \\
\hline USC00107644 & REXBURG BYU IDAHO & 0.41 & 0.48 & 0.64 & 0.87 & 1.03 & 1.19 & 1.41 & 1.57 & 1.74 & 1.98 \\
\hline USC00108022 & SAINT ANTHONY & 0.52 & 0.60 & 0.80 & 1.09 & 1.29 & 1.49 & 1.75 & 1.96 & 2.17 & 2.47 \\
\hline USC00108818 & SUGAR CITY & 0.45 & 0.53 & 0.71 & 0.96 & 1.13 & 1.31 & 1.54 & 1.72 & 1.91 & 2.16 \\
\hline USC00108937 & SWAN VALLEY & 0.51 & 0.59 & 0.79 & 1.07 & 1.26 & 1.46 & 1.72 & 1.92 & 2.13 & 2.41 \\
\hline USC00109065 & TETONIA EXP STN & 0.47 & 0.55 & 0.73 & 0.99 & 1.17 & 1.35 & 1.59 & 1.78 & 1.98 & 2.24 \\
\hline USC00480027 & AFTON & 0.50 & 0.59 & 0.78 & 1.06 & 1.26 & 1.45 & 1.71 & 1.91 & 2.12 & 2.41 \\
\hline USC00480140 & ALTA 1 NNW & 0.54 & 0.63 & 0.85 & 1.15 & 1.36 & 1.57 & 1.85 & 2.07 & 2.29 & 2.60 \\
\hline USC00484910 & JACKSON & 0.56 & 0.65 & 0.87 & 1.18 & 1.40 & 1.61 & 1.90 & 2.12 & 2.36 & 2.67 \\
\hline USS0011G33S & Giveout & 0.61 & 0.71 & 0.95 & 1.29 & 1.53 & 1.76 & 2.08 & 2.32 & 2.58 & 2.92 \\
\hline USW00024145 & IDAHO FALLS FANNING FLD & 0.39 & 0.45 & 0.60 & 0.81 & 0.96 & 1.11 & 1.31 & 1.46 & 1.62 & 1.84 \\
\hline USW00024151 & MALAD CITY & 0.49 & 0.57 & 0.76 & 1.03 & 1.22 & 1.40 & 1.65 & 1.85 & 2.05 & 2.33 \\
\hline USW00024156 & POCATELLO RGNL AP & 0.44 & 0.52 & 0.69 & 0.94 & 1.11 & 1.28 & 1.51 & 1.68 & 1.87 & 2.12 \\
\hline
\end{tabular}


Table A-3. Region1 regionally factored 95\% confidence interval (24-hour).

\begin{tabular}{|c|c|c|c|c|c|c|c|c|c|c|c|}
\hline & & \multicolumn{10}{|c|}{ Exceedance Probability } \\
\hline \multicolumn{2}{|r|}{ 24-Hour Total (inches) } & 0.90 & 0.80 & 0.50 & 0.20 & 0.10 & 0.05 & 0.02 & 0.01 & 0.005 & 0.002 \\
\hline \multicolumn{2}{|r|}{ 95\% Confidence Interval } & \multicolumn{10}{|c|}{ Return Period (years) } \\
\hline ID & Station Name & 1.11 & 1.25 & 2 & 5 & 10 & 20 & 50 & 100 & 200 & 500 \\
\hline USC00100010 & ABERDEEN EXP STN & 0.45 & 0.51 & 0.66 & 0.90 & 1.08 & 1.25 & 1.49 & 1.68 & 1.88 & 2.16 \\
\hline USC00100915 & BLACKFOOT FIRE DEPT & 0.51 & 0.57 & 0.75 & 1.02 & 1.22 & 1.41 & 1.68 & 1.89 & 2.12 & 2.43 \\
\hline USC00102676 & DRIGGS & 0.54 & 0.62 & 0.80 & 1.09 & 1.30 & 1.51 & 1.80 & 2.03 & 2.27 & 2.60 \\
\hline USC00103297 & FT HALL 1 NNE & 0.45 & 0.51 & 0.67 & 0.91 & 1.09 & 1.26 & 1.50 & 1.70 & 1.89 & 2.17 \\
\hline USC00103732 & GRACE & 0.50 & 0.57 & 0.74 & 1.01 & 1.20 & 1.40 & 1.67 & 1.88 & 2.10 & 2.41 \\
\hline USC00104455 & IDAHO FALLS - KIFI & 0.52 & 0.59 & 0.77 & 1.05 & 1.24 & 1.44 & 1.72 & 1.93 & 2.16 & 2.47 \\
\hline USC00104456 & IDAHO FALLS 16 SE & 0.62 & 0.71 & 0.92 & 1.25 & 1.49 & 1.73 & 2.06 & 2.32 & 2.60 & 2.97 \\
\hline USC00105275 & LIFTON PUMPING STN & 0.46 & 0.52 & 0.68 & 0.93 & 1.11 & 1.29 & 1.53 & 1.73 & 1.93 & 2.22 \\
\hline USC00105716 & MCCAMMON & 0.69 & 0.79 & 1.03 & 1.40 & 1.66 & 1.92 & 2.28 & 2.57 & 2.87 & 3.28 \\
\hline USC00107208 & POCATELLO 2 NE & 0.54 & 0.61 & 0.80 & 1.09 & 1.29 & 1.50 & 1.78 & 2.00 & 2.23 & 2.55 \\
\hline USC00107346 & PRESTON & 0.71 & 0.81 & 1.07 & 1.45 & 1.72 & 2.00 & 2.37 & 2.67 & 2.98 & 3.41 \\
\hline USC00107644 & REXBURG BYU IDAHO & 0.49 & 0.55 & 0.73 & 0.99 & 1.17 & 1.35 & 1.61 & 1.81 & 2.02 & 2.31 \\
\hline USC00108022 & SAINT ANTHONY & 0.59 & 0.66 & 0.87 & 1.18 & 1.41 & 1.64 & 1.95 & 2.19 & 2.45 & 2.81 \\
\hline USC00108818 & SUGAR CITY & 0.52 & 0.59 & 0.77 & 1.04 & 1.24 & 1.44 & 1.71 & 1.93 & 2.16 & 2.48 \\
\hline USC00108937 & SWAN VALLEY & 0.58 & 0.65 & 0.86 & 1.17 & 1.39 & 1.61 & 1.91 & 2.16 & 2.41 & 2.76 \\
\hline USC00109065 & TETONIA EXP STN & 0.54 & 0.62 & 0.81 & 1.10 & 1.31 & 1.51 & 1.80 & 2.02 & 2.26 & 2.59 \\
\hline USC00480027 & AFTON & 0.58 & 0.66 & 0.86 & 1.17 & 1.39 & 1.61 & 1.92 & 2.16 & 2.41 & 2.77 \\
\hline USC00480140 & ALTA 1 NNW & 0.62 & 0.70 & 0.91 & 1.24 & 1.47 & 1.71 & 2.04 & 2.30 & 2.57 & 2.95 \\
\hline USC00484910 & JACKSON & 0.63 & 0.72 & 0.94 & 1.28 & 1.52 & 1.77 & 2.11 & 2.37 & 2.65 & 3.04 \\
\hline USS0011G33S & Giveout & 0.71 & 0.81 & 1.06 & 1.44 & 1.71 & 1.98 & 2.35 & 2.64 & 2.95 & 3.38 \\
\hline USW00024145 & IDAHO FALLS FANNING FLD & 0.44 & 0.50 & 0.65 & 0.88 & 1.05 & 1.22 & 1.45 & 1.64 & 1.83 & 2.10 \\
\hline USW00024151 & MALAD CITY & 0.55 & 0.63 & 0.82 & 1.12 & 1.33 & 1.54 & 1.84 & 2.07 & 2.31 & 2.65 \\
\hline USW00024156 & POCATELLO RGNL AP & 0.50 & 0.57 & 0.74 & 1.01 & 1.20 & 1.39 & 1.66 & 1.87 & 2.09 & 2.40 \\
\hline
\end{tabular}


Table A-4. Region 1 regionally factored $5 \%$ confidence interval (24-hour).

\begin{tabular}{|c|c|c|c|c|c|c|c|c|c|c|c|}
\hline & & & & & & xceeda & babili & & & & \\
\hline & 24-Hour Total (inches) & 0.90 & 0.80 & 0.50 & 0.20 & 0.10 & 0.05 & 0.02 & 0.01 & 0.005 & 0.002 \\
\hline & $\%$ Confidence Interval & & & & & Return & (years & & & & \\
\hline ID & Station Name & 1.11 & 1.25 & 2 & 5 & 10 & 20 & 50 & 100 & 200 & 500 \\
\hline USC00100010 & ABERDEEN EXP STN & 0.36 & 0.43 & 0.58 & 0.79 & 0.92 & 1.05 & 1.22 & 1.35 & 1.48 & 1.65 \\
\hline USC00100915 & BLACKFOOT FIRE DEPT & 0.40 & 0.48 & 0.66 & 0.88 & 1.03 & 1.17 & 1.36 & 1.51 & 1.65 & 1.85 \\
\hline USC00102676 & DRIGGS & 0.43 & 0.51 & 0.70 & 0.93 & 1.09 & 1.25 & 1.45 & 1.60 & 1.76 & 1.97 \\
\hline USC00103297 & FT HALL 1 NNE & 0.36 & 0.43 & 0.59 & 0.79 & 0.92 & 1.05 & 1.23 & 1.36 & 1.49 & 1.66 \\
\hline USC00103732 & GRACE & 0.40 & 0.48 & 0.65 & 0.87 & 1.02 & 1.17 & 1.36 & 1.50 & 1.65 & 1.84 \\
\hline USC00104455 & IDAHO FALLS - KIFI & 0.40 & 0.47 & 0.64 & 0.85 & 1.00 & 1.14 & 1.33 & 1.47 & 1.62 & 1.81 \\
\hline USC00104456 & IDAHO FALLS 16 SE & 0.48 & 0.57 & 0.78 & 1.05 & 1.23 & 1.40 & 1.63 & 1.80 & 1.98 & 2.22 \\
\hline USC00105275 & LIFTON PUMPING STN & 0.37 & 0.44 & 0.60 & 0.80 & 0.94 & 1.07 & 1.25 & 1.38 & 1.51 & 1.69 \\
\hline USC00105716 & MCCAMMON & 0.52 & 0.61 & 0.83 & 1.12 & 1.31 & 1.50 & 1.75 & 1.94 & 2.13 & 2.38 \\
\hline USC00107208 & POCATELLO 2 NE & 0.40 & 0.47 & 0.64 & 0.86 & 1.01 & 1.16 & 1.35 & 1.49 & 1.64 & 1.84 \\
\hline USC00107346 & PRESTON & 0.53 & 0.63 & 0.86 & 1.15 & 1.35 & 1.54 & 1.80 & 1.99 & 2.19 & 2.46 \\
\hline USC00107644 & REXBURG BYU IDAHO & 0.36 & 0.42 & 0.57 & 0.77 & 0.90 & 1.03 & 1.20 & 1.33 & 1.46 & 1.64 \\
\hline USC00108022 & SAINT ANTHONY & 0.46 & 0.55 & 0.74 & 1.00 & 1.17 & 1.34 & 1.55 & 1.72 & 1.89 & 2.12 \\
\hline USC00108818 & SUGAR CITY & 0.40 & 0.48 & 0.65 & 0.87 & 1.02 & 1.17 & 1.36 & 1.50 & 1.65 & 1.84 \\
\hline USC00108937 & SWAN VALLEY & 0.45 & 0.53 & 0.72 & 0.97 & 1.14 & 1.30 & 1.51 & 1.67 & 1.84 & 2.05 \\
\hline USC00109065 & TETONIA EXP STN & 0.41 & 0.49 & 0.66 & 0.89 & 1.04 & 1.19 & 1.39 & 1.53 & 1.68 & 1.89 \\
\hline USC00480027 & AFTON & 0.44 & 0.53 & 0.72 & 0.96 & 1.13 & 1.29 & 1.50 & 1.66 & 1.82 & 2.03 \\
\hline USC00480140 & ALTA 1 NNW & 0.49 & 0.58 & 0.79 & 1.06 & 1.24 & 1.42 & 1.65 & 1.83 & 2.00 & 2.24 \\
\hline USC00484910 & JACKSON & 0.50 & 0.59 & 0.81 & 1.09 & 1.27 & 1.45 & 1.69 & 1.87 & 2.05 & 2.30 \\
\hline USS0011G33S & Giveout & 0.53 & 0.63 & 0.86 & 1.16 & 1.35 & 1.55 & 1.80 & 1.99 & 2.19 & 2.45 \\
\hline USW00024145 & IDAHO FALLS FANNING FLD & 0.34 & 0.41 & 0.56 & 0.75 & 0.87 & 1.00 & 1.16 & 1.28 & 1.41 & 1.58 \\
\hline USW00024151 & MALAD CITY & 0.43 & 0.51 & 0.70 & 0.94 & 1.10 & 1.26 & 1.46 & 1.62 & 1.78 & 1.99 \\
\hline USW00024156 & POCATELLO RGNL AP & 0.40 & 0.47 & 0.64 & 0.87 & 1.01 & 1.15 & 1.34 & 1.49 & 1.63 & 1.82 \\
\hline
\end{tabular}




\section{A.3.2 Region 2 regionally factored quantiles (24-hour)}

Table A-5. Region 2 regionally factored quantiles (24-hour).

\begin{tabular}{|c|c|c|c|c|c|c|c|c|c|c|c|}
\hline & & \multicolumn{10}{|c|}{ Exceedance Probability } \\
\hline \multicolumn{2}{|c|}{ 24-Hour Total (inches) } & 0.90 & 0.80 & 0.50 & 0.20 & 0.10 & 0.05 & 0.02 & 0.01 & 0.005 & 0.002 \\
\hline & & \multicolumn{10}{|c|}{ Return Period (years) } \\
\hline ID & Station Name & 1.11 & 1.25 & 2 & 5 & 10 & 20 & 50 & 100 & 200 & 500 \\
\hline USS0010F23S & Phillips Bench & 1.20 & 1.34 & 1.68 & 2.15 & 2.47 & 2.78 & 3.19 & 3.51 & 3.83 & 4.26 \\
\hline USS0010G08S & Salt River Summit & 0.74 & 0.83 & 1.04 & 1.33 & 1.53 & 1.72 & 1.97 & 2.17 & 2.37 & 2.63 \\
\hline USS0010G12S & Kelley R.S. & 0.83 & 0.92 & 1.16 & 1.48 & 1.70 & 1.92 & 2.20 & 2.42 & 2.64 & 2.94 \\
\hline USS0010G23S & Willow Creek & 1.26 & 1.41 & 1.77 & 2.27 & 2.60 & 2.93 & 3.37 & 3.70 & 4.04 & 4.49 \\
\hline USSO010G25S & Cottonwood Creek & 0.97 & 1.08 & 1.36 & 1.74 & 2.00 & 2.25 & 2.58 & 2.84 & 3.10 & 3.45 \\
\hline USS0011F02S & Pine Creek Pass & 0.91 & 1.02 & 1.28 & 1.63 & 1.87 & 2.11 & 2.42 & 2.66 & 2.91 & 3.23 \\
\hline USS0011F11S & Sheep Mtn. & 0.71 & 0.80 & 1.00 & 1.28 & 1.46 & 1.65 & 1.89 & 2.08 & 2.27 & 2.53 \\
\hline USS0011G01S & Somsen Ranch & 0.69 & 0.77 & 0.97 & 1.24 & 1.42 & 1.60 & 1.84 & 2.02 & 2.21 & 2.45 \\
\hline USS0011G05S & Slug Creek Divide & 0.83 & 0.93 & 1.17 & 1.49 & 1.72 & 1.93 & 2.22 & 2.44 & 2.66 & 2.96 \\
\hline USS0011G06S & Emigrant Summit & 1.12 & 1.26 & 1.58 & 2.02 & 2.31 & 2.61 & 2.99 & 3.29 & 3.59 & 3.99 \\
\hline USS0011G30S & Sedgwick Peak & 1.02 & 1.14 & 1.43 & 1.83 & 2.10 & 2.37 & 2.72 & 2.99 & 3.26 & 3.63 \\
\hline USS0011G32S & Franklin Basin & 1.39 & 1.56 & 1.95 & 2.50 & 2.86 & 3.23 & 3.70 & 4.07 & 4.44 & 4.94 \\
\hline USS0012G17S & Wildhorse Divide & 0.99 & 1.11 & 1.39 & 1.78 & 2.05 & 2.30 & 2.65 & 2.91 & 3.17 & 3.53 \\
\hline USS0012G18S & Oxford Spring & 0.92 & 1.03 & 1.29 & 1.65 & 1.89 & 2.13 & 2.45 & 2.69 & 2.94 & 3.27 \\
\hline
\end{tabular}


Table A-6. Region 2 regionally factored 95\% confidence interval (24-hour).

\begin{tabular}{|c|c|c|c|c|c|c|c|c|c|c|c|}
\hline \multirow{2}{*}{\multicolumn{2}{|c|}{ 24-Hour Total (inches) }} & \multicolumn{10}{|c|}{ Exceedance Probability } \\
\hline & & 0.90 & 0.80 & 0.50 & 0.20 & 0.10 & 0.05 & 0.02 & 0.01 & 0.005 & 0.002 \\
\hline \multicolumn{2}{|c|}{ 95\% Confidence Interval } & \multicolumn{10}{|c|}{ Return Period (years) } \\
\hline ID & Station Name & 1.11 & 1.25 & 2 & 5 & 10 & 20 & 50 & 100 & 200 & 500 \\
\hline USS0010F23S & Phillips Bench & 1.38 & 1.50 & 1.83 & 2.35 & 2.74 & 3.14 & 3.70 & 4.15 & 4.61 & 5.29 \\
\hline USS0010G08S & Salt River Summit & 0.85 & 0.93 & 1.13 & 1.45 & 1.69 & 1.94 & 2.29 & 2.56 & 2.86 & 3.27 \\
\hline USS0010G12S & Kelley R.S. & 0.95 & 1.04 & 1.26 & 1.62 & 1.89 & 2.17 & 2.55 & 2.86 & 3.18 & 3.65 \\
\hline USS0010G23S & Willow Creek & 1.45 & 1.58 & 1.93 & 2.48 & 2.89 & 3.31 & 3.90 & 4.37 & 4.86 & 5.57 \\
\hline USS0010G25S & Cottonwood Creek & 1.12 & 1.22 & 1.48 & 1.91 & 2.22 & 2.54 & 2.99 & 3.36 & 3.74 & 4.29 \\
\hline USS0011F02S & Pine Creek Pass & 1.05 & 1.15 & 1.40 & 1.80 & 2.10 & 2.40 & 2.82 & 3.17 & 3.53 & 4.04 \\
\hline USS0011F11S & Sheep Mtn. & 0.82 & 0.89 & 1.09 & 1.40 & 1.63 & 1.86 & 2.19 & 2.45 & 2.74 & 3.13 \\
\hline USS0011G01S & Somsen Ranch & 0.79 & 0.86 & 1.05 & 1.35 & 1.58 & 1.81 & 2.13 & 2.39 & 2.66 & 3.06 \\
\hline USS0011G05S & Slug Creek Divide & 0.96 & 1.04 & 1.27 & 1.63 & 1.90 & 2.18 & 2.57 & 2.88 & 3.21 & 3.68 \\
\hline USS0011G06S & Emigrant Summit & 1.29 & 1.41 & 1.71 & 2.20 & 2.57 & 2.94 & 3.46 & 3.88 & 4.33 & 4.97 \\
\hline USS0011G30S & Sedgwick Peak & 1.18 & 1.29 & 1.58 & 2.02 & 2.35 & 2.69 & 3.16 & 3.54 & 3.95 & 4.52 \\
\hline USS0011G32S & Franklin Basin & 1.60 & 1.74 & 2.12 & 2.73 & 3.17 & 3.64 & 4.28 & 4.80 & 5.34 & 6.13 \\
\hline USS0012G17S & Wildhorse Divide & 1.15 & 1.25 & 1.52 & 1.95 & 2.27 & 2.60 & 3.07 & 3.44 & 3.84 & 4.40 \\
\hline USS0012G18S & Oxford Spring & 1.06 & 1.16 & 1.41 & 1.81 & 2.11 & 2.41 & 2.83 & 3.18 & 3.54 & 4.06 \\
\hline
\end{tabular}


Table A-7. Region 2 regionally factored $5 \%$ confidence interval (24-hour).

\begin{tabular}{|c|c|c|c|c|c|c|c|c|c|c|c|}
\hline & & \multicolumn{10}{|c|}{ Exceedance Probability } \\
\hline \multicolumn{2}{|c|}{ 24-Hour Total (inches) } & 0.90 & 0.80 & 0.50 & 0.20 & 0.10 & 0.05 & 0.02 & 0.01 & 0.005 & 0.002 \\
\hline \multicolumn{2}{|c|}{ 5\% Confidence Interval } & \multicolumn{10}{|c|}{ Return Period (years) } \\
\hline ID & Station Name & 1.11 & 1.25 & 2 & 5 & 10 & 20 & 50 & 100 & 200 & 500 \\
\hline USS0010F23S & Phillips Bench & 1.06 & 1.21 & 1.55 & 1.94 & 2.19 & 2.42 & 2.71 & 2.92 & 3.13 & 3.39 \\
\hline USS0010G08S & Salt River Summit & 0.65 & 0.75 & 0.96 & 1.20 & 1.36 & 1.50 & 1.68 & 1.81 & 1.93 & 2.10 \\
\hline USS0010G12S & Kelley R.S. & 0.73 & 0.84 & 1.07 & 1.34 & 1.51 & 1.67 & 1.87 & 2.02 & 2.16 & 2.33 \\
\hline USS0010G23S & Willow Creek & 1.12 & 1.28 & 1.64 & 2.06 & 2.32 & 2.56 & 2.87 & 3.09 & 3.31 & 3.59 \\
\hline USS0010G25S & Cottonwood Creek & 0.85 & 0.98 & 1.25 & 1.57 & 1.77 & 1.96 & 2.20 & 2.36 & 2.53 & 2.74 \\
\hline USS0011F02S & Pine Creek Pass & 0.80 & 0.91 & 1.17 & 1.47 & 1.65 & 1.83 & 2.05 & 2.21 & 2.36 & 2.56 \\
\hline USS0011F11S & Sheep Mtn. & 0.63 & 0.72 & 0.92 & 1.15 & 1.30 & 1.44 & 1.61 & 1.74 & 1.86 & 2.01 \\
\hline USS0011G01S & Somsen Ranch & 0.61 & 0.70 & 0.90 & 1.12 & 1.27 & 1.40 & 1.56 & 1.69 & 1.80 & 1.95 \\
\hline USS0011G05S & Slug Creek Divide & 0.73 & 0.84 & 1.08 & 1.35 & 1.52 & 1.68 & 1.88 & 2.03 & 2.18 & 2.36 \\
\hline USS0011G06S & Emigrant Summit & 0.99 & 1.14 & 1.46 & 1.83 & 2.06 & 2.27 & 2.55 & 2.75 & 2.94 & 3.19 \\
\hline USS0011G30S & Sedgwick Peak & 0.90 & 1.03 & 1.31 & 1.65 & 1.86 & 2.05 & 2.30 & 2.48 & 2.65 & 2.88 \\
\hline USS0011G32S & Franklin Basin & 1.23 & 1.41 & 1.80 & 2.26 & 2.54 & 2.81 & 3.15 & 3.39 & 3.63 & 3.92 \\
\hline USS0012G17S & Wildhorse Divide & 0.87 & 1.00 & 1.28 & 1.61 & 1.81 & 2.01 & 2.25 & 2.42 & 2.59 & 2.80 \\
\hline USS0012G18S & Oxford Spring & 0.81 & 0.93 & 1.19 & 1.49 & 1.68 & 1.86 & 2.08 & 2.24 & 2.40 & 2.60 \\
\hline
\end{tabular}




\section{A.3.3 Region 1 regionally factored quantiles (48-hour)}

Table A-8. Region 1 regionally factored quantiles (48-hour).

\begin{tabular}{|c|c|c|c|c|c|c|c|c|c|c|c|}
\hline & & \multicolumn{10}{|c|}{ Exceedance Probability } \\
\hline \multicolumn{2}{|c|}{ 48-Hour Total (inches) } & 0.90 & 0.80 & 0.50 & 0.20 & 0.10 & 0.05 & 0.02 & 0.01 & 0.005 & 0.002 \\
\hline & & \multicolumn{10}{|c|}{ Return Period (years) } \\
\hline ID & Station Name & 1.11 & 1.25 & 2 & 5 & 10 & 20 & 50 & 100 & 200 & 500 \\
\hline USC00100010 & ABERDEEN EXP STN & 0.47 & 0.55 & 0.73 & 0.99 & 1.16 & 1.33 & 1.56 & 1.74 & 1.92 & 2.17 \\
\hline USC00100915 & BLACKFOOT FIRE DEPT & 0.55 & 0.63 & 0.85 & 1.14 & 1.34 & 1.54 & 1.81 & 2.01 & 2.22 & 2.50 \\
\hline USC00102676 & DRIGGS & 0.57 & 0.66 & 0.88 & 1.18 & 1.39 & 1.59 & 1.87 & 2.08 & 2.30 & 2.59 \\
\hline USC00103297 & FT HALL 1 NNE & 0.49 & 0.57 & 0.76 & 1.02 & 1.20 & 1.38 & 1.62 & 1.80 & 1.99 & 2.24 \\
\hline USC00103732 & GRACE & 0.58 & 0.67 & 0.90 & 1.21 & 1.43 & 1.64 & 1.92 & 2.14 & 2.36 & 2.66 \\
\hline USC00104455 & IDAHO FALLS - KIFI & 0.54 & 0.63 & 0.84 & 1.13 & 1.33 & 1.53 & 1.79 & 1.99 & 2.20 & 2.48 \\
\hline USC00104456 & IDAHO FALLS 16 SE & 0.66 & 0.77 & 1.02 & 1.38 & 1.62 & 1.86 & 2.18 & 2.43 & 2.68 & 3.02 \\
\hline USC00105275 & LIFTON PUMPING STN & 0.51 & 0.59 & 0.79 & 1.06 & 1.25 & 1.43 & 1.68 & 1.87 & 2.06 & 2.33 \\
\hline USC00105716 & MCCAMMON & 0.73 & 0.84 & 1.12 & 1.52 & 1.78 & 2.05 & 2.40 & 2.67 & 2.95 & 3.33 \\
\hline USC00107208 & POCATELLO 2 NE & 0.55 & 0.64 & 0.85 & 1.15 & 1.35 & 1.55 & 1.82 & 2.03 & 2.24 & 2.52 \\
\hline USC00107346 & PRESTON & 0.71 & 0.83 & 1.10 & 1.49 & 1.75 & 2.01 & 2.35 & 2.62 & 2.89 & 3.26 \\
\hline USC00107644 & REXBURG BYU IDAHO & 0.53 & 0.61 & 0.82 & 1.10 & 1.30 & 1.49 & 1.74 & 1.94 & 2.14 & 2.42 \\
\hline USC00108022 & SAINT ANTHONY & 0.62 & 0.72 & 0.96 & 1.30 & 1.53 & 1.75 & 2.06 & 2.29 & 2.53 & 2.85 \\
\hline USC00108818 & SUGAR CITY & 0.52 & 0.61 & 0.81 & 1.09 & 1.29 & 1.48 & 1.73 & 1.93 & 2.13 & 2.40 \\
\hline USC00108937 & SWAN VALLEY & 0.59 & 0.68 & 0.91 & 1.23 & 1.44 & 1.66 & 1.94 & 2.16 & 2.39 & 2.70 \\
\hline USC00109065 & TETONIA EXP STN & 0.58 & 0.68 & 0.90 & 1.22 & 1.43 & 1.64 & 1.93 & 2.14 & 2.37 & 2.67 \\
\hline USC00480027 & AFTON & 0.62 & 0.72 & 0.96 & 1.30 & 1.53 & 1.76 & 2.06 & 2.29 & 2.53 & 2.85 \\
\hline USC00480140 & ALTA 1 NNW & 0.67 & 0.77 & 1.03 & 1.39 & 1.63 & 1.88 & 2.20 & 2.45 & 2.70 & 3.05 \\
\hline USC00484910 & JACKSON & 0.68 & 0.79 & 1.06 & 1.42 & 1.68 & 1.92 & 2.26 & 2.51 & 2.77 & 3.13 \\
\hline USS0011G33S & Giveout & 0.81 & 0.94 & 1.25 & 1.69 & 1.99 & 2.29 & 2.68 & 2.98 & 3.29 & 3.71 \\
\hline USW00024145 & IDAHO FALLS FANNING FLD & 0.45 & 0.53 & 0.70 & 0.94 & 1.11 & 1.28 & 1.49 & 1.66 & 1.84 & 2.07 \\
\hline USW00024151 & MALAD CITY & 0.62 & 0.72 & 0.95 & 1.29 & 1.51 & 1.74 & 2.04 & 2.27 & 2.50 & 2.83 \\
\hline USW00024156 & POCATELLO RGNL AP & 0.53 & 0.62 & 0.83 & 1.11 & 1.31 & 1.50 & 1.76 & 1.96 & 2.17 & 2.44 \\
\hline
\end{tabular}


Table A-9. Region 1 regionally factored 95\% confidence interval (48-hour).

\begin{tabular}{|c|c|c|c|c|c|c|c|c|c|c|c|}
\hline \multirow{2}{*}{\multicolumn{2}{|c|}{ 48-Hour Total (inches) }} & \multicolumn{10}{|c|}{ Exceedance Probability } \\
\hline & & 0.90 & 0.80 & 0.50 & 0.20 & 0.10 & 0.05 & 0.02 & 0.01 & 0.005 & 0.002 \\
\hline \multicolumn{2}{|c|}{$95 \%$ Confidence Interval } & \multicolumn{10}{|c|}{ Return Period (years) } \\
\hline ID & Station Name & 1.11 & 1.25 & 2 & 5 & 10 & 20 & 50 & 100 & 200 & 500 \\
\hline USC00100010 & ABERDEEN EXP STN & 0.54 & 0.61 & 0.78 & 1.06 & 1.26 & 1.46 & 1.74 & 1.95 & 2.18 & 2.49 \\
\hline USC00100915 & BLACKFOOT FIRE DEPT & 0.63 & 0.70 & 0.91 & 1.22 & 1.46 & 1.69 & 2.01 & 2.27 & 2.53 & 2.89 \\
\hline USC00102676 & DRIGGS & 0.65 & 0.73 & 0.94 & 1.27 & 1.52 & 1.76 & 2.09 & 2.35 & 2.62 & 3.00 \\
\hline USC00103297 & FT HALL 1 NNE & 0.56 & 0.63 & 0.81 & 1.09 & 1.30 & 1.52 & 1.80 & 2.03 & 2.26 & 2.59 \\
\hline USC00103732 & GRACE & 0.67 & 0.75 & 0.96 & 1.30 & 1.55 & 1.80 & 2.14 & 2.41 & 2.68 & 3.06 \\
\hline USC00104455 & IDAHO FALLS - KIFI & 0.64 & 0.72 & 0.92 & 1.25 & 1.48 & 1.72 & 2.04 & 2.29 & 2.55 & 2.90 \\
\hline USC00104456 & IDAHO FALLS 16 SE & 0.77 & 0.86 & 1.11 & 1.50 & 1.78 & 2.07 & 2.46 & 2.76 & 3.08 & 3.52 \\
\hline USC00105275 & LIFTON PUMPING STN & 0.58 & 0.65 & 0.84 & 1.14 & 1.36 & 1.57 & 1.87 & 2.10 & 2.34 & 2.68 \\
\hline USC00105716 & MCCAMMON & 0.86 & 0.97 & 1.25 & 1.68 & 2.00 & 2.31 & 2.74 & 3.08 & 3.43 & 3.91 \\
\hline USC00107208 & POCATELLO 2 NE & 0.65 & 0.74 & 0.95 & 1.28 & 1.52 & 1.76 & 2.09 & 2.35 & 2.61 & 2.98 \\
\hline USC00107346 & PRESTON & 0.84 & 0.95 & 1.23 & 1.66 & 1.96 & 2.27 & 2.69 & 3.02 & 3.36 & 3.83 \\
\hline USC00107644 & REXBURG BYU IDAHO & 0.63 & 0.71 & 0.92 & 1.24 & 1.47 & 1.70 & 2.01 & 2.26 & 2.51 & 2.86 \\
\hline USC00108022 & SAINT ANTHONY & 0.72 & 0.81 & 1.04 & 1.41 & 1.68 & 1.95 & 2.31 & 2.60 & 2.90 & 3.31 \\
\hline USC00108818 & SUGAR CITY & 0.61 & 0.69 & 0.88 & 1.19 & 1.42 & 1.64 & 1.95 & 2.19 & 2.44 & 2.78 \\
\hline USC00108937 & SWAN VALLEY & 0.69 & 0.77 & 0.99 & 1.34 & 1.59 & 1.85 & 2.20 & 2.47 & 2.75 & 3.14 \\
\hline USC00109065 & TETONIA EXP STN & 0.69 & 0.77 & 1.00 & 1.34 & 1.60 & 1.85 & 2.20 & 2.46 & 2.74 & 3.13 \\
\hline USC00480027 & AFTON & 0.73 & 0.82 & 1.06 & 1.43 & 1.69 & 1.97 & 2.34 & 2.63 & 2.92 & 3.33 \\
\hline USC00480140 & ALTA 1 NNW & 0.77 & 0.86 & 1.11 & 1.49 & 1.78 & 2.07 & 2.46 & 2.76 & 3.08 & 3.52 \\
\hline USC00484910 & JACKSON & 0.79 & 0.89 & 1.14 & 1.54 & 1.83 & 2.13 & 2.53 & 2.84 & 3.17 & 3.61 \\
\hline USS0011G33S & Giveout & 0.96 & 1.08 & 1.39 & 1.88 & 2.23 & 2.59 & 3.07 & 3.45 & 3.84 & 4.38 \\
\hline USW00024145 & IDAHO FALLS FANNING FLD & 0.53 & 0.59 & 0.76 & 1.02 & 1.22 & 1.42 & 1.68 & 1.89 & 2.11 & 2.41 \\
\hline USW00024151 & MALAD CITY & 0.72 & 0.80 & 1.03 & 1.40 & 1.66 & 1.93 & 2.29 & 2.58 & 2.87 & 3.28 \\
\hline USW00024156 & POCATELLO RGNL AP & 0.62 & 0.69 & 0.89 & 1.20 & 1.43 & 1.66 & 1.97 & 2.22 & 2.47 & 2.82 \\
\hline
\end{tabular}


Table A-10. Region 1 regionally factored $5 \%$ confidence interval (48-hour).

\begin{tabular}{|c|c|c|c|c|c|c|c|c|c|c|c|}
\hline & & \multicolumn{10}{|c|}{ Exceedance Probability } \\
\hline \multicolumn{2}{|r|}{ 48-Hour Total (inches) } & 0.90 & 0.80 & 0.50 & 0.20 & 0.10 & 0.05 & 0.02 & 0.01 & 0.005 & 0.002 \\
\hline \multicolumn{2}{|r|}{ 5\% Confidence Interval } & \multicolumn{10}{|c|}{ Return Period (years) } \\
\hline ID & Station Name & 1.11 & 1.25 & 2 & 5 & 10 & 20 & 50 & 100 & 200 & 500 \\
\hline USC00100010 & ABERDEEN EXP STN & 0.42 & 0.50 & 0.69 & 0.91 & 1.06 & 1.20 & 1.38 & 1.52 & 1.66 & 1.84 \\
\hline USC00100915 & BLACKFOOT FIRE DEPT & 0.48 & 0.58 & 0.79 & 1.06 & 1.22 & 1.39 & 1.60 & 1.76 & 1.92 & 2.13 \\
\hline USC00102676 & DRIGGS & 0.50 & 0.60 & 0.82 & 1.09 & 1.26 & 1.43 & 1.65 & 1.81 & 1.98 & 2.20 \\
\hline USC00103297 & FT HALL 1 NNE & 0.43 & 0.52 & 0.71 & 0.95 & 1.10 & 1.24 & 1.43 & 1.58 & 1.72 & 1.91 \\
\hline USC00103732 & GRACE & 0.51 & 0.61 & 0.84 & 1.12 & 1.30 & 1.47 & 1.70 & 1.87 & 2.04 & 2.26 \\
\hline USC00104455 & IDAHO FALLS - KIFI & 0.47 & 0.56 & 0.77 & 1.02 & 1.18 & 1.34 & 1.54 & 1.70 & 1.86 & 2.07 \\
\hline USC00104456 & IDAHO FALLS 16 SE & 0.58 & 0.69 & 0.94 & 1.25 & 1.45 & 1.65 & 1.90 & 2.09 & 2.28 & 2.54 \\
\hline USC00105275 & LIFTON PUMPING STN & 0.45 & 0.54 & 0.74 & 0.98 & 1.14 & 1.29 & 1.48 & 1.63 & 1.78 & 1.98 \\
\hline USC00105716 & MCCAMMON & 0.63 & 0.75 & 1.02 & 1.35 & 1.57 & 1.78 & 2.06 & 2.27 & 2.48 & 2.76 \\
\hline USC00107208 & POCATELLO 2 NE & 0.47 & 0.56 & 0.77 & 1.02 & 1.19 & 1.35 & 1.55 & 1.71 & 1.87 & 2.08 \\
\hline USC00107346 & PRESTON & 0.61 & 0.73 & 0.99 & 1.32 & 1.53 & 1.74 & 2.01 & 2.21 & 2.42 & 2.70 \\
\hline USC00107644 & REXBURG BYU IDAHO & 0.45 & 0.54 & 0.73 & 0.97 & 1.13 & 1.28 & 1.48 & 1.63 & 1.79 & 1.99 \\
\hline USC00108022 & SAINT ANTHONY & 0.55 & 0.65 & 0.89 & 1.19 & 1.38 & 1.56 & 1.80 & 1.99 & 2.17 & 2.41 \\
\hline USC00108818 & SUGAR CITY & 0.46 & 0.55 & 0.75 & 0.99 & 1.15 & 1.31 & 1.51 & 1.66 & 1.81 & 2.02 \\
\hline USC00108937 & SWAN VALLEY & 0.51 & 0.61 & 0.84 & 1.12 & 1.29 & 1.47 & 1.69 & 1.86 & 2.03 & 2.26 \\
\hline USC00109065 & TETONIA EXP STN & 0.50 & 0.60 & 0.82 & 1.09 & 1.26 & 1.44 & 1.66 & 1.83 & 2.00 & 2.22 \\
\hline USC00480027 & AFTON & 0.54 & 0.65 & 0.88 & 1.17 & 1.36 & 1.54 & 1.78 & 1.96 & 2.14 & 2.39 \\
\hline USC00480140 & ALTA 1 NNW & 0.59 & 0.70 & 0.96 & 1.28 & 1.49 & 1.69 & 1.94 & 2.14 & 2.34 & 2.60 \\
\hline USC00484910 & JACKSON & 0.60 & 0.72 & 0.98 & 1.31 & 1.52 & 1.72 & 1.98 & 2.18 & 2.38 & 2.65 \\
\hline USS0011G33S & Giveout & 0.70 & 0.83 & 1.13 & 1.51 & 1.75 & 1.99 & 2.30 & 2.53 & 2.77 & 3.08 \\
\hline USW00024145 & IDAHO FALLS FANNING FLD & 0.40 & 0.47 & 0.65 & 0.86 & 1.00 & 1.14 & 1.31 & 1.44 & 1.57 & 1.75 \\
\hline USW00024151 & MALAD CITY & 0.54 & 0.65 & 0.89 & 1.17 & 1.36 & 1.54 & 1.78 & 1.96 & 2.14 & 2.38 \\
\hline USW00024156 & POCATELLO RGNL AP & 0.47 & 0.56 & 0.77 & 1.02 & 1.19 & 1.35 & 1.55 & 1.71 & 1.87 & 2.07 \\
\hline
\end{tabular}




\section{A.3.4 Region 2 regionally factored quantiles (48-hour)}

Table A-11. Region 2 regionally factored quantiles (24-hour).

\begin{tabular}{|c|c|c|c|c|c|c|c|c|c|c|c|}
\hline & & \multicolumn{10}{|c|}{ Exceedance Probability } \\
\hline \multicolumn{2}{|c|}{ 48-Hour Total (inches) } & 0.90 & 0.80 & 0.50 & 0.20 & 0.10 & 0.05 & 0.02 & 0.01 & 0.005 & 0.002 \\
\hline & & \multicolumn{10}{|c|}{ Return Period (years) } \\
\hline ID & Station Name & 1.11 & 1.25 & 2 & 5 & 10 & 20 & 50 & 100 & 200 & 500 \\
\hline USS0010F23S & Phillips Bench & 1.62 & 1.81 & 2.27 & 2.91 & 3.35 & 3.79 & 4.38 & 4.83 & 5.30 & 5.94 \\
\hline USS0010G08S & Salt River Summit & 1.02 & 1.14 & 1.42 & 1.82 & 2.10 & 2.38 & 2.75 & 3.03 & 3.33 & 3.73 \\
\hline USS0010G12S & Kelley R.S. & 1.14 & 1.27 & 1.59 & 2.04 & 2.35 & 2.66 & 3.07 & 3.39 & 3.72 & 4.17 \\
\hline USS0010G23S & Willow Creek & 1.67 & 1.87 & 2.34 & 3.00 & 3.45 & 3.90 & 4.51 & 4.98 & 5.46 & 6.12 \\
\hline USSO010G25S & Cottonwood Creek & 1.33 & 1.49 & 1.86 & 2.39 & 2.75 & 3.11 & 3.59 & 3.96 & 4.35 & 4.88 \\
\hline USS0011F02S & Pine Creek Pass & 1.24 & 1.39 & 1.74 & 2.23 & 2.56 & 2.90 & 3.35 & 3.70 & 4.06 & 4.55 \\
\hline USS0011F11S & Sheep Mtn. & 0.94 & 1.05 & 1.32 & 1.69 & 1.95 & 2.20 & 2.54 & 2.81 & 3.08 & 3.45 \\
\hline USS0011G01S & Somsen Ranch & 1.00 & 1.12 & 1.40 & 1.79 & 2.07 & 2.34 & 2.70 & 2.98 & 3.27 & 3.66 \\
\hline USS0011G05S & Slug Creek Divide & 1.17 & 1.31 & 1.64 & 2.10 & 2.42 & 2.73 & 3.16 & 3.49 & 3.82 & 4.29 \\
\hline USS0011G06S & Emigrant Summit & 1.54 & 1.72 & 2.16 & 2.77 & 3.19 & 3.61 & 4.17 & 4.60 & 5.05 & 5.66 \\
\hline USS0011G30S & Sedgwick Peak & 1.41 & 1.57 & 1.97 & 2.53 & 2.91 & 3.29 & 3.80 & 4.20 & 4.61 & 5.17 \\
\hline USS0011G32S & Franklin Basin & 1.71 & 1.91 & 2.40 & 3.07 & 3.54 & 4.00 & 4.62 & 5.11 & 5.60 & 6.28 \\
\hline USS0012G17S & Wildhorse Divide & 1.29 & 1.44 & 1.80 & 2.31 & 2.66 & 3.01 & 3.48 & 3.84 & 4.21 & 4.72 \\
\hline USS0012G18S & Oxford Spring & 1.26 & 1.41 & 1.76 & 2.26 & 2.61 & 2.95 & 3.40 & 3.76 & 4.12 & 4.62 \\
\hline
\end{tabular}


Table A-12. Region 2 regionally factored 95\% confidence interval (48-hour).

\begin{tabular}{|c|c|c|c|c|c|c|c|c|c|c|c|}
\hline \multirow{2}{*}{\multicolumn{2}{|c|}{ 48-Hour Total (inches) }} & \multicolumn{10}{|c|}{ Exceedance Probability } \\
\hline & & 0.90 & 0.80 & 0.50 & 0.20 & 0.10 & 0.05 & 0.02 & 0.01 & 0.005 & 0.002 \\
\hline \multicolumn{2}{|c|}{ 95\% Confidence Interval } & \multicolumn{10}{|c|}{ Return Period (years) } \\
\hline ID & Station Name & 1.11 & 1.25 & 2 & 5 & 10 & 20 & 50 & 100 & 200 & 500 \\
\hline USS0010F23S & Phillips Bench & 1.83 & 2.00 & 2.47 & 3.18 & 3.71 & 4.27 & 5.06 & 5.73 & 6.46 & 7.54 \\
\hline USS0010G08S & Salt River Summit & 1.15 & 1.26 & 1.55 & 2.00 & 2.33 & 2.68 & 3.18 & 3.60 & 4.05 & 4.72 \\
\hline USS0010G12S & Kelley R.S. & 1.28 & 1.41 & 1.73 & 2.24 & 2.61 & 3.00 & 3.56 & 4.02 & 4.53 & 5.29 \\
\hline USS0010G23S & Willow Creek & 1.88 & 2.06 & 2.54 & 3.28 & 3.83 & 4.40 & 5.22 & 5.90 & 6.65 & 7.75 \\
\hline USS0010G25S & Cottonwood Creek & 1.50 & 1.65 & 2.03 & 2.62 & 3.06 & 3.51 & 4.18 & 4.72 & 5.32 & 6.19 \\
\hline USS0011F02S & Pine Creek Pass & 1.42 & 1.55 & 1.91 & 2.45 & 2.86 & 3.29 & 3.91 & 4.41 & 4.97 & 5.78 \\
\hline USS0011F11S & Sheep Mtn. & 1.06 & 1.16 & 1.43 & 1.85 & 2.16 & 2.48 & 2.94 & 3.32 & 3.75 & 4.36 \\
\hline USS0011G01S & Somsen Ranch & 1.13 & 1.23 & 1.52 & 1.96 & 2.29 & 2.64 & 3.13 & 3.54 & 4.00 & 4.65 \\
\hline USS0011G05S & Slug Creek Divide & 1.32 & 1.45 & 1.78 & 2.29 & 2.68 & 3.08 & 3.66 & 4.14 & 4.66 & 5.44 \\
\hline USS0011G06S & Emigrant Summit & 1.74 & 1.91 & 2.35 & 3.03 & 3.53 & 4.06 & 4.82 & 5.45 & 6.14 & 7.14 \\
\hline USS0011G30S & Sedgwick Peak & 1.61 & 1.76 & 2.17 & 2.79 & 3.25 & 3.74 & 4.43 & 5.02 & 5.65 & 6.56 \\
\hline USS0011G32S & Franklin Basin & 1.93 & 2.11 & 2.60 & 3.36 & 3.92 & 4.51 & 5.36 & 6.06 & 6.82 & 7.93 \\
\hline USS0012G17S & Wildhorse Divide & 1.46 & 1.60 & 1.97 & 2.53 & 2.96 & 3.41 & 4.05 & 4.58 & 5.15 & 5.99 \\
\hline USS0012G18S & Oxford Spring & 1.43 & 1.56 & 1.92 & 2.48 & 2.89 & 3.32 & 3.94 & 4.47 & 5.03 & 5.86 \\
\hline
\end{tabular}


Table A-13. Region 2 regionally factored $5 \%$ confidence interval (48-hour).

\begin{tabular}{|c|c|c|c|c|c|c|c|c|c|c|c|}
\hline \multirow{2}{*}{\multicolumn{2}{|c|}{ 48-Hour Total (inches) }} & \multicolumn{10}{|c|}{ Exceedance Probability } \\
\hline & & 0.90 & 0.80 & 0.50 & 0.20 & 0.10 & 0.05 & 0.02 & 0.01 & 0.005 & 0.002 \\
\hline \multicolumn{2}{|c|}{$5 \%$ Confidence Interval } & \multicolumn{10}{|c|}{ Return Period (years) } \\
\hline ID & Station Name & 1.11 & 1.25 & 2 & 5 & 10 & 20 & 50 & 100 & 200 & 500 \\
\hline USS0010F23S & Phillips Bench & 1.45 & 1.65 & 2.09 & 2.64 & 2.99 & 3.32 & 3.72 & 4.02 & 4.31 & 4.68 \\
\hline USS0010G08S & Salt River Summit & 0.91 & 1.04 & 1.31 & 1.66 & 1.88 & 2.08 & 2.34 & 2.53 & 2.70 & 2.93 \\
\hline USS0010G12S & Kelley R.S. & 1.02 & 1.16 & 1.47 & 1.85 & 2.10 & 2.33 & 2.61 & 2.82 & 3.03 & 3.28 \\
\hline USS0010G23S & Willow Creek & 1.49 & 1.70 & 2.15 & 2.72 & 3.09 & 3.42 & 3.85 & 4.16 & 4.45 & 4.83 \\
\hline USS0010G25S & Cottonwood Creek & 1.19 & 1.35 & 1.71 & 2.16 & 2.44 & 2.71 & 3.05 & 3.29 & 3.53 & 3.83 \\
\hline USS0011F02S & Pine Creek Pass & 1.10 & 1.25 & 1.59 & 2.00 & 2.27 & 2.52 & 2.84 & 3.06 & 3.28 & 3.56 \\
\hline USS0011F11S & Sheep Mtn. & 0.84 & 0.96 & 1.21 & 1.53 & 1.73 & 1.92 & 2.16 & 2.33 & 2.50 & 2.71 \\
\hline USS0011G01S & Somsen Ranch & 0.89 & 1.02 & 1.29 & 1.63 & 1.85 & 2.05 & 2.31 & 2.49 & 2.67 & 2.89 \\
\hline USS0011G05S & Slug Creek Divide & 1.05 & 1.19 & 1.51 & 1.91 & 2.16 & 2.40 & 2.69 & 2.91 & 3.12 & 3.38 \\
\hline USS0011G06S & Emigrant Summit & 1.38 & 1.57 & 2.00 & 2.52 & 2.86 & 3.17 & 3.57 & 3.85 & 4.13 & 4.47 \\
\hline USS0011G30S & Sedgwick Peak & 1.25 & 1.42 & 1.80 & 2.28 & 2.58 & 2.86 & 3.22 & 3.48 & 3.74 & 4.06 \\
\hline USS0011G32S & Franklin Basin & 1.53 & 1.74 & 2.21 & 2.79 & 3.15 & 3.50 & 3.94 & 4.25 & 4.57 & 4.96 \\
\hline USS0012G17S & Wildhorse Divide & 1.15 & 1.31 & 1.66 & 2.09 & 2.37 & 2.63 & 2.95 & 3.19 & 3.42 & 3.71 \\
\hline USS0012G18S & Oxford Spring & 1.13 & 1.28 & 1.63 & 2.06 & 2.33 & 2.58 & 2.90 & 3.14 & 3.37 & 3.65 \\
\hline
\end{tabular}


Table A-14. Region 1 regionally factored quantiles (72-hour).

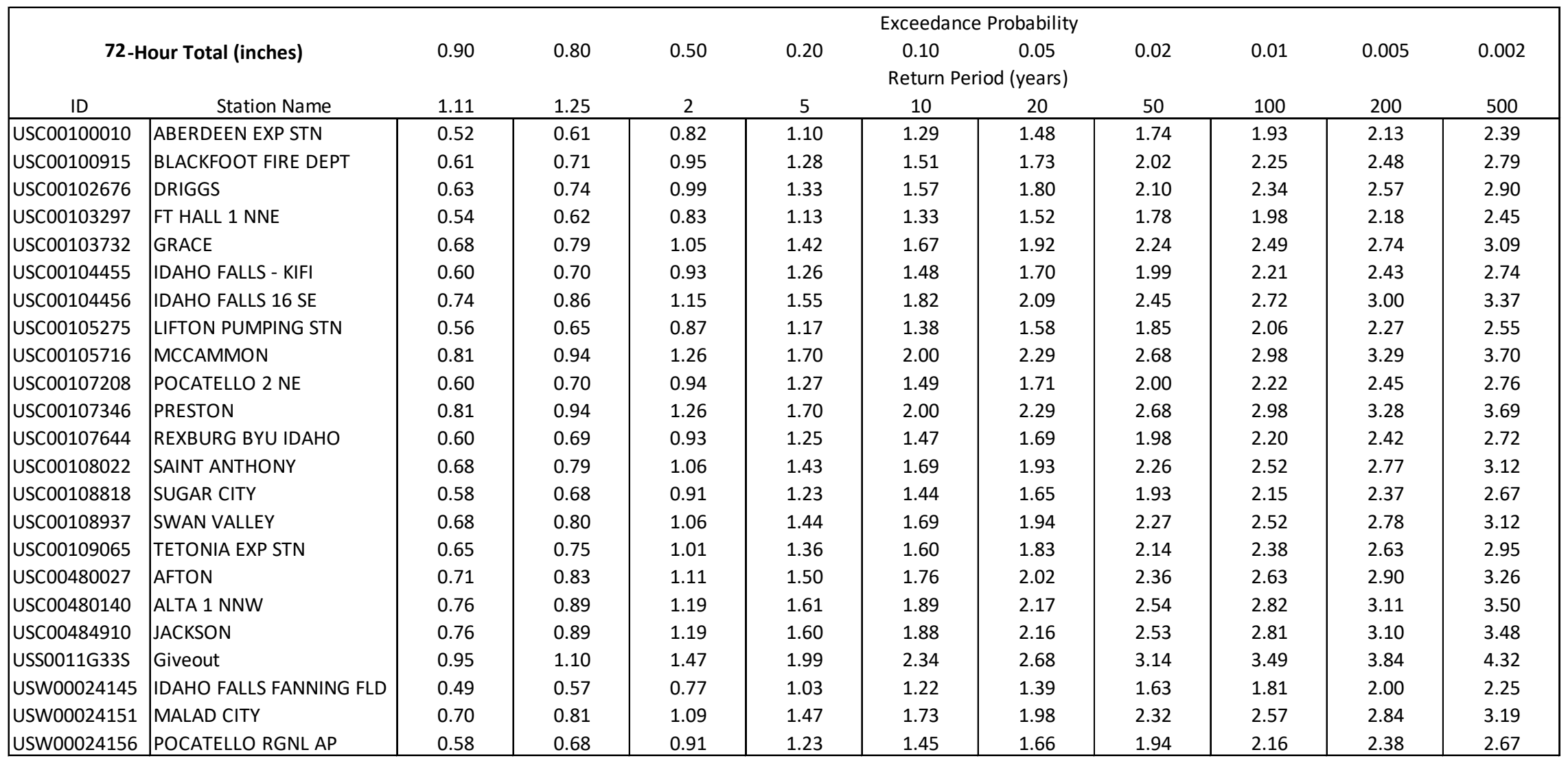


Table A-15. Region 1 regionally factored 95\% confidence interval (72-hour).

\begin{tabular}{|c|c|c|c|c|c|c|c|c|c|c|c|}
\hline \multirow{2}{*}{\multicolumn{2}{|c|}{ 72-Hour Total (inches) }} & \multicolumn{10}{|c|}{ Exceedance Probability } \\
\hline & & 0.90 & 0.80 & 0.50 & 0.20 & 0.10 & 0.05 & 0.02 & 0.01 & 0.005 & 0.002 \\
\hline \multicolumn{2}{|c|}{ 95\% Confidence Interval } & \multicolumn{10}{|c|}{ Return Period (years) } \\
\hline ID & Station Name & 1.11 & 1.25 & 2 & 5 & 10 & 20 & 50 & 100 & 200 & 500 \\
\hline USC00100010 & ABERDEEN EXP STN & 0.60 & 0.67 & 0.87 & 1.18 & 1.41 & 1.63 & 1.94 & 2.17 & 2.42 & 2.75 \\
\hline USC00100915 & BLACKFOOT FIRE DEPT & 0.70 & 0.79 & 1.02 & 1.38 & 1.64 & 1.90 & 2.26 & 2.54 & 2.82 & 3.21 \\
\hline USC00102676 & DRIGGS & 0.73 & 0.82 & 1.06 & 1.44 & 1.71 & 1.98 & 2.35 & 2.64 & 2.94 & 3.35 \\
\hline USC00103297 & FT HALL 1 NNE & 0.62 & 0.69 & 0.89 & 1.21 & 1.44 & 1.67 & 1.98 & 2.23 & 2.48 & 2.82 \\
\hline USC00103732 & GRACE & 0.78 & 0.87 & 1.12 & 1.52 & 1.82 & 2.11 & 2.50 & 2.81 & 3.12 & 3.56 \\
\hline USC00104455 & IDAHO FALLS - KIFI & 0.70 & 0.79 & 1.02 & 1.39 & 1.65 & 1.91 & 2.26 & 2.54 & 2.82 & 3.21 \\
\hline USC00104456 & IDAHO FALLS 16 SE & 0.86 & 0.97 & 1.25 & 1.69 & 2.01 & 2.33 & 2.76 & 3.10 & 3.44 & 3.92 \\
\hline USC00105275 & LIFTON PUMPING STN & 0.64 & 0.72 & 0.93 & 1.26 & 1.50 & 1.74 & 2.07 & 2.32 & 2.58 & 2.94 \\
\hline USC00105716 & MCCAMMON & 0.96 & 1.08 & 1.40 & 1.89 & 2.23 & 2.58 & 3.06 & 3.43 & 3.81 & 4.34 \\
\hline USC00107208 & POCATELLO 2 NE & 0.72 & 0.81 & 1.05 & 1.42 & 1.68 & 1.94 & 2.30 & 2.58 & 2.86 & 3.26 \\
\hline USC00107346 & PRESTON & 0.96 & 1.08 & 1.40 & 1.90 & 2.25 & 2.59 & 3.07 & 3.44 & 3.82 & 4.35 \\
\hline USC00107644 & REXBURG BYU IDAHO & 0.71 & 0.80 & 1.04 & 1.41 & 1.67 & 1.93 & 2.29 & 2.56 & 2.84 & 3.22 \\
\hline USC00108022 & SAINT ANTHONY & 0.79 & 0.89 & 1.15 & 1.56 & 1.85 & 2.15 & 2.55 & 2.86 & 3.18 & 3.62 \\
\hline USC00108818 & SUGAR CITY & 0.68 & 0.76 & 0.99 & 1.34 & 1.59 & 1.84 & 2.18 & 2.45 & 2.72 & 3.10 \\
\hline USC00108937 & SWAN VALLEY & 0.80 & 0.90 & 1.16 & 1.57 & 1.87 & 2.16 & 2.56 & 2.87 & 3.19 & 3.63 \\
\hline USC00109065 & TETONIA EXP STN & 0.76 & 0.86 & 1.11 & 1.50 & 1.78 & 2.06 & 2.44 & 2.74 & 3.04 & 3.46 \\
\hline USC00480027 & AFTON & 0.84 & 0.94 & 1.22 & 1.65 & 1.95 & 2.26 & 2.68 & 3.01 & 3.34 & 3.80 \\
\hline USC00480140 & ALTA 1 NNW & 0.88 & 0.99 & 1.28 & 1.73 & 2.06 & 2.39 & 2.84 & 3.19 & 3.55 & 4.04 \\
\hline USC00484910 & JACKSON & 0.88 & 0.99 & 1.28 & 1.73 & 2.06 & 2.39 & 2.84 & 3.18 & 3.54 & 4.03 \\
\hline USS0011G33S & Giveout & 1.12 & 1.26 & 1.63 & 2.21 & 2.62 & 3.03 & 3.58 & 4.02 & 4.46 & 5.08 \\
\hline USW00024145 & IDAHO FALLS FANNING FLD & 0.57 & 0.64 & 0.83 & 1.12 & 1.33 & 1.55 & 1.83 & 2.06 & 2.29 & 2.61 \\
\hline USW00024151 & MALAD CITY & 0.81 & 0.91 & 1.18 & 1.60 & 1.90 & 2.20 & 2.61 & 2.92 & 3.25 & 3.71 \\
\hline USW00024156 & POCATELLO RGNL AP & 0.68 & 0.76 & 0.98 & 1.32 & 1.58 & 1.83 & 2.16 & 2.43 & 2.70 & 3.08 \\
\hline
\end{tabular}


Table A-16. Region 1 regionally factored $5 \%$ confidence interval (72-hour).

\begin{tabular}{|c|c|c|c|c|c|c|c|c|c|c|c|}
\hline & & & & & & xceeda & babili & & & & \\
\hline & 2-Hour Total (inches) & 0.90 & 0.80 & 0.50 & 0.20 & 0.10 & 0.05 & 0.02 & 0.01 & 0.005 & 0.002 \\
\hline & $\%$ Confidence Interval & & & & & Return & (years & & & & \\
\hline ID & Station Name & 1.11 & 1.25 & 2 & 5 & 10 & 20 & 50 & 100 & 200 & 500 \\
\hline USC00100010 & ABERDEEN EXP STN & 0.46 & 0.56 & 0.77 & 1.02 & 1.18 & 1.34 & 1.54 & 1.70 & 1.85 & 2.05 \\
\hline USC00100915 & BLACKFOOT FIRE DEPT & 0.54 & 0.65 & 0.89 & 1.18 & 1.37 & 1.55 & 1.79 & 1.97 & 2.14 & 2.37 \\
\hline USC00102676 & DRIGGS & 0.56 & 0.67 & 0.92 & 1.22 & 1.42 & 1.61 & 1.85 & 2.03 & 2.22 & 2.46 \\
\hline USC00103297 & FT HALL 1 NNE & 0.47 & 0.57 & 0.79 & 1.04 & 1.21 & 1.37 & 1.58 & 1.73 & 1.89 & 2.09 \\
\hline USC00103732 & GRACE & 0.60 & 0.72 & 0.99 & 1.31 & 1.52 & 1.72 & 1.99 & 2.18 & 2.38 & 2.64 \\
\hline USC00104455 & IDAHO FALLS - KIFI & 0.52 & 0.62 & 0.85 & 1.13 & 1.31 & 1.49 & 1.71 & 1.88 & 2.05 & 2.28 \\
\hline USC00104456 & IDAHO FALLS 16 SE & 0.64 & 0.77 & 1.06 & 1.41 & 1.63 & 1.85 & 2.13 & 2.34 & 2.55 & 2.83 \\
\hline USC00105275 & LIFTON PUMPING STN & 0.49 & 0.59 & 0.82 & 1.09 & 1.26 & 1.43 & 1.64 & 1.81 & 1.97 & 2.18 \\
\hline USC00105716 & MCCAMMON & 0.69 & 0.83 & 1.14 & 1.52 & 1.76 & 2.00 & 2.31 & 2.54 & 2.78 & 3.09 \\
\hline USC00107208 & POCATELLO 2 NE & 0.51 & 0.62 & 0.84 & 1.12 & 1.31 & 1.48 & 1.71 & 1.88 & 2.05 & 2.28 \\
\hline USC00107346 & PRESTON & 0.69 & 0.83 & 1.13 & 1.51 & 1.75 & 1.99 & 2.29 & 2.52 & 2.75 & 3.06 \\
\hline USC00107644 & REXBURG BYU IDAHO & 0.51 & 0.61 & 0.83 & 1.10 & 1.28 & 1.45 & 1.68 & 1.84 & 2.01 & 2.23 \\
\hline USC00108022 & SAINT ANTHONY & 0.60 & 0.72 & 0.99 & 1.31 & 1.52 & 1.73 & 1.99 & 2.18 & 2.38 & 2.64 \\
\hline USC00108818 & SUGAR CITY & 0.51 & 0.61 & 0.84 & 1.11 & 1.29 & 1.47 & 1.69 & 1.86 & 2.02 & 2.24 \\
\hline USC00108937 & SWAN VALLEY & 0.59 & 0.71 & 0.98 & 1.30 & 1.51 & 1.71 & 1.97 & 2.17 & 2.36 & 2.63 \\
\hline USC00109065 & TETONIA EXP STN & 0.56 & 0.67 & 0.91 & 1.21 & 1.41 & 1.60 & 1.84 & 2.03 & 2.21 & 2.45 \\
\hline USC00480027 & AFTON & 0.62 & 0.74 & 1.02 & 1.35 & 1.57 & 1.78 & 2.05 & 2.25 & 2.46 & 2.73 \\
\hline USC00480140 & ALTA 1 NNW & 0.67 & 0.81 & 1.11 & 1.48 & 1.72 & 1.95 & 2.24 & 2.46 & 2.69 & 2.98 \\
\hline USC00484910 & JACKSON & 0.67 & 0.80 & 1.10 & 1.47 & 1.70 & 1.93 & 2.22 & 2.45 & 2.67 & 2.96 \\
\hline USS0011G33S & Giveout & 0.81 & 0.97 & 1.33 & 1.77 & 2.06 & 2.33 & 2.69 & 2.96 & 3.23 & 3.59 \\
\hline USW00024145 & IDAHO FALLS FANNING FLD & 0.43 & 0.52 & 0.71 & 0.94 & 1.10 & 1.24 & 1.43 & 1.57 & 1.72 & 1.91 \\
\hline USW00024151 & MALAD CITY & 0.61 & 0.73 & 1.01 & 1.33 & 1.55 & 1.75 & 2.02 & 2.22 & 2.42 & 2.69 \\
\hline USW00024156 & POCATELLO RGNL AP & 0.51 & 0.62 & 0.85 & 1.13 & 1.31 & 1.49 & 1.71 & 1.88 & 2.05 & 2.28 \\
\hline
\end{tabular}




\section{A.3.5 Region 2 regionally factored quantiles (72-hour)}

Table A-17. Region 2 regionally factored quantiles (72-hour).

\begin{tabular}{|c|c|c|c|c|c|c|c|c|c|c|c|}
\hline & & \multicolumn{10}{|c|}{ Exceedance Probability } \\
\hline \multicolumn{2}{|c|}{ 72-Hour Total (inches) } & 0.90 & 0.80 & 0.50 & 0.20 & 0.10 & 0.05 & 0.02 & 0.01 & 0.005 & 0.002 \\
\hline & & \multicolumn{10}{|c|}{ Return Period (years) } \\
\hline ID & Station Name & 1.11 & 1.25 & 2 & 5 & 10 & 20 & 50 & 100 & 200 & 500 \\
\hline USS0010F23S & Phillips Bench & 1.96 & 2.18 & 2.72 & 3.52 & 4.08 & 4.66 & 5.46 & 6.09 & 6.76 & 7.70 \\
\hline USS0010G08S & Salt River Summit & 1.21 & 1.35 & 1.69 & 2.18 & 2.54 & 2.89 & 3.39 & 3.78 & 4.20 & 4.78 \\
\hline USS0010G12S & Kelley R.S. & 1.35 & 1.50 & 1.88 & 2.43 & 2.82 & 3.22 & 3.77 & 4.21 & 4.67 & 5.32 \\
\hline USS0010G23S & Willow Creek & 2.03 & 2.25 & 2.82 & 3.64 & 4.23 & 4.83 & 5.65 & 6.31 & 7.00 & 7.97 \\
\hline USSO010G25S & Cottonwood Creek & 1.61 & 1.79 & 2.24 & 2.89 & 3.36 & 3.83 & 4.48 & 5.01 & 5.56 & 6.33 \\
\hline USS0011F02S & Pine Creek Pass & 1.52 & 1.69 & 2.12 & 2.73 & 3.17 & 3.62 & 4.24 & 4.73 & 5.25 & 5.98 \\
\hline USS0011F11S & Sheep Mtn. & 1.16 & 1.29 & 1.61 & 2.08 & 2.42 & 2.76 & 3.23 & 3.61 & 4.00 & 4.56 \\
\hline USS0011G01S & Somsen Ranch & 1.21 & 1.35 & 1.69 & 2.18 & 2.53 & 2.89 & 3.38 & 3.78 & 4.19 & 4.77 \\
\hline USS0011G05S & Slug Creek Divide & 1.44 & 1.60 & 2.00 & 2.59 & 3.00 & 3.43 & 4.01 & 4.48 & 4.97 & 5.66 \\
\hline USS0011G06S & Emigrant Summit & 1.90 & 2.11 & 2.64 & 3.41 & 3.96 & 4.52 & 5.29 & 5.91 & 6.56 & 7.47 \\
\hline USS0011G30S & Sedgwick Peak & 1.69 & 1.88 & 2.35 & 3.04 & 3.52 & 4.02 & 4.71 & 5.25 & 5.83 & 6.64 \\
\hline USS0011G32S & Franklin Basin & 2.09 & 2.33 & 2.92 & 3.77 & 4.37 & 4.99 & 5.84 & 6.52 & 7.24 & 8.25 \\
\hline USS0012G17S & Wildhorse Divide & 1.49 & 1.66 & 2.08 & 2.69 & 3.12 & 3.56 & 4.16 & 4.65 & 5.16 & 5.88 \\
\hline USS0012G18S & Oxford Spring & 1.49 & 1.66 & 2.08 & 2.69 & 3.12 & 3.56 & 4.16 & 4.65 & 5.16 & 5.88 \\
\hline
\end{tabular}


Table A-18. Region 2 regionally factored $95 \%$ confidence interval (72-hour).

\begin{tabular}{|c|c|c|c|c|c|c|c|c|c|c|c|}
\hline & & \multicolumn{10}{|c|}{ Exceedance Probability } \\
\hline \multicolumn{2}{|c|}{ 72-Hour Total (inches) } & 0.90 & 0.80 & 0.50 & 0.20 & 0.10 & 0.05 & 0.02 & 0.01 & 0.005 & 0.002 \\
\hline \multicolumn{2}{|c|}{ 95\% Confidence Interval } & \multicolumn{10}{|c|}{ Return Period (years) } \\
\hline ID & Station Name & 1.11 & 1.25 & 2 & 5 & 10 & 20 & 50 & 100 & 200 & 500 \\
\hline USS0010F23S & Phillips Bench & 2.19 & 2.41 & 2.97 & 3.87 & 4.56 & 5.31 & 6.43 & 7.39 & 8.50 & 10.16 \\
\hline USS0010G08S & Salt River Summit & 1.36 & 1.49 & 1.84 & 2.40 & 2.83 & 3.30 & 3.99 & 4.60 & 5.27 & 6.30 \\
\hline USS0010G12S & Kelley R.S. & 1.51 & 1.66 & 2.05 & 2.67 & 3.15 & 3.66 & 4.43 & 5.10 & 5.86 & 7.02 \\
\hline USS0010G23S & Willow Creek & 2.27 & 2.49 & 3.08 & 4.01 & 4.72 & 5.50 & 6.65 & 7.66 & 8.81 & 10.52 \\
\hline USS0010G25S & Cottonwood Creek & 1.81 & 1.98 & 2.45 & 3.19 & 3.76 & 4.37 & 5.29 & 6.09 & 7.00 & 8.37 \\
\hline USS0011F02S & Pine Creek Pass & 1.72 & 1.88 & 2.33 & 3.03 & 3.57 & 4.14 & 5.01 & 5.76 & 6.62 & 7.93 \\
\hline USS0011F11S & Sheep Mtn. & 1.30 & 1.42 & 1.76 & 2.29 & 2.70 & 3.14 & 3.80 & 4.39 & 5.03 & 6.02 \\
\hline USS0011G01S & Somsen Ranch & 1.36 & 1.49 & 1.84 & 2.39 & 2.82 & 3.29 & 3.98 & 4.58 & 5.25 & 6.28 \\
\hline USS0011G05S & Slug Creek Divide & 1.62 & 1.77 & 2.18 & 2.84 & 3.35 & 3.90 & 4.72 & 5.43 & 6.23 & 7.47 \\
\hline USS0011G06S & Emigrant Summit & 2.12 & 2.33 & 2.88 & 3.75 & 4.42 & 5.14 & 6.22 & 7.17 & 8.24 & 9.85 \\
\hline USS0011G30S & Sedgwick Peak & 1.90 & 2.09 & 2.59 & 3.37 & 3.97 & 4.61 & 5.57 & 6.41 & 7.34 & 8.77 \\
\hline USS0011G32S & Franklin Basin & 2.34 & 2.58 & 3.18 & 4.14 & 4.87 & 5.68 & 6.87 & 7.92 & 9.11 & 10.91 \\
\hline USS0012G17S & Wildhorse Divide & 1.68 & 1.84 & 2.28 & 2.97 & 3.49 & 4.07 & 4.92 & 5.67 & 6.51 & 7.79 \\
\hline USS0012G18S & Oxford Spring & 1.67 & 1.83 & 2.26 & 2.96 & 3.49 & 4.07 & 4.92 & 5.66 & 6.50 & 7.78 \\
\hline
\end{tabular}


Table A-19. Region 2 regionally factored $5 \%$ confidence interval (72-hour).

\begin{tabular}{|c|c|c|c|c|c|c|c|c|c|c|c|}
\hline \multirow{2}{*}{\multicolumn{2}{|c|}{ 72-Hour Total (inches) }} & \multicolumn{10}{|c|}{ Exceedance Probability } \\
\hline & & 0.90 & 0.80 & 0.50 & 0.20 & 0.10 & 0.05 & 0.02 & 0.01 & 0.005 & 0.002 \\
\hline \multicolumn{2}{|c|}{$5 \%$ Confidence Interval } & \multicolumn{10}{|c|}{ Return Period (years) } \\
\hline ID & Station Name & 1.11 & 1.25 & 2 & 5 & 10 & 20 & 50 & 100 & 200 & 500 \\
\hline USS0010F23S & Phillips Bench & 1.76 & 1.99 & 2.52 & 3.19 & 3.64 & 4.06 & 4.60 & 5.00 & 5.39 & 5.89 \\
\hline USS0010G08S & Salt River Summit & 1.09 & 1.23 & 1.56 & 1.98 & 2.25 & 2.51 & 2.84 & 3.09 & 3.32 & 3.63 \\
\hline USS0010G12S & Kelley R.S. & 1.21 & 1.37 & 1.73 & 2.20 & 2.51 & 2.79 & 3.17 & 3.44 & 3.71 & 4.05 \\
\hline USS0010G23S & Willow Creek & 1.82 & 2.06 & 2.60 & 3.31 & 3.77 & 4.21 & 4.78 & 5.18 & 5.59 & 6.10 \\
\hline USS0010G25S & Cottonwood Creek & 1.44 & 1.63 & 2.06 & 2.61 & 2.98 & 3.33 & 3.76 & 4.08 & 4.39 & 4.79 \\
\hline USS0011F02S & Pine Creek Pass & 1.35 & 1.53 & 1.93 & 2.46 & 2.80 & 3.13 & 3.55 & 3.85 & 4.15 & 4.54 \\
\hline USS0011F11S & Sheep Mtn. & 1.04 & 1.18 & 1.48 & 1.88 & 2.14 & 2.40 & 2.71 & 2.94 & 3.16 & 3.46 \\
\hline USS0011G01S & Somsen Ranch & 1.09 & 1.24 & 1.56 & 1.99 & 2.26 & 2.52 & 2.85 & 3.09 & 3.33 & 3.64 \\
\hline USS0011G05S & Slug Creek Divide & 1.29 & 1.46 & 1.85 & 2.35 & 2.68 & 2.98 & 3.38 & 3.66 & 3.94 & 4.31 \\
\hline USS0011G06S & Emigrant Summit & 1.70 & 1.93 & 2.44 & 3.10 & 3.52 & 3.93 & 4.44 & 4.83 & 5.20 & 5.67 \\
\hline USS0011G30S & Sedgwick Peak & 1.50 & 1.70 & 2.15 & 2.73 & 3.11 & 3.48 & 3.94 & 4.28 & 4.61 & 5.04 \\
\hline USS0011G32S & Franklin Basin & 1.88 & 2.13 & 2.69 & 3.42 & 3.90 & 4.35 & 4.92 & 5.34 & 5.75 & 6.29 \\
\hline USS0012G17S & Wildhorse Divide & 1.34 & 1.52 & 1.91 & 2.42 & 2.76 & 3.08 & 3.49 & 3.79 & 4.07 & 4.45 \\
\hline USS0012G18S & Oxford Spring & 1.34 & 1.51 & 1.91 & 2.43 & 2.78 & 3.10 & 3.51 & 3.81 & 4.10 & 4.49 \\
\hline
\end{tabular}




\section{A.3.6 Region 1 regionally factored quantiles (96-hour)}

Table A-20. Region 1 regionally factored quantiles (96-hour).

\begin{tabular}{|c|c|c|c|c|c|c|c|c|c|c|c|}
\hline & & & & & & xceeda & babilit & & & & \\
\hline $96-\mathrm{H}$ & lour Total (inches) & 0.90 & 0.80 & 0.50 & 0.20 & 0.10 & 0.05 & 0.02 & 0.01 & 0.005 & 0.002 \\
\hline & & & & & & Return & (years) & & & & \\
\hline ID & Station Name & 1.11 & 1.25 & 2 & 5 & 10 & 20 & 50 & 100 & 200 & 500 \\
\hline USC00100010 & ABERDEEN EXP STN & 0.55 & 0.64 & 0.86 & 1.16 & 1.36 & 1.56 & 1.82 & 2.02 & 2.23 & 2.50 \\
\hline USC00100915 & BLACKFOOT FIRE DEPT & 0.63 & 0.74 & 0.99 & 1.34 & 1.57 & 1.80 & 2.10 & 2.34 & 2.57 & 2.89 \\
\hline USC00102676 & DRIGGS & 0.69 & 0.81 & 1.08 & 1.46 & 1.71 & 1.96 & 2.29 & 2.55 & 2.80 & 3.15 \\
\hline USC00103297 & FT HALL 1 NNE & 0.56 & 0.66 & 0.88 & 1.19 & 1.39 & 1.60 & 1.87 & 2.07 & 2.28 & 2.57 \\
\hline USC00103732 & GRACE & 0.72 & 0.84 & 1.12 & 1.52 & 1.78 & 2.04 & 2.39 & 2.65 & 2.92 & 3.28 \\
\hline USC00104455 & IDAHO FALLS - KIFI & 0.63 & 0.73 & 0.98 & 1.32 & 1.56 & 1.78 & 2.09 & 2.32 & 2.55 & 2.87 \\
\hline USC00104456 & IDAHO FALLS 16 SE & 0.81 & 0.94 & 1.26 & 1.70 & 2.00 & 2.29 & 2.68 & 2.98 & 3.28 & 3.68 \\
\hline USC00105275 & LIFTON PUMPING STN & 0.58 & 0.68 & 0.91 & 1.23 & 1.44 & 1.65 & 1.93 & 2.15 & 2.36 & 2.66 \\
\hline USC00105716 & MCCAMMON & 0.87 & 1.02 & 1.36 & 1.84 & 2.16 & 2.48 & 2.90 & 3.22 & 3.55 & 3.98 \\
\hline USC00107208 & POCATELLO 2 NE & 0.62 & 0.73 & 0.97 & 1.31 & 1.54 & 1.77 & 2.07 & 2.30 & 2.53 & 2.84 \\
\hline USC00107346 & PRESTON & 0.87 & 1.02 & 1.36 & 1.83 & 2.16 & 2.47 & 2.89 & 3.21 & 3.53 & 3.97 \\
\hline USC00107644 & REXBURG BYU IDAHO & 0.65 & 0.75 & 1.01 & 1.36 & 1.60 & 1.83 & 2.14 & 2.38 & 2.62 & 2.94 \\
\hline USC00108022 & SAINT ANTHONY & 0.72 & 0.84 & 1.12 & 1.52 & 1.78 & 2.04 & 2.39 & 2.65 & 2.92 & 3.28 \\
\hline USC00108818 & SUGAR CITY & 0.62 & 0.72 & 0.96 & 1.30 & 1.53 & 1.75 & 2.04 & 2.27 & 2.50 & 2.81 \\
\hline USC00108937 & SWAN VALLEY & 0.73 & 0.86 & 1.15 & 1.55 & 1.82 & 2.09 & 2.44 & 2.71 & 2.98 & 3.35 \\
\hline USC00109065 & TETONIA EXP STN & 0.70 & 0.81 & 1.09 & 1.46 & 1.72 & 1.97 & 2.31 & 2.56 & 2.82 & 3.17 \\
\hline USC00480027 & AFTON & 0.77 & 0.90 & 1.21 & 1.63 & 1.91 & 2.19 & 2.57 & 2.85 & 3.14 & 3.52 \\
\hline USC00480140 & ALTA 1 NNW & 0.85 & 0.99 & 1.32 & 1.79 & 2.10 & 2.41 & 2.82 & 3.13 & 3.44 & 3.87 \\
\hline USC00484910 & JACKSON & 0.83 & 0.96 & 1.29 & 1.74 & 2.05 & 2.35 & 2.74 & 3.04 & 3.35 & 3.77 \\
\hline USS0011G33S & Giveout & 1.08 & 1.26 & 1.68 & 2.27 & 2.67 & 3.06 & 3.58 & 3.97 & 4.37 & 4.91 \\
\hline USW00024145 & IDAHO FALLS FANNING FLD & 0.52 & 0.60 & 0.81 & 1.09 & 1.28 & 1.47 & 1.72 & 1.91 & 2.10 & 2.36 \\
\hline USW00024151 & MALAD CITY & 0.74 & 0.86 & 1.15 & 1.55 & 1.83 & 2.09 & 2.45 & 2.72 & 2.99 & 3.36 \\
\hline USW00024156 & POCATELLO RGNL AP & 0.62 & 0.73 & 0.97 & 1.31 & 1.54 & 1.77 & 2.07 & 2.29 & 2.53 & 2.84 \\
\hline
\end{tabular}


Table A-21. Region 1 regionally factored 95\% confidence interval (96-hour).

\begin{tabular}{|c|c|c|c|c|c|c|c|c|c|c|c|}
\hline \multirow{2}{*}{\multicolumn{2}{|c|}{96 -Hour Total (inches) }} & \multicolumn{10}{|c|}{ Exceedance Probability } \\
\hline & & 0.90 & 0.80 & 0.50 & 0.20 & 0.10 & 0.05 & 0.02 & 0.01 & 0.005 & 0.002 \\
\hline \multicolumn{2}{|c|}{$95 \%$ Confidence Interval } & \multicolumn{10}{|c|}{ Return Period (years) } \\
\hline ID & Station Name & 1.11 & 1.25 & 2 & 5 & 10 & 20 & 50 & 100 & 200 & 500 \\
\hline USC00100010 & ABERDEEN EXP STN & 0.64 & 0.72 & 0.91 & 1.24 & 1.48 & 1.72 & 2.05 & 2.30 & 2.56 & 2.91 \\
\hline USC00100915 & BLACKFOOT FIRE DEPT & 0.74 & 0.83 & 1.06 & 1.44 & 1.72 & 2.00 & 2.38 & 2.67 & 2.97 & 3.38 \\
\hline USC00102676 & DRIGGS & 0.82 & 0.91 & 1.16 & 1.57 & 1.88 & 2.18 & 2.59 & 2.91 & 3.24 & 3.68 \\
\hline USC00103297 & FT HALL 1 NNE & 0.66 & 0.73 & 0.94 & 1.27 & 1.52 & 1.77 & 2.10 & 2.36 & 2.62 & 2.99 \\
\hline USC00103732 & GRACE & 0.84 & 0.94 & 1.20 & 1.63 & 1.95 & 2.26 & 2.69 & 3.02 & 3.37 & 3.84 \\
\hline USC00104455 & IDAHO FALLS - KIFI & 0.75 & 0.84 & 1.08 & 1.46 & 1.74 & 2.02 & 2.40 & 2.69 & 2.98 & 3.40 \\
\hline USC00104456 & IDAHO FALLS 16 SE & 0.95 & 1.07 & 1.37 & 1.86 & 2.22 & 2.57 & 3.06 & 3.43 & 3.81 & 4.34 \\
\hline USC00105275 & LIFTON PUMPING STN & 0.68 & 0.76 & 0.97 & 1.32 & 1.58 & 1.84 & 2.18 & 2.45 & 2.73 & 3.10 \\
\hline USC00105716 & MCCAMMON & 1.05 & 1.18 & 1.51 & 2.05 & 2.43 & 2.82 & 3.35 & 3.75 & 4.18 & 4.75 \\
\hline USC00107208 & POCATELLO 2 NE & 0.75 & 0.85 & 1.09 & 1.47 & 1.75 & 2.02 & 2.40 & 2.69 & 2.98 & 3.39 \\
\hline USC00107346 & PRESTON & 1.05 & 1.18 & 1.52 & 2.05 & 2.43 & 2.82 & 3.33 & 3.74 & 4.15 & 4.72 \\
\hline USC00107644 & REXBURG BYU IDAHO & 0.79 & 0.88 & 1.14 & 1.53 & 1.82 & 2.10 & 2.49 & 2.79 & 3.10 & 3.53 \\
\hline USC00108022 & SAINT ANTHONY & 0.85 & 0.95 & 1.22 & 1.65 & 1.97 & 2.28 & 2.71 & 3.04 & 3.39 & 3.85 \\
\hline USC00108818 & SUGAR CITY & 0.73 & 0.82 & 1.04 & 1.42 & 1.69 & 1.96 & 2.33 & 2.61 & 2.90 & 3.30 \\
\hline USC00108937 & SWAN VALLEY & 0.87 & 0.98 & 1.25 & 1.69 & 2.02 & 2.34 & 2.78 & 3.12 & 3.46 & 3.94 \\
\hline USC00109065 & TETONIA EXP STN & 0.83 & 0.93 & 1.20 & 1.63 & 1.93 & 2.24 & 2.65 & 2.97 & 3.30 & 3.75 \\
\hline USC00480027 & AFTON & 0.92 & 1.03 & 1.33 & 1.80 & 2.14 & 2.48 & 2.94 & 3.30 & 3.67 & 4.18 \\
\hline USC00480140 & ALTA 1 NNW & 0.99 & 1.11 & 1.42 & 1.93 & 2.30 & 2.68 & 3.18 & 3.56 & 3.96 & 4.51 \\
\hline USC00484910 & JACKSON & 0.97 & 1.09 & 1.39 & 1.89 & 2.25 & 2.61 & 3.11 & 3.49 & 3.88 & 4.41 \\
\hline USS0011G33S & Giveout & 1.29 & 1.45 & 1.87 & 2.53 & 3.01 & 3.49 & 4.14 & 4.65 & 5.16 & 5.87 \\
\hline USW00024145 & IDAHO FALLS FANNING FLD & 0.61 & 0.68 & 0.87 & 1.19 & 1.41 & 1.64 & 1.95 & 2.18 & 2.43 & 2.77 \\
\hline USW00024151 & MALAD CITY & 0.87 & 0.98 & 1.25 & 1.69 & 2.02 & 2.34 & 2.78 & 3.12 & 3.47 & 3.95 \\
\hline USW00024156 & POCATELLO RGNL AP & 0.73 & 0.82 & 1.05 & 1.42 & 1.69 & 1.96 & 2.33 & 2.62 & 2.92 & 3.32 \\
\hline
\end{tabular}


Table A-22. Region 1 regionally factored $5 \%$ confidence interval (96-hour).

\begin{tabular}{|c|c|c|c|c|c|c|c|c|c|c|c|}
\hline \multirow{2}{*}{\multicolumn{2}{|c|}{ 96-Hour Total (inches) }} & \multicolumn{10}{|c|}{ Exceedance Probability } \\
\hline & & 0.90 & 0.80 & 0.50 & 0.20 & 0.10 & 0.05 & 0.02 & 0.01 & 0.005 & 0.002 \\
\hline \multicolumn{2}{|c|}{$5 \%$ Confidence Interval } & \multicolumn{10}{|c|}{ Return Period (years) } \\
\hline ID & Station Name & 1.11 & 1.25 & 2 & 5 & 10 & 20 & 50 & 100 & 200 & 500 \\
\hline USC00100010 & ABERDEEN EXP STN & 0.48 & 0.58 & 0.81 & 1.07 & 1.24 & 1.40 & 1.60 & 1.76 & 1.92 & 2.12 \\
\hline USC00100915 & BLACKFOOT FIRE DEPT & 0.55 & 0.67 & 0.93 & 1.23 & 1.42 & 1.61 & 1.85 & 2.03 & 2.20 & 2.44 \\
\hline USC00102676 & DRIGGS & 0.60 & 0.73 & 1.01 & 1.34 & 1.54 & 1.75 & 2.00 & 2.20 & 2.39 & 2.65 \\
\hline USC00103297 & FT HALL 1 NNE & 0.49 & 0.60 & 0.83 & 1.10 & 1.27 & 1.43 & 1.65 & 1.81 & 1.97 & 2.18 \\
\hline USC00103732 & GRACE & 0.63 & 0.76 & 1.05 & 1.40 & 1.61 & 1.82 & 2.09 & 2.30 & 2.50 & 2.76 \\
\hline USC00104455 & IDAHO FALLS - KIFI & 0.54 & 0.65 & 0.89 & 1.19 & 1.37 & 1.55 & 1.78 & 1.96 & 2.13 & 2.36 \\
\hline USC00104456 & IDAHO FALLS 16 SE & 0.70 & 0.84 & 1.16 & 1.54 & 1.78 & 2.02 & 2.32 & 2.54 & 2.77 & 3.06 \\
\hline USC00105275 & LIFTON PUMPING STN & 0.51 & 0.62 & 0.85 & 1.13 & 1.31 & 1.48 & 1.70 & 1.86 & 2.03 & 2.25 \\
\hline USC00105716 & MCCAMMON & 0.74 & 0.90 & 1.23 & 1.64 & 1.89 & 2.14 & 2.47 & 2.71 & 2.95 & 3.27 \\
\hline USC00107208 & POCATELLO 2 NE & 0.53 & 0.64 & 0.87 & 1.16 & 1.34 & 1.52 & 1.75 & 1.92 & 2.09 & 2.32 \\
\hline USC00107346 & PRESTON & 0.74 & 0.89 & 1.22 & 1.62 & 1.88 & 2.12 & 2.44 & 2.68 & 2.92 & 3.24 \\
\hline USC00107644 & REXBURG BYU IDAHO & 0.54 & 0.65 & 0.90 & 1.19 & 1.38 & 1.56 & 1.80 & 1.98 & 2.15 & 2.39 \\
\hline USC00108022 & SAINT ANTHONY & 0.62 & 0.75 & 1.04 & 1.38 & 1.60 & 1.81 & 2.08 & 2.28 & 2.49 & 2.75 \\
\hline USC00108818 & SUGAR CITY & 0.53 & 0.64 & 0.89 & 1.17 & 1.36 & 1.54 & 1.77 & 1.94 & 2.11 & 2.34 \\
\hline USC00108937 & SWAN VALLEY & 0.63 & 0.76 & 1.05 & 1.40 & 1.62 & 1.83 & 2.10 & 2.31 & 2.51 & 2.78 \\
\hline USC00109065 & TETONIA EXP STN & 0.60 & 0.72 & 0.98 & 1.31 & 1.51 & 1.71 & 1.96 & 2.16 & 2.35 & 2.60 \\
\hline USC00480027 & AFTON & 0.66 & 0.80 & 1.10 & 1.47 & 1.70 & 1.91 & 2.20 & 2.42 & 2.63 & 2.91 \\
\hline USC00480140 & ALTA 1 NNW & 0.74 & 0.89 & 1.24 & 1.64 & 1.90 & 2.14 & 2.46 & 2.70 & 2.94 & 3.25 \\
\hline USC00484910 & JACKSON & 0.72 & 0.87 & 1.20 & 1.59 & 1.84 & 2.08 & 2.39 & 2.62 & 2.85 & 3.16 \\
\hline USS0011G33S & Giveout & 0.92 & 1.10 & 1.52 & 2.02 & 2.33 & 2.64 & 3.04 & 3.34 & 3.64 & 4.04 \\
\hline USW00024145 & IDAHO FALLS FANNING FLD & 0.45 & 0.54 & 0.75 & 0.99 & 1.15 & 1.30 & 1.49 & 1.64 & 1.78 & 1.97 \\
\hline USW00024151 & MALAD CITY & 0.64 & 0.77 & 1.06 & 1.41 & 1.63 & 1.85 & 2.12 & 2.33 & 2.53 & 2.80 \\
\hline USW00024156 & POCATELLO RGNL AP & 0.54 & 0.65 & 0.91 & 1.20 & 1.39 & 1.57 & 1.80 & 1.98 & 2.15 & 2.38 \\
\hline
\end{tabular}




\section{A.3.7 Region 2 regionally factored quantiles (96-hour)}

Table A-23. Region 2 regionally factored quantiles (96-hour).

\begin{tabular}{|c|c|c|c|c|c|c|c|c|c|c|c|}
\hline & & \multicolumn{10}{|c|}{ Exceedance Probability } \\
\hline \multicolumn{2}{|c|}{ 96-Hour Total (inches) } & 0.90 & 0.80 & 0.50 & 0.20 & 0.10 & 0.05 & 0.02 & 0.01 & 0.005 & 0.002 \\
\hline & & \multicolumn{10}{|c|}{ Return Period (years) } \\
\hline ID & Station Name & 1.11 & 1.25 & 2 & 5 & 10 & 20 & 50 & 100 & 200 & 500 \\
\hline USS0010F23S & Phillips Bench & 2.19 & 2.45 & 3.09 & 4.03 & 4.69 & 5.38 & 6.32 & 7.07 & 7.87 & 8.99 \\
\hline USS0010G08S & Salt River Summit & 1.38 & 1.55 & 1.96 & 2.55 & 2.98 & 3.41 & 4.00 & 4.48 & 4.99 & 5.69 \\
\hline USS0010G12S & Kelley R.S. & 1.52 & 1.70 & 2.15 & 2.81 & 3.27 & 3.75 & 4.40 & 4.93 & 5.48 & 6.26 \\
\hline USS0010G23S & Willow Creek & 2.30 & 2.57 & 3.25 & 4.23 & 4.94 & 5.66 & 6.65 & 7.44 & 8.28 & 9.45 \\
\hline USSO010G25S & Cottonwood Creek & 1.81 & 2.02 & 2.55 & 3.33 & 3.88 & 4.44 & 5.22 & 5.85 & 6.50 & 7.43 \\
\hline USS0011F02S & Pine Creek Pass & 1.69 & 1.89 & 2.38 & 3.11 & 3.62 & 4.15 & 4.87 & 5.46 & 6.07 & 6.93 \\
\hline USS0011F11S & Sheep Mtn. & 1.31 & 1.46 & 1.85 & 2.41 & 2.81 & 3.22 & 3.78 & 4.23 & 4.71 & 5.37 \\
\hline USS0011G01S & Somsen Ranch & 1.36 & 1.52 & 1.92 & 2.50 & 2.92 & 3.34 & 3.93 & 4.40 & 4.89 & 5.58 \\
\hline USS0011G05S & Slug Creek Divide & 1.62 & 1.81 & 2.29 & 2.98 & 3.47 & 3.98 & 4.68 & 5.23 & 5.82 & 6.65 \\
\hline USS0011G06S & Emigrant Summit & 2.12 & 2.37 & 3.00 & 3.91 & 4.55 & 5.21 & 6.13 & 6.86 & 7.63 & 8.72 \\
\hline USS0011G30S & Sedgwick Peak & 1.86 & 2.08 & 2.63 & 3.43 & 4.00 & 4.58 & 5.38 & 6.03 & 6.70 & 7.66 \\
\hline USS0011G32S & Franklin Basin & 2.31 & 2.59 & 3.27 & 4.26 & 4.97 & 5.69 & 6.69 & 7.49 & 8.33 & 9.52 \\
\hline USS0012G17S & Wildhorse Divide & 1.64 & 1.84 & 2.32 & 3.03 & 3.53 & 4.04 & 4.75 & 5.32 & 5.91 & 6.75 \\
\hline USS0012G18S & Oxford Spring & 1.67 & 1.87 & 2.36 & 3.07 & 3.59 & 4.11 & 4.83 & 5.40 & 6.01 & 6.86 \\
\hline
\end{tabular}


Table A-24. Region 2 regionally factored 95\% confidence interval (96-hour).

\begin{tabular}{|c|c|c|c|c|c|c|c|c|c|c|c|}
\hline & & \multicolumn{10}{|c|}{ Exceedance Probability } \\
\hline \multicolumn{2}{|c|}{ 96-Hour Total (inches) } & 0.90 & 0.80 & 0.50 & 0.20 & 0.10 & 0.05 & 0.02 & 0.01 & 0.005 & 0.002 \\
\hline \multicolumn{2}{|c|}{ 95\% Confidence Interval } & \multicolumn{10}{|c|}{ Return Period (years) } \\
\hline ID & Station Name & 1.11 & 1.25 & 2 & 5 & 10 & 20 & 50 & 100 & 200 & 500 \\
\hline USS0010F23S & Phillips Bench & 2.50 & 2.74 & 3.38 & 4.44 & 5.29 & 6.21 & 7.60 & 8.81 & 10.19 & 12.28 \\
\hline USS0010G08S & Salt River Summit & 1.58 & 1.73 & 2.14 & 2.82 & 3.35 & 3.93 & 4.82 & 5.58 & 6.44 & 7.78 \\
\hline USS0010G12S & Kelley R.S. & 1.74 & 1.91 & 2.36 & 3.11 & 3.70 & 4.34 & 5.32 & 6.16 & 7.11 & 8.60 \\
\hline USS0010G23S & Willow Creek & 2.63 & 2.87 & 3.55 & 4.67 & 5.56 & 6.53 & 7.98 & 9.27 & 10.71 & 12.95 \\
\hline USS0010G25S & Cottonwood Creek & 2.07 & 2.27 & 2.81 & 3.70 & 4.39 & 5.15 & 6.30 & 7.28 & 8.43 & 10.16 \\
\hline USS0011F02S & Pine Creek Pass & 1.94 & 2.13 & 2.63 & 3.46 & 4.11 & 4.82 & 5.88 & 6.80 & 7.86 & 9.49 \\
\hline USS0011F11S & Sheep Mtn. & 1.50 & 1.64 & 2.03 & 2.66 & 3.16 & 3.71 & 4.53 & 5.26 & 6.07 & 7.34 \\
\hline USS0011G01S & Somsen Ranch & 1.56 & 1.70 & 2.10 & 2.77 & 3.28 & 3.86 & 4.72 & 5.47 & 6.32 & 7.63 \\
\hline USS0011G05S & Slug Creek Divide & 1.84 & 2.02 & 2.50 & 3.29 & 3.91 & 4.60 & 5.63 & 6.51 & 7.54 & 9.09 \\
\hline USS0011G06S & Emigrant Summit & 2.42 & 2.65 & 3.28 & 4.32 & 5.14 & 6.03 & 7.39 & 8.57 & 9.89 & 11.94 \\
\hline USS0011G30S & Sedgwick Peak & 2.14 & 2.35 & 2.91 & 3.82 & 4.54 & 5.33 & 6.52 & 7.56 & 8.72 & 10.52 \\
\hline USS0011G32S & Franklin Basin & 2.64 & 2.90 & 3.58 & 4.71 & 5.60 & 6.59 & 8.04 & 9.35 & 10.79 & 13.03 \\
\hline USS0012G17S & Wildhorse Divide & 1.89 & 2.06 & 2.55 & 3.36 & 3.99 & 4.69 & 5.73 & 6.64 & 7.69 & 9.26 \\
\hline USS0012G18S & Oxford Spring & 1.91 & 2.10 & 2.59 & 3.41 & 4.05 & 4.74 & 5.80 & 6.71 & 7.77 & 9.38 \\
\hline
\end{tabular}


Table A-25. Region 2 regionally factored $5 \%$ confidence interval (96-hour).

\begin{tabular}{|c|c|c|c|c|c|c|c|c|c|c|c|}
\hline \multirow{2}{*}{\multicolumn{2}{|c|}{ 96-Hour Total (inches) }} & \multicolumn{10}{|c|}{ Exceedance Probability } \\
\hline & & 0.90 & 0.80 & 0.50 & 0.20 & 0.10 & 0.05 & 0.02 & 0.01 & 0.005 & 0.002 \\
\hline \multicolumn{2}{|c|}{$5 \%$ Confidence Interval } & \multicolumn{10}{|c|}{ Return Period (years) } \\
\hline ID & Station Name & 1.11 & 1.25 & 2 & 5 & 10 & 20 & 50 & 100 & 200 & 500 \\
\hline USS0010F23S & Phillips Bench & 1.93 & 2.22 & 2.84 & 3.62 & 4.13 & 4.61 & 5.21 & 5.66 & 6.09 & 6.63 \\
\hline USS0010G08S & Salt River Summit & 1.22 & 1.40 & 1.80 & 2.30 & 2.62 & 2.92 & 3.30 & 3.58 & 3.86 & 4.21 \\
\hline USS0010G12S & Kelley R.S. & 1.34 & 1.54 & 1.97 & 2.52 & 2.87 & 3.21 & 3.63 & 3.93 & 4.23 & 4.61 \\
\hline USS0010G23S & Willow Creek & 2.03 & 2.33 & 2.99 & 3.81 & 4.35 & 4.86 & 5.50 & 5.97 & 6.42 & 7.01 \\
\hline USS0010G25S & Cottonwood Creek & 1.59 & 1.82 & 2.34 & 2.98 & 3.40 & 3.80 & 4.29 & 4.66 & 5.01 & 5.45 \\
\hline USS0011F02S & Pine Creek Pass & 1.48 & 1.69 & 2.16 & 2.76 & 3.14 & 3.51 & 3.97 & 4.31 & 4.64 & 5.05 \\
\hline USS0011F11S & Sheep Mtn. & 1.16 & 1.32 & 1.70 & 2.16 & 2.46 & 2.74 & 3.10 & 3.37 & 3.63 & 3.95 \\
\hline USS0011G01S & Somsen Ranch & 1.20 & 1.37 & 1.76 & 2.25 & 2.56 & 2.86 & 3.24 & 3.52 & 3.79 & 4.13 \\
\hline USS0011G05S & Slug Creek Divide & 1.43 & 1.64 & 2.10 & 2.69 & 3.06 & 3.41 & 3.86 & 4.18 & 4.50 & 4.90 \\
\hline USS0011G06S & Emigrant Summit & 1.87 & 2.14 & 2.76 & 3.52 & 4.01 & 4.47 & 5.05 & 5.48 & 5.90 & 6.42 \\
\hline USS0011G30S & Sedgwick Peak & 1.63 & 1.87 & 2.39 & 3.05 & 3.48 & 3.89 & 4.40 & 4.78 & 5.15 & 5.61 \\
\hline USS0011G32S & Franklin Basin & 2.04 & 2.34 & 3.00 & 3.83 & 4.36 & 4.87 & 5.51 & 6.00 & 6.45 & 7.03 \\
\hline USS0012G17S & Wildhorse Divide & 1.44 & 1.66 & 2.12 & 2.71 & 3.09 & 3.45 & 3.90 & 4.23 & 4.56 & 4.96 \\
\hline USS0012G18S & Oxford Spring & 1.47 & 1.69 & 2.16 & 2.76 & 3.14 & 3.50 & 3.96 & 4.29 & 4.63 & 5.04 \\
\hline
\end{tabular}




\section{Appendix B: Geographic Projection Metadata}

Table B-1 details the projection information for the UA and SNODAS datasets along with the projection used in our SWE analysis.

Table B-1. GIS metadata for the gridded SWE analyses.

\begin{tabular}{|c|c|c|c|}
\hline Parameter & UA SWE & SNODAS & Project \\
\hline Projection & Geographic & Geographic & Conic \\
\hline False_Easting & $\mathrm{N} / \mathrm{A}$ & N/A & 0.0 \\
\hline False_Northing & N/A & N/A & 0.0 \\
\hline Standard_Parallel_1 & N/A & N/A & 29.5 \\
\hline Standard_Parallel_2 & $\mathrm{N} / \mathrm{A}$ & N/A & 45.5 \\
\hline Longitude of Center & N/A & N/A & 23 \\
\hline Latitude of Center & N/A & N/A & -96 \\
\hline Linear Unit & Degrees & Degrees & Meter \\
\hline $\begin{array}{l}\text { Geographic Coordinate } \\
\text { System }\end{array}$ & WGS 84 & WGS 84 & Albers Equal Area \\
\hline PROJ4 string & $\begin{array}{l}\text { +proj=longlat } \\
\text { +datum=WGS84 } \\
\text { +no_defs }\end{array}$ & $\begin{array}{l}\text { + proj=longlat } \\
\text { + datum=WGS84 } \\
\text { +no_defs }\end{array}$ & $\begin{array}{l}\text { +proj=aea +lat_1=29.5 } \\
\text { +lat_2=45.5 +lat_0=23 } \\
\text { +lon_0=-96 +x_0=0 } \\
\text { +y_0=0 +datum=WGS84 } \\
\text { +units=m +no_defs }\end{array}$ \\
\hline \multicolumn{4}{|l|}{ GIS Data Extents } \\
\hline Parameter & UA SWE & SNODAS & Project \\
\hline ncols & 1405 & 6935 & $\begin{array}{l}\text { UA: } 1488 \\
\text { SNODAS: } 5818\end{array}$ \\
\hline nrows & 621 & 3351 & $\begin{array}{l}\text { UA: } 802 \\
\text { SNODAS: } 3404\end{array}$ \\
\hline xllcorner & -125.0208 & -124.7333 & $\begin{array}{l}\text { UA: }-2950369.125 \\
\text { SNODAS: }-2893169.485\end{array}$ \\
\hline yllcorner & 49.9375 & 52.8750 & $\begin{array}{l}\text { UA: } 115038.092 \\
\text { SNODAS: } 3616789.6355\end{array}$ \\
\hline Cell Size & $0.04166^{\circ}$ & $0.00833^{\circ}$ & $\begin{array}{l}\text { UA: } 4 \mathrm{~km} \\
\text { SNODAS: } 1 \mathrm{~km}\end{array}$ \\
\hline
\end{tabular}




\section{Appendix C: SWE Quantiles}

Tables C- 1 through C- 5 list the spatially averaged UA SWE. We used these values to estimate the log-normal quantiles shown in the report and in this appendix.

Table C-1. Grays Lake Subbasin maximum SWE (inches) values from spatially averaged UA data.

\begin{tabular}{|c|c|c|c|c|c|c|c|}
\hline WY & Oct & Nov & Dec & Jan & Feb & Mar & Annual Maximum \\
\hline 1982 & 0.55 & 1.69 & 5.60 & 9.49 & 11.68 & 14.42 & 14.42 \\
\hline 1983 & 0.69 & 1.93 & 4.99 & 6.50 & 8.45 & 10.09 & 10.09 \\
\hline 1984 & 0.02 & 3.33 & 7.87 & 9.01 & 10.99 & 12.79 & 12.79 \\
\hline 1985 & 0.93 & 3.89 & 6.16 & 7.15 & 9.24 & 11.98 & 11.98 \\
\hline 1986 & 0.60 & 3.79 & 5.28 & 7.91 & 12.60 & 13.54 & 13.54 \\
\hline 1987 & 0.52 & 1.94 & 2.24 & 4.37 & 5.84 & 6.21 & 6.21 \\
\hline 1988 & 0.00 & 0.47 & 2.73 & 5.48 & 6.19 & 7.41 & 7.41 \\
\hline 1989 & 0.00 & 3.18 & 4.86 & 7.94 & 9.76 & 11.22 & 11.22 \\
\hline 1990 & 0.48 & 1.26 & 2.03 & 5.00 & 6.40 & 7.16 & 7.16 \\
\hline 1991 & 0.20 & 1.22 & 3.36 & 4.90 & 5.10 & 8.16 & 8.16 \\
\hline 1992 & 0.49 & 2.52 & 3.30 & 4.02 & 4.77 & 4.65 & 4.77 \\
\hline 1993 & 0.13 & 1.40 & 4.91 & 7.47 & 10.05 & 11.51 & 11.51 \\
\hline 1994 & 0.14 & 0.89 & 2.42 & 3.82 & 6.84 & 6.81 & 6.84 \\
\hline 1995 & 0.41 & 2.23 & 4.26 & 7.21 & 8.15 & 9.90 & 9.90 \\
\hline 1996 & 0.15 & 1.15 & 3.39 & 8.18 & 9.51 & 11.88 & 11.88 \\
\hline 1997 & 0.96 & 2.05 & 8.98 & 13.18 & 14.61 & 16.02 & 16.02 \\
\hline 1998 & 0.32 & 0.91 & 2.01 & 6.16 & 7.80 & 9.33 & 9.33 \\
\hline 1999 & 0.08 & 1.30 & 3.14 & 6.28 & 9.47 & 10.14 & 10.14 \\
\hline 2000 & 0.02 & 0.92 & 2.25 & 5.53 & 7.36 & 8.75 & 8.75 \\
\hline 2001 & 0.54 & 1.50 & 3.37 & 4.33 & 5.20 & 5.67 & 5.67 \\
\hline 2002 & 0.28 & 1.24 & 4.33 & 6.00 & 6.45 & 8.19 & 8.19 \\
\hline 2003 & 0.34 & 1.69 & 3.26 & 4.53 & 5.55 & 6.57 & 6.57 \\
\hline 2004 & 0.25 & 2.33 & 5.14 & 7.22 & 8.30 & 8.88 & 8.88 \\
\hline 2005 & 1.08 & 1.21 & 2.68 & 4.92 & 5.43 & 6.82 & 6.82 \\
\hline 2006 & 0.08 & 0.95 & 2.96 & 6.78 & 8.28 & 10.20 & 10.20 \\
\hline 2007 & 0.06 & 1.05 & 3.14 & 4.36 & 5.56 & 6.14 & 6.14 \\
\hline 2008 & 0.79 & 0.42 & 2.31 & 5.19 & 7.61 & 8.70 & 8.70 \\
\hline 2009 & 0.63 & 0.66 & 4.09 & 6.81 & 7.70 & 9.15 & 9.15 \\
\hline 2010 & 0.28 & 0.35 & 1.61 & 3.67 & 4.67 & 5.95 & 5.95 \\
\hline 2011 & 0.33 & 2.84 & 5.78 & 8.05 & 9.61 & 12.65 & 12.65 \\
\hline 2012 & 0.63 & 2.18 & 3.34 & 6.52 & 8.12 & 9.22 & 9.22 \\
\hline
\end{tabular}




\begin{tabular}{|c|c|c|c|c|c|c|c|}
\hline WY & Oct & Nov & Dec & Jan & Feb & Mar & Annual Maximum \\
\hline 2013 & 0.56 & 0.95 & 3.89 & 5.38 & 6.64 & 7.83 & 7.83 \\
\hline 2014 & 0.13 & 0.42 & 1.96 & 3.96 & 7.66 & 10.15 & 10.15 \\
\hline 2015 & 0.01 & 2.59 & 5.22 & 6.73 & 7.58 & 7.43 & 7.58 \\
\hline 2016 & 0.08 & 1.72 & 4.07 & 6.62 & 7.36 & 9.79 & 9.79 \\
\hline 2017 & 0.54 & 0.91 & 4.35 & 8.81 & 12.38 & 13.18 & 13.18 \\
\hline
\end{tabular}

Table C-2. Ririe Upstream Subbasin maximum SWE (inches) values from spatially averaged UA data.

\begin{tabular}{|l|c|c|c|c|c|c|c|}
\hline WY & Oct & Nov & Dec & Jan & Feb & Mar & Annual Maximum \\
\hline 1982 & 0.30 & 1.40 & 4.60 & 8.34 & 8.74 & 9.20 & 9.20 \\
\hline 1983 & 0.34 & 1.70 & 5.03 & 5.33 & 7.07 & 6.76 & 7.07 \\
\hline 1984 & 0.00 & 2.68 & 6.90 & 7.48 & 9.94 & 10.90 & 10.90 \\
\hline 1985 & 0.95 & 3.03 & 5.50 & 6.47 & 8.44 & 10.73 & 10.73 \\
\hline 1986 & 0.45 & 3.32 & 4.77 & 6.22 & 9.45 & 11.21 & 11.21 \\
\hline 1987 & 0.55 & 1.60 & 1.74 & 3.50 & 4.96 & 4.87 & 4.96 \\
\hline 1988 & 0.00 & 0.33 & 2.12 & 5.01 & 5.42 & 5.17 & 5.42 \\
\hline 1989 & 0.00 & 3.28 & 5.50 & 7.79 & 9.25 & 8.79 & 9.25 \\
\hline 1990 & 0.49 & 1.08 & 1.64 & 3.72 & 4.61 & 4.99 & 4.99 \\
\hline 1991 & 0.14 & 0.77 & 2.65 & 3.96 & 3.89 & 5.25 & 5.25 \\
\hline 1992 & 0.31 & 2.00 & 2.40 & 2.84 & 3.56 & 3.35 & 3.56 \\
\hline 1993 & 0.07 & 1.46 & 4.61 & 7.04 & 9.16 & 9.23 & 9.23 \\
\hline 1994 & 0.05 & 0.61 & 1.97 & 2.86 & 5.21 & 4.73 & 5.21 \\
\hline 1995 & 0.30 & 1.95 & 3.97 & 5.72 & 6.63 & 6.91 & 6.91 \\
\hline 1996 & 0.22 & 0.86 & 2.10 & 6.99 & 7.83 & 7.82 & 7.83 \\
\hline 1997 & 0.85 & 1.53 & 7.71 & 9.27 & 10.53 & 11.46 & 11.46 \\
\hline 1998 & 0.34 & 0.89 & 1.73 & 5.22 & 7.36 & 8.48 & 8.48 \\
\hline 1999 & 0.05 & 1.23 & 2.17 & 5.04 & 8.52 & 7.95 & 8.52 \\
\hline 2000 & 0.00 & 0.73 & 1.91 & 4.15 & 6.43 & 6.84 & 6.84 \\
\hline 2001 & 0.60 & 1.28 & 3.10 & 3.98 & 4.60 & 5.24 & 5.24 \\
\hline 2002 & 0.27 & 1.17 & 4.37 & 5.67 & 5.85 & 6.57 & 6.57 \\
\hline 2003 & 0.26 & 0.86 & 2.44 & 3.76 & 4.75 & 4.97 & 4.97 \\
\hline 2004 & 0.30 & 1.82 & 5.17 & 7.04 & 7.48 & 7.90 & 7.90 \\
\hline 2005 & 0.82 & 0.98 & 2.05 & 3.90 & 4.00 & 4.77 & 4.77 \\
\hline 2006 & 0.14 & 1.22 & 3.04 & 6.32 & 7.96 & 9.11 & 9.11 \\
\hline 2007 & 0.03 & 0.98 & 2.28 & 3.16 & 4.09 & 4.25 & 4.25 \\
\hline 2008 & 0.68 & 0.43 & 2.39 & 5.00 & 6.57 & 7.35 & 7.35 \\
\hline 2009 & 0.39 & 0.42 & 3.19 & 5.08 & 5.59 & 5.53 & 5.59 \\
\hline 2010 & 0.23 & 0.32 & 1.44 & 3.60 & 4.42 & 4.82 & 4.82 \\
\hline 2011 & 0.22 & 2.48 & 5.67 & 7.74 & 9.00 & 11.27 & 11.27 \\
\hline
\end{tabular}




\begin{tabular}{|c|c|c|c|c|c|c|c|}
\hline WY & Oct & Nov & Dec & Jan & Feb & Mar & Annual Maximum \\
\hline 2012 & 0.62 & 1.81 & 2.86 & 5.28 & 6.66 & 7.49 & 7.49 \\
\hline 2013 & 0.63 & 0.54 & 3.22 & 4.76 & 5.50 & 6.72 & 6.72 \\
\hline 2014 & 0.13 & 0.50 & 1.63 & 3.58 & 6.38 & 8.29 & 8.29 \\
\hline 2015 & 0.00 & 1.81 & 3.91 & 5.23 & 5.55 & 4.00 & 5.55 \\
\hline 2016 & 0.05 & 1.62 & 4.08 & 6.85 & 7.18 & 8.26 & 8.26 \\
\hline 2017 & 0.22 & 0.85 & 4.60 & 8.34 & 11.28 & 11.08 & 11.28 \\
\hline
\end{tabular}

Table C-3. Ririe Subbasin maximum SWE (inches) values from spatially averaged UA data. Note the highlighted values were not used to estimate the lognormal parameters.

\begin{tabular}{|l|l|l|l|l|l|l|c|}
\hline WY & Oct & Nov & Dec & Jan & Feb & Mar & Annual Maximum \\
\hline 1982 & 0.08 & 0.81 & 2.79 & 5.19 & 5.37 & 3.25 & 5.37 \\
\hline 1983 & 0.10 & 0.95 & 3.10 & 3.39 & 4.23 & 4.20 & 4.23 \\
\hline 1984 & 0.00 & 1.71 & 4.78 & 5.15 & 6.66 & 7.04 & 7.04 \\
\hline 1985 & 0.64 & 1.72 & 3.51 & 4.31 & 5.53 & 6.86 & 6.86 \\
\hline 1986 & 0.27 & 2.13 & 3.13 & 3.99 & 4.34 & 5.50 & 5.50 \\
\hline 1987 & 0.07 & 1.03 & 1.22 & 2.29 & 3.57 & 3.13 & 3.57 \\
\hline 1988 & 0.00 & 0.17 & 1.04 & 2.58 & 2.66 & 2.24 & 2.66 \\
\hline 1989 & 0.00 & 2.16 & 4.01 & 5.03 & 5.02 & 4.61 & 5.03 \\
\hline 1990 & 0.26 & 0.62 & 0.88 & 1.49 & 2.20 & 2.20 & 2.20 \\
\hline 1991 & 0.04 & 0.46 & 1.25 & 1.94 & 1.55 & 1.62 & 1.94 \\
\hline 1992 & 0.20 & 0.93 & 1.24 & 1.30 & 1.90 & 1.30 & 1.90 \\
\hline 1993 & 0.01 & 0.93 & 3.12 & 4.43 & 5.97 & 6.05 & 6.05 \\
\hline 1994 & 0.00 & 0.35 & 1.14 & 1.65 & 2.87 & 2.16 & 2.87 \\
\hline 1995 & 0.21 & 1.30 & 3.01 & 3.46 & 3.96 & 3.39 & 3.96 \\
\hline 1996 & 0.04 & 0.47 & 0.80 & 4.29 & 4.47 & 3.83 & 4.47 \\
\hline 1997 & 0.53 & 0.51 & 3.73 & 4.08 & 4.72 & 5.17 & 5.17 \\
\hline 1998 & 0.41 & 0.52 & 1.02 & 2.68 & 4.16 & 5.14 & 5.14 \\
\hline 1999 & 0.01 & 0.34 & 0.75 & 2.70 & 4.59 & 3.57 & 4.59 \\
\hline 2000 & 0.00 & 0.26 & 1.11 & 2.03 & 3.39 & 3.20 & 3.39 \\
\hline 2001 & 0.19 & 0.83 & 1.88 & 2.38 & 2.89 & 3.65 & 3.65 \\
\hline 2002 & 0.24 & 0.67 & 2.77 & 3.26 & 3.56 & 3.83 & 3.83 \\
\hline 2003 & 0.22 & 0.26 & 0.79 & 1.60 & 1.83 & 2.12 & 2.12 \\
\hline 2004 & 0.13 & 0.85 & 3.01 & 4.37 & 4.10 & 4.12 & 4.37 \\
\hline 2005 & 0.41 & 0.51 & 0.73 & 1.90 & 1.74 & 1.74 & 1.90 \\
\hline 2006 & 0.04 & 0.49 & 1.22 & 2.38 & 3.41 & 3.74 & 3.74 \\
\hline 2007 & 0.08 & 0.49 & 0.56 & 0.90 & 0.88 & 1.01 & 1.01 \\
\hline 2008 & 0.26 & 0.17 & 1.39 & 2.92 & 3.73 & 3.83 & 3.83 \\
\hline 2009 & 0.17 & 0.10 & 2.30 & 3.31 & 3.49 & 2.53 & 3.49 \\
\hline 2010 & 0.10 & 0.21 & 0.89 & 2.31 & 2.92 & 2.87 & 2.92 \\
\hline 2011 & 0.33 & 1.59 & 3.26 & 4.70 & 5.20 & 5.27 & 5.27 \\
\hline
\end{tabular}




\begin{tabular}{|c|c|c|c|c|c|c|c|}
\hline WY & Oct & Nov & Dec & Jan & Feb & Mar & Annual Maximum \\
\hline 2012 & 0.07 & 0.76 & 1.11 & 2.27 & 2.79 & 3.15 & 3.15 \\
\hline 2013 & 0.46 & 0.25 & 1.42 & 2.20 & 2.34 & 2.71 & 2.71 \\
\hline 2014 & 0.05 & 0.22 & 0.83 & 1.75 & 2.73 & 3.12 & 3.12 \\
\hline 2015 & 0.00 & 0.74 & 1.68 & 2.50 & 2.11 & 0.50 & 2.50 \\
\hline 2016 & 0.01 & 0.81 & 2.41 & 4.66 & 4.85 & 3.40 & 4.85 \\
\hline 2017 & 0.02 & 0.38 & 2.72 & 4.57 & 5.39 & 3.63 & 5.39 \\
\hline
\end{tabular}

Table C-4. Lognormal average by month and basin. Note these are based on taking the natural log of the maximum SWE values, and values below 1.5 times the interquartile range were removed as outliers.

\begin{tabular}{|l|l|l|l|l|l|l|}
\hline \multicolumn{1}{|c|}{ Basin } & November & December & January & February & March & \multicolumn{1}{c|}{ Annual } \\
\hline Willow Creek Basin & 0.0535 & 0.4867 & 0.7073 & 0.8031 & 0.8360 & 0.8703 \\
\hline Ririe Subbasin & -0.2423 & 0.2183 & 0.4469 & 0.5253 & 0.5303 & 0.5711 \\
\hline Ririe Upstream Subbasin & 0.0608 & 0.4941 & 0.7151 & 0.8110 & 0.8394 & 0.8619 \\
\hline Grays Lake Subbasin & 0.1402 & 0.5588 & 0.7859 & 0.8869 & 0.9556 & 0.9657 \\
\hline
\end{tabular}

Table C-5. Lognormal standard deviation by month and basin. Note these are based on taking the natural log of the maximum SWE values, and values below 1.5 times the interquartile range were removed as outliers.

\begin{tabular}{|l|l|l|l|l|l|l|}
\hline \multicolumn{1}{|c|}{ Basin } & November & December & January & February & \multicolumn{1}{c|}{ March } & \multicolumn{1}{c|}{ Annual } \\
\hline Willow Creek Basin & 0.2737 & 0.1948 & 0.1373 & 0.1320 & 0.1407 & 0.1221 \\
\hline Ririe Subbasin & 0.3284 & 0.2612 & 0.1910 & 0.1909 & 0.1736 & 0.1590 \\
\hline Ririe Upstream Subbasin & 0.2735 & 0.1996 & 0.1398 & 0.1347 & 0.1454 & 0.1388 \\
\hline Grays Lake Subbasin & 0.2708 & 0.1760 & 0.1275 & 0.1243 & 0.1267 & 0.1262 \\
\hline
\end{tabular}




\section{Appendix D: Infiltration-Reduction Probabilities}

We divided the daily time series output from the FSIM model by month to determine the empirical distribution for infiltration reduction factors. We used the local weighted regression method (LOESS) to graphically fit the infiltration-reduction data. Based on graphical inspection, a smoothing parameter for the LOESS fit was assumed to be o.1. The R package "stats" (R Core Team 2019) was used to perform the LOESS fit on our data. Table D1 summarizes the infiltration-reduction factor values. Figures D- 1 through D-6 show the ranked output data from FSIM along with the LOESS fitted curve.

Table D-1. Infiltration reduction factor probability by month.

\begin{tabular}{|l|c|c|c|c|c|c|c|c|c|}
\hline & \multicolumn{7}{|c|}{ Percent Exceedance } \\
\cline { 2 - 11 } \multicolumn{1}{|c|}{ Month } & $\mathbf{1 0}$ & $\mathbf{2 0}$ & $\mathbf{3 0}$ & $\mathbf{4 0}$ & $\mathbf{5 0}$ & $\mathbf{6 0}$ & $\mathbf{7 0}$ & $\mathbf{8 0}$ & $\mathbf{9 0}$ \\
\hline Oct & 1.000 & 1.000 & 1.000 & 1.000 & 1.000 & 1.000 & 1.000 & 1.000 & 1.000 \\
\hline Nov & 1.000 & 1.000 & 1.000 & 1.000 & 0.959 & 0.960 & 0.960 & 0.960 & 0.968 \\
\hline Dec & 0.958 & 0.960 & 0.960 & 0.960 & 0.960 & 0.960 & 0.960 & 0.822 & 0.624 \\
\hline Jan & 0.960 & 0.960 & 0.960 & 0.960 & 0.960 & 0.960 & 0.910 & 0.617 & 0.403 \\
\hline Feb & 0.998 & 0.960 & 0.960 & 0.960 & 0.960 & 0.960 & 0.796 & 0.518 & 0.397 \\
\hline Mar & 1.000 & 1.000 & 1.000 & 0.987 & 0.960 & 0.960 & 0.878 & 0.547 & 0.395 \\
\hline
\end{tabular}

Figure D-1. LOESS fit of infiltration-reduction factor for October.

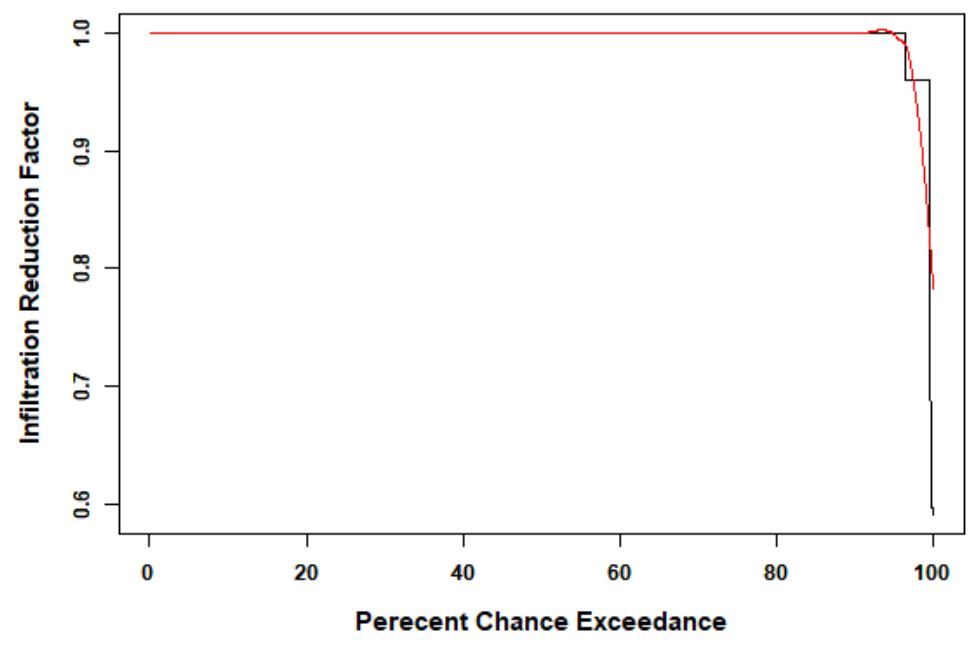


Figure D-2. LOESS fit of infiltration-reduction factor for November.

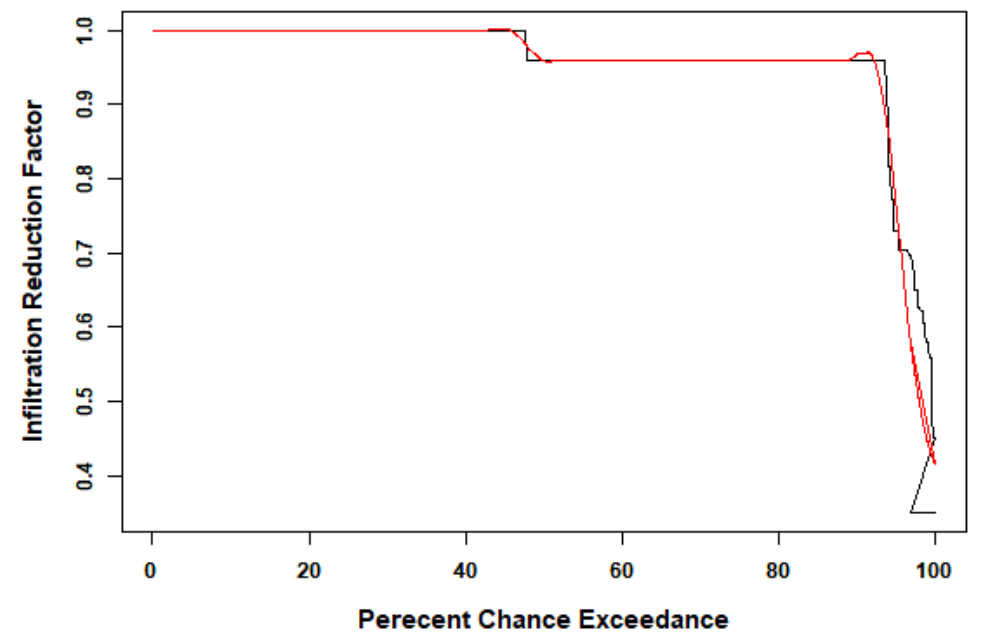

Figure D-3. LOESS fit of infiltration-reduction factor for December.

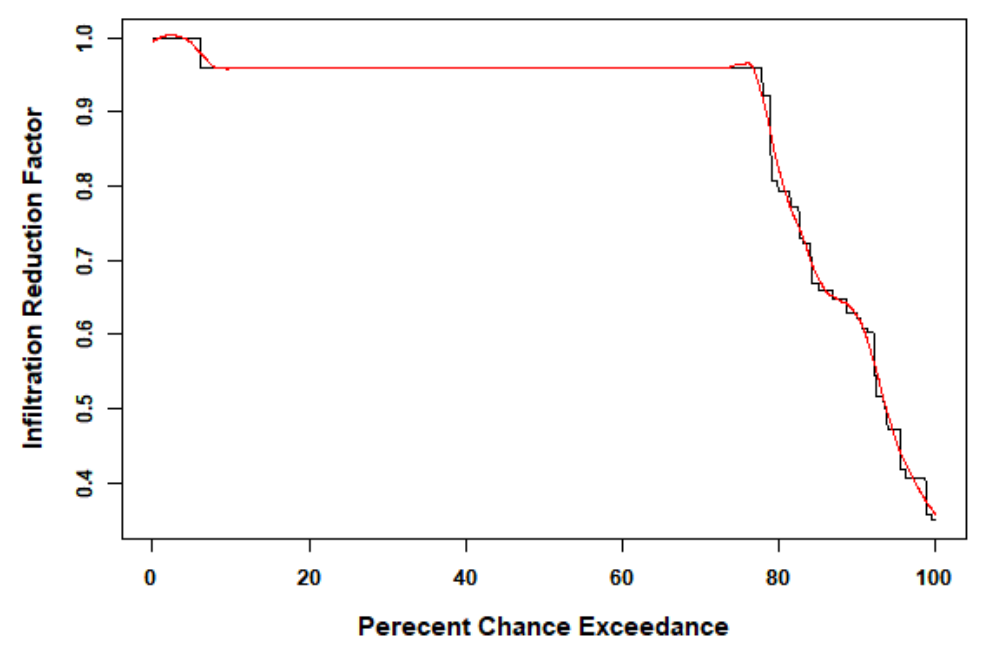

Figure D-4. LOESS fit of infiltration-reduction factor for January.

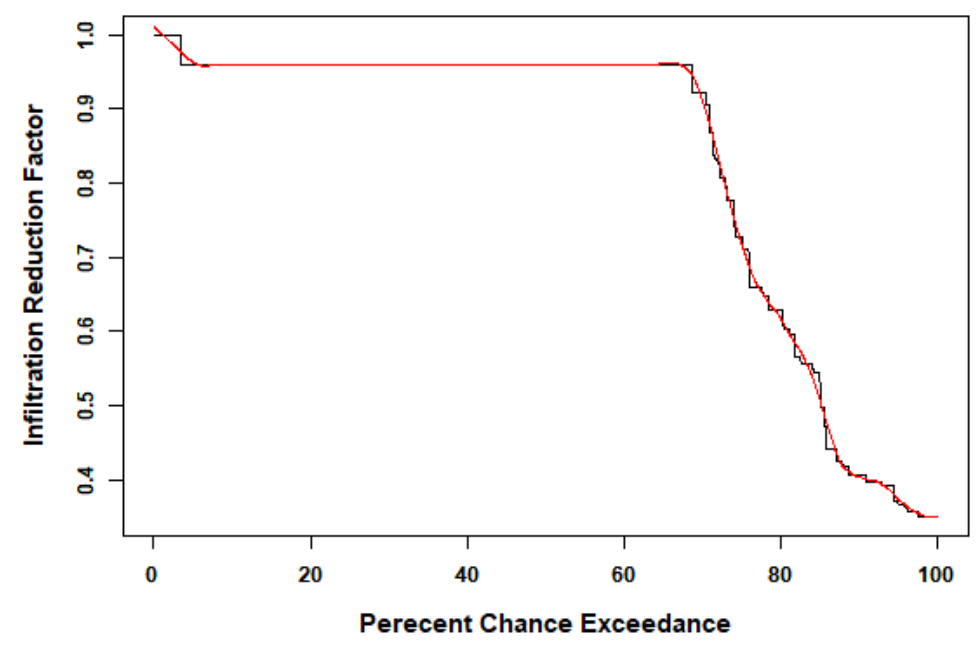


Figure D-5. LOESS fit of infiltration-reduction factor for February.

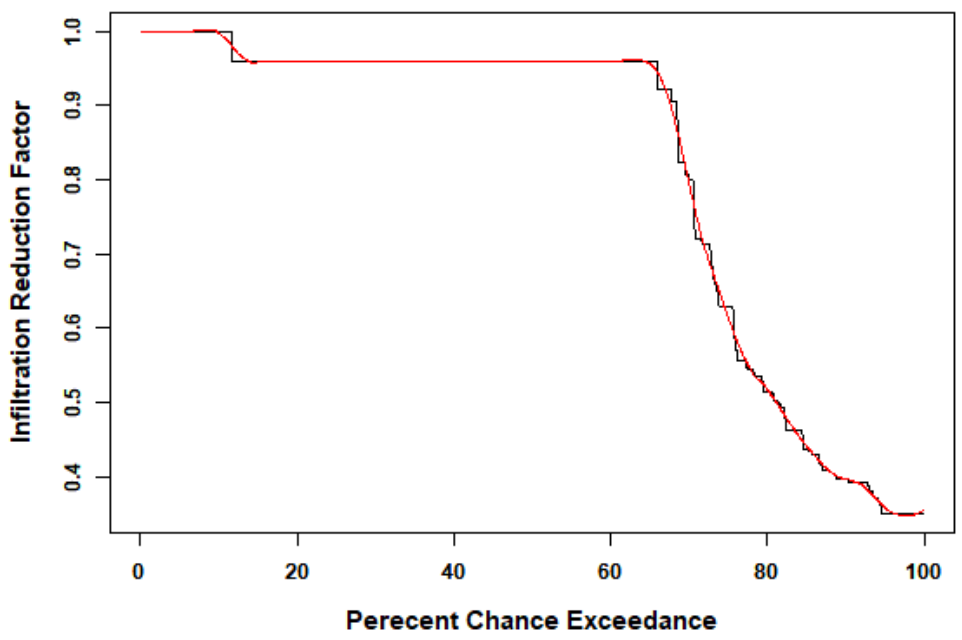

Figure D-6. LOESS fit of infiltration-reduction factor for March

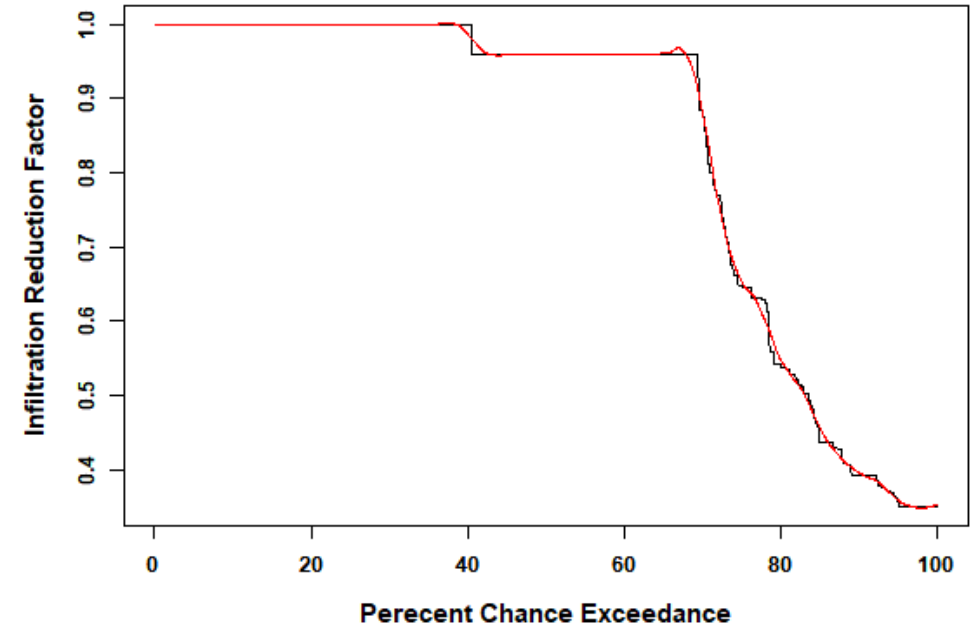




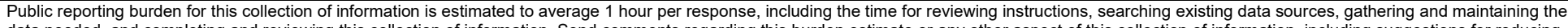

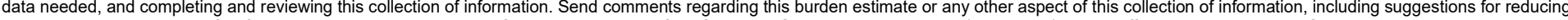

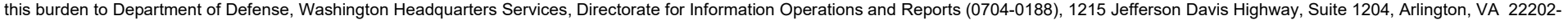

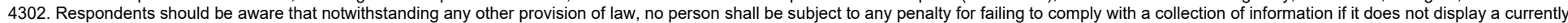
valid OMB control number. PLEASE DO NOT RETURN YOUR FORM TO THE ABOVE ADDRESS.

\begin{tabular}{l|l} 
valid OMB control number. PLEASE DO NOT RETURN YOUR FORM TO THE ABOVE ADDRESS. \\
\hline 1. REPORT DATE (DD-MM-YYYY) & 2. REPOR1
\end{tabular}

April 2021

Technical Report / Final

4. TITLE AND SUBTITLE

Wintertime Snow and Precipitation Conditions in the Willow Creek Watershed above Ririe Dam, Idaho

\section{AUTHOR(S)}

Jeremy Giovando, Chandler Engel, Steven F. Daly, Michael Warner, Daniel Hamill, and Evan Heisman

3. DATES COVERED (From - To)

FY19-FY21

5a. CONTRACT NUMBER

\section{5b. GRANT NUMBER}

5c. PROGRAM ELEMENT

5d. PROJECT NUMBER

5e. TASK NUMBER

5f. WORK UNIT NUMBER

8. PERFORMING ORGANIZATION REPORT NUMBER

ERDC/CRREL TR-21-6

U.S. Army Engineer Research and Development Center (ERDC)

Cold Regions Research and Engineering Laboratory (CRREL)

72 Lyme Road

Hanover, NH $03755^{-1290}$

\section{SPONSORING / MONITORING AGENCY NAME(S) AND ADDRESS(ES)}

U.S. Army Corps of Engineers-Walla Walla District

201 North 3 rd Ave.

Walla Walla, WA 99362-1876

11. SPONSOR/MONITOR'S REPORT NUMBER(S)

\section{DISTRIBUTION / AVAILABILITY STATEMENT}

Approved for public release; distribution is unlimited.

\section{SUPPLEMENTARY NOTES}

AMSCO for this work is 478350 ; the funding account is G4116713

\section{ABSTRACT}

The Ririe Dam and Reservoir project is located on Willow Creek near Idaho Falls, Idaho, and is important for flood risk reduction and water supply. The current operating criteria is based on fully storing a large winter runoff event. These winter runoff events are generally from large storm events, termed atmospheric rivers, which produce substantial precipitation. In addition to the precipitation, enhanced runoff is produced due to frozen soil and snowmelt. However, the need for additional water supply by local stakeholders has prompted the U.S. Army Corps of Engineers to seek to better understand the current level of flood risk reduction provided by Ririe Dam and Reservoir.

Flood risk analysis using hydrologic modeling software requires quantification of the probability for all of the hydrometeorologic inputs. Our study develops the precipitation, SWE, and frozen ground probabilities that are required for the hydrologic modeling necessary to quantify the current winter flood risk.

\section{SUBJECT TERMS}

Flood control, Hydrologic models, Precipitation (Meteorology), Ririe Dam (Idaho), Runoff, Snow, Willow Creek (Bingham County and Bonneville County, Idaho)

\begin{tabular}{|c|c|c|c|c|c|}
\hline \multicolumn{3}{|c|}{ 16. SECURITY CLASSIFICATION OF: } & \multirow{2}{*}{$\begin{array}{l}\text { 17. LIMITATION } \\
\text { OF ABSTRACT } \\
\text { SAR }\end{array}$} & \multirow{2}{*}{$\begin{array}{l}\text { 18. NUMBER } \\
\text { OF PAGES }\end{array}$} & 19a. NAME OF RESPONSIBLE PERSON \\
\hline $\begin{array}{l}\text { a. REPORT } \\
\text { Unclassified }\end{array}$ & $\begin{array}{l}\text { b. ABSTRACT } \\
\text { Unclassified }\end{array}$ & $\begin{array}{l}\text { c. THIS PAGE } \\
\text { Unclassified }\end{array}$ & & & $\begin{array}{l}\text { 19b. TELEPHONE NUMBER } \\
\text { (include area code) }\end{array}$ \\
\hline
\end{tabular}

